\title{
DISCLA IMER
}

This report was prepared as an account of work sponsored by an agency of the United States Government. Neither the United States Government nor any agency thereof, nor any of their employees, makes any warranty, express or implied, or assumes any legal liability or responsibility for the accuracy, completeness, or usefulness of any information, apparatus, product, or process disclosed, or represents that its use would not infringe privately owned rights. Reference herein to any specific commercial product, process, or service by trade name, trademark, manufacturer, or otherwise does not necessarily constitute or imply its endorsement, recommendation, or favoring by the United States Government or any agency thereof. The views and opinions of authors expressed herein do not necessarily state or reflect those of the United States Government or any agency thereof.

This report has been reproduced directly from the best available copy.

Available to DOE and DOE contractors from the Office of Scientific and Technical Information, 175 Oak Ridge Turnpike, Oak Ridge, TN 37831; prices available at (615) 576-8401.

Available to the public from the National Technical Information Service, U.S. Department of Commerce, 5285 Port Royal Road, Springfield, VA 22161; phone orders accepted at $(703) 487-4650$. 


\title{
Task 3.0
}

Advanced Power Systems

Semi-Annual Report

April 1 - June 30, 1993

Donald P. McCollor

Christopher J. Zygarlicke

Michael D. Mann

Warrack G. Willson

John P. Hurley

Work Performed Under Contract No.: DE-FC21-93MC30097

For

U.S. Department of Energv

Office of Fossil Energy

Morgantown Energy Technology Center

P.O. Box 880

Morgantown, West Virginia 26507-0880

\author{
By \\ University of North Dakota \\ Energy and Environmental Research Center \\ P.O. Box 9018 \\ Grand Forks, North Dakota 58202-9018
}

July 1993 
LIST OF FIGURES $\ldots \ldots \ldots \ldots \ldots \ldots \ldots \ldots \ldots \ldots \ldots \ldots \ldots \ldots \ldots$ ii

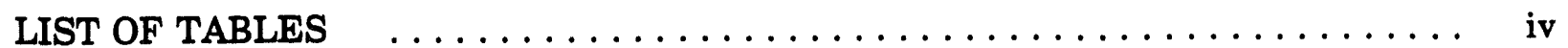

EXECUTIVE SUMMARY $\ldots \ldots \ldots \ldots \ldots \ldots \ldots \ldots \ldots \ldots \ldots \ldots \ldots$

TASK 3.0 ADVANCED POWER SYSTEMS $\ldots \ldots \ldots \ldots \ldots \ldots \ldots \ldots \ldots$

Subtask 3.1 Fuel Utilization Properties $\ldots \ldots \ldots \ldots \ldots \ldots \ldots \ldots \ldots \ldots \ldots \ldots$

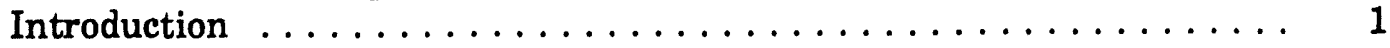

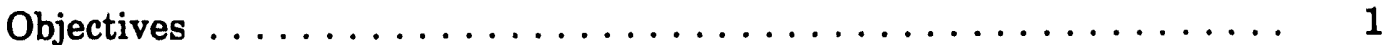

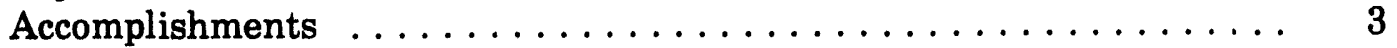

References .......................... 46

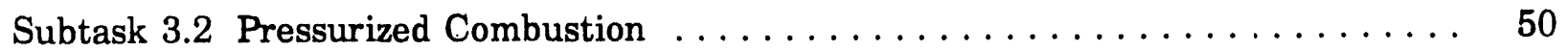

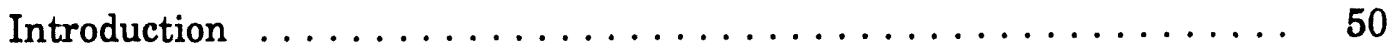

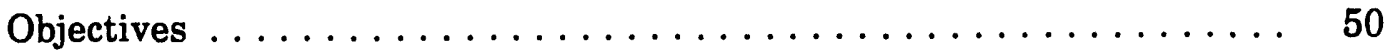

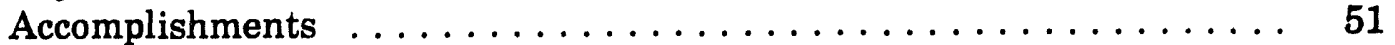

References .......................... 67

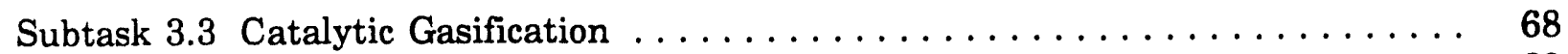

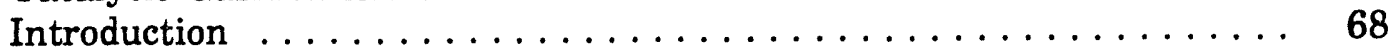

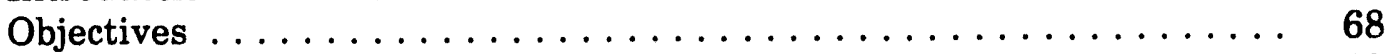

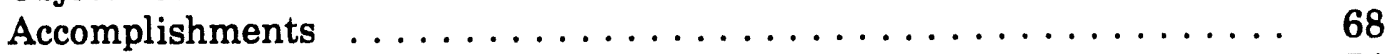

References .......................... 74

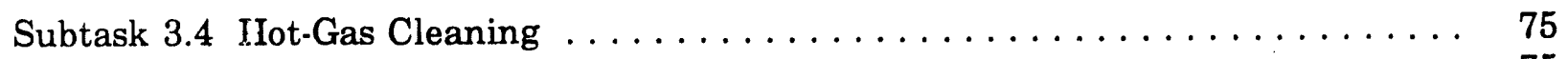

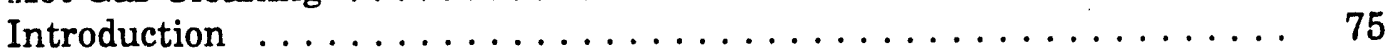

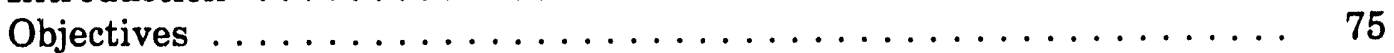

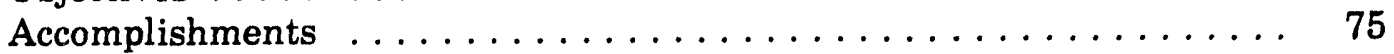

References ........................... 99 


\section{LIST OF FIGURES}

Figure

3.1-1 Size distributions for SEM-IA results for Eagle Butte ash, using a freeze-dried sample preparation $\ldots \ldots \ldots \ldots \ldots \ldots \ldots \ldots \ldots$

3.1-2 Optical access drop-tube furnace $\ldots \ldots \ldots \ldots \ldots \ldots \ldots \ldots \ldots \ldots \ldots$

3.1-3 Ash deposition probe $\ldots \ldots \ldots \ldots \ldots \ldots \ldots \ldots \ldots \ldots \ldots \ldots \ldots$

3.1.4 Conceptual design of convective pass simulator $\ldots \ldots \ldots \ldots \ldots \ldots$

3.1.5 Cross section of Illinois No. 6 deposic ash island showing grey deformed ash particles adhering to the substrate at bottom of photo with other particles attaching to build the ash island .................

3.1.6 Plot of $\log _{10}$ mass and cumulative $\%$ mass versus $\log _{10}$ viscosity for the Illinois No. 6 deposit grown at $21 \% \mathrm{O}_{2}$. Dashed lines delimit the regions

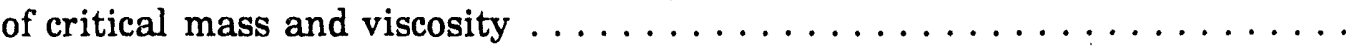

3.1-7 Plot of $\log _{10}$ mass and cumulative $\%$ mass versus $\log _{10}$ viscosity for the Beulah-Zap deposit grown at $21 \% \mathrm{O}_{2}$. Dashed lines delimit the regions of

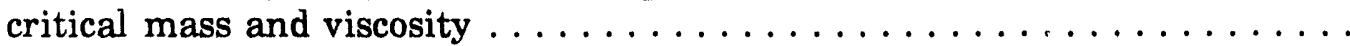

3.1.8 Plot of $\log _{10}$ mass and cumulative $\%$ mass versus $\log _{10}$ viscosity for the Dietz deposit grown at $21 \% \mathrm{O}_{2}$. Dashed lines delimit the regions of critical

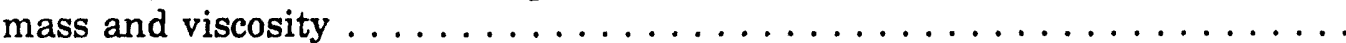

3.1.9 Plot of cumulative \% mass versus $\log _{10}$ viscosity for the Illinois bulk filter fly ash produced at $21 \% \mathrm{O}_{2}$. Shaded area delimits the fraction of total mass below the critical viscosity

3.1-10 Plot of cumulative \% mass versus $\log _{10}$ viscosity for the Dietz bulk filter fly ash produced at $21 \% \mathrm{O}_{2}$. Shaded area delimits the fraction of total mass

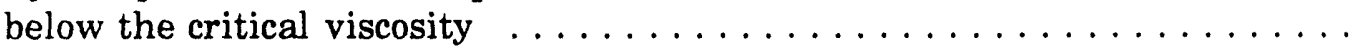

3.1-11 Inorganic transformations and ash deposition process $\ldots \ldots \ldots \ldots \ldots$

3.1-12 Group I deposit model calculated and experimental adhesion strength ....

3.1-13 Group II deposit model calculated and experimental adhesion strength ...

3.1.14 Group II deposit model calculated and experimental crushing strengths ...

3.1-15 Initial deposit of material on steel coupon generated from Beulah

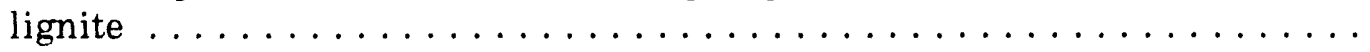

3.2-1 SEM micrograph of the reaction layer between the slag and an SiC castable refractory exposed to a $\mathrm{PRB}$ coal ash at $1260^{\circ} \mathrm{C}$ for 45 hours . . . . . . 


\section{LIST OF FIGURES (continued)}

Figure

Page

3.2-2 SEM micrograph of the slag/refractory boundary in an SiC castable refractory exposed to an Illinois No. 6 coal ash at $1260^{\circ} \mathrm{C}$ for 45 hours . . . . . . . .

3.3-1 Metal-clay catalyzed Illinois No. 6 char-steam reaction at $800^{\circ} \mathrm{C}$.

First order in carbon rate constants are shown

3.3-2 Gas production from Ni-clay catalyzed Illinios No. 6-steam reaction in the IBG at $800^{\circ} \mathrm{C}$ and nominally $50 \mathrm{psig}$

3.4-1 The weight percent of each element collected in each size fraction for the tests of kaolin as an alkali getter in the A) atmospheric

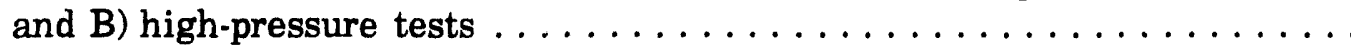

3.4-2 The calculated concentrations of vapor-phase sodium species versus temperature and ratio of kaolin added to ASTM ash

3.4-3 SEM backscattered electron image of the SiC/slag interface showing the remains of the tantalum pentoxide film

3.4-4 SEM secondary electron image of the tantalum pentoxide grains at higher magnification 


\section{LIST OF TABLES}

Table

$\underline{\text { Page }}$

3.1-1 Analysis Progress $\ldots \ldots \ldots \ldots \ldots \ldots \ldots \ldots \ldots \ldots \ldots \ldots \ldots$

3.1-2 Compositions, in Weight Percentages, for Eagle Butte Fly Ash . . . . . . 8

3.1.3 Compositions, in Weight Percentages, for Eagle Butte/Kentucky

No. 9 Blend Ash . . . . . . . . . . . . . . . . . . . . . 10

3.1-4 Bulk Ash Composition $\ldots \ldots \ldots \ldots \ldots \ldots \ldots$

3.1.5 Coal Mineral Content $\ldots \ldots \ldots \ldots \ldots \ldots \ldots \ldots \ldots \ldots \ldots \ldots \ldots \ldots$

3.1-6 Included Mineral Content in Five Coals $\ldots \ldots \ldots \ldots \ldots$

3.1-7 Major Elemental Compositions of Adhering Particles Percentage of

Particles with Each Major Composition . . . . . . . . . . . . . 22

3.1-8 Properties of Initial Deposit Particles $\ldots \ldots \ldots \ldots \ldots$

3.1-9 Properties of Bulk Fly Ash Particles $\ldots \ldots \ldots \ldots \ldots$

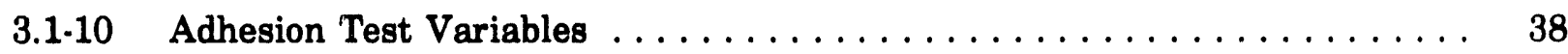

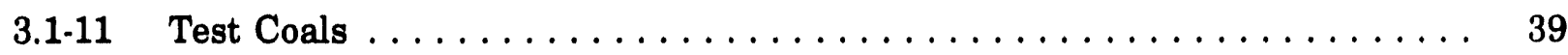

3.1-12 Groups I and II Adhesion Test Conditions . . . . . . . . . . . . 39

3.1-12 Summary of Model Parameters for the Group I Adhesion

Test Data .............................. 41

3.2-1 Technical Data for the SiC Refractories $\ldots \ldots \ldots \ldots \ldots$

3.2-2 Compositions of the Powder River Basin Ash and the Illinois

No. 6 Ash Used in the Corrosion Experiments ................ 54

3.2-3 Resultant Slag Compositions for the $1260^{\circ} \mathrm{C}, 45$-hour

Exposure ............................... 56

3.2-4 Resultant Slag Compositions for the $1430^{\circ} \mathrm{C}, 40$-hour Test $\ldots \ldots \ldots$. . . 58

3.2-5 Penetration Rates for SiC Castable Refractories Exposed to

Powder River Basin and Illinois No. 6 Ashes $\ldots \ldots \ldots \ldots \ldots$

3.2-6 Technical Data for Alumina-Based Refractories $\ldots \ldots \ldots \ldots \ldots$

3.2-7 Penetration Rates for Castable Refractories Exposed to Powder River

Basin and Illinois No. 6 Ashes $\ldots \ldots \ldots \ldots \ldots \ldots \ldots$ 


\section{LIST OF TABLES (continued)}

Table

$\underline{\text { Page }}$

3.3-1 Proximate Analyses of Feed Coal and Feed Coal $+10 \% \mathrm{Ni}$

Catalyst

3.3-2 First-Order Reactivities for Catalyzed and Uncatalyzed

Illinois No. 6 Steam Gasification

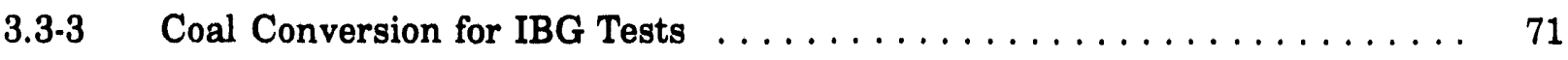

3.3-4 Percentage of Hydrogen in Product Gas $\ldots \ldots \ldots \ldots \ldots$

3.3.5 Percentage of Carbon Monoxide in Product Gas $\ldots \ldots \ldots \ldots \ldots$

3.3-6 Percentage of Methane in Product Gas $\ldots \ldots \ldots \ldots \ldots$

3.4-1 Thermal Expansion Coefficients and Viscosities for

Selected Silivate Glasses Taken from the Handbook of

Glass Properties

3.4-2 Physical Properties of Materials That May Be Used as Binders

for $\mathrm{SiC}$

3.4-3 Composition of the Tantalum Oxide Grains and

Adjacent Slag 


\section{EXECUTIVE SUMMARY}

A variety of activities are incorporated into the Advanced Power Systems program. Tasks included are 1) fuel utilization properties, 2) pressurized combustion, 3) catalytic gasification, and 4) hot-gas cleanup.

Work in each of these has progressed during the past 6 months. Development of the predictive tools ATRAN and ASHPERT has continued. ATRAN is stochastic and simply combines initial coal inorganics in a random manner in order to predict the resulting fly ash particle size and composition. ASHPERT, on the other hand, is an expert system yielding a first-order estimate of fly ash size and composition. Both models are designed to emulate pulverized-coal combustion. Input data required include identity, chemistry, size, quantity, and mineral-to- coal associations. Recent work has added a graphics user interface.

Analytic methods development has been an important part of the work at the Energy \& Environmental Research Center (EERC) on coal inorganics. Currently, a round-robin study using computer-controlled scanning electron microscopy (CCSEM) has been organized. Six laboratories have agreed to participate, and analysis of a suite of samples is underway. This effort should greatly assist in accelerating acceptance of the technique for detailed analysis of coal inorganics.

Work continues on understanding this key factor in the initiation of ash deposition. Recent work has produced the following conclusions:

- Oxygen concentration appears to have only a minor effect on deposit initiation. Such effects may be partial reduction of iron species at low oxygen concentrations and increased agglomeration of mineral species due to higher combustion temperatures at high oxygen concentrations.

- Seven general species make up the bulk of the initially adhering particle compositions. These are iron species, iron-calcium, iron-silica, iron-silica-alumina species, calcium-silica-alumina species, barium, and barium sulfate species.

- The initially adhering species are common to all coals, with particle abundance being governed by concentration in the original coals.

- The great majority of the initial ash particles masses and viscosities cluster in a grouping above a certain "critical" mass and below a certain "critical" viscosity regardless of individual composition. This indicates that the initial adhering particles are those with sufficient kinetic energy to impact the substrate and sufficiently low viscosity to adhere upon impaction.

- Propensity for the initial ash deposition can be roughly related to the fraction of particles in the bulk fly ash possessing these required mass and viscosity requirements. However, the effect of volatilized or organically bound inorganic material is not assessed by this relationship. 
The pressurized combustion task has focused on the construction of a versatile reactor system to simulate pressurized fluidized-bed combustion. Results of the work should appear in August of this year.

Many advanced power systems will include zones where slagging will occur. A major issue i: the ability of refractory material to exhibit a reasonable lifetime under given conditions. Both castable and monolithic refractories have been investigated in determining slag prevention under a variety of conditions, including both basic and acidic slags. Results to date indicate problems may arise from the use of many of the materials currently available.

Catalytic gasification coupled with a molten carbonate fuel cell offers an extremely efficient and environmentally sound power generating system using coal. An ideal situation would be that a suitable hydrogasification catalyst were found which would allow for residence times in the order of minutes at $650^{\circ} \mathrm{C}$ and $500 \mathrm{psi}$. Work with an Illinois No. 6 bituminous coal has not been successful. Continued efforts will focus on using the more reactive low-rank coals to try to achieve this goal.

Hot-gas cleanup is the critical issue in many of the proposed advanced power system operations on coal. To achieve the desired results, techniques must be found that allow for the removal of particulates at a high temperature $\left(1800^{\circ} \mathrm{F}\right)$, as well as control of alkali metals. The key to successful ash removal is an understanding of the properties of the ash to be collected as well as the interactions of this material with the barrier itself. The knowledge base under development will assist in assessing many of these barrier material issues for a variety of coal ashes.

A variety of strategies have been considered to mitigate the problem of alkali control. Work has shown that injection of reasonable levels of kaolin has removed vaporphase alkali to levels compatible with modern turbine systems. 


\section{TASK 3.0 ADVANCED POWER SYSTEMS}

\section{Subtask 3.1 Fuel Utilization Properties}

\section{Introduction}

The mission of the Department of Energy and the Energy \& Environmental Research Center (EERC) Cooperative Agreement is to promote the clean and efficient use of energy resources through a program of research and development efforts. These efforts include research characterization, air quality impacts and controls, advanced power systems, and advanced fuel forms. The goals of the Cooperative Agreement are energy efficiency, preserving the environment, securing the domestic energy supply, diversifying the coal industry, and fortifying foundations in research, education, and technology commercialization.

\section{Objectives}

This report covers the activities of Task 3.1, "Fuel Utilization Properties." Its overall goal is to determine the fundamental physical and chemical transformations of coal inorganic constituents and the relationship of the resulting ash intermediates to the formation of ash deposits in advanced power systems.

The overall objectives of Task 3.1 are 1) to determine the mechanisms of inorganic transformations during coal conversion processes, 2) to develop algorithms to predict the transport mechanisms of an ash/particulate flux to heat-transfer surfaces, 3) to study the effect of deposit characteristics on deposit strength and heat-transfer properties, and 4) to examine the effects of deposit characteristics on deposit removability.

The Fuel Utilization Properties program spans a 5-year period. The following details the objectives of each subtask over the time of the project.

\section{INORGANIC TRANSFORMATIONS AND PRODUCTION OF ASH INTERMEDIATES}

There are three objectives:

- To perform inorganic transformation studies on three coals using standard combustion, fuel-rich combustion, pressurized combustion, fuel-rich pressurized combustion, and low- $\mathrm{NO}_{\mathrm{x}}$ combustion similar to the private sector.

- To refine a mechanistic model for fly ash composition and size prediction for advanced coal conversion systems. Refine the ASHPERT model to be more userfriendly. These models are research tools and are not being considered for development as stand-alone software packages.

- Develop advanced analytical methods in the area of the particle-by-particle CCSEM method and standardize the CCSEM method through round-robin collaborative testing. 


\section{ASH TRANSPORT AND DEPOSIT INITIATION AND GROWTH}

There are five objectives:

- Perform a literature review in the area of ash transport and deposit initiation.

- Perform modifications of the optical drop-tube furnace (ODTF) to add a second furnace for generating longer particle residence times and greater particle velocities, develop a convective pass simulator for the ODTF, and install gas analyzers, additional computer control, and image analysis capabilities.

- Perform deposit initiation studies, including deposition on ceramic surfaces and deposition in different combustion systems.

- Develop transport algorithms to determine sticking fractions of entrained particulates.

- Determine deposit growth rates for fouling and slagging deposits.

\section{DEPOSIT STRENGTH DEVELOPMENT AND THERMAL PROPERTIES}

There are five objectives:

- Conduct a literature review in the area of the principles of silicate and sulfate sintering and in the area of deposit thermal conductivity.

- Perform sintering and deposit thermal conductivity experiments.

- Develop a first-order correlation between deposit porosity, composition, degree of sulfonation, and liquid-phase viscosity with deposit growth rates, strength development, and removability.

- Develop algorithms that predict thermal conductivity and strength development of deposits on a particle-by-particle basis.

- Develop a more effective slag viscosity model, conducted as a doctoral research project at the Pennsylvania State University. The project will evaluate existing slag viscosity models and devise a more effective model for higher-calcium coals such as the western U.S. types, acquire test data for improving the slag viscosity model using a penetrometer in addition to the existing rotating bob viscometer data, revise the viscosity calculation routine in the EERC scanning electron microscope point count routine to take into account different valence states of elements, effects of different oxygen levels, and viscosity data derived from a rotating bob viscometer, and relate the new viscosity model to deposit strength.

\section{INORGANIC TRANSFORMATIONS AND PRODUCTION OF ASH} INTERMEDIATES

The first-year goals were to 1) perform inorganic transformation studies on one new coal (Wyodak) under standard combustion conditions, 2) refine the stochastic ATRAN 
model for fly ash composition and size prediction and improve the user-friendliness of ASHPERT, and 3) evaluate the particle-by-particle CCSEM method and develop

standardization of the CCSEM method through round-robin collaborative testing.

\section{Accomplishments}

\section{- INORGANIC TRANSFORMATION STUDIES}

Combustion tests have been performed under standard conditions in the drop-tube furnace system on Wyodak and Beulah coals. Analysis of the ash collected is currently in progress, and the results will be presented in the next semiunnual report. Additional ash transformation studies of a coal to be selected will be performed in collaboration with Physical Sciences Incorporated (PSI). Further tests are planned for the Beulah and Wyodak coals to study the effects of low $\mathrm{NO}_{3}$ conditions on ash transformations.

\section{REFINING ATRAN MODEL AND IMPROVING ASHPERT MODEL}

Two models have been developed at the EERC for use as research tools in predicting fly ash particle size and composition from CCSEM analyses of coal. Both models are phenomenological, requiring detailed coal input data and empirically derived knowledge of inorganic transformation phenomena occurring during combustion. The first model, ATRAN1, is stochastic and simply combines initial coal inorganics in a random manner in order to predict the resultant fly ash particle size and composition. The acronym is derived by shortening the phrase "ash transformation" and adding the number " 1 " to indicate future refinements and modifications of the code. ATRAN1 is considered stochastic because it randomly combines data from coal mineral analyses to produce predictions of fly ash compositions. The model does not operate in a completely random manner in that associations among coal minerals (i.e., locked vs. liberated) influence the predictions. The second model, ASHPERT, is an expert system yielding a first-order estimate of fly ash size and composition. Both models are designed to emulate pulverized coal combustion and, hence, use data derived from coals ground to $70 \%-80 \% \cdot 200 \mathrm{mesh}$.

Both ATRAN1 and ASHPERT use CCSEM data as their primary input regarding the identity, chemistry, size, quantity, and mineral-to-coal association (locked or liberated) of the minerals. Data are required on an individual-particle basis in order to model transformations and interactions between individual minerals locked within and liberated from coal particles. CCSEM data provide all of the above parameters for minerals greater than $1 \mu \mathrm{m}$ in average diameter, whereas chemical fractionation results are used for information on organically bound inorganics or minerals less than $1 \mu \mathrm{m}$ in size.

A graphics user interface has been added to the ATRAN1 code to improve the usability. In addition, a preliminary manual has been written detailing the operating instructions. Updating of the fly ash composition and size prediction algorithms is currently underway. Work will continue to make ATRAN1 a user-friendly ash transformation predictive tool. Similar work is being done to make ASHPERT more user. friendly. The ASHPERT database will be made available in the near future. 


\section{- Round-Robin CCSEM Analysis Study}

A round-robin study of the computer-controlled scanning electron microscopy method of coal mineral analysis was initiated April 1992. The primary intent of this effort is to perform a general evaluation of the method. Six laboratories are currently participating in the project. Each laboratory is expected to perform a total of five analyses on three prepared coal samples: the Illinois No. 6 and Pittsburgh No. 8 from the Argonne Premium Coal Sample Program and the Prince coal from the European Centre for Coal Specimens.

Participation in the round-robin has been great; five out of the six participating laboratories have analyzed the Pittsburgh No. $8 \mathrm{coal}$ and two laboratories have analyzed the Illinois No. 6 and Prince coals (Table 3.1-1). The Illinois No. 6 and Prince coals were recently sent, June 30 , to the R.J. Lee group for analysis. A statistical analysis of the results will be performed when all the results have been obtained.

\section{ASSESSMENT OF FINE-PARTICLE ANALYSIS TECHNIQUE}

Electron microscope techniques are commonly applied to coal mineral and ash particles with minimum diameters of $1 \mu \mathrm{m}$. However, individual-particle analysis is also important for submicron ash particles, which form during combustion from both organically associated elements and from minerals in coal.

Organically associated elements in low-rank coals, including $\mathrm{Na}, \mathrm{Mg}$, and $\mathrm{Ca}$ and, to a lesser extent, $\mathrm{K}, \mathrm{Fe}$, and $\mathrm{Al}$, commonly vaporize during combustion. $\mathrm{Na}, \mathrm{Mg}$, and $\mathrm{K}$ are particularly volatile and can condense homogeneously as submicron particles if the ratio of vapor-phase alkali elements to ash surface area is large. These particles usually react with $\mathrm{SO}_{2}$ to form submicron sulfate particles by the time they reach the outlet of the boiler.

TABLE 3.1-1

Analysis Progress

\begin{tabular}{lccc}
\hline & \multicolumn{3}{c}{ Coal } \\
\cline { 2 - 4 } Laboratory & $\begin{array}{c}\text { Pittsburgh } \\
\text { No. 8 }\end{array}$ & $\begin{array}{c}\text { Illinois } \\
\text { No. 6 }\end{array}$ & Prince \\
\hline AMES & & & \\
CSIRO & $\mathrm{X}^{*}$ & $\mathrm{X}$ & $\mathrm{X}$ \\
EERC & $\mathrm{X}$ & $\mathrm{X}$ & $\mathrm{X}$ \\
Kentucky & $\mathrm{X}$ & & \\
R.J. Lee & $\mathrm{X}$ & & \\
Sandia & $\mathrm{X}$ & & \\
\hline
\end{tabular}

* Analysis completed. 
Mineral particles in coal undergo much less vaporization and condensation during combustion. The extent of vaporization depends on the composition of the local gas. If air is not vigorously mixed with the burning coal particles, reducing zones can exist in the flame. Within the reducing zones, $\mathrm{SiO}_{2}$ can be reduced to $\mathrm{SiO}$, which is volatile. In cooler zones of the furnace, the $\mathrm{SiO}$ vapor will oxidize and condense as small $\mathrm{SiO}_{2}$ particles in much the same way as the vaporized $\mathrm{Na}$ species.

Submicron particles can also be produced through size reduction of larger mineral particles when decomposition or fragmentation occurs during heating. When rapidly heated, pyrite fractures and, upon partial oxidation, forms FeS fragments before melting at $1075^{\circ} \mathrm{C}(1)$. Calcite $\left(\mathrm{CaCO}_{3}\right)$, siderite $\left(\mathrm{FeCO}_{3}\right)$, and ankerite $\left(\mathrm{Ca}, \mathrm{Fe}\left[\mathrm{CO}_{3} \mathrm{l}_{2}\right)\right.$ also fragment upon decomposition to form submicron particles (1).

Once formed, submicron particles are difficult to remove from the flue gas stream. When emitted, these fine particles contribute far more to plume opacity per unit mass than do larger particles (2). The effect of the fine particles on plume opacity is maximized because their size distribution peaks near a diameter equal to the wavelength of visible light, the particle size with the greatest amount of scattering per unit mass $(3,4)$. Understanding the composition and formation of submicron particles is thus important in mitigating particulate emissions.

Submicron particles are difficult to analyze with automated techniques because their small size places them near the imaging and analytical detection limits of the conventional scanning electron microscupe. Using a new sample preparation method involving freeze-drying, individual ash particles with diameters as small as $0.1 \mu \mathrm{m}$ can be analyzed automatically in the Tracor-Northern automated digital electron microscope (ADEM). The new technique is termed scanning electron microscopy with image analysis (SEM-IA) and is generally similar to computer-controlled scanning electron microscopy (CCSEM). The technique and test results are described below.

\section{METHODS}

\section{- Sample Preparation}

Coal fly ash was produced in a bench-scale drop-tube furnace, as described elsewhere (5). Samples were prepared by freeze-drying a small amount of dispersed particles onto a substrate of vitreous carbon (6). Vitreous carbon is used because its exceptionally smooth surface allows unambiguous identification of small particles. Freeze-drying maintains a uniform separation between particles.

\section{- Data Acquisition}

The Tracor-Northern ADEM is used for SEM-IA of the freeze-dried sample preparations. It has a spatial resolution of $0.1 \mu \mathrm{m}$, allowing analysis of the smallest ash particles. A low accelerating voltage $(7 \mathrm{kV})$ is used to keep the excitation volume within the particles and to improve imaging. Secondary electron imaging (at 10,000x magnification) and derived binary images are used to locate and measure the size of each particle. The image analysis consists of acquiring 25 digital images of each field of view, then averaging them to remove noise. 
After an average image has been formed, individual ash particles are automatically sized, then analyzed for chemical composition using energy-dispersive $x$-ray spectrometry (EDS). The system is configured to detect $\mathrm{Na}, \mathrm{Mg}, \mathrm{Al}, \mathrm{Si}, \mathrm{P}, \mathrm{S}, \mathrm{Cl}, \mathrm{K}, \mathrm{Ca}, \mathrm{Fe}, \mathrm{Ba}$, and $\mathrm{Ti}$. Spectra are acquired for 15 seconds at $300 \mathrm{pA}$. A relatively low beam current is used to minimize sample damage. Spectra collected using these parameters generally contain sufficient $x$-ray counts to identify the elemental composition of most submicron particles. The use of a low accelerating voltage results in decreased detection efficiency for many metals, but this does not detract from the analysis of typical submicron particles.

Region-of-interest (ROI) integrated counts and particle-sizing information is saved in the ADEM computer as each field of view, containing approximately 20 individual ash particles, is completed. The light loading of particles is necessary to prevent electron beam overlap onto adjacent particles during analysis. Currently, only approximately 200 particles per sample are analyzed because of the operator time required to manually select each field of view.

- Data Reduction

After each sample analysis is complete, the data files are transferred to the TracorNorthern TN-8500 computer and reduced using the same routines applied to CCSEM data (7). The particle classification program PARTCHAR, developed at the University of North Dakota EERC, was modified to apply more specifically to submicron particles through the inclusion of more sulfate-, phosphate-, and chloride-bearing types and fewer metal-rich types.

\section{- RESULTS AND DISCUSSION}

Fly ash samples produced from Eagle Butte coal and from a blend of Eagle Butte (70\%) and Kentucky No. $9(30 \%)$ coals were analyzed to test the SEM-IA method. The tests were designed to investigate any sampling bias and to compare SEM-IA with CCSEM results for identical samples.

- Morphology

Visual inspection of the freeze-dried sample preparations in the ADEM shows that many submicron particles are present. In some instances, several submicron particles are fused together, forming irregularly shaped aggregates. Such aggregates are common in fly ash and probably form at elevated temperatures prior to emission (8, 9). Alternatively, vapor-phase condensation may have occurred following aggregation, smoothing the spherule surfaces together through deposition of coatings. No attempt was made to break up these aggregates, as this would alter the size distribution of the original sample.

\section{- Test of Sampling Bias: Eagle Butte Ash}

It is possible that operator selection of fields of view could result in overrepresentation of the smallest particles. However, large agglomerated groupings of particles are sometimes present in the sample preparation (probably the result of overloading the sample suspension), and so some operator discretion is necessary. A single freeze-dried preparation of Eagle Butte fly ash was analyzed twice using the 
SEM-IA method: first using fields of view selected because they contained relatively high proportions of submicron particles, then using randomly selected areas.

Size distributions for the two runs are shown in Figure 3.1-1. The results were similar, with both size distributions peaking at a particle diameter of $0.4 \mu \mathrm{m}$. The run emphasizing submicron particles has a second peak at a particle diameter of $25 \mu \mathrm{m}$, indicating large particle agglomerates were encountered in the areas analyzed. As mentioned above, these agglomerates are an artifact of the sample preparation procedure. The agglomerates are readily identified by their size distribution curve, which is distinctly separate from the curve representing the submicron particles and can easily bo removed from the data set after the analysis is completed.

The results of these two runs suggest that the true size distribution of the sample is accurately measured by the SEM-IA method. The peak at diameter $0.4 \mu \mathrm{m}$ may indicate a uniformity of ash formation processes leading to a consistent particle size.

\section{- Comparison of SEM-IA and CCSEM Methods: Eagle Butte Ash}

In order to directly compare SEM-IA and CCSEM results, the same freeze-dried dispersion of Eagle Butte fly ash was analyzed using both SEM-IA and CCSEM. In addition, a standard dispersion of the same ash sample was prepared and analyzed using CCSEM. Results are shown in Table 3.1-2. Particle compositions for the SEM-IA and CCSEM analyses are completely different, whereas the results for the two CCSEM runs are similar. Particles detected using SEM-IA are predominantly sulfate-, phosphate-, and chloride-rich, whereas those detected through CCSEM represent an assortment of minerals, mostly Ca-rich, including $\mathrm{Ca}$ aluminate, $\mathrm{Ca}$ silicate, gypsum/Al-silicate, $\mathrm{Ca}-\mathrm{Al}$ silicate, and others. A minor number of sulfate-rich particles were also detected through CCSEM.

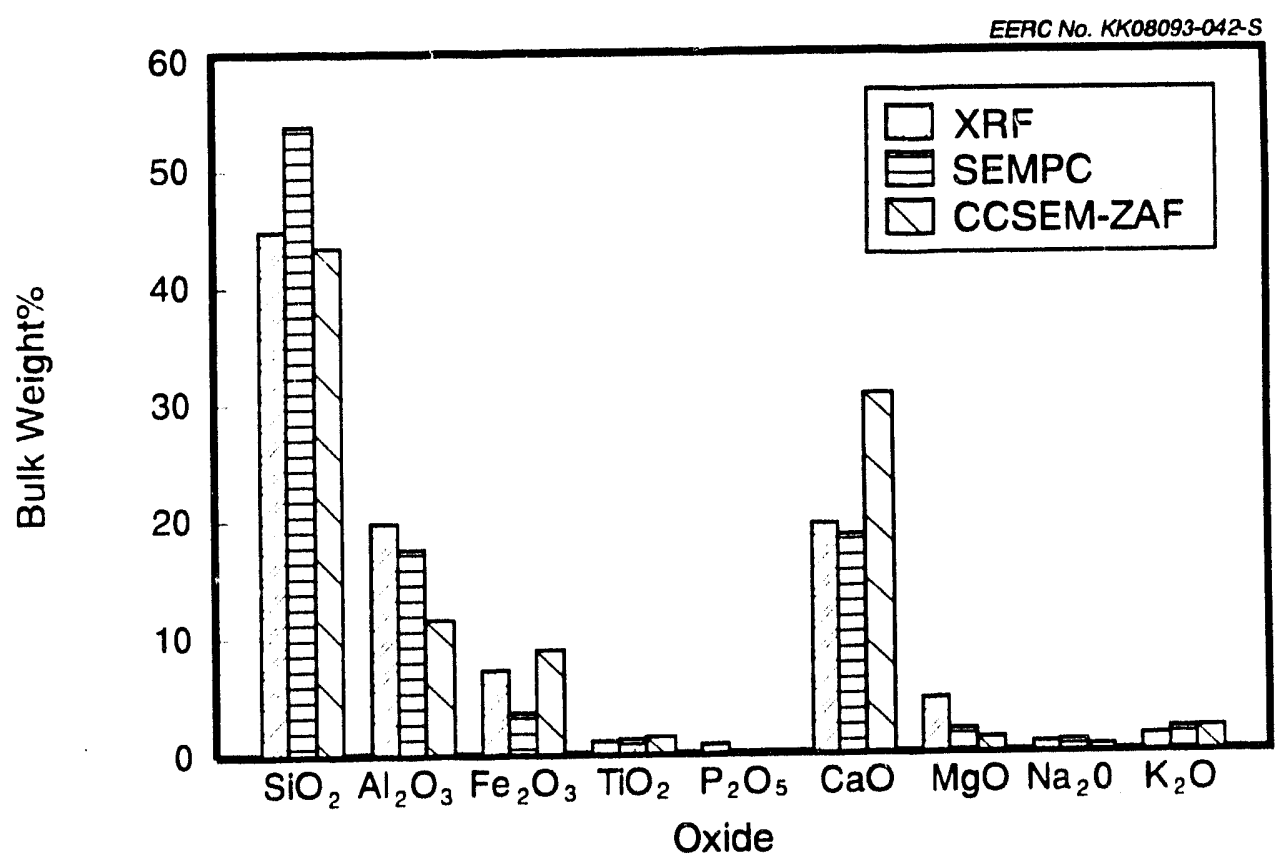

Figure 3.1-1. Size distributions for SEM-IA results for Eagle Butte ash, using a freeze-dried sample preparation. 
TABLE 3.1-2

Compositions, in Weight Percentages, for Eagle Butte Fly Ash

\begin{tabular}{lccc}
\hline $\begin{array}{c}\text { Particle } \\
\text { Type }\end{array}$ & $\begin{array}{c}\text { SEM-IA Run } \\
\text { (freeze-dried) }\end{array}$ & $\begin{array}{c}\text { CCSEM Run } \\
\text { (freeze-dried) }\end{array}$ & $\begin{array}{c}\text { CCSEM Run } \\
\text { (standard) }\end{array}$ \\
\hline Quartz & 0 & 3.8 & 6.5 \\
Iron Oxide & 0 & 1.6 & 0.2 \\
Periclase & 1.6 & 0 & 0 \\
Alumina & 0 & 0.3 & 0 \\
Calcite & 0 & 0.7 & 0.8 \\
Dolomite & 0 & 3.0 & 5.0 \\
Kaolinite & 0 & 1.5 & 0 \\
Ca Al-Silicate & 0 & 5.0 & 6.2 \\
Na Al-Silicate & 0 & 4.3 & 2.3 \\
Mixed Al-Silicate & 0 & 1.6 & 1.1 \\
Ca Silicate & 0 & 6.5 & 2.6 \\
Ca Aluminate & 0 & 17.3 & 24.4 \\
Sulfate-Rich & 42.7 & 2.0 & 1.3 \\
Phosphate-Rich & 16.2 & 0 & 0 \\
Chloride-Rich & 11.4 & 0 & 0 \\
Gypsum/Al-Silicate & 0 & 5.8 & 2.8 \\
Si-Rich & 0 & 0.6 & 1.6 \\
Ca-Rich & 0 & 5.9 & 2.9 \\
Ca-Si-Rich & 0 & 2.2 & 2.6 \\
Unknown & 28.1 & 37.7 & 39.9 \\
TOTALS & 100.0 & 100.0 & 100.0 \\
\hline
\end{tabular}

The compositional variations between the SEM-IA and CCSEM data sets reflect the different size ranges represented by the two types of analyses. In the SEM-IA run, the maximum particle dianictor in Table 3.1.2 was $1.6 \mu \mathrm{m}$. Large agglomerates, with diameters of $25 \mu \mathrm{m}$ and greater, are sample preparation artifacts and were not included in the table. The CCSEM analyses include only particles with diameters $>1 \mu \mathrm{m}$, and so most of the particles detected using SEM-IA would not be included in the CCSEM results.

It is less clear why the SEM-IA results do not include many particles with diameters in the low end of the CCSEM size range, i.e., those with diameters of 2 to $10 \mu \mathrm{m}$.

Apparently the fields of view selected for SEM-IA analysis contained few or no particles in this range, in contrast to the areas used for CCSEM. Only a very small area of the sample was used to obtain data for 226 particles through SEM-IA. The CCSEM analysis of the same freeze-dried preparation included a much larger area (at lower magnification), yielding data for 453 particles. The CCSEM analysis of the standard dispersion included 1013 particles. In the future, SEM-IA runs will be lengthened to make them more directly comparable with CCSEM analyses. 
The distinct compositional variation between the submicron size fraction (as measured using SEM-IA) and the supermicron fraction (measured using CCSEM) confirms that they are formed through different processes. Condensation of alkali vapors is evidently the primary mechanism for formation of submicron particles, while the mineralrich content of the supermicron particles indicates they probably formed through decomposition and fragmentation.

- Comparison of SEM-IA and CCSEM Methods: Eagle Butte/Kentucky No. 9 Blend Ash

The SEM-IA method was also evaluated by comparison with CCSEM results for ash from the Eagle Butte/Kentucky No. $970 \% / 30 \%$ blend. In this case, a freeze-dried dispersion was analyzed using SEM-IA, and a standard dispersion prepared from the same sample was analyzed using CCSEM (Table 3.1-3). As for the Eagle Butte ash samples discussed above, the results for the blend ash show distinct size-related compositional variations. The SEM-IA results, which include data for particles with a maximum diameter of $1.6 \mu \mathrm{m}$ only, are dominated by sulfates, phosphates, and chlorides. No typical coal minerals were identified in the SEM-IA data set. Almost half of the particles identified using SEM-IA did not fit into any of the defined compositional categories and were thus classified as "unknown." These unclassified particles contain $\mathrm{Si}, \mathrm{Al}, \mathrm{Mg}, \mathrm{Ca}$, $\mathrm{Na}, \mathrm{S}, \mathrm{Cl}$, and other elements in varied proportions and may represent coated mineral particles.

The CCSEM data for the blend ash indicate a range of minerals. As for the Eagle Butte ash, the mass of the blend ash analyzed using CCSEM is concentrated in particles with diameters from 1 to $10 \mu \mathrm{m}$. The CCSEM results for the blend ash indicate more sulfate-rich particles and fewer $\mathrm{Ca}$-bearing particles than do the results for the Eagle Butte ash.

\section{CONCLUSIONS}

SEM-IA results clearly indicate a size-related shift in composition, from mineral-rich particles in the supermicron fractions, to sulfate-, phosphate-, and chloride-rich particles in the submicron fractions of both Eagle Butte and Eagle Butte/Kentucky No. 9 blend ashes. The distinct compositions of the two size fractions confirm that they form through different processes, probably primarily fragmentation and coalescence for the supermicron particles and vaporization and condensation for the submicron particles. The unique compositions of particles in the submicron fraction suggest that individual-particle analysis of these smallest particles is essential to achieving an overall understanding of the transformations occurring during combustion.

\section{ASH TRANSPORT AND DEPOSIT INITIATION AND GROWTH}

The specific goals for the first year are to 1) conduct a literature search on the areas of ash transport, deposit initiation, and ash deposition; 2) perform modifications to the ODTF, including a second furnace, convective pass simulator, gas analyzers, and improved computer control and image analysis capabilities; 3) perform studies of deposit initiation; 4) develop transport algorithm to determine sticking fractions of entrained particulate; and 5) determine deposit growth rates. 
TABLE 3.1-3

Compositions, in Weight Percentages, for Eagle Butte/Kentucky No. 9 Blend Ash

\begin{tabular}{lcc}
\hline Particle Type & SEM-IA (freeze-dried) & CCSEM (standard) \\
\hline Quartz & 0 & 6.5 \\
Iron Oxide & 0 & 0.5 \\
Rutile & 0 & 0.1 \\
Alumina & 0 & 0.1 \\
Calcite & 0 & 1.4 \\
Ankerite & 0 & 0.2 \\
Kaolinite & 0 & 6.3 \\
Montmorillonite & 0 & 1.8 \\
K Al-Silicate & 0 & 0.5 \\
Fe Al-Silicate & 0 & 3.9 \\
Ca Al-Silicate & 0 & 9.2 \\
Na Al-Silicate & 0 & 9.7 \\
Aluminosilicate & 0 & 0.1 \\
Mixed Al-Silicate & 0 & 2.4 \\
Ca Silicate & 0 & 1.9 \\
Ca Aluminate & 0 & 1.4 \\
Sulfate-Rich & 24.5 & 17.7 \\
Phosphate-Rich & 13.4 & 0 \\
Chloride-Rich & 14.7 & 0 \\
Gypsum/Al-Silicate & 0 & 3.0 \\
Si-Rich & 0 & 3.0 \\
Ca-Rich & 0 & 0.1 \\
Ca-Si-Rich & 0 & 0.6 \\
Unknown & 47.4 & 29.4 \\
TOTALS & 100.0 & 100.0 \\
\hline
\end{tabular}

- Literature Search of Ash Transport, Deposit Initiation, and Ash Deposition

As part of the program to develop an understanding of ash transport and deposition, as well as to assist in the development of the transport algorithms, a literature search will be conducted covering the topics of ash transport, deposit initiation, and ash deposition. Data from the literature will supplement the ongoing experimental deposition program, and literature transport and deposition models will be examined for approaches and features of interest to the ash transport and deposition algorithms under development.

A preliminary literature survey has been completed, covering much of the recent literature. This will serve as a starting point for keywords, authors, and references to significant articles for the more comprehensive literature search. A summary of the literature is given in the references. 


\section{- Modifications to the ODTF}

The ODTF is a laboratory-scale, entrained-flow, vertical downfired tube furnace with the ability to combust coal and produce ash under closely controlled conditions. Combustion parameters such as initial hot zone temperature, residence time, and gas cooling rate can be closely controlled and monitored. The furnace is equipped with an optical section in which a deposition probe can be inserted. This optical section allows visual monitoring of deposit formation and in situ strength adhesion measurements of the deposit on the probe. The optical access section allows in situ temperature measurements by optical pyrometry and entrained particle size determinations by near-forward-angle laser scattering. Collection of entrained ash and process gas analyses can also be performed in conjunction with deposition tests.

The furnace system is housed in a laboratory that provides a clean environment for operation of the system. The furnaces are mounted on a common furnace bar and can be reconfigured to accommodate specific applications. The furnace system is designed for gas flow rates of 5 standard liters per minute. Oxygen and nitrogen mass flow controllers vary the oxygen concentration of the primary and secondary gas from $0-21 \%$. Flowmeters split the gas mixture from the flow controllers between primary and secondary air. Approximately one liter/minute of the gas mixture is used for primary air, and the remaining is introduced into the furnace as preheated secondary air. The unheated primary air (used as the sample carrier gas) entrains the coal from the sample feeder and carries it through the injector into the furnace. The secondary air is preheated before it enters the furnace through the top of the reactor tube.

The furnace assembly consists of a $2 \frac{1}{2}$ " ID alumina reaction tube heated externally by a series of tube furnaces illustrated in Figure 3.1-2. These furnaces possess a total of five independently controlled, electrically heated zones. This provides maximum flexibility and precise control over combustion conditions. A preheat furnace heats the secondary air before it enters the reaction tube. A split shell, two-zone furnace provides the heat for obtaining the desired reaction zone temperature. A bottom furnace is utilized to maintain the temperature of the collection zone located in the optical access section. Coal and primary air are introduced into the furnace system by means of a water-cooled injector. This injects ambient temperature primary air and coal into the furnace at the center of the tube. Secondary air is typically heated to $1000^{\circ} \mathrm{C}$ and introduced into the furnace through the top of the alumina tube and travels down through the tube around the injector. The material to be combusted is introduced into the furnace with the primary air through the injector and combines with the preheated secondary air. The coal and gas travel down the furnace in a laminar flow regime and pass through an accelerator just above an optical access section where the deposition probe is located. The ash not adhering to the probe and the combustion gases flow into a water-cooled particulate collection probe located below the optical access section where they are quenched with nitrogen. The fly ash quenching probe is attached to the bottom of the drop-tube furnace to cool the fly ash before collection. This system is reliable and versatile. Ash collection devices can be added to the probe such as a multicyclone and impactor to size segregate the ash. Bulk ash is collected on a filter placed in a $21 / 2$ " filter holder. 


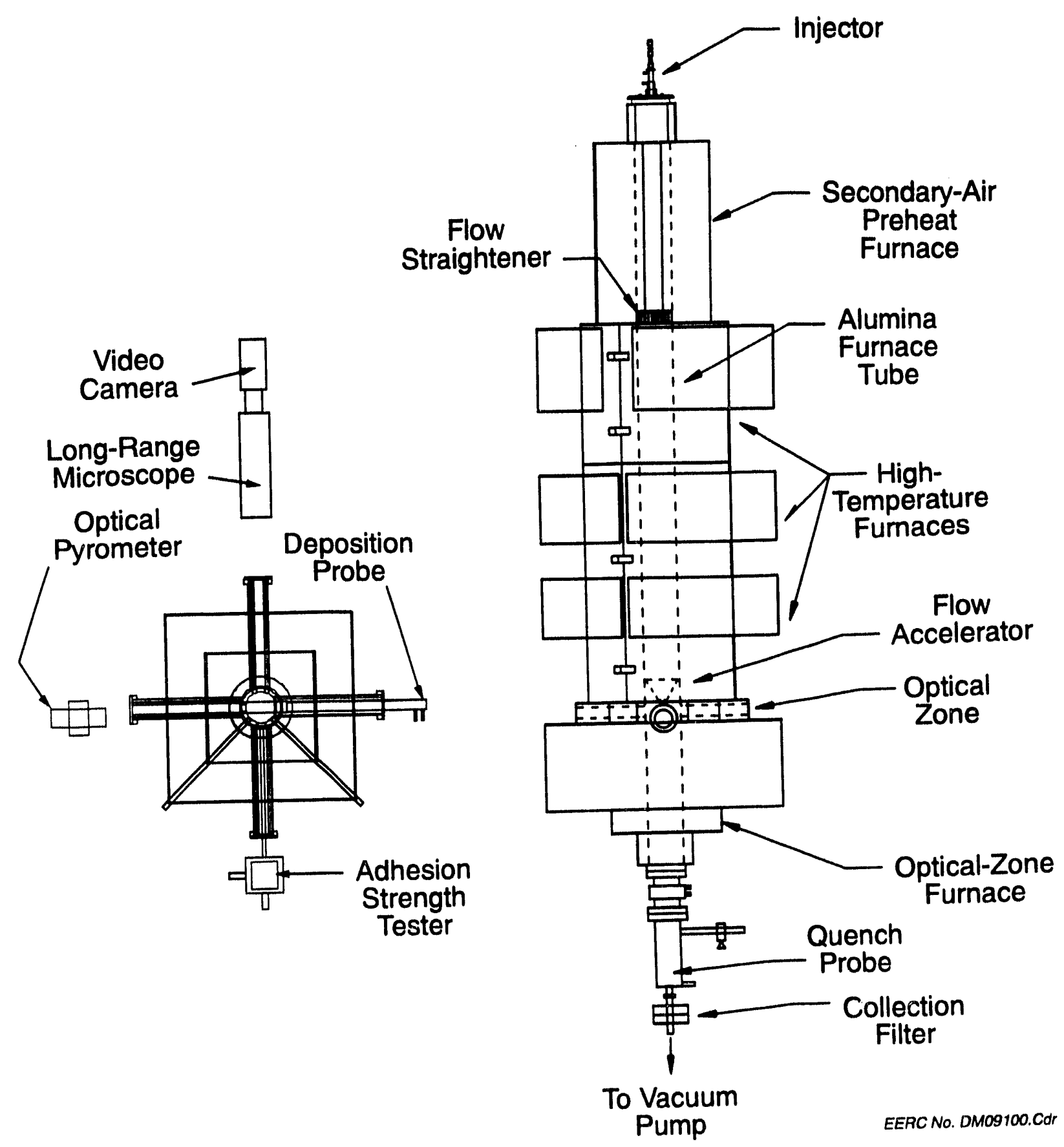

Figure 3.1-2. Optical access drop-tube furnace.

Downstream of the sampling probe and collection filter, the combustion gas is cooled and passes through a filter before it enters an airtight diaphragm pump. The gas leaving the positive pressure side of the pump is passed through a flowmeter, which measures the volume of gas being pulled through the probe.

The coal feed system is designed to feed particles of various sizes in the pulverized coal range at rates of 0.05 to $0.5 \mathrm{~g}$ per minute and at primary carrier gas rates of approximately one liter per minute. The basic apparatus consists of a pressurized cylinder in which a container filled with coal is placed. A rotating brush and stirrer attached to a variable-speed motor feeds the coal from the container into a funnel where it 
is transported through the feed tubing into the furnace injector by the carrier gas. The coal feeder is mounted on a Mettler top-loading balance that monitors real-time coal feed rates. The balance is connected via an RS232 to a computer that records the feed rate.

The ODTF deposition probe, as shown in Figure 3.1-3, is designed to simulate a boiler tube typical of those found in full-scale utility boilers. The probe is designed to maintain a sacrificial sample coupon attached to the probe at a specific temperature. This is accomplished by aspirating water with nitrogen in an inner shell that houses the coupon. Provisions have been made for achieving and controlling the coupon temperature over a broad temperature range by adjusting, or fine tuning, the nitrogen/water mixture in the deposition probe. The deposition probe consists of three basic parts: a series of annular tubes in an inner shell that carry the nitrogen and water to and from the probe, an outer shell that houses the inner shell, and, to which is attached the end of, the probe that accepts the sample coupon. The deposits are grown on the end of the deposition probe which consists of a machined 304 SS tube 2.625" long x $0.875 "$ OD x 0.5" ID. Dovetailed slots are cut into the top middle of the probe to accept the sacrificial coupons that can be machined from any desired metal. The coupon has a flat base which measures $0.5^{\prime \prime}$ wide $x 1^{\prime \prime}$ long and is $0.1^{\prime \prime}$ at its thickest part. The upper surface is curved, matching the radius of the deposition probe. A hole is drilled in the end of the coupon aligned with a hole in the probe to accept a 0.020 " type $\mathrm{K}$ thermocouple, which provides the temperature measurement. The probe is welded to the outer shell, and the inner shell consists of a series of annular tubes that provide the aspirated water to cool the probe end and also help keep the outer shell cool. The nitrogen and mist water flow back along the probe in the space between the inner and outer probe shells and exit to a drain line. The outer shell is insulated with a high-temperature insulation to minimize temperature loss in the optical zone and to help keep the shell from oxidizing. It also provides a sheath that covers the thermocouple that leads to the coupon. A constrictor is used to accelerate the gas flow to approximately $15 \mathrm{~m} / \mathrm{sec}$ before it impinges on the deposit probe. The constrictor is made of a 11/2"-thick disk of alumina insulation board (Zircar AL-30) 2-5/16" in diameter. A $0.25 "$ hole is drilled in the center and beveled out from inside to approximately 45 degrees to form the nozzle. The deposit probe is located 1.0 " below the constrictor.

The temperature of the coupon mounted on the probe is maintained at a selected temperature between $350^{\circ}$ and $540^{\circ} \mathrm{C}$ to simulate a boiler heat-transfer surface when the air and water cooling flows are adjusted. Coupon temperature is monitored by a type $K$ thermocouple in contact with the middle of the coupon, which provides feedback to regulate the probe cooling air flow.

Samples are tested in the drop-tube furnace to determine sticking coefficients, deposit strengths, and deposit compositions. The combustion conditions have been designed to mimic full-scale boiler fouling and slagging conditions. Particle residence times and gas cooling rates can be varied to simulate specific slagging/fouling regions of interaction within the boiler.

A fourth high-temperature furnace has been installed on the optical access drop-tube furnace, shown in Figure 3.1-2. This will allow longer particle residence times and higher particle velocities. At the same time, several other minor modifications and improvements were made to the ODTF. 


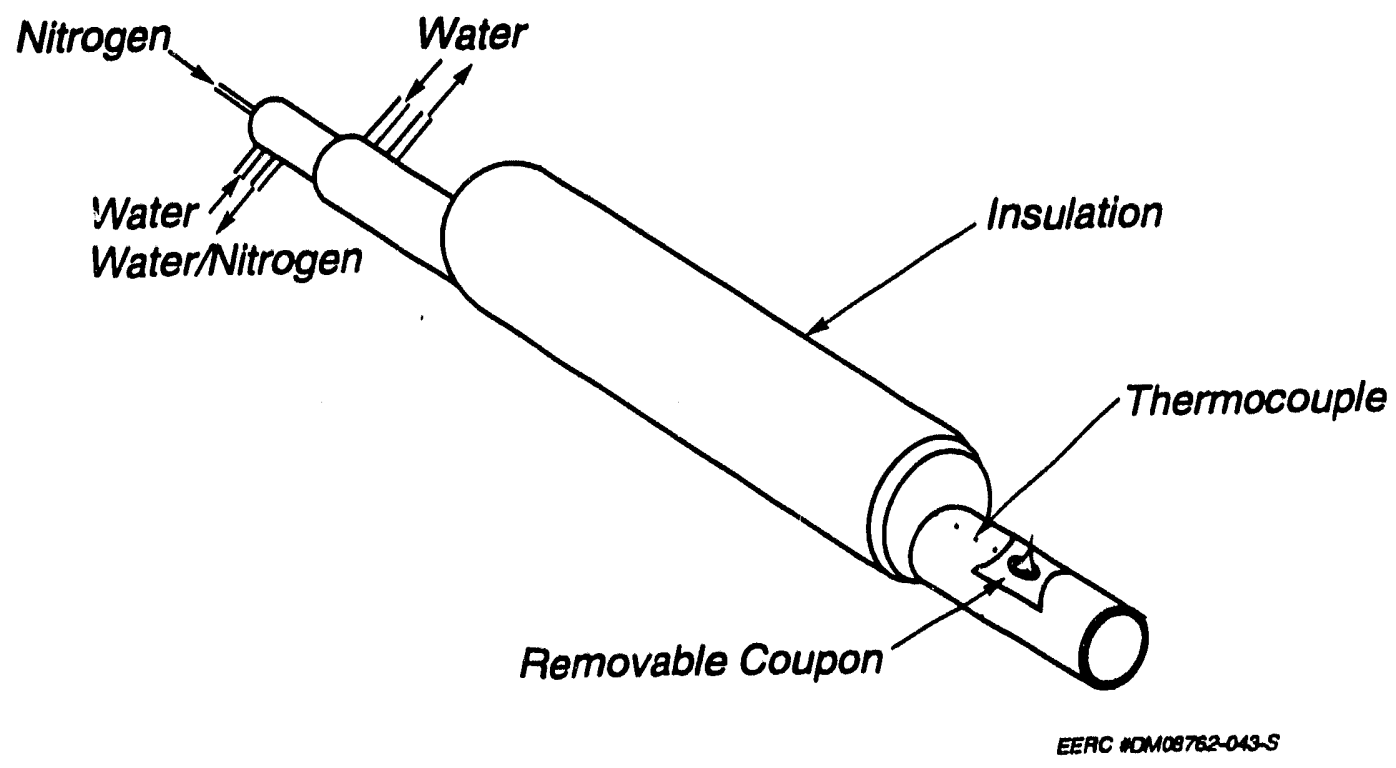

Figure 3.1-3. Ash deposition probe.

The conceptual design of the convective pass simulator (CPS) for the ODTF is shown in Figure 3.1-4. The purpose of the CPS is to trap and remove the larger particulate material in the high-temperature region of the furnace, while allowing finer particulate material to continue on and impact the deposition probe. This will more closely simulate the conditions in the convective pass of a utility boiler. As envisioned, the CPS is a ceramic single-stage impactor that can be readily inserted and removed from the main furnace tube. Larger particles will be collected in a removable impactor cup, probably as a slag, while the smaller particles will follow the gas stream and impact the probe.

Evaluation of gas analyzer specifications and image analysis hardware and software is currently underway to determine the most cost-effective components to purchase. Improvements to the computer control of the ODTF are being made, including an interface to allow the computer to monitor and control the coal feed rate.

\section{- DEPOSIT INITIATION STUDIES}

The process of coal ash deposition on heat-transfer surfaces has long been a subject of practical as well as academic interest. Of particular interest is the manner by which an ash deposit first begins to form-the initial adhesion of ash particles to the metal heattransfer surfaces. Ash deposition occurs by the mechanisms of inertial impaction, thermophoresis, and condensation. Of these, inertial impaction is the dominant mode of deposition and of primary interest. Fundamental studies by Austin and others first 


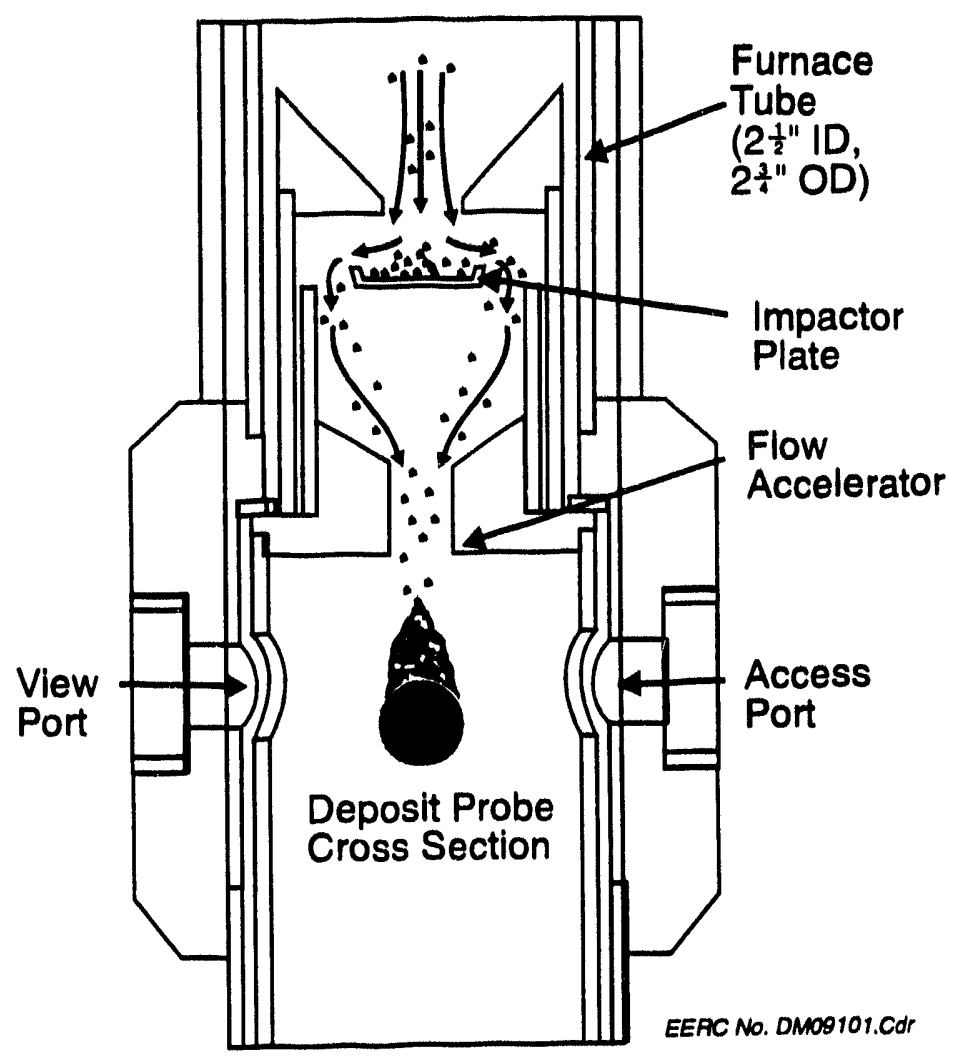

Figure 3.1-4. Conceptual design of convective pass simulator.

identified the factors contributing to the sticking of coal slags to steel surfaces (10-15). The factors included both particle substrate composition and temperature. Subsequent studies examining deposit initiation in a drop-tube furnace using actual coals were performed by Abbott and Austin (16) and Benson and Austin (17). Particles with significant concentrations of iron, iron and sulfur, iron and silicon, calcium and sulfur, calcium and phosphorus, barium, barium and sulfur, and strontium and sulfur were found to form strongly adhering initial deposits. Srinivasachar, Helble, and Boni (18), in experiments with synthetic ashes and a San Miguel coal under effectively slagging conditions, identified the particle viscosity as the dominant factor in ash deposition. Further, they identified a "critical" viscosity above which little or no deposition occurred and noted that the critical viscosity for adhesion was inversely proportional to particle kinetic energy. It should be noted, however, that particle impaction efficiency is directly proportional to particle size and mass. Thus the process of deposition may be seen as a process between the competing requirements for particle impaction and particle adhesion.

\section{- RESULTS}

Five coals were used in the deposit initiation tests: Pittsburgh No. 8, Illinois No. 6, and Utah Blind Canyon bituminous coals; a Dietz western subbituminous coal; and a lowrank Beulah-Zap lignite. Bulk ash compositions from $x$-ray fluorescence analysis for the coals are given in Table 3.1-4. Particle mineral phases, as determined from CCSEM 
TABLE 3.1.4

\section{Bulk Ash Composition}

\begin{tabular}{lccccc}
\hline & $\begin{array}{c}\text { Dietz, } \\
\text { wt\% }\end{array}$ & $\begin{array}{c}\text { Utah Blind } \\
\text { Canyon, } \\
\text { wt\% }\end{array}$ & $\begin{array}{c}\text { Illinois No. 6, } \\
\text { wt\% }\end{array}$ & $\begin{array}{c}\text { Pittsburgh No. 8, } \\
\text { wt\% }\end{array}$ & $\begin{array}{c}\text { Beulah-Zap, } \\
\text { wt\% }\end{array}$ \\
\hline $\mathrm{SiO}_{2}$ & 36.0 & 45.9 & 43.7 & 45.9 & 21.5 \\
$\mathrm{Al}_{2} \mathrm{O}_{3}$ & 20.8 & 16.6 & 18.3 & 25.2 & 13.5 \\
$\mathrm{Fe}_{2} \mathrm{O}_{3}$ & 4.9 & 10.0 & 18.0 & 19.5 & 10.8 \\
$\mathrm{TiO}_{2}$ & 2.2 & 1.2 & 1.0 & 1.2 & 1.0 \\
$\mathrm{P}_{2} \mathrm{O}_{5}$ & 0.7 & 0.3 & 0.2 & 0.0 & 0.9 \\
$\mathrm{CaO}$ & 13.3 & 9.9 & 7.9 & 2.6 & 16.1 \\
$\mathrm{MgO}$ & 4.5 & 1.5 & 1.2 & 1.3 & 4.0 \\
$\mathrm{Na}_{2} \mathrm{O}$ & 2.2 & 3.6 & 0.0 & 0.0 & 6.2 \\
$\mathrm{~K}_{2} \mathrm{O}$ & 0.3 & 1.2 & 2.9 & 2.1 & 0.2 \\
$\mathrm{SO}_{3}$ & 14.9 & 9.8 & 6.8 & 2.0 & 25.7 \\
$\mathrm{Total}_{\text {Ash }}$ & 4.6 & 6.1 & 16.6 & 9.3 & 6.9 \\
\hline
\end{tabular}

analysis, are given for the coals in Table 3.1.5. In general, the Illinois No. 6 and Pittsburgh No. 8 are representative of eastern bituminous coals with high pyrite content. The Dietz and Utah Blind Canyon coals are typical of the western subbituminous and bituminous coals with substantial aluminosilicate and gypsum content and lower pyrite content. The Dietz coal also has a relatively high level of barite $(5 \%$ of the mineral content). The Beulah-Zap lignite coal sample has a high level of organically bound sodium that may play a role in deposit initiation. The percentages of included and excluded mineral content in the coals are given in Table 3.1.6. Approximately half of the pyrite in the Pittsburgh No. 8 and Illinois No. 6 coals is classified as included, as is a third of the pyrite in the Dietz and Utah Blind Canyon coals.

Preliminary deposition tests indicated that the substrate quickly became covered with a layer of loosely adhering, easily removed ash. This ash prevented particles that might have been strongly adhering from reaching the substrate surface. A miniature soot blower was incorporated with the deposition probe to remove loosely adhering ash by periodically blowing off the substrate plate with puffs of nitrogen gas. The soot blowing was done at 1-min intervals during the course of deposit formation.

Downstream of the deposition probe, the gas stream was cooled and quenched with nitrogen gas before it passed through a filter. The filter collects entrained ash that has bypassed the deposition probe. 
TABLE 3.1.5

Coal Mineral Content

\begin{tabular}{|c|c|c|c|c|c|}
\hline & $\begin{array}{c}\text { Dietz, } \\
\text { wt\% }\end{array}$ & $\begin{array}{c}\text { Utah Blind } \\
\text { Canyon, } \\
\text { wt\% }\end{array}$ & $\begin{array}{l}\text { Illinois } \\
\text { No. } 6 \text {, } \\
\text { wt\% }\end{array}$ & $\begin{array}{c}\text { Pittsburgh } \\
\text { No. 8, } \\
\text { wt\% }\end{array}$ & $\begin{array}{c}\text { Boulah. } \\
\text { Zap. } \\
\text { wt\% }\end{array}$ \\
\hline Quartz & 15.4 & 14.9 & 10.9 & 14.7 & 18.0 \\
\hline Iron Oxide & 2.9 & 4.0 & 0.3 & 0.7 & 1.4 \\
\hline Aluminosilicate & 39.9 & 22.6 & 9.0 & 25.4 & 41.7 \\
\hline Ca-Aluminosilicate & 1.7 & 0.3 & 0.0 & 0.2 & 0.2 \\
\hline Fe-Aluminosilicate & 0.0 & 1.3 & 2.6 & 1.2 & 0.3 \\
\hline K-Aluminosilicate & 8.0 & 16.5 & 17.2 & 25.0 & 0.8 \\
\hline Ankerice & 0.0 & 0.8 & 0.0 & 0.1 & 0.0 \\
\hline Pyrite & 13.9 & 14.4 & 40.2 & 25.5 & 25.7 \\
\hline Gypsum & 3.9 & 3.2 & 9.6 & 0.3 & 2.1 \\
\hline Barite & 5.5 & 0.2 & 0.0 & 0.0 & 1.6 \\
\hline Gypsum.Barite & 0.1 & 0.0 & 0.0 & 0.0 & 0.3 \\
\hline Ca-Silicate & 0.1 & 0.2 & 0.0 & 0.0 & 0.1 \\
\hline Aluminosilicate-Gypsum & 0.0 & 0.2 & 0.2 & 0.1 & 0.0 \\
\hline Alumina & 0.0 & 0.2 & 0.0 & 0.0 & 0.4 \\
\hline Calcite & 1.0 & 7.8 & 5.3 & 0.8 & 0.1 \\
\hline Rutile & 0.3 & 0.1 & 0.2 & 0.0 & 0.3 \\
\hline Dolomite & 0.0 & 0.2 & 0.0 & 0.0 & 0.0 \\
\hline Ca-Rich & 0.0 & 1.2 & 0.0 & 0.1 & 0.0 \\
\hline Si-Rich & 0.9 & 5.9 & 0.5 & 0.4 & 0.3 \\
\hline Periclase & 0.0 & 0.1 & 0.0 & 0.0 & 0.0 \\
\hline Unknown & 6.4 & 6.1 & 4.1 & 5.5 & 6.8 \\
\hline Coal, wt\% & 3.7 & 6.1 & 17.5 & 10.2 & 5.6 \\
\hline Total Ash & 4.6 & 6.1 & 16.6 & 9.3 & 6.9 \\
\hline
\end{tabular}


TABLE 3.1-6

Included Mineral Content in Five Coals

\begin{tabular}{|c|c|c|c|c|c|}
\hline & $\begin{array}{l}\text { Dietz, } \\
\text { wt\% }\end{array}$ & $\begin{array}{c}\text { Utah Blind } \\
\text { Canyon, } \\
\text { wt\% }\end{array}$ & $\begin{array}{c}\text { Illinois } \\
\text { No. 6, } \\
\text { wt\% }\end{array}$ & $\begin{array}{c}\text { Pittsburgh } \\
\text { No. 8, } \\
\text { wt\% }\end{array}$ & $\begin{array}{c}\text { Beulah-Zap, } \\
\text { wt } \%\end{array}$ \\
\hline Quartz & 34 & 35 & 53 & 48 & 49 \\
\hline Iron Oxide-Siderite & 50 & 43 & 67 & 100 & 80 \\
\hline Aluminosilicate & 37 & 32 & 43 & 54 & 69 \\
\hline Ca-Aluminosilicate & 80 & 20 & 67 & 50 & 67 \\
\hline Fe-Aluminosilicate & 38 & 67 & 50 & 70 & 56 \\
\hline K-Aluminosilicate & 44 & 27 & 54 & 57 & 100 \\
\hline Ankerite & $\cdots$ & 56 & $\cdots$ & $\cdots$ & $\cdots$ \\
\hline Pyrite & 33 & 30 & 49 & 42 & 64 \\
\hline Gypsum & 35 & 37 & 54 & 50 & 67 \\
\hline Barite & 50 & 67 & 0 & $\cdots$ & $\cdots$ \\
\hline Gypsum-Barite & 0 & $\cdots$ & $\cdots$ & $\cdots$ & $\cdots$ \\
\hline Aluminosilicate-Gypsum & 100 & 60 & 80 & $\cdots$ & $-\cdots$ \\
\hline Calcite & 38 & 32 & 32 & 80 & 100 \\
\hline Rutile & 0 & $\cdots$ & $\cdots$ & 100 & 33 \\
\hline Dolomite & -- & 0 & $\cdots$ & $\cdots$ & $\cdots$ \\
\hline Apatite & $\cdots$ & 100 & $\cdots$ & $\cdots$ & $\cdots$ \\
\hline Apatite-Crandallite & 50 & $\cdots$ & $\cdots$ & 50 & $\cdots$ \\
\hline Aluminosilicate-Rutile & 100 & 0 & $\cdots$ & $\cdots$ & $\cdots$ \\
\hline Aluminosilicate-Pyrite & 0 。 & 0 & 57 & 50 & 100 \\
\hline Aluminosilicate-Barite & 50 & $\cdots$ & $\cdots$ & $\cdots$ & 100 \\
\hline Gypsum-Quartz & -- & 100 & 75 & 60 & 50 \\
\hline Quartz-Calcite & $\cdots$ & 0 & 0 & 100 & 100 \\
\hline Quartz-Pyrite & $\cdots$ & 100 & 62 & 56 & 100 \\
\hline Quartz-Rutile & $\cdots$ & $\cdots$ & $\cdots$ & 50 & 100 \\
\hline K-Aluminosilicate-Pyrite & $\cdots$ & $\cdots$ & $\cdots$ & 25 & $\cdots$ \\
\hline Unknown & $\cdots$ & 33 & 50 & 67 & $\cdots$ \\
\hline
\end{tabular}


The furnace conditions chosen were 3.5-sec residence time, gas temperature at the coal injection point $-1500^{\circ} \mathrm{C}$, gas temperature at the deposition point $-1200^{\circ} \mathrm{C}$, and gas velocities at the collection point-approximately 2.6 and $10.6 \mathrm{~m} / \mathrm{sec}$. The change in gas velocity resulted from the introduction of an accelerator with a smaller nozzle diameter during the course of the tests. Nominal substrate temperatures of $500^{\circ} \mathrm{C}$ and oxygen concentrations of $21 \%$ oxygen (air), $12 \%$ oxygen, and $6 \%$ oxygen were tested. The strongly adhering initial deposits were isolated and examined for morphology and composition.

The ash deposits on the removable substrate were first examined visually with an optical stereomicroscope to determine the overall deposit morphology and to note any features of interest. The deposit was then brushed with a camel-hair brush to remove the loosely adhering portion of the ash deposit. After brushing, the substrate was then thoroughly blown off with a pressure can of freon (normally used for dusting optical and SEM components) to remove residual loose ash particles. The residual strongly adhering ash on the substrate was then visually examined with the stereomicroscope to determine morphology and features of interest prior to carbon coating and SEM examination.

Neither of the standard automated SEM image analysis procedures was well suited for determining the composition of the adhering particles. CCSEM had difficulty distinguishing discrete particles due to the poor contrast between the predominantly ironrich particles and the steel substrate. SEM point count (SEMPC), which assumes a continuous sample layer, could not be used due to the paucity of adhering particles.

A program was written allowing the operator to target a number of individual particles manually, the coordinates of which were stored, allowing the SEM analysis routine to return to each particle and perform analyses unattended. The individual ash particles were also sized manually during the course of the analysis.

Bulk ash samples collected from the filter of the drop-tube furnace sampling system were dispersed in epoxy as a slurry, allowed to hardened, and then cross-sectioned, polished, and analyzed by the normal CCSEM analysis methods.

- Initial Deposit Morphology

- Pittsburgh No. 8

All three varying oxygen level deposits showed numerous "spattered" or deformed particles. There were very few isolated single particles with no other ash particles connected. There was usually an anchoring ash particle with one or more additional particles attached to it. These attached particles varied from a deformed state to spherical. The anchoring particles seemed, on the average, to have a particle diameter greater than $25 \mu \mathrm{m}$, before correction for deformation. There was an order of ten increase in the number of initial particles from $6 \%$ and $21 \%$ to $12 \% \mathrm{O}_{2}$, possibly due to the higher gas velocity at $12 \% \mathrm{O}_{2}$.

\section{- Illinois No. 6}

Again, numerous spattered or deformed particles were present. More isolated single particles occurred in the Illinois No. 6 samples as compared to the Pittsburgh No. 8 samples. The anchoring particles were generally larger than the additional attached 
particles adhering to it. Also, the additional particles when smaller than approximately $20 \mu \mathrm{m}$ generally held their spherical shape. The 6\% and $21 \% \mathrm{O}_{2}$ samples had

approximately the same amount of particles, with the $21 \% \mathrm{O}_{2}$ samples having a few more clusters of particles or "ash islands" starting. Increasing velocity in the $12 \% \mathrm{O}_{2}$ had a profound effect on the sample. The increased velocity produced a large initial particle deposit with hundreds of additional attached particles. Scattered anchor particles were found all around a large ash island, which was not removed by the brushing and blowing. This sample was subsequently covered in epoxy and cross-sectioned normal to the substrate surface to show the ash island. The ash island showed evidence, as shown in Figure 3.1.5, of how anchoring particles start an ash island by the adhesion of other ash particles to the anchoring particle. These additional attached particles then melt as they build away from the cooled steel substrate surface, which causes the voids between the particles to be filled, thus strengthening the deposit.

- Dietz

There was very little deformation of the Dietz initial ash particles. Also, no significant ash islands occurred; most of the anchoring particles were isolated. The particles that did adhere to the anchoring particles tended to be rather small $(<15 \mu \mathrm{m})$. The change in velocity (both $12 \%$ and $21 \%$ had higher velocities) did not appear to affect the number or size of adhering ash particles, with all three samples appearing to have approximately the same number of adhering ash particles.

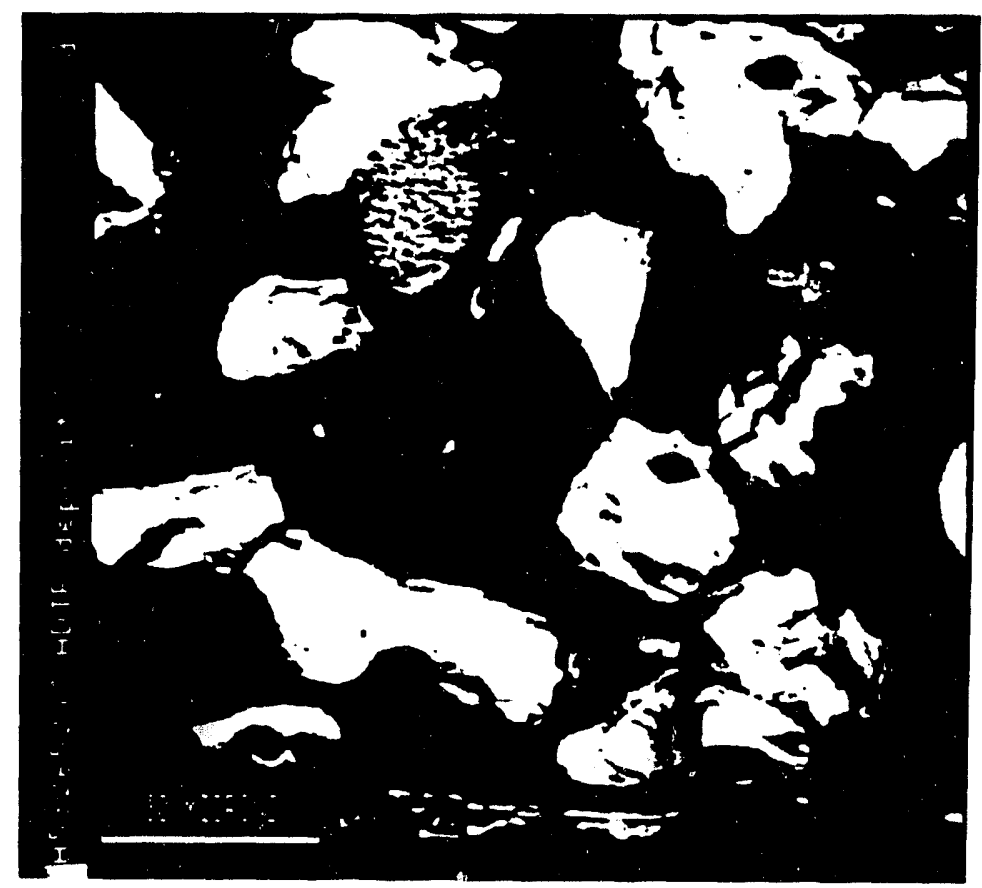

Figure 3.1-5. Cross section of Illinois No. 6 deposit ash island showing grey deformed ash particles adhering to the substrate at bottom of photo with other particles attaching to build the ash island. 
The Beulah deposit ash particles were all spherical, with crystalline growths appearing on some of the particles. The $6 \% \mathrm{O}_{2}$ sample ash particles were widely scattered, with only a very few of the anchoring particles having any additional attached particles, which were small. The $12 \% \mathrm{O}_{2}$ sample had considerably more particles, but, again, most of them were isolated, with no additional particles attached. A large amount of very fine loosely bonded particles, too small to analyze, covered the coupon around the anchoring particles. The Beulah deposit at $12 \% \mathrm{O}_{2}$ was not analyzed because of possible sample contamination.

\section{- Initial Deposit Composition}

Initial deposit particles were examined by SEMPC to determine size and composition. It was immediately noted that the initial deposits were dominated by groups of particles with quite narrow and similar ranges of composition. Table 3.1-7 gives a breakdown by major elemental compositions with size. Elements are listed when present in $10 \%$ or greater concentration. The Pittsburgh No. 8 deposits were composed primarily of iron particles, with a lesser number of particles containing $\mathrm{Fe}-\mathrm{Si}, \mathrm{Fe}-\mathrm{Ca}$, and $\mathrm{Fe}-\mathrm{Al}-\mathrm{Si}$. Illinois No. 6 deposits were also dominated by Fe particles, along with $\mathrm{Fe}$-Si and $\mathrm{Fe}-\mathrm{Al}-\mathrm{Si}$, and also had substantial numbers of Fe-Ca particles. The deposits were found, in the course of examination with the optical microscope, to contain numerous magnetic particles, presumably magnetite, which would be attracted to a steel probe used to manipulate the deposit.

The western coal ash deposits also contained significant numbers of Fe particles, but $\mathrm{Fe}-\mathrm{Ca}-, \mathrm{Si}-\mathrm{Ca}-, \mathrm{Al}-\mathrm{Ca}-\mathrm{Al}-\mathrm{Si}-\mathrm{Ca}$, Ba-S-, and $\mathrm{Ba}-$ containing particles are present in substantial quantities. Further, occasional $\mathrm{Si}$ and $\mathrm{Al}-\mathrm{Si}$ particles were present. The Beulah and Dietz deposits also had a loose coating of very fine, slightly sulfate-rich particulate. Particle sizes of this coating ranged from less than 1 micron to 3 microns. The Beulah coating was composed mostly of calcium aluminosilicate material enriched in $\mathrm{Na}, \mathrm{Mg}$, and Fe. The Dietz fine particulate, which was sparser than that of the Beulah, was primarily Ca-S-aluminosilicate rich. However, no unequivocal evidence was found for "gluing" by sulfate or sodium species.

\section{- Viscosity of Deposit Particles}

Morphological examination of the deposits revealed frequent examples of spattered or deformed adhering particles, indicating that the particle had impacted the substrate in a semimolten state, as shown in Figure 3.1-5. Viscosities were calculated based on the compositions obtained from SEMPC analysis of the deposits. Particle mass was estimated by treating the particle as a sphere, converting elemental composition to oxide composition, and calculating particle density from the oxide densities and composition. Plots of the cumulative percentage of total calculated deposit mass versus $\log _{10}$ viscosity in poise are shown for three of the initial deposits in Figures 3.1-6 through 3.1-8. In all cases, the initial deposits show that $80 \%$ to $90 \%$ of the total deposit mass falls into a very narrow viscosity range. The particle masses also fall into a somewhat broader, but still restricted range, as shown in the plots of $\log _{10}$ viscosity versus $\log _{10}$ mass in Figures 3.1-6 through 3.1-8. 


\begin{tabular}{|c|c|c|c|c|c|c|c|c|c|c|c|}
\hline \multirow{8}{*}{ 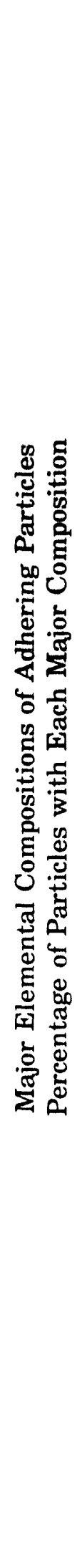 } & 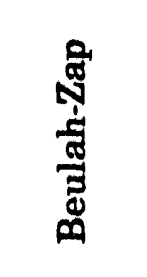 & $\begin{array}{l}\frac{8}{\mathrm{~N}} 0^{-1} \\
80 \\
80\end{array}$ & 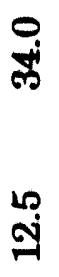 & 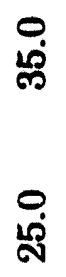 & $\underset{*}{*}$ & ขุ & ㅇ. & $\stackrel{0}{0}$ & $\stackrel{\circ}{0}$ & $\stackrel{ }{\circ}$ & \begin{tabular}{l}
5 \\
\multirow{2}{*}{}
\end{tabular} \\
\hline & 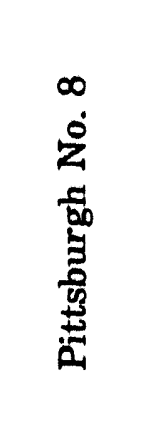 & 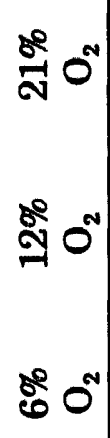 & 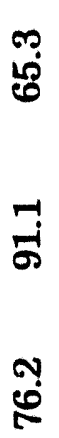 & $\begin{array}{l}\stackrel{0}{0} \\
\stackrel{-1}{n} \\
\stackrel{0}{0} \\
\stackrel{0}{0}\end{array}$ & $\begin{array}{l}\stackrel{0}{0} \\
\text { ơ }\end{array}$ & 5 & 웅 & $\stackrel{0}{0}$ & $\stackrel{0}{0}$ & 웅 & $\begin{array}{l}5 \\
5 \\
5 \\
0 \\
5\end{array}$ \\
\hline & 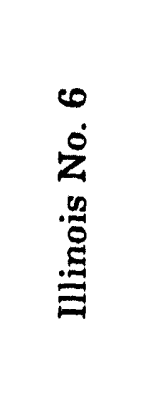 & 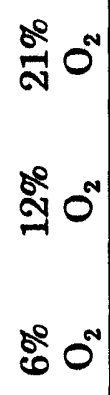 & 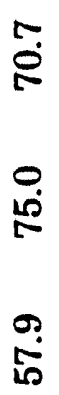 & 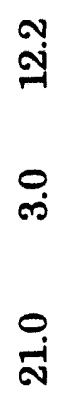 & مْ & 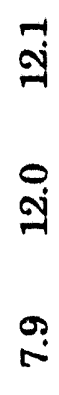 & 0 & $\begin{array}{l}0 \\
0 \\
0 \\
0 \\
0 \\
\stackrel{0}{0}\end{array}$ & $\begin{array}{l}\stackrel{0}{0} \\
\stackrel{0}{0} \\
0 \\
0\end{array}$ & $\begin{array}{l}\stackrel{0}{0} \\
\ddot{0}\end{array}$ & 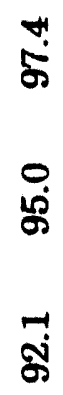 \\
\hline & 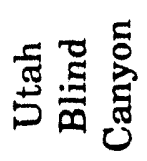 & $\Varangle 0^{N}$ & ஜ̊̊ి & $\begin{array}{l}0 \\
\not{q} \\
q\end{array}$ & $\stackrel{\circ}{\circ}$ & $\stackrel{0}{\circ}$ & $\overrightarrow{\text { ò }}$ & $\stackrel{0}{0}$ & $\stackrel{0}{0}$ & $\stackrel{\vartheta}{\forall}$ & ผั \\
\hline & & $\frac{\circ}{3} 0^{\circ}$ & $\stackrel{\not}{E}$ & $\underset{\text { Ju }}{\stackrel{N}{ }}$ & $\stackrel{0}{0}$ & $\stackrel{0}{0}$ & $\stackrel{0}{0}$ & $\stackrel{\circ}{\circ}$ & $\stackrel{\circ}{0}$ & $\stackrel{\circ}{0}$ & $\stackrel{0}{\infty}$ \\
\hline & 莡 & $\stackrel{\text { ఫ̊ }}{\circ}$ & $\stackrel{\circ}{\circ}$ & $\stackrel{\infty}{-}$ & $\stackrel{0}{0}$ & $\underset{-\infty}{\infty}$ & $\stackrel{\infty}{\infty}$ & $\stackrel{-1}{\infty}$ & $\stackrel{\circ}{0}$ & $\stackrel{\#}{\stackrel{+}{+}}$ & $\stackrel{\infty}{\infty}$ \\
\hline & & $\stackrel{8}{6}$ & कृ & कृ & $\stackrel{0}{0}$ & $\tilde{-1}$ & $\stackrel{0}{0}$ & जึ & कृ & هُ & ช્త \\
\hline & & 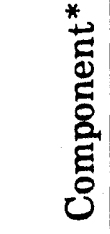 & 岂 & 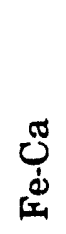 & is & $\begin{array}{l}7 \\
\dot{4} \\
0 \\
0 \\
0\end{array}$ & Zَّ & $\mathscr{m}$ & 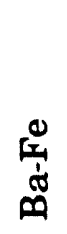 & صి & 졍 \\
\hline
\end{tabular}




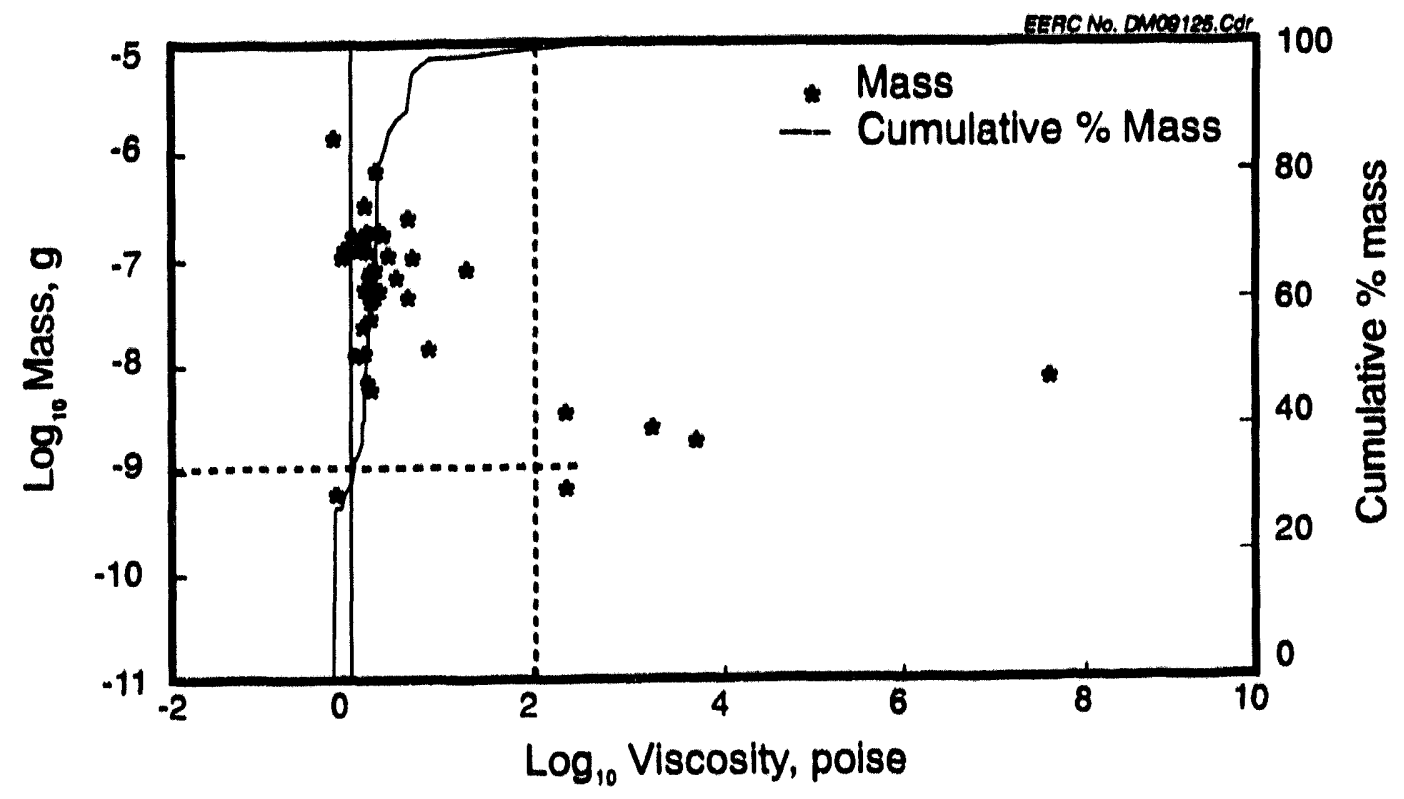

Figure 3.1-6. Plot of $\log _{10}$ mass and cumulative $\%$ mass versus $\log _{10}$ viscosity for the Illinois No. 6 deposit grown at $21 \% \mathrm{O}_{2}$. Dashed lines delimit the regions of critical mass and viscosity.

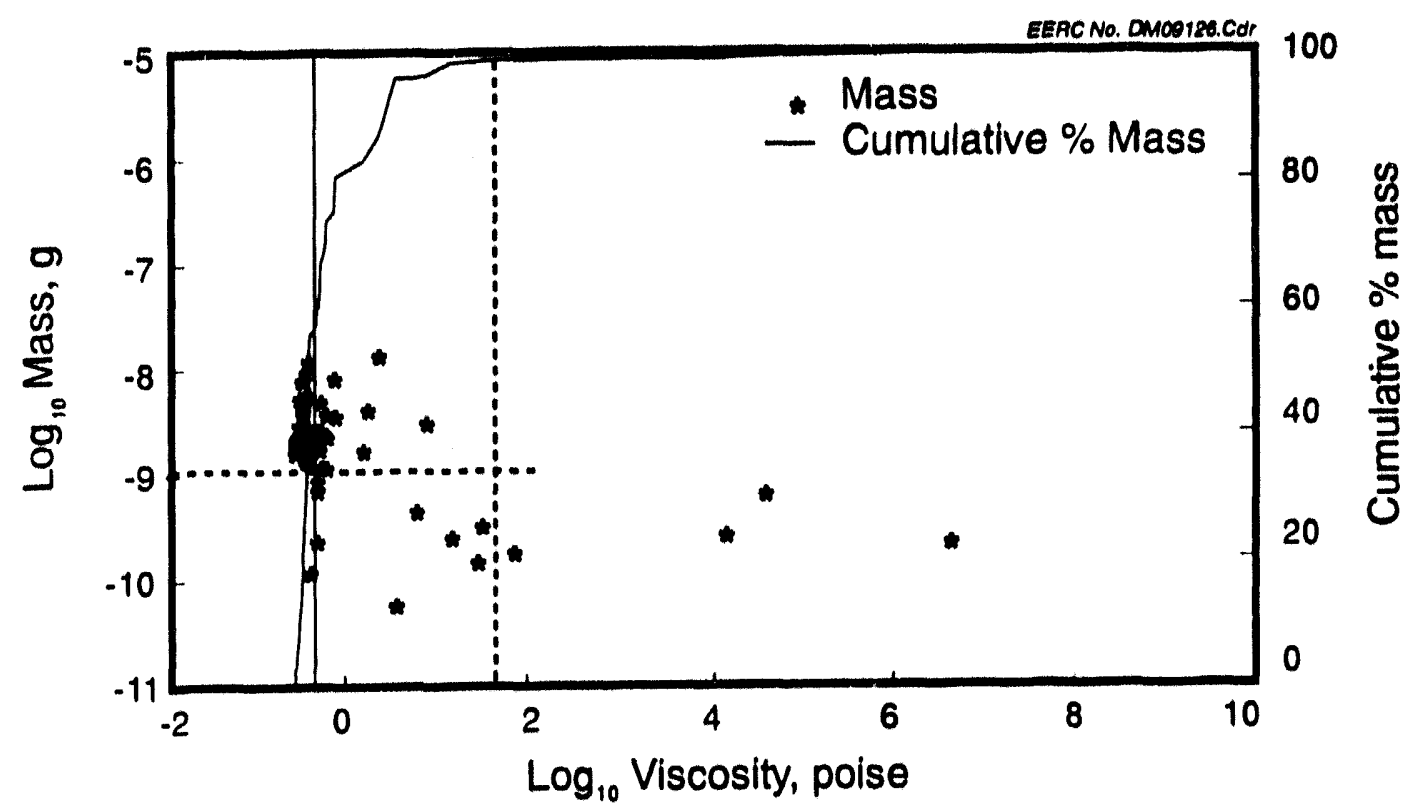

Figure 3.1.7 Plot of $\log _{10}$ mass and cumulative \% mass versus $\log _{10}$ viscosity for the Beulah-Zap deposit grown at $21 \% \mathrm{O}_{2}$. Dashed lines delimit the regions of critical mass and viscosity. 


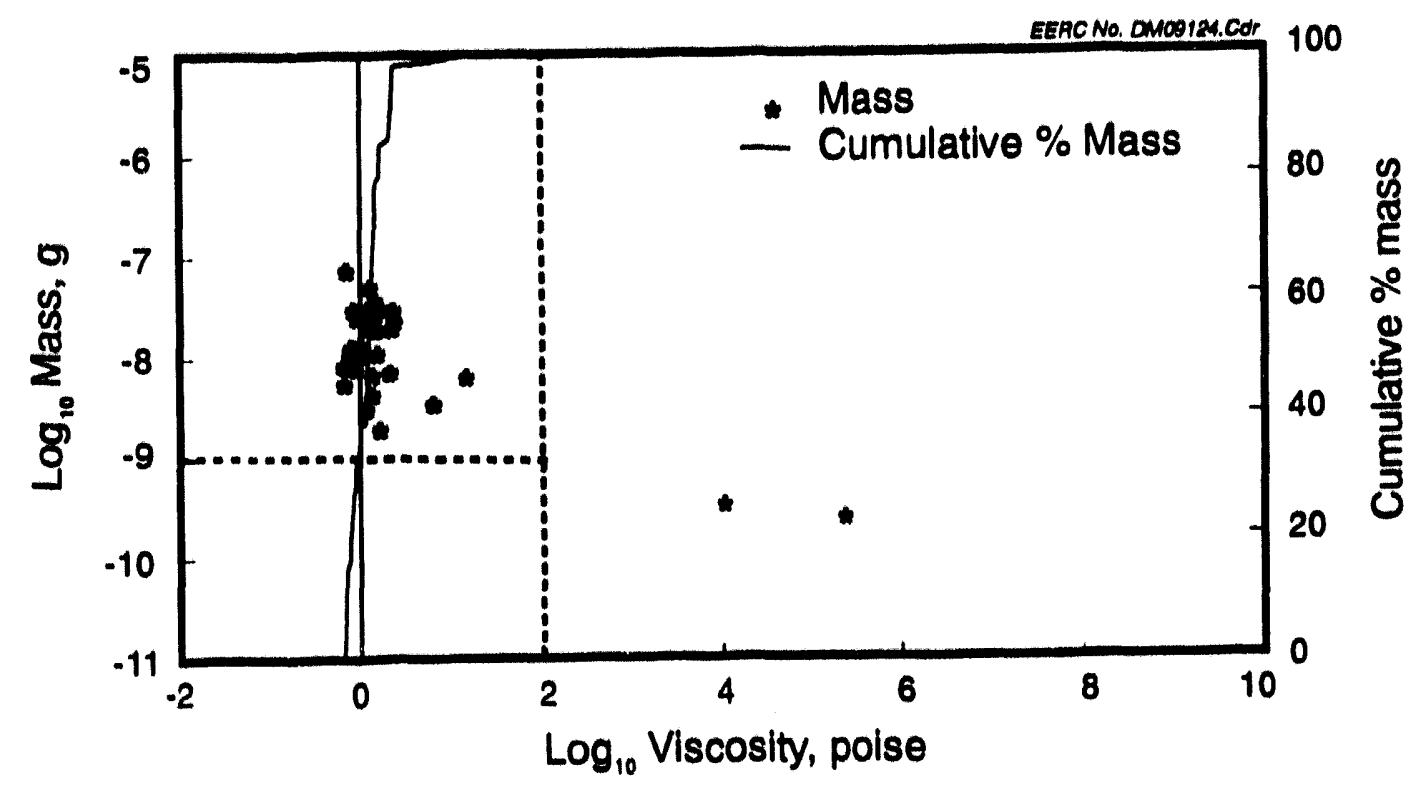

Figure 3.1-8. Plot of $\log _{10}$ mass and cumulative $\%$ mass versus $\log _{10}$ viscosity for the Dietz deposit grown at $21 \% \mathrm{O}_{2}$. Dashed lines delimit the regions of critical mass and viscosity.

The striking feature of the deposit mass and viscosity distributions is that they are similar for all of the initial deposits studied. Further, although the particle compositions vary, their calculated viscosities are concentrated in a narrow range. This indicates that the initial deposit is formed by particles with sufficient kinetic energy to allow inertial impaction to occur and with viscosities below a critical value which permits adhesion of the particles to the substrate. Table 3.1.8 summarizes the average deposit particle sizes, viscosities, densities, masses, and particle kinetic energies. The kinetic energies are in the same range, with the increased gas velocity counteracted with a somewhat smaller particle size. These results support the model developed by Srinivasachar and others (18) for deposition under slagging conditions.

\section{- Effect of Oxygen}

The effect of oxygen concentration on the composition of the adhering particles has been noted previously in the results of the deposit analysis. However, although particle composition changes, the particles remain in the same range of viscosities. Assessment of the effect of oxygen is further complicated by the two gas velocities used. Pittsburgh No. 8 appears to show a slight trend toward increased particle viscosity with increasing oxygen concentration. This increase may be due, in part, to slightly hotter ash, with concurrent lower ash viscosity due to higher coal particle temperatures during combustion 


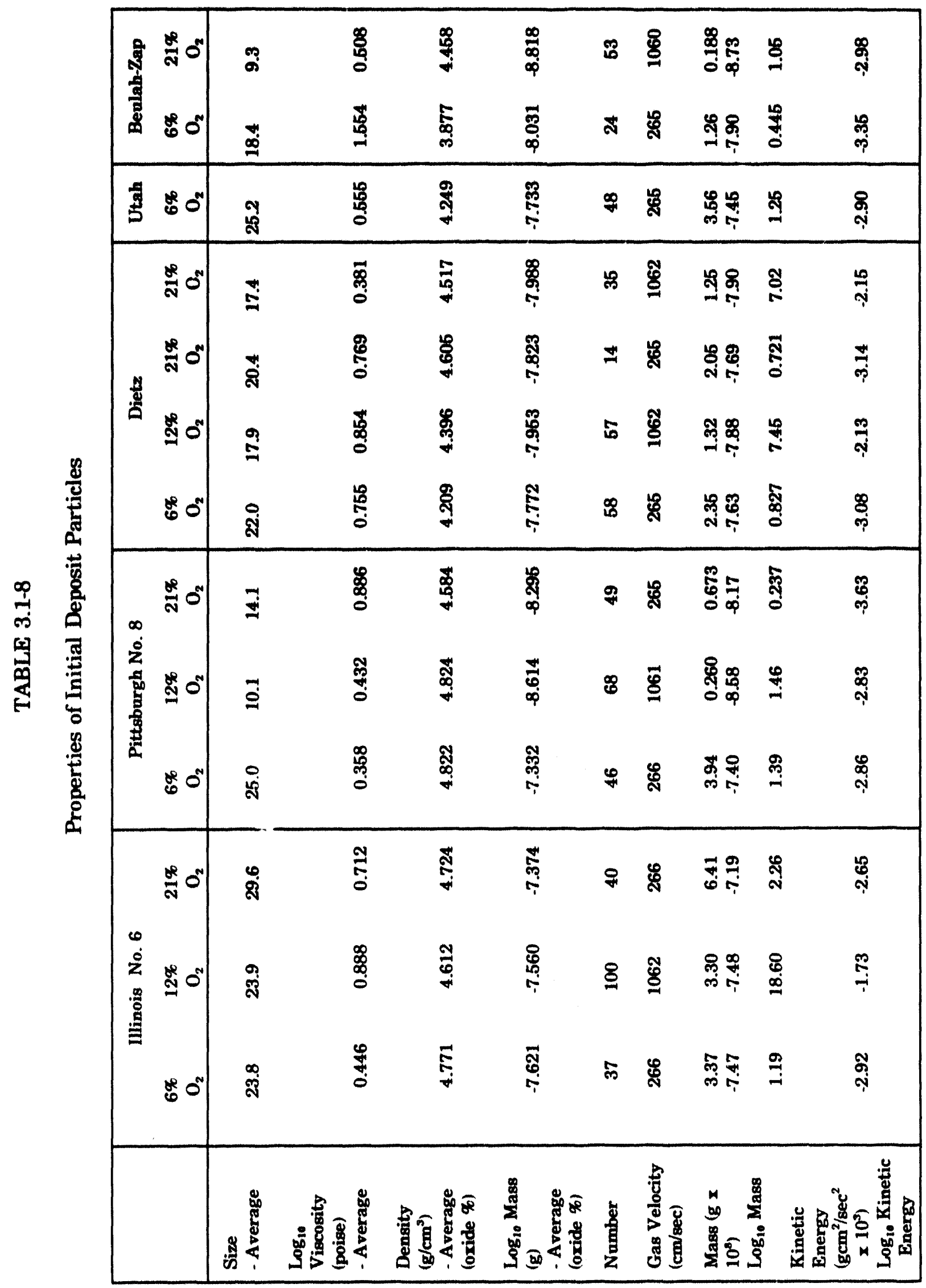


and, in part, to increased assimilation of higher viscosity material into ash particles during combustion. However, no similar clear trends appear for the other deposits.

- Properties of the Bulk Fly Ash

Samples of the bulk fly ash were also collected on filters and analyzed using CCSEM. Calculations of individual particle viscosities and particle mass based on oxide composition and densities were performed for the bulk fly ashes. Since the fly ashes were examined at several magnifications, the particle masses used to compute total fly ash mass were corrected to reflect actual abundance. Figures 3.1.9 and 3.1.10 show plots of cumulative percent of total fly ash mass versus $\log _{10}$ viscosity for two typical fly ashes. It is immediately apparent that only a small fraction of the fly ash has viscosities in the range of the initial deposit particles. When consideration is also taken of fly ash particles with the same range of mass as the initial deposit particles, this fraction is reduced still further. Table 3.1.9 gives average particle size, density, and calculated average kinetic energy for the deposit particles, as well as the percentage of total fly ash mass meeting the criteria of mass and viscosity similar to that of the initial deposit particles. These were selected to be $\log _{10}$ mass greater than .9 and $\log _{10}$ viscosity less than 2.0 . The percentage of fly ash particles meeting this criterion is in the order Illinois No. $6=$ Beulah > Pittsburgh No. $8>$ Utah Blind Canyon $\geq$ Dietz. The deposit-initiating characteristics do not necessarily correlate with overall fouling severity in a utility boiler. A coal may have optimum mineral characteristics for initiating a deposit, but may lack the other requirements for forming a strong fouling deposit, such as the development of a low.viscosity liquid phase in the deposit as it grows away from the cooled substrate. As an example, the Illinois No. 6 initial deposit developed as ash islands that grew in a columnar fashion away from the anchoring sites on the substrate. The anchoring sites and ash islands were much more numerous for the Illinois No. 6 deposit, as compared to the Beulah deposit. However, the particles in the Illinois No. 6 deposit did not melt and interact to form liquid phases that sintered the deposit as readily as the particles in the Beulah-Zap lignite did. The Beulah deposited particles became surrounded with more alkali-rich fine particulate that could interact with the larger impacted silicate material to form low melting point silicate liquid phases that are lower in viscosity than material in the Illinois No. 6 deposit. These liquid phases eventually close off and fill void spaces in the deposits and act to solidify the deposit to make it tenacious and resistant to removal. From bench-, pilot-scale, and field experience, the Beulah lignite exhibits much more of a fouling tendency than the Illinois No. 6 coal.

\section{- CONCLUSIONS}

The primary objectives of this research were to investigate the key factors in ash deposit initiation during pulverized coal combustion. Several conclusions were drawn from this work, including the following:

- Oxygen concentration appears to have only a minor effect on deposit initiation. Such effects may be partial reduction of iron species at low oxygen concentrations and increased agglomeration of mineral species due to higher combustion temperatures at high oxygen concentrations. 


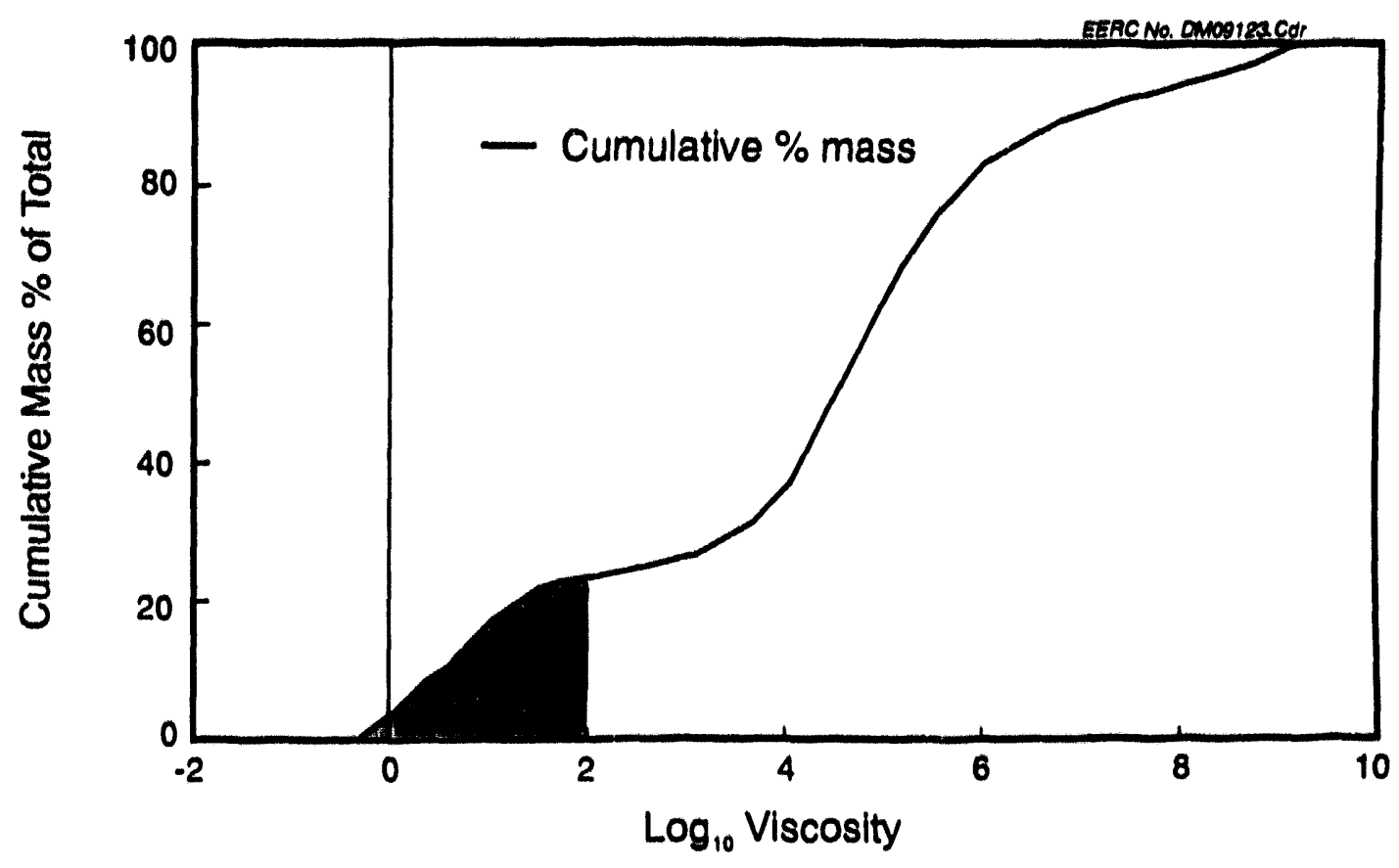

Figure 3.1.9. Plot of cumulative \% mass versus $\log _{10}$ viscosity for the Illinois bulk filter fly ash produced at $21 \% \mathrm{O}_{2}$. Shaded area delimits the fraction of total mass below the critical viscosity.

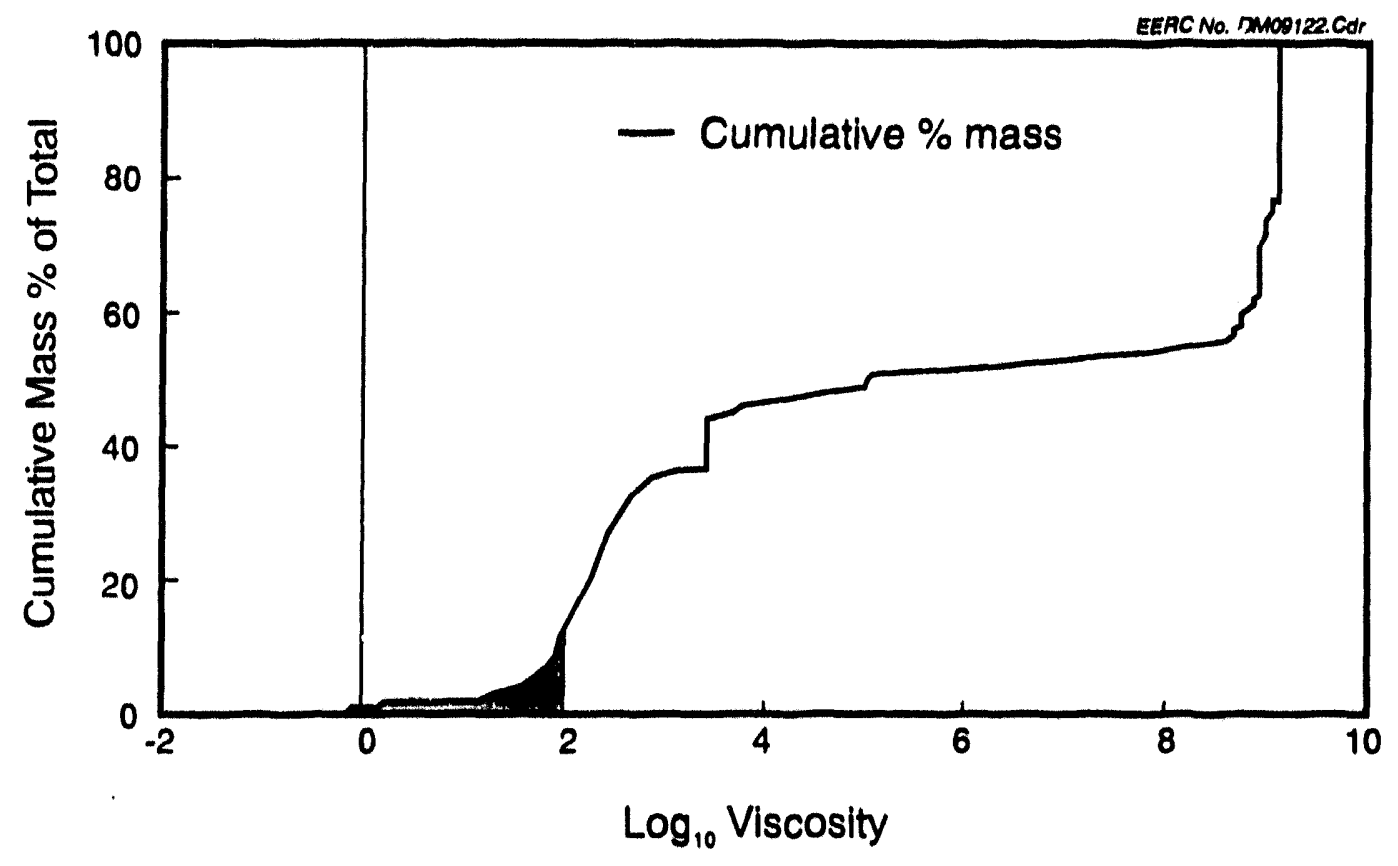

Figure 3.1-10. Plot of cumulative \% mass versus $\log _{10}$ viscosity for the Dietz bulk filter fly ash produced at $21 \% \mathrm{O}_{2}$. Shaded area delimits the fraction of total mass below the critical viscosity. 
TABLE 3.1-9

Properties of Bulk Fly Ash Particles

\begin{tabular}{lccccc}
\hline Property & $\begin{array}{c}\text { Illinois } \\
\text { No.6 }\end{array}$ & $\begin{array}{c}\text { Pittsburgh } \\
\text { No. 8 }\end{array}$ & Dietz & $\begin{array}{c}\text { Utah Blind } \\
\text { Canyon }\end{array}$ & Beulah.Zap \\
\hline $\begin{array}{l}\text { \% Meeting } \\
\begin{array}{l}\text { Mass } \\
\text { Criteria }\end{array}\end{array}$ & 69.4 & 62.1 & 80.2 & 81.0 & 61.1 \\
$\begin{array}{l}\% \text { Meeting } \\
\begin{array}{l}\text { Viscosity } \\
\text { Criteria }\end{array}\end{array}$ & 23.7 & 19.8 & 12.7 & 13.5 & 39.0 \\
$\begin{array}{l}\% \text { Meeting } \\
\text { Both } \\
\text { Criteria }\end{array}$ & 21.6 & 15.5 & 8.2 & 11.0 & 20.2 \\
$\begin{array}{l}\text { Average } \\
\text { Diameter } \\
(\mu \mathrm{m}){ }^{*}\end{array}$ & 28.7 & 20.2 & 13.4 & 14.1 & 10.7 \\
\hline
\end{tabular}

* Not corrected for multiple magnifications.

- Seven general species make up the bulk of the initially adhering particle compositions. These are iron species, iron-calcium, iron-silica, iron-silica-alumina species, calcium-silica-alumina species, barium, and barium sulfate species.

- The initially adhering species are common to all coals, with particle abundance being governed by concentration in the original coals.

- The great majority of the initial ash particles masses and viscosities cluster in a grouping above a certain "critical" mass and below a certain "critical" viscosity regardless of individual composition. This indicates that the initial adhering particles are those with sufficient kinetic energy to impact the substrate and sufficiently low viscosity to adhere upon impaction.

- Propensity for the initial ash deposition can be roughly related to the fraction of particles in the bulk fly ash possessing these required mass and viscosity requirements. However, the effect of volatilized or organically bound inorganic material is not assessed by this relationship.

\section{DEVELOPMENT OF TRANSPORT AND DEPOSITION ALGORITHMS}

The modeling effort under the Fuels Utilization Project (FUP) will concentrate on the ash deposition process, dealing with the movement of inorganic material to and from a heat-transfer surface. The model will consider the fluid dynamic conditions in the vicinity of the surface as well as the physical and chemical properties of the inorganic material. The inorganic transformations during the combustion process and during entrainment in 
the gas stream will not be considered; i.e., the physical and chemical properties of the entrained inorganic material before the deposition process occurs will be inputs to the model. Similarly, the system operating parameters, such as gas and surface temperatures and gas flow, which control the initial fluid dynamics of the deposition process, will be treated as inputs to the model. However, the model code will be in a modular form to allow future integration into a larger, more comprehensive system. The purpose of this model is its application as a research tool to better understand the ash deposition process. It is not the intent of the FUP project to develop a stand-alone ash deposition software package for distribution. However, the model's theory, algorithms, and principles of operation as well as the model itself will provide valuable insight into the mechanisms of ash deposition that will be used in other applied projects, such as the Fouling Performance Indices project.

\section{BACKGROUND}

Models dealing with combustion and combustion systems are abundant in the literature. Their complexity ranges from the exhaustively comprehensive and ponderous 87.PCGC-2 and 90-PCGC.3 simulations developed by Brigham Young University, to mechanistic models such as Ash Deposit Local Viscosity, Index of refraction, and Composition (ADLVIC) being developed by Baxter (19), and LEADER $(20,21)$ being developed by the EERC to the EERC PCQUEST (22), which is a set of slagging and fouling indices based on coal properties and experience. The goal of the FUP modeling effort is to develop a model that will act as a research tool to address deposition as comprehensively as possible, while remaining fast and easy to use.

The EERC has previously developed several models relating to ash transformations and combustion, including PHOEBE (23), PCQUEST, ATRAN1, LEADER (20, 21), and the FOULER portion of the EPRI Coal Quality Expert (CQE) model, scheduled for release in late 1994. The EERC is also scheduled to be coding the slagging algorithms for the CQE model in cooperation with Physical Sciences Incorporated and Black and Veatch.

Experience gained during the development of the CQE FOULER project will be the most applicable to the FUP deposition modeling. The FOULER algorithms are considerably simplified because of the execution time constraints placed on FOULER by the main CQE model. In particular, the time dependence of deposit properties such as strength and thermal conductivity is handled with empirical equations defining trends rather than actual recursion and recalculation.

The EERC has a large database of information relating to ash and ash deposition to draw upon in formulating the FUP model. Information from bench-and pilot-scale tests is available, as well as the results from field tests performed by the EERC, such as those for Project Calcium.

\section{MODEL APPROACH}

The FUP model is to be a mechanistic model which is versatile-able to be used with systems having several deposition geometries and covering a wide range of temperatures and surface materials. The model is to be as comprehensive and accurate as possible, accounting for several deposition mechanisms and employing "best values" from the literature as well as the results of bench-, pilot-, and full-scale combustion test data. It is envisioned to be a research tool rather than a full-blown boiler simulation model. 
Although some algorithms and principles developed for FOULER will be utilized, the model will be able to circumvent limitations imposed on FOULER and have improved capacity.

\section{- Input Parameters}

As noted previously, the FUP model is not envisioned to be all-inclusive. Figure 3.1-11 outlines the significant phases of inorganic transformations and ash deposition during the combustion process. The emphasis of the FUP model is the region involving the ash deposition process itself. Therefore, conditions in the overall combustion system and properties of the entrained inorganic material will be required as input to the model. A conceptual diagram has been formulated as to the content and scope of the model.

- Gas Properties

- Gas temperature

- Gas composition

- Gas velocity

- Gas physical and thermodynamic properties

- Heat-Exchange Surface Properties

- Surface temperature

- Surface geometry

- Surface material

- Deposit physical and thermodynamic properties

- Ash Properties

- Partitioning of gas, vapor, submicron ash, entrained ash

- Size/composition distribution of submicron and entrained ash

- Ash/mineral physical, chemical, and thermodynamic properties

- Inorganic Transport Mechanisms

- Thermophoresis, Electrophoresis, and Other Phoresic Mechanisms

Under certain conditions, such as biomass-derived ash with a predominance of $<5 \cdot \mu \mathrm{m}$ particulate material, thermophoresis may play a significant role in the transport of ash to the heat-exchange surface (19). This effect will be greatest with a clean surface and decrease as deposit accumulates, because of the decreasing temperature differential between entrained particulate and the surface. Exact calculation of thermophoretic deposition requires the value of the temperature gradient between gas and surface, which is not known.

Calculation of thermophoretic deposition will be on a semitheoretical basis with a reasonable estimation of the temperature gradient An excellent database of characteristics of thermophoretically deposited material was generated during full-scale testing under the EERC Project Calcium program $(24,25)$. This work and other data such as that of Rosner (26) will be used to provide empirical correlations. Other work in the 


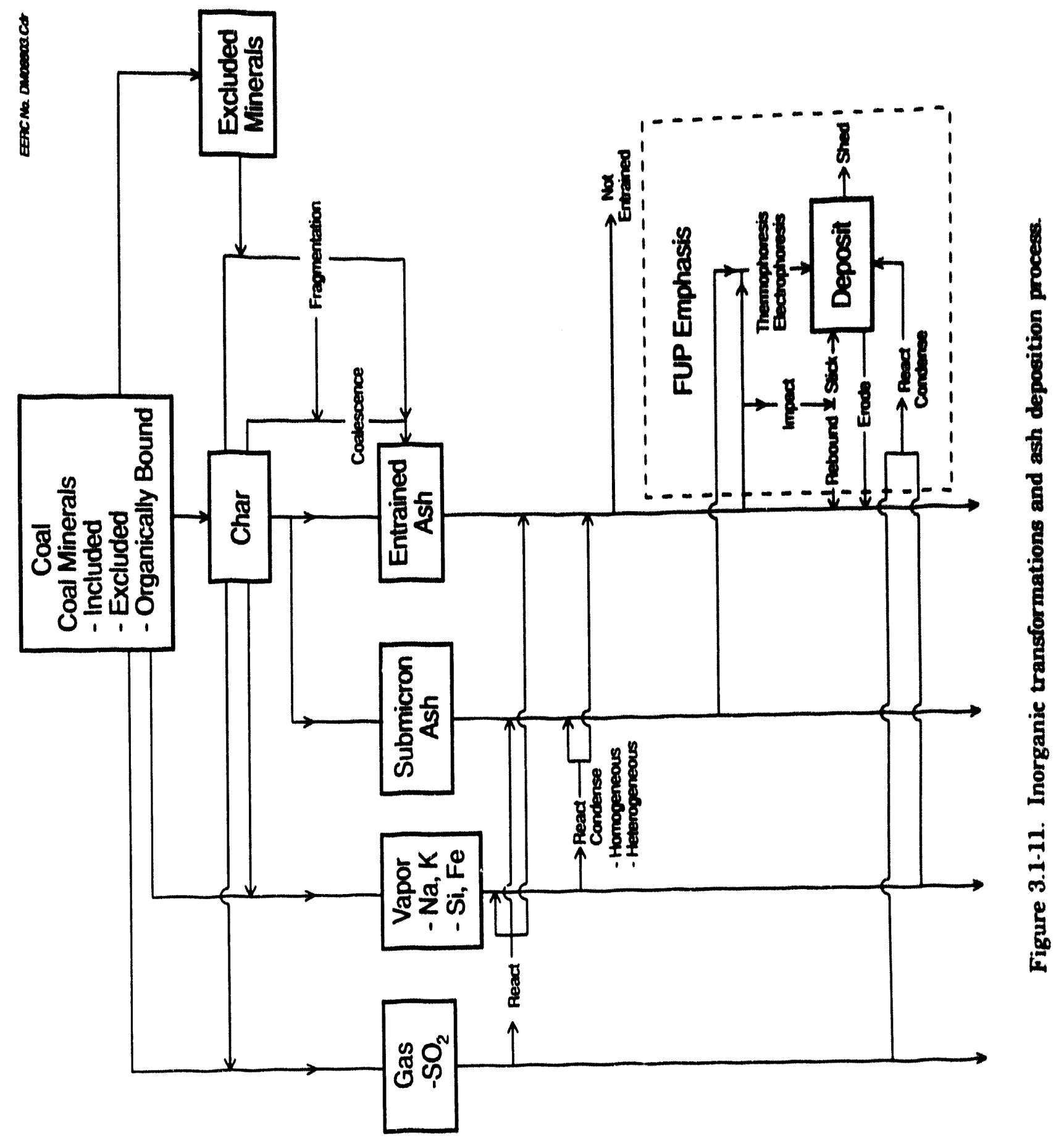


literature on thermophoresis-based particulate collection devices may aid in the estimation of the temperature gradient and thermophoretic deposition efficiency. No experimental work in this area is planned. Electrophoresis, like thermophoresis, may be significant in the deposition of small particulate with high conductivity, such as alkali-enriched silicate material (19). Again, exact calculation of deposition is not possible, since the potential gradient near the surface and the permittivity of the particles is required. It appears that electrophoretic deposition in an ash deposit setting has not been extensively studied, and the magnitude of its contribution is not known.

Calculation of electrophoretic deposition will be on a theoretical basis using a reasonable estimation of potential gradient and permittivity. Estimates of these terms will be based on available measurements of boiler electrical fields, if any. An extensive literature database is available on electrostatic precipitator performance, which should be of use for estimating ash electrical properties. No experimental work in this area is planned.

Other similar deposition mechanisms such as photophoresis and Brownian motion will be considered from a theoretical basis for inclusion in the model.

\section{- Condensation and Reaction of Gaseous Inorganic Species}

This mode of deposition includes both the simple condensation of vapors on a sufficiently cool deposit surface and the reaction of a gaseous species with material of the deposit, such as $\mathrm{SO}_{2}$ with $\mathrm{CaO}$.

Condensation of gaseous species is fairly straightforward, being dependent on surface temperature, concentration, vapor pressure, and gas properties. The contribution of simple condensation to deposition is expected to be small, unless unusual concentrations of inorganic species are volatilized. No experimental work in this area is planned.

Reaction of gaseous species, particularly of $\mathrm{SO}_{2}$, is significant in the deposition process and in the development of deposit sintering and strength. The transport of $\mathrm{SO}_{2}$ to the deposit surface is similar to that of condensing species; what is not certain is the degree of reaction of the $\mathrm{SO}_{2}$ with suitable deposit phases. The effect of sulfur capture on the degree of sintering and strength development is also currently unclear. The literature reports of studies involving additives such as limestone for sulfur removal should provide reasonable values for the degree of reaction. A limited degree of experimentation is currently ongoing under the coal quality expert (CQE) project on deposit strength development, including the effect of sulfates on deposit strength.

\section{- Particle Impaction and Erosion}

Inertial impaction of particulate ash material is the primary mechanism of deposit growth. As such, the portions of the model dealing with impaction are covered in greater detail than the previous deposition mechanisms. Inertial deposition is affected by the target geometry and composition and particle size, kinetic energy, and viscosity. Deposit formation depends on, first, particles impacting the target, second, sticking rather than rebounding, and, third, whether rebounding particles dislodge or erode existing deposit 
material. Further, the deposit can be either the "initial layer" forming on the bare heat-exchange surface or the bulk deposit proper.

\section{Target Geometry}

Target geometry addresses the fluid mechanics governing the impaction of ash on the heat-transfer surface or existing deposit. The geometries of interest are the cylinder perpendicular to the gas flow, a flat plate perpendicular to the gas flow, and a flat plate parallel to or at an acute angle to the gas flow. The impaction of particulate on a cylinder perpendicular to the gas flow has been treated by Israel and Rosner (27). Wessel and Righi (28) have developed generalized correlations for this geometry that are more tractable for modeling purposes. This case corresponds to the arrangement of boiler tubes in the convective pass of a utility boiler, as well as to the deposit probe of the EERC optical access drop-tube furnace (ODTF).

The flat plate perpendicular to the gas flow typifies an experimental case corresponding to the older deposition probe used in the EERC atmospheric drop-tube furnace (ADTF). Golovin and Putnam (29) treat a similar case of a rectangular half body. Their results indicate that the impaction efficiency is significantly different from that of the perpendicular cylinder. This geometry will be included to allow the correlation of the existing database from deposits grown in the ADTF with the model. As this case is effectively that of an impactor collection device, more recent treatments of this geometry are expected to be uncovered in the literature.

The flat plate in parallel or acute angle flow corresponds to that of deposition in the main furnace box and on the walls of the convective pass. The SLAGGER portion of the CQE model assumes parallel flow and transport of ash by turbulent fluctuation (30). Additional treatments of the impaction of particles at acute angles to a flat surface have $(31,32)$ appeared recently in the literature.

The cases hereto covered apply to a "clean" surface or tube. As a deposit forms, the target geometry and aerodynamics change as a result. Although the exact effect of the deposit on the target fluid dynamics is not well-studied, airfoil (streamlined) shapes studied by Golovin and Putnam (29) indicate that impaction probability decreases markedly for such bodies compared to a cylinder.

\section{Surface Material}

The effect of surface material is significant in the initial deposition phase. Raask (33) has compiled studies which show that the thermal and chemical compatibility of the surface with impinging particulate material results in firmly adhering initial deposit layers. One of the intriguing phenomena which is well-known at utility boilers is the "honeymoon" period with new boiler tubes, or tubes which have been exceptionally wellcleaned, during which little or no deposits accumulate. Recent surface studies $(34,35)$ of steel and nickel surfaces suggest that minor components in the metal, specifically aluminum, may provide sites where initial deposition occurs. 


\section{Adhesion/Rebound/Erosion of Particles}

The process of deposition is a combination of two competing effects: first, a particle must have sufficient kinetic energy to push through the boundary layer surrounding the target surface. Second, the particle kinetic energy, viscosity, and adhesive forces must be low enough for the particle to dissipate the kinetic energy by deformation on impact and adhere rather than rebounding. The first process favors larger and denser particles, as the particle kinetic energy is proportional to the mass. The second process favors smaller, less dense particles of low viscosity. The result is an approximately bell-shaped distribution of particles with the required mass and viscosity that will impact and adhere to the target. This expected result has been noted by Walsh and others (36). It should be noted that a higher kinetic energy requires a lower viscosity for adhesion to occur. For a material of uniform size and composition, there is a critical viscosity where a sharp increase in the percentage of adhering particles occurs, as demonstrated by Srinivasachar and others (18). Given the distribution of size and composition, the "critical viscosity" was found not to be nearly as distinct for an actual fly ash. A similar critical viscosity was seen for the initially adhering particles of fly ashes derived from several western coals by Zygarlicke and others (37).

Once the initial deposit layer forms, the process of deposition rapidly becomes more complex due to 1) changes in the shape of the target, with accompanying change in impaction probability; 2) the deposit forming a heterogeneous surface of varying viscosity, i.e., hard and soft areas; and 3) an increase in the temperature of the deposit as the heat-exchange surface becomes insulated, further lowering the surface viscosity. This will also promote sintering between ash particles and induce further changes in the surface viscosities.

The dynamics of erosion of ash deposits by particles in conjunction with particle adhesion has not been well studied. Studies and models of low-temperature systems dealing with environmental sampling of particulates such as that of Braaten and Paw $U$ (38) will be of use in estimating erosive effects.

\section{- Deposit Physical and Thermodynamic Properties}

Over time, the deposit physical and thermodynamic properties are altered by the process of sintering, as well as by reaction with gas-phase species such as $\mathrm{SO}_{2}$. The sintering increases the strength of the deposit, making removal more difficult. Sintering also increases the deposit density and conductivity, which in turn affects the deposition process.

The present CQE FOULER model bases deposit conductivity on the work of Mulcahy and others (39). These values are quite similar to those used by Black and Veatch in the main CQE boiler code (40). Deposit conductivity is, to a first approximation, independent of deposit composition, but dependent on deposit porosity. Deposit composition is important only as to how the sintering behavior will affect porosity. Deposit conductivity increases uniformly with temperature up to the point where extensive sintering begins to occur-increasing very rapidly thereafter. Further, the conductivity exhibits hysteresis; once sintering at higher temperature has increased the porosity, the conductivity remains higher when the temperature is reduced again. Thus, for a valid deposition model, the time-temperature history of the deposit has to be taken into account. 
Deposit strength, porosity, density, and conductivity are interrelated properties dependent on the initial deposit characteristics and the degree of sintering which has occurred. The CQE FOULER model sintering is semiempirically based on the Frenkel model of neck growth between particles. A "unitless" time is calculated corresponding to an arbitrary neck growth, and the degree of sintering assumed to be inversely proportional to this unitless time. This allows the degree of sintering, as well as the other deposit properties, to be related to deposit temperature, particle size, and particle viscosity by this term multiplied by an empirical constant. Current experiments are ongoing under CQE to improve the value of the empirical constant.

Deposit physical property predictions using the Frenkel model are currently limited by the uncertainty in the value for the surface tension, which appears in the numerator of the equation. Examples reported in Raask (41) assume a constant value for the surface tension, when one would suspect that it should be dependent on temperature and particle composition. Further uncertainty results from changes in viscosity upon coalescence of particles of dissimilar composition and from the effect of sulfation on sintering and deposit strength. Careful examination of ash and slag properties data at the EERC $(42,43)$ as well as work reported in the literature, such as that of Jung and Schobert (44) should allow reasonable empirical correlations to be determined.

\section{- Deposit Removal Properties}

Deposit removal may occur by thermal shedding, gravity shedding, and soot blowing. The relationship of deposit removal to the physical properties of ash deposits is a relatively sparsely investigated area. Wain and others have made a correlation of the relationship of deposit porosity to soot blower effectiveness (45). The factors affecting ash adhesion strength in a bench-scale system are currently being studied at the EERC (46). Raask (33) summarizes the effects of thermal expansion and contraction of substrate and deposit on thermal shedding. It is expected that estimates of deposit removability can be made from the literature information. These estimates are expected to be somewhat crude initially and will be refined later.

\section{ENTRAINED ASH PROPERTIES}

The properties and the partitioning between the gas- and vapor-phase material and the submicron and entrained ash are seen to be of eventual importance in a comprehensive model of ash transformation and deposition. For the present, this area is beyond the scope of the FUP emphasis on the deposition aspect proper.

\section{- Deposit Strength Development and Thermal Properties}

The specific goals for the first year are to 1) conduct a literature review of silicate and sulfate sintering behavior, 2) conduct sintering and deposit thermal conductivity experiments, 3) develop a first-order correlation between deposit physical and chemical properties with deposit growth rates, strength development, and removability, and 4) develop a first version of a deposit conductivity algorithm. 


\section{- Literature Review of Silicate and Sulfate Sintering}

A preliminary survey of the literature on silicate and sulfate sintering has been performed in conjunction with the preliminary survey covering ash transport and deposition. This will provide the keyword and key author basis for a detailed literature search.

\section{- Sintering and Deposit Thermal Conductivity Measurements}

Ash deposition on boiler heat-exchange surfaces and the subsequent necessity for its removal have long been of concern to the utility industry, especially with the growing popularity of lower-rank coals, many of which have lower sulfur content and lower cost compared to bituminous coals. Empirical experience over the years has resulted in boiler designs and ash removal strategies tailored to specific coals. With regard to boiler design, the general practice has been to build boilers with bigger main furnace areas and more wall blowers for the combustion of lower-rank coals. Larger furnace areas allow for more dissipation of heat into the steam cycle, thereby reducing tendencies for molten deposits to form in hot spots. Keeping ash off heat-exchange surfaces has usually entailed costly deratings caused by continual lower loads to reduce furnace temperatures or scheduling load swings to induce thermal contraction stresses for the shedding of deposited material. Current economic and regulatory pressures have made coal blending and firing of non. design coals increasingly attractive because reasonable loads can be maintained at lower costs and/or lower sulfur emission levels. However, such changes in coal diet may result in the introduction of ash with significantly different deposition and removability behavior from that of the design coal, with concurrent operational and economic penalties. It is to the advantage of a utility company to carefully screen coals before coal switching or blending, such as by conducting combustion performance tests. Full-scale and pilotscale test burns are costly as well as impractical when a suite of coals or blends are under consideration. The University of North Dakota Energy \& Environmental Research Center (EERC) has developed a bench-scale method of growing ash deposits under fouling conditions simulating those encountered in the convective pass of a utility boiler and measuring in situ the force required to remove deposits. Using this method, many coals or coal blends can be rapidly tested under conditions expected to be attained in a particular boiler.

\section{- EXPERIMENTAL}

Eight coals were selected to test the effects of coal quality and deposition conditions on fouling deposit removability. The coals included a wide range of known full-scale fouling deposition behavior. The Beulah lignite from North Dakota and Anderson-Dietz subbituminous coal from Montana are high-alkali coals that are notorious for causing fouling problems. The Wyodak coal from Wyoming is a moderately fouling subbituminous coal. A 70\% Wyodak and 30\% bituminous Oklahoma Croweburg blend, termed Wyodak $70 / 30$ blend, also had intermediate or moderate fouling tendencies. Two bituminous Illinois coals, one termed Illinois A consisted of a mixture of Illinois No. 2, No. 3, No. 5, and No. 5 a coals, the other termed Illinois B consisted of Illinois No. 6 coal. The final coal used was a bituminous Western Kentucky No. 11. All four bituminous coals were fairly low-fouling coals from field experience. 


\section{EQUTPMENT}

The bench-scale method employed to assess deposit removability of the eight test coals was developed using a laboratory-scale, entrained-flow, vertically downfired tube furnace. The furnace system is a drop-tube furnace with the ability to combust coal and produce ash under closely controlled conditions simulating the time/temperature profile of a utility boiler. The furnace is equipped with an optical zone in which the deposition probe is mounted. This optical section allows visual and video monitoring of deposit formation and measurement of deposit temperature with optical pyrometry, as well as access for a miniature soot blower and adhesion measurement probe. Collection of entrained ash and process gas analyses can also be performed in conjunction with the deposition tests.

The furnace assembly consists of a $2.5 \cdot \mathrm{in}(6.35 \cdot \mathrm{cm})$ alumina reaction tube heated externally by a series four independently controlled electrically heated tube furnaces as shown in Figure 3.1-2. The first furnace zone is used to preheat secondary combustion air prior to contacting the primary air and coal stream. The second through fourth furnace zones provide the desired temperature profile with residence time, and the lowermost fourth furnace is used to maintain the temperature of the optical zone. Ambient temperature primary air and entrained coal are introduced into the furnace system by means of a vertically traversing water-cooled injector. The coal feed rate ranges from $0.04 .0 .30 \mathrm{~g} / \mathrm{min}$, with the actual value adjusted to maintain a calculated ash feed rate of $0.007 \mathrm{~g} / \mathrm{min}$ for each coal. Secondary air is introduced and preheated in the annulus between the reaction tube and the injector before mixing with the primary air and coal. The coal and gases flow relatively slowly down the combustion zone of the reaction tube in a laminar flow regime. Just prior to the optical zone, the gas velocity is increased by passing the gas through the restricting nozzle of a ceramic accelerator. The accelerator raises gas velocities to values in the range found in a utility boiler convective pass while permitting long particle residence times in the relatively short combustion zone. Exiting the accelerator, the gas stream and entrained ash enters the optical zone and impinges on the deposition probe (Figure 3.1-3). The deposition probe is a $0.875 \cdot \mathrm{in}(2.22 \cdot \mathrm{cm})$ cylindrical probe simulating a boiler tube. An inner water cooling loop and an outer nitrogen/water spray cooling loop cools the probe. The ash deposit is grown on a removable sample coupon machined to maintain the round contour of the probe and fitted into dovetail slots on the upper probe surface. The arrangement causes thermal expansion to press the coupon tightly against the probe, maintaining good thermal contact at elevated temperatures. A small thermocouple inserted into the center coupon is used to maintain the coupon temperature. The coupon and intact deposit can be removed from the probe for subsequent examination and analysis. The gas, along with ash bypassing the probe, is drawn into a water-cooled collection zone below the optical zone, where the gas is cooled with a nitrogen quench and the ash collected on a backup filter. Flow through the furnace system is maintained by a vacuum pump downstream of the filter.

Physical and optical access to the optical zone is through a cruciform arrangement of four alumina tubes cemented into the cast optical zone and extending horizontally through the optical zone furnace to the exterior. The deposition probe itself is inserted through the lowermost and largest tube. Opposite the deposition probe, a tube with sight port permits measurement of deposit temperature with a manual optical pyrometer. A second tube with sight port at right angles to the probe axis is used to view and videotape the deposit formation with a long-range microscope and video camera. The soot blower 
and adhesion measurement device are inserted at right angles to the probe axis in the tube opposite the microscope.

The soot blower is a straight, uncooled length of $0.087 \cdot$ in $(0.312-\mathrm{cm}) \cdot$ diameter alumina tubing sliding inside a slightly larger alumina tube fixed in an insulating plug. In use, the soot blower is manually inserted to a stop which positions it 0.3 in $(0.8 \mathrm{~cm})$ from the deposit. A solenoid valve is then triggered to deliver a consistent "puff" of compressed nitrogen.

The adhesion measuring device is a 0.065 -in $(0.165 \cdot \mathrm{cm})$-diameter ceramic rod glued to a stainless steel rod supported inside a water-cooled sheath with 2.25 in $(5.7 \mathrm{~cm})$ of uncooled rod extending forward of the sheath. The rear of the stainless steel rod presses against a miniature pressure transducer mounted in an aluminum holder on a small motor-driven micrometer stage. The entire assembly is attached to two large manual translation stages and a rail assembly. In operation, the adhesion measuring probe is moved forward on the rail assembly into the optical zone and the ceramic rod centered on the deposit with the manual translation stages. With the ceramic rod close to the deposit, the micrometer is motored forward until the rod detaches the deposit from the probe substrate, while the adhesion force is displayed on a chart recorder.

\section{TEST CONDITIONS}

The fouling deposit adhesion tests conducted are presented in two groups. The first group consists of tests performed while the deposit adhesion test protocol was developed and include the eight test coals of varying rank. Due to the exploratory nature of these tests and "nonstandard" test protocols, the scatter in the measured adhesion forces is fairly large. Further, based on the experience with the Group II tests, "nonstandard" test conditions of Group I were approximated in terms of standard Group II conditions. The definitions of variables examined for possible significance in both Groups I and II tests are given in Table 3.1-10. Table 3.1-11 gives the coal name, rank, and fouling index for the test coals. Table 3.1.12 gives the definition and range of key variables for the Groups I and II tests. The full range of each variable was not examined for each specific coal. It was found to be experimentally difficult to examine the effect of a single variable, as changes in one variable generally perturbed several others.

TABLE 3.1.10

Adhesion Test Variables

\begin{tabular}{ll}
\hline $\begin{array}{l}\text { Furnace Temperature } \\
\text { (Furnace } 3 \text { temperature) }\end{array}$ & $\begin{array}{l}\text { Deposit Time } \\
\text { (growth time }+ \text { bake time) }\end{array}$ \\
Optical Zone Temperature & Total Run Time \\
Coupon Temperature & Soot-Blowing Frequency \\
Excess Air & Number of Soot Blowings \\
Feed Time & Number of Noneffective Soot Blowings \\
Growth Time & Fouling Index \\
(time grown after last effective & Normalized Fouling Index \\
soot blowing) & (fouling index/Beulah fouling index) \\
& Base Area \\
Bake Time & Adhesion Strength \\
\hline
\end{tabular}


TABLE 3.1.11

Test Coals

\begin{tabular}{|c|c|c|c|}
\hline Coal & Rank & $\begin{array}{l}\text { High.Temperature } \\
\text { Fouling Index }\end{array}$ & Remarks \\
\hline Beulah & Lignite & 24 & High Fouling \\
\hline Anderson-Dietz & Subbituminous & 26 & High Fouling \\
\hline Wyodak & Bituminous & 16 & $\begin{array}{l}\text { Intermediate } \\
\text { Fouling }\end{array}$ \\
\hline Wyodak 70/30 Blend & Bituminous & 8 & $\begin{array}{l}\text { Intermediate } \\
\text { Fouling }\end{array}$ \\
\hline Croweburg & Bituminous & 10 & $\begin{array}{l}\text { Intermediate } \\
\text { Fouling }\end{array}$ \\
\hline Illinois $\mathbf{A}$ & Bituminous & 3 & Low Fouling \\
\hline Western Kentucky 11 & Bituminous & 5 & Low Fouling \\
\hline Illinois B & Bituminous & 7 & Low Fouling \\
\hline
\end{tabular}

TABLE 3.1.12

Groups I and II Adhesion Test Conditions

\begin{tabular}{lll}
\hline & Group I & Group II \\
\hline Furnace 3 Temperature, ${ }^{\circ} \mathrm{C}$ & 1300 & 1200 \\
Optical Zone Temperature, ${ }^{\circ} \mathrm{C}$ & $1186-1420$ & 1186 \\
Coupon Temperature, ${ }^{\circ} \mathrm{C}$ & 350.630 & 540 \\
Excess Air, \% & 10.1332 & $10-62$ \\
Feed Time, min & $6-332$ & $12-100$ \\
Growth Time, min & 1.40 & $5-18$ \\
Bake Time, min & 0.75 & $30-47$ \\
Number of Soot Blowings & $0-282$ & $0-17$ \\
Number of Noneffective Soot Blowings & $0-13$ & 0.7 \\
\hline
\end{tabular}

The second group of adhesion tests was conducted on the test coals with the purpose of systematically examining the effect of key variables on deposit adhesion strength. Experience and the development of standardized procedures resulted in improved quality of adhesion force measurements for the Group II tests. These deposits were recovered after detachment from the coupons and their room temperature crushing strengths determined in order to compare these with the in situ adhesion strength measurements.

\section{FOULING INDEX}

For a single coal, the effect of variables in Table 3.1-10, such as excess air and bake time, on adhesion strength can be studied. However, the effect of coal type on adhesion strength requires an independent measurement of relative coal fouling ability. The 
measurement used for this study was a fouling index, which does not employ adhesion strength measurements in its predictions. The EERC has developed a set of indices that ranks coals according to their slagging and fouling propensity in utility boilers, based on advanced analytical techniques for identifying and quantifying coal inorganic materials. The indices provide much more accurate diagnostic information for predicting coal ash deposition behavior than conventional ASTM analysis-based indices. The accuracy of these indices has been demonstrated through their repeated use by several utilities in the midwestern United States for screening different coals, largely from the Powder River Basin, for use in their boilers. The algorithm produces a slagging index indicative of main furnace wall slagging, a high-temperature fouling index (47) for the superheater and reheater region of a boiler in the convective pass, and a low-temperature index corresponding to the economizer and primary superheater region. The high-temperature fouling index most closely corresponds to the test conditions of the Group I and Group II adhesion tests.

\section{RESULTS}

Upon inspection, no obvious trends relating adhesion strength to test variables were readily discernible in either the Group I or Group II tests. A set of statistical analysis programs for use on a personal computer, PC.SAS*, was used to identify and quantify significant test variables. The regression procedure STEPWISE MAXR was used in conjunction with the test variables and combinations of test variables to determine the most significant factors affecting adhesion and crushing strength. A general linear regression procedure, REG, was then used to evaluate the results of STEPWISE and to compare experimental and predicted deposit strengths.

\section{- Group I Adhesion Tests}

The statistical analysis of the adhesion strengths of the Group I tests indicated that the (relative high-temperature fouling index) ${ }^{2}$ [(the ratio of the high-temperature fouling index to that for the Beulah coal) $)^{2}$ ] variable was the first selected by the procedure, with an $r^{2}$ value of 0.60 . A four-variable model was selected as the most appropriate, with the independent variables being (relative high-temperature fouling index) ${ }^{2}, 1$ (bake time noneffective soot blowing), the high-temperature fouling index, and the coupon temperature. This model produced a fit to the experimental adhesion strengths with an $r^{2}$ value of 0.69 . A summary of the analysis is given in Table 3.1.13, and a plot of experimental versus calculated adhesion strengths in Figure 3.1.12. Although the fit of the model is only moderately good, as indicated by the modest $r^{2}$ value, it indicates that the experimental adhesion strength can be correlated with coal fouling behavior and droptube furnace conditions despite the heterogeneity of the test procedures involved. Further, the variables and signs of the parameter estimates make qualitative physical sense: there is a positive correlation of adhesion strength with high-temperature fouling index, and because of the negative parameter estimates, increased numbers of noneffective soot blowings and increased bake and feed time correlate with higher deposit strength. Noneffective soot blowings are an indication of the adhesive strength of the deposit, while longer bake times allow the deposit to sinter and develop strength. 
TABLE 3.1.13

Summary of Model Parameters for the Group I Adhesion Test Data

\begin{tabular}{|c|c|c|c|c|c|c|}
\hline \multicolumn{2}{|l|}{ Variables } & \multirow[b]{2}{*}{ Step } & \multirow{2}{*}{\multicolumn{2}{|c|}{$r^{2}$}} & \multirow[b]{2}{*}{ F Value } & \multirow[b]{2}{*}{$\begin{array}{c}\text { Probability } \\
>\text { F }\end{array}$} \\
\hline Entered & Removed & & & & & \\
\hline $\mathrm{RHII}^{2}$ & - & 1 & & 04 & 70.24 & 0.0001 \\
\hline $1 /(\mathrm{BT} 13 \cdot \mathrm{SN}+0.001)$ & - & 2 & & 46 & 41.12 & 0.0001 \\
\hline HII & - & 3 & & 75 & 30.41 & 0.0001 \\
\hline CT & - & 4 & & 91 & 24.09 & 0.0001 \\
\hline \multicolumn{7}{|c|}{ Final Parameter Estimates: } \\
\hline $\begin{array}{l}\mathrm{N} \\
\text { Intercept } \\
\mathrm{RH}^{2} \\
\mathrm{~V}(\mathrm{BT} \cdot \mathrm{SN}+0.001)\end{array}$ & $\begin{array}{l}= \\
=-0 . \\
=0 . \\
=-0 .\end{array}$ & & $\begin{array}{l}\text { HII } \\
\mathrm{CT}\end{array}$ & $\begin{array}{l}= \\
=\end{array}$ & $\begin{array}{r}-0.0247 \\
0.0006\end{array}$ & \\
\hline \multicolumn{7}{|c|}{$\begin{array}{l}\text { RHI = High-temperature fouling index/Beulah high-temperature fouling index } \\
\text { BT = Deposit bake time } \\
\text { SN = Number of noneffective soot blowings } \\
\text { HI = High-temperature fouling index } \\
\text { CT = Coupon temperature }\end{array}$} \\
\hline
\end{tabular}

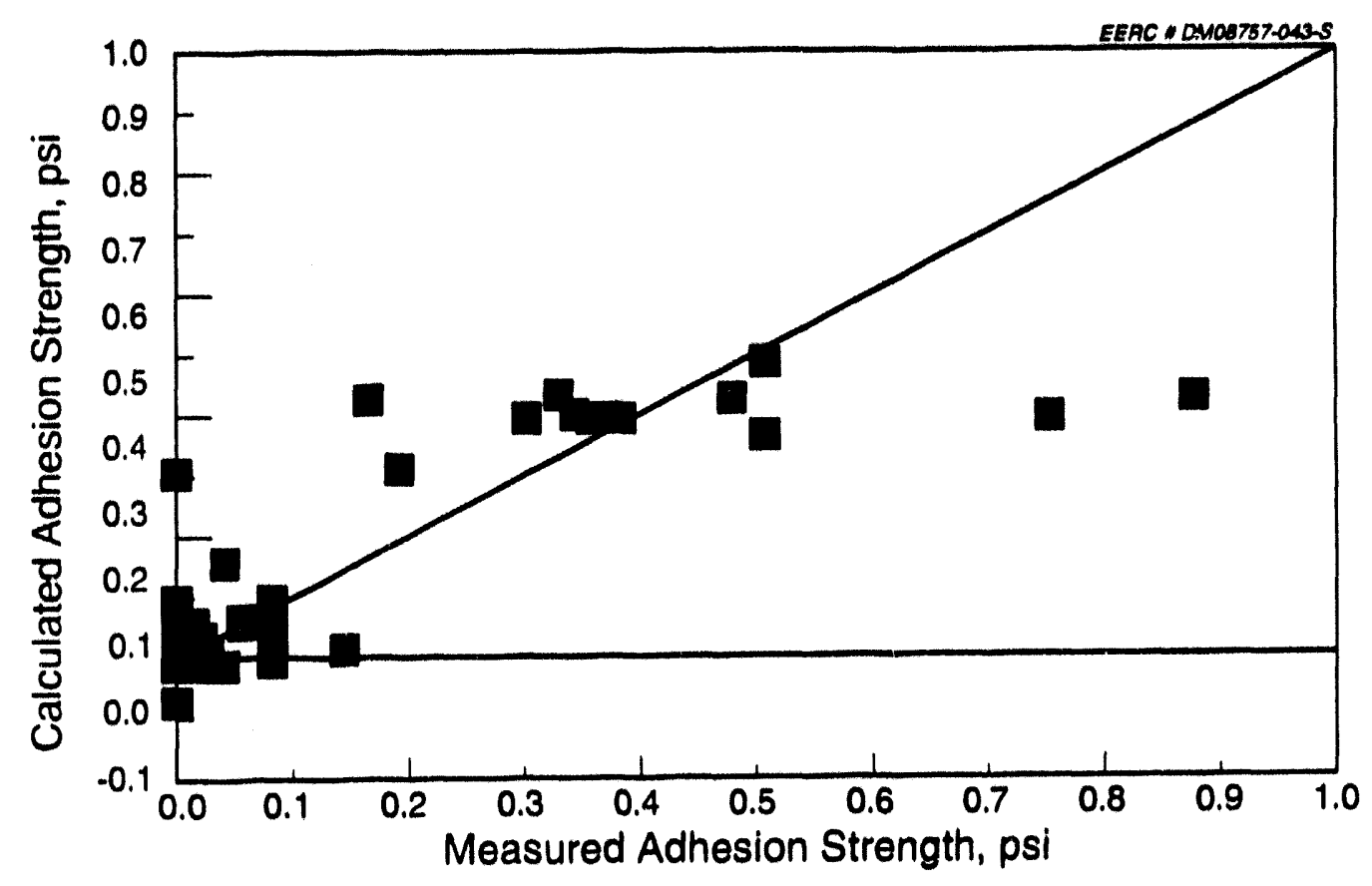

Figure 3.1-12. Group I deposit model calculated and experimental adhesion strength. 


\section{- Group II Adhesion Tests}

The statistical examination of the Group II tests was generally similar to that of the Group I tests. A subset of the Group II data for the Beulah coal was first examined in detail to identify significant experimental parameters influencing the adhesion strength. As it was expected that the area of the deposit base could affect the measured adhesion strength (i.e., a deposit weakly adhering over a large area could have adhesion strength comparable to a deposit strongly adhering over a small area), the projected base areas of each deposit were carefully measured and a normalized adhesion strength calculated. However, models with the normalized adhesion strength as the dependent variable resulted in no significant improvement of fit over those with the nonnormalized adhesion strength. Further examination found that, surprisingly, the deposit base area itself was highly correlated with three of the experimental parameters: the time from last effective soot blowing to the end of test (including bake time), the same term squared, and 1 (bake time - noneffective soot blowings). This three-variable model, with area as the dependent variable, fit extremely well, with an $r^{2}$ value of 0.94 . The development of this model and others, which are discussed further on, produced statistical data of a similar form to that shown in Table 3.1.13, and for brevity these data will not be further presented.

With the assurance that the effect of deposit base area could be accounted for in terms of experimental test parameters, the STEPWISE MAXR and REG procedures were performed on the Beulah subset of the Group II data with the measured adhesion strength as the dependent variable. A very good fit, with a $r^{2}$ value of 0.96 for a three-variable model, was found. Significant experimental variables were 1 feed time, number of soot blowings, and (noneffective soot blowings) ${ }^{2}$. Further adhesion tests for other Group II coals were carried out and the deposit adhesion strengths compared to those of the Beulah tests. It was found empirically that an adjustment of the calculated deposit strength based on the Beulah parameters by the ratio of the coal high-temperature fouling index to that of the Beulah coal gave quite acceptable agreement between calculated and measured adhesion strength. This indication of the dependence on the high-temperature fouling index was subsequently verified using the statistical procedures described previously. A plot of calculated versus experimental deposit adhesion strength is given in Figure 3.1-13.

Comparison of the deposit adhesion strengths with deposit crushing strengths also revealed no immediately obvious relationship between the two. In fact, the crushing strengths of the Beulah deposits varied by a factor of two, indicating that furnace test conditions were as significant as coal type in determining crushing strength. The crushing strength data were analyzed by the same procedures to ascertain any correlations with experimental conditions. The STEPWISE MAXR procedure immediately selected the low-temperature fouling index as the first significant variable $\left(r^{2}=0.63\right)$. However, it later replaced this variable with the high-temperature fouling index to produce a marginal improvement in the overall $r^{2}$ value. Since both indices follow approximately the same trends with coal type, the initial selection of the low-temperature rather than the high-temperature index for both the Group II adhesion and crushing strengths is not of importance. The procedure also indicated that the deposit growth time and whether the deposit was soot blown were also of significance. A plot of calculated versus measured crushing strengths is given in Figure 3.1-14. The crushing strength data 


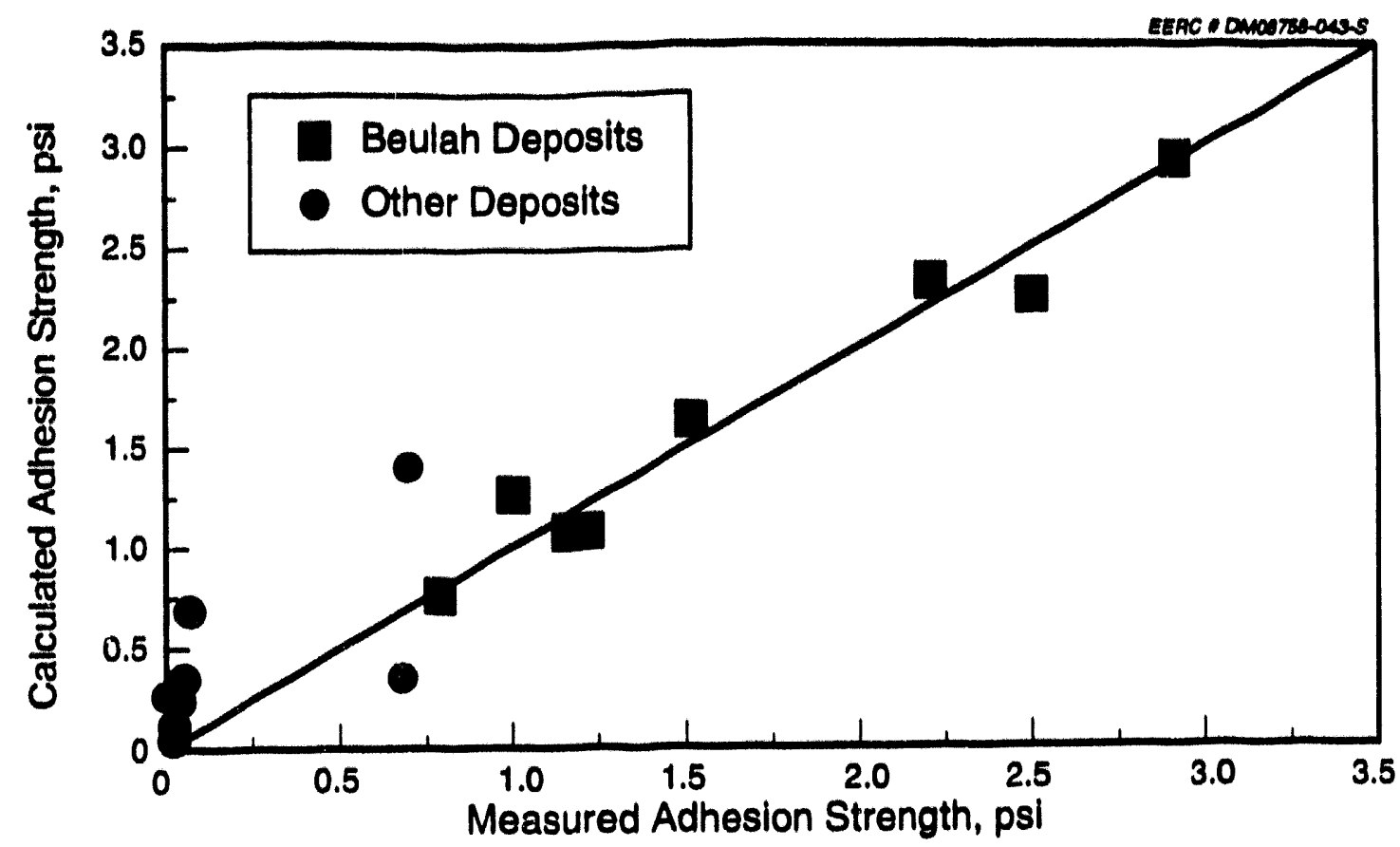

Figure 3.1-13. Group II deposit model calculated and experimental adhesion strength.

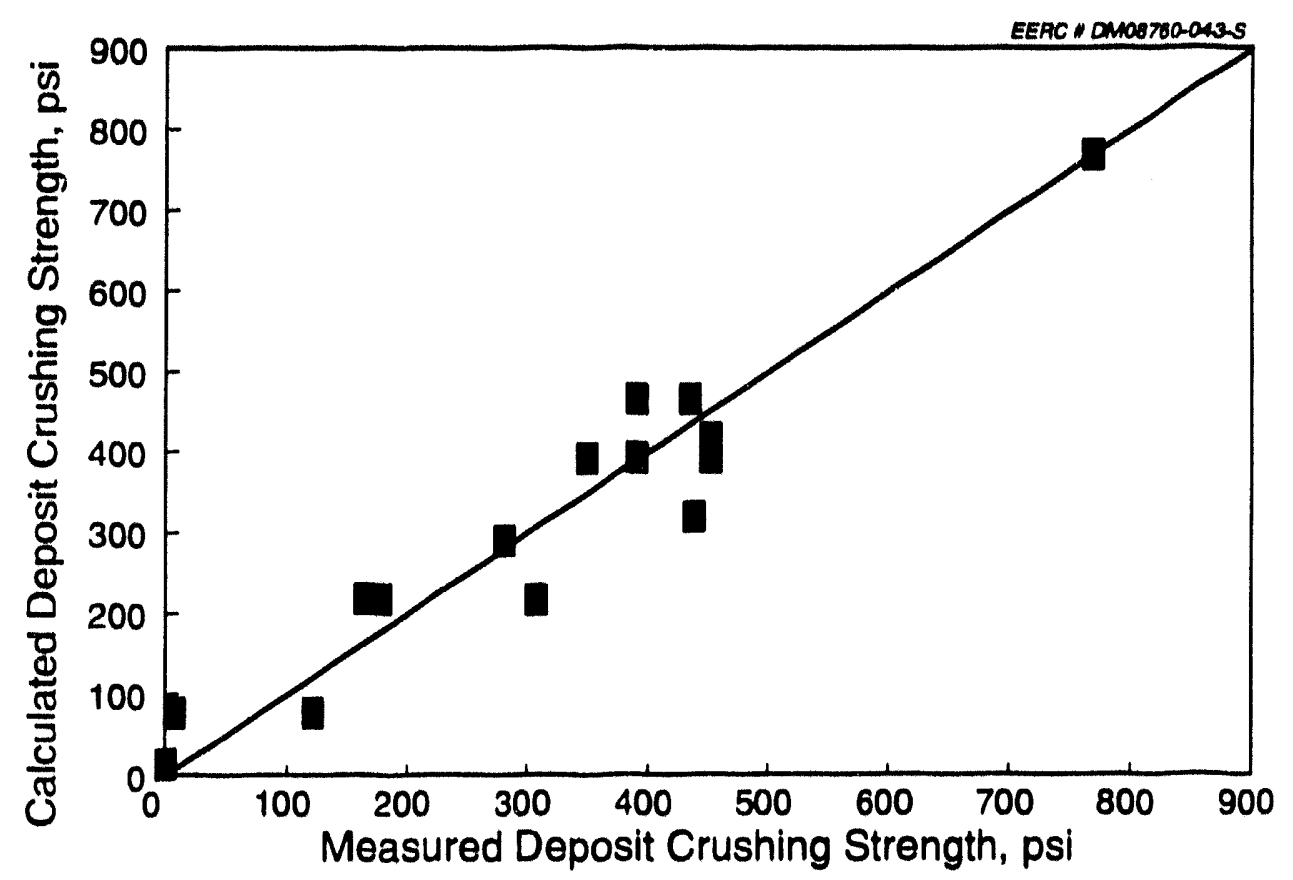

Figure 3.1-14. Group II deposit model calculated and experimental crushing strengths. 
were also fitted to the same variables identified as significant for the adhesion strength data using the REG regression procedure, resulting in an $r^{2}$ value of 0.80 . This indicates that in situ adhesion strength and crushing strength are related, but not highly correlated.

Previous studies of slag droplet adhesion by Meza and Austin (48) and Moza and others (49) and deposit adhesion by Raask (33) have shown that adhesive strength increases with increasing substrate metal temperature and is greater for mild steel as compared to stainless steel substrates. Ashes with high iron and calcium content were found to produce the most strongly adhering deposits. This is consistent with the rapid rates of deposition for low-rank coals with high calcium and sodium content observed by Tufte and others (50) and Sondreal and others (51). Tufte and Beckering (52) found that the presence of sodium and calcium results in the formation of low-viscosity $\mathrm{Na} \cdot \mathrm{Ca} \cdot \mathrm{Al} \cdot \mathrm{Si}$ phases, such as melilite, increasing the deposit strength.

\section{- CONCLUSIONS}

A laboratory-scale entrained furnace system with optical access has been constructed for the in situ determination of ash deposits. For ash deposits grown under fouling conditions from a Bculah coal, the in situ deposit adhesion strengths determined were found to be correlated with 1 feed time, number of soot blowings, and (noneffective soot blowings) ${ }^{2}$. By taking into account the coal high-temperature fouling index, a similar good correlation was found for several other Group II coals. A similar, but lower, correlation was found for older Group I coals in which coupon temperature, 1/bake time noneffective soot blowings), the high-temperature fouling index, and relative hightemperature fouling index ${ }^{2}$ were contributing factors. Room-temperature crushing strengths for the Group II deposits were found to be correlated with the high-temperature fouling index, the deposit growth time, and whether the deposit was soot blown or not. A moderately good correlation between in situ adhesion strength and room-temperature crushing strength was found.

The inverse dependence of deposit adhesion strength on coal feed time appears to reflect the degree of adhesiveness of a given deposit. A long feed time corresponds to the deposit being repeatedly removed by soot blowing until a sufficiently tenacious base has accumulated. Such a deposit would be expected to have a low adhesion strength. Conversely, a deposit that quickly adheres well enough not to be removed by soot blowing would have a higher adhesion strength. Coupled with the coal feed time is the total number of soot blowings, since longer feed times result from the deposit being repeatedly removed by soot blowing. Each soot blowing also appears to remove loosely adhering ash, allowing the gradual accumulation of ash more firmly anchored to the substrate. Once the deposit is no longer removed by soot blowing, additional soot blowings no longer contribute to strengthening the deposit adhesion and may actually weaken because of thermal shock.

The development of deposit crushing strength proceeds somewhat differently than adhesion strength. The negative correlation of crushing strength with soot blowing suggests that soot blowing may thermally shock the deposit, weakening the crushing strength. The deposit growth time also has a negative correlation with deposit crushing strength. This may be explained by rapid deposit growth reflecting lower ash viscosities 
and a higher degree of fusing, which, upon cooling, would result in a higher crushing strength.

Both deposit adhesion strength and crushing strength are correlated with the independently derived fouling index, which is based on the concentrations of inorganic constituents notable for cnusing fouling deposits. Coals with abundant alkali-alkaline earth inorganics present typically show severe fouling behavior. For example, the Beulah lignite contains significant organically bound sodium which enters the vapor phase early in the combustion process and subsequently condenses on the cool deposit surface and reacts with aluminosilicate particles deposited by inertial impaction. Figure 3.1.15 shows fine $(<3 \mu \mathrm{m}) \mathrm{Na} \cdot \mathrm{Mg} \cdot \mathrm{Ca} \cdot$ rich particles deposited thermophoretically and by condensation during the formation of a Beulah lignite deposit in the drop-tube furnace. These fine particles act to depress the melting points of the silicates present in the deposit, creating highly sintered and stronger deposits.

The results have shown that both deposit adhesion and crushing strength can be related to an index of coal fouling propensity in a utility boller. However, several interrelated deposition test conditions also were found to contribute strongly to measured deposit adhesion and crushing strengths, even for a single coal type. Because of this interdependence, the analysis procedure does not select the same variables in every case. The important consideration, though, is that the strength is related to deposit soot blowing and to bake time. Two general conclusions can be drawn. First, the interpretation and use of deposit strength determinations must be done with caution. Second, specific operating conditions in a full-scale boiler will have a significant impact on the properties and behavior of ash deposits for a specific coal.

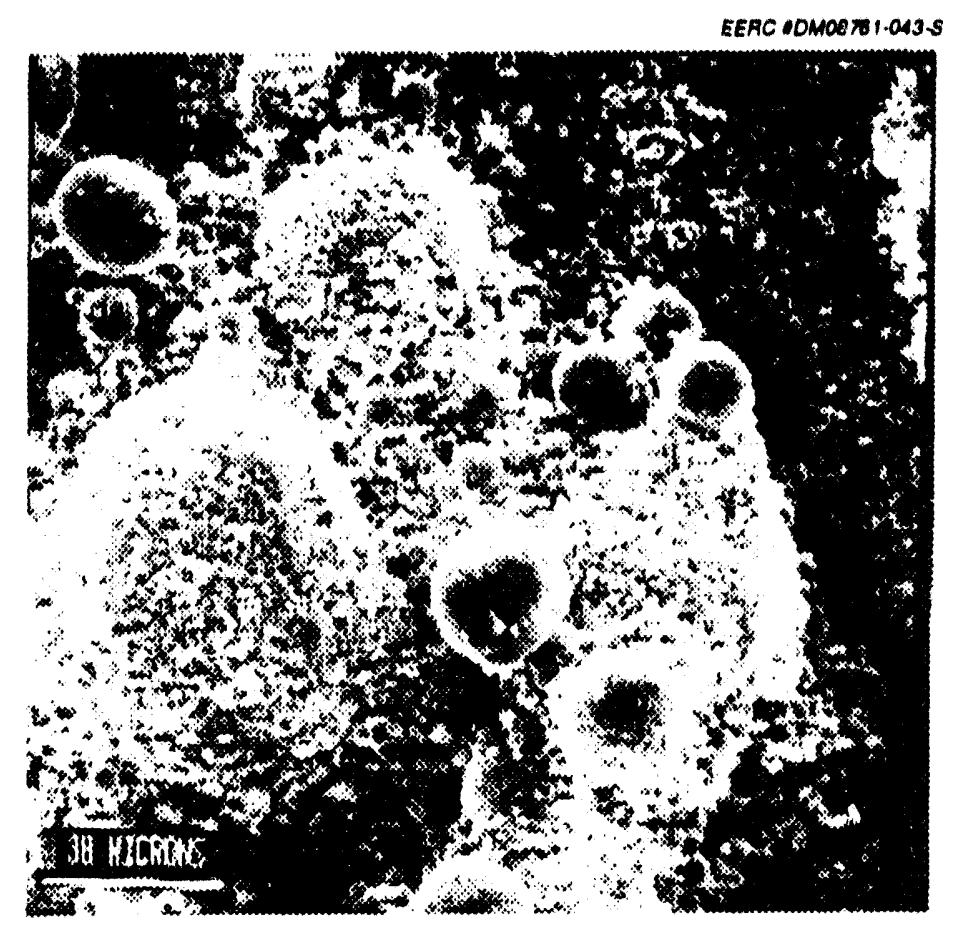

Figure 3.1-15. Initial deposit of material on steel coupon generated from Beulah lignite. 
A project plan has been formulated for developing an improved viscosity model. In conjunction with this, Mr. Bruce Folkedahl began a doctoral research program at the Pennsylvania State University. He will develop a more effective slag viscosity model for higher-calcium coals such as the western U.S. types, acquire test data for improving the slag viscosity model using a penetrometer in addition to the existing rotating bob viscometer data, revise the viscosity calculation routine in the EERC scanning electron microscope point count routine to take into account different valence states of elements, effects of different oxygen levels, and viscosity data derived from a rotating bob viscometer, and relate the new viscosity model to deposit strength. A detailed project plan for this research program will be included as part of the next semiannual report.

\section{References}

1. Raask, E. Mineral Impurities in Coal Combustion; Hemisphere Publishing: New York, 1985; Chapter 7.

2. Balfour, D.A.; Meserole, F.M.; Defries, T. "Utility Stack Opacity Troubleshooting Guidelines," final report; EPRI Research Project No. 2250-3, 1991.

3. Mie, G. "Beitrage zur Optik truber Medien speziell kolloidaler Metallosungen," Ann. Phys. 1908, 25, 377-445.

4. Bohren, C.F.; Huffman, D.R. "Absorption and Scattering of Light by Small Particles," John Wiley \& Sons: New York, 1983, 530 p.

5. Zygarlicke, C.J.; McCollor, D.P. "The Effect of Coal Blending on Inorganic Transformations: A Study of an Eagle Butte/Kentucky \#9 Blend," In Proceedings of the Ninth Annual International Pittsburgh Coal Conference; 1992, pp 775-789.

6. Katrinak, K.A.; Brekke, D.W.; Hurley, J.P. "Freeze-Dried Dispersions for Automated Scanning Electron Microscope Analysis of Individual Submicron Airborne Particulates," In Proceedings of the 50th Annual Meeting of the Electron Microscopy Society of America; San Francisco Press, Inc.: San Francisco, 1992, pp 408-409.

7. Zygarlicke, C.J.; Stea 'man, E.N. "Advanced SEM Techniques to Characterize Coal Minerals," Scanning Microscopy Intl. 1990, 4 (3), 579-589.

8. Hazrati, A.; Schrodt, J.T. "Microcharacterization of Micron/Submicron Fly Ash from a Pulverized-Dry-Coal-Burning Power Plant," Surf. Interface Anal. 1988, 13, 142-148.

9. Kaufherr, N.; Lichtman, D. "Comparison of Micron and Submicron Fly Ash Particles Using Scanning Electron Microscopy and X-Ray Elemental Analysis," Environ. Sci. Technol 1984, 18 (7), 544-547.

10. Moza, A.K.; Austin, L.G. "Studies on Slag Deposit Formation in Pulverized Coal Combustors: 1. Results on the Wetting and Adherence of Synthetic Coal Ash Drops on Steel," Fuel 1981, 60, 1057-1064. 
11. Abbott, M.F.; Moza, A.K.; Austin, L.G. "Studies on Slag Deposit Formation in Pulverized Coal Combustors: 1. Results on the Wetting and Adhesion of Synthetic Ash Drops on Different Steel Substrates," Fuel 1981, 60, 1065-1072.

12. Moza, A.K.; Austin, L.G. "Studies on Slag Deposit Formation in Pulverized-Coal Combustors: 3. Preliminary Hypothesis for the Sticking Behavior of Slag Drops on Steels," Fuel 1982, 61, 161-165.

13. Abbott, M.F.; Austin, L.G. "Studies on Slag Deposit Formation in Pulverized Coal Combustors: 4. Comparison of Sticking Behavior of Minerals and Low-Temperature and ASTM High-Temperature Coal Ash on Medium Carbon Steel Substrates," Fuel 1982, 61, 765-770.

14. Abbott, M.F.; Conn, R.E.; Austin, L.G. "Studies on Slag Deposit Formation in Pulverized Coal Combustors: 5. Effect of Flame Temperature, Thermal Cycling of the Steel Substrate, and Time on the Adhesion of Slag Drops to Oxidized Boiler Steels," Fuel 1985, 64, 827-831.

15. Abbott, M.F.; Austin, L.G. "Studies on Slag Deposit Formation in Pulverized Coal Combustors: 6. Sticking Behavior of Slag Drops from Three Pennsylvania Steam Coals," Fuel 1985, 64, 823-838.

16. Abbott, M.F.; Austin, L.G. "Slag Deposit Initiation Using a Drop-Tube Furnace," In Mineral Matter and Ash in Coal; Vorres, K.S., Ed.; ACS Symposium Series 301, Washington D.C., 1986.

17. Benson, S.A.; Austin, L.G. "Study of Slag Deposit Initiation Using a Laboratory-Scale Furnace," In Mineral Matter and Ash Deposition; Bryers, R.W.; Vorres, K.S., Eds.; Engineering Foundation: New York, 1990; pp 261-278.

18. Srinivasachar, S; Helble, J.J.; Boni, A.A. "An Experimental Study of the Inertial Deposition of Ash under Coal Combustion Conditions," In Proceedings of the TwentyThird Symposium (International) on Combustion; The Combustion Institute, Pittsburgh, PA, 1990; p 1305-1312.

19. Baxter, L.L. Biomass and Bioenergy 1993, 4 (2), 85-102.

20. Benson, S.A.; Hurley, J.P.; Zygarlicke, C.J.; Steadman, E.N.; Erickson, T.A. "Predicting Ash Behavior in Utility Boilers: Assessment of Current Status," In Proceedings of the Third International Conference on the Effects of Coal Quality on Power Plants; La Jolla, CA, Aug. 25-27, 1992.

21. Erickson, T.A.; O'Leary, E.M.; Folkedahl, B.C.; Ramanathan, M.; Zygarlicke, C.J.; Steadman, E.N.; Hurley, J.P.; Benson, S.A. "Coal Ash Behavior and Management Tools," Presented at the Engineering Foundation Conference The Impact of Ash Deposition on Coal-Fired Plants, Birmingham, UK, June 20-25, 1993.

22. PCQUEST is an improved version of The Fouling Index. 
23. Jones, M.L.; Haley, J.S.; Hurley, J.P.; Ljubičić, B.R.; Ramanathan, M. "Semiannual Technical Progress Report for Hot-Gas Cleanup," Jan.-June 1992, DE-FC2186MC10637 EERC publicaiton, 1992.

24. Hurley, J.P.; Erickson, T.A.; Benson, S.A.; Brobjorg, J.N. "Ash Deposition at Low Temperatures in Boilers Firing Western U.S. Coals," Presented at the International Joint Power Generation Conference, University of North Dakota-EERC, Grand Forks, ND, 1991, 8 p.

25. Benson, S.A.; Hurley, J.P.; Zygarlicke, C.J.; Selle, S.J. "Studies on Calcium-Based Ash Deposition in Utility Boilers," In Proceedings of the Conference on Effects of Coal Quality on Power Plants; St. Louis, MO, Sept. 19.21, 1990.

26. Rosner, D.E. Final Technical Report, DOE/PC/90756-T4, May 1991.

27. Israel, R.; Rosner, D.E. Aerosol Science and Technology 1983, 2, 45-51.

28. Wessel, R.A.; Righi, J. Aerosol Science and Technology 1988, 9, 29-60.

29. Golovin, M.N; Putnam, A.A. Industrial Engineering Chemistry, Fundamentals; 1962, p 1265.

30. Morgan, M.; Srinivasachar, S. DOE and EPRI Monthly Report, PSIT-1148, July 1992.

31. Xu, M.; Willeke, K.; Biswas, P.; Pratsinis, S.E. Aerosol Science and Technology 1993, $18,143-155$.

32. Benson, S.A.; Jones, M.L.; Haarb, J.N. "Ash Formation and Deposition," Coal Science and Technology Vol. 20, Fundamentals of Coal Combustion; Smoot, L.D., Ed.; Elsevier: New York, NY, 1993; Chapter 10.

33. Raask, E. Mineral Impurities in Coal Combustion; Hemisphere Publishing: New York, 1985; Chapter 11.

34. Ersez, T.; Liesegang, J.; Nyberg, G.L. Applied Surface Science 1992, 59, 163-170.

35. Ersez, T.; Liesegang, J. Applied Surface Science 1991, 51, 35.

36. Walsh, P.M.; Sarofim, A.F.; Beer, J.M. Energy and Fuels 1992, 6, 709-715.

37. Zygarlicke, C.J.; Allen, S.A.; Benson, S.A.; McCollor, D.P. "Ash Deposit Initiation in a Simulated Fouling Regime," Energy and Fuels, in review.

38. Braaten, D.A.; Paw U, K.T. Aerosol Science and Technology 1992, 17, 289-302.

39. Mulcahy, M.F.R.; Boow, J.; Goard, P.R.C. J. Inst. Fuel 1966, 39 (308), 385.

40. Ohmine, S. Report \#ESD-78-29, October 1978, reproduced in CE Combustion Textbook; 1991 ed. 
41. Raask, E. Mineral Impurities in Coal Combustion; Hemisphere Publishing: New York, 1985; Chapter 10.

42. Nowok, J.W.; Benson, S.A.; Jones, M.L; Kalmanovitch, D.P. Fuel 1990, 69, 1020-1029.

43. Nowok, J.W.; Hurley, J.P.; Steadman, E.N. "A New Approach to Calculating Coal Ash Viscosities," Presented at the Engineering Foundation Conference The Impact of Ash Deposition on Coal-Fired Plants, June 20-25, 1993, Birmingham, UK.

44. Jung, B.; Schobert, H.H. Energy and Fuels 1992, 6, 59-68.

45. Wain, S.E.; Livingston, W.R.; Sanyal, A.; Williamson, J. Inorganic Transformations and Ash Deposition During Combustion; Benson, S.A., Ed.; ASME for the Engineering Foundation, New York, NY, 1992; pp 459-470.

46. McCollor, D.P.; Zygarlicke, C.J.; Toman, D.L.; Evenstad, D.N. "A Laboratory-Scale Method to Assess Ash Deposit Removability," Presented at the Engineering Foundation Conference, The Impact of Ash Deposition on Coal-Fired Plants, June 20-25, 1993, Birmingham, UK.

47. Weisbecker, T.; Zygarlicke, C.J.; Jones, M.L. "Correlation of Inorganic Components in U.S. Powder River Basin Coals to Full-Scale Performance," In Inorganic

Transformations and Ash Deposition during Combustion; Benson, S.A., Ed.; American Society of Mechanical Engineers: New York, 1992; pp 699-711.

48. Moza, A.K.; Austin, L.G. Inst. Energy 1979, 52, 15.

49. Moza, A.K.; Shoji, K.; Austin, L.G. Inst. Fuel, 1980, 53, 17.

50. Tufte, P.H.; Gronhovd, G.H.; Sondreal, E.H.; Selle, S.J. "Ash-Fouling Potentials of Western Subbituminous Coals as Determined in a Pilot Plant Test Furnace," American Power Conference, Chicago, IL, 1976.

51. Sondreal, E.A.; Gronhovd, G.H.; Tufte, P.H.; Beckering, W. "Ash-Fouling Studies of Low-Rank Western Coals, Ash Deposition and Corrosion Due to Impurities in Combustion Gases Conf.," Bryers, R.W., Ed.; Hemisphere: Washington, D.C., p 85.

52. Tufte, P.H.; Beckering, W. ASME J. Eng. for Power 1975, 407. 


\section{Subtask 3.2 Pressurized Combustion}

\section{Introduction}

One of the overall goals of the U.S. Department of Energy is the development of the technology necessary to provide for a secure, reliable, affordable, and environmentally sound source of energy. This is important in order to ensure economic stability and growth in the next century as well as to reduce current, and minimize future, environmental impacts associated with power generation in the United States and the world as a whole. The continued and potentially expanded use of abundant coal reserves is one key to a secure and affordable source of energy in the United States.

Throughout the world, coal will play an expanded role in the production of affordable energy necessary to meet the demands of economic development and growth. The development of more efficient and environmentally sound technology in the United States may present export market opportunities throughout the world; specific examples include Eastern Europe and the Pacific Rim. In Eastern Europe, where substantial coal utilization has occurred for decades, an urgent need exists for commercial emissions control technology as well as for current clean coal technology. The lack of emission control technology in Eastern Europe is exacting a high price in terms of human health and long-term environmental damage. In contrast, the Pacific Rim has only recently begun to expand the use of coal to meet energy demands motivated by economic growth. Therefore, the need in the Pacific Rim is for commercial and developing technologies to allow new coal-fired plants to meet current and future energy demands in an environmentally sound manner.

In order for coal to play a key role in the U.S. energy mix, it will be necessary to develop and commercialize technologies capable of producing electricity at significantly higher overall system efficiencies than the $30 \%-35 \%$ levels currently observed in conventional coal-fired systems. Also, the production of liquid and gaseous fuels from coal will be necessary in order to effectively meet the broad spectrum of future energy needs. In order to achieve overall system efficiencies of $40 \%$ to $60 \%$ in an environmentally acceptable manner, development and demonstration of advanced second-generation utilization and conversion technology will be necessary. Examples include 1) advanced pc-fired combustion systems; 2) high-temperature heat exchangers for indirect firing of gas turbines; 3) pressurized combustion in staged, entrained-, slagging, and fluidized-bed modes; and 4) integrated gasification and direct gas-fired turbines.

A number of barrier issues exist that are not unique to individual technologies but are in some manner common to all advanced power system processes for both oxidizing and reducing environments. Examples include materials issues, specifically ceramic and refractory components, and operational issues unique to high-temperature pressurized systems.

\section{Objectives}

The goal of the pressurized fluidized-bed combustion (PFBC) activity is to generate fundamental process information that will further the development of an economical and environmentally acceptable second-generation PFBC. The immediate objectives focus on generic issues, including the fate of alkali, the sulfide species in the carbonizer char, and 
the RCRA heavy metals in PFBC. A great deal of PFBC performance relates to the chemistry of the bed and the gas-solids contacting that occur during combustion. These factors can be studied in a suitably designed bench-scale reactor. Studies will focus on the emission control strategies applying in the bed, rather than in hot-gas cleaning. Emissions include alkali and heavy metals in addition to $\mathrm{SO}_{2}, \mathrm{NO}_{2}, \mathrm{~N}_{2} \mathrm{O}$, and $\mathrm{CO}$. No work is proposed on the pilot-scale carbonizer. However, some of the chemistry of the carbonizer can be simulated in the small-scale reactor.

The goal of the proposed research on slagging combustion is to understand and predict the effect of low-rank coal properties on the design and operation of such units. Barrier issues to be studied over time include slag rejection, sulfur capture, alkali partitioning, and slag corrosion. The objective of slag attack research is to mitigate slag corrosion of ceramic materials in a slagging coal-fired combustor.

\section{Accomplishments}

\section{- CONSTRUCTION OF BENCH-SCALE REACTOR}

The bench-scale PFB reactor is nearing completion. A thorough stress analysis of the system was performed to establish the limits for hydrostatic pressure testing. The unit is rated to operate at $982^{\circ} \mathrm{C}\left(1800^{\circ} \mathrm{F}\right)$ at a pressure of $89 \mathrm{psig}$ and at $760^{\circ} \mathrm{C}\left(1400^{\circ} \mathrm{F}\right)$ at a pressure of $579 \mathrm{psig}$. Heaters on the reaction chamber are being installed. An indirect flue gas heat-exchange system to cool the flue gas to less than $300^{\circ} \mathrm{C}$ (the limit of the letdown valve) prior to pressure letdown has been constructed. An instrument panel from another system has been moved to the control room, and the electrical work, including the installation of heaters, pressure transmitters, and thermocouples, is underway. A computer-controlled data acquisition system for displaying, recording, and controlling process conditions is being programmed and interfaced with the instrument panel.

Several modifications have been made to the room that will house the reactor. A canopy-type fume hood was constructed to draw heat and possible fugitive emissions from the room. A window made of impact-resistant plastic was installed between the reactor room and the control room. A high-pressure nitrogen line is already in the room; a highpressure air line has been located and will be brought into the room this month. During the next three months, construction and installation of the PFBR will be completed. The computer data acquisition system will be refined. Shakedown testing will be performed to verify design conditions and develop operating procedures for the unit. Data collected during shakedown will be used to develop data reduction proceàres. Parametric testing will begin following successful shakedown.

\section{- Corrosion of Monolithic Refractories}

Silicon carbide-based monolithic refractories are commonly used in coal combustion environments. Their thermal conductivities are superior to conventional materials, such as alumina or chrome-based refractories, so they are useful as replaceable, corrosion. resistant coatings on surfaces through which heat flow is required. Therefore, they are ideal for use as protective coatings on ceramic heat exchangers in advanced coal combustion systems. For areas where heat transfer is not critical, alumina-based 
refractories are commonly used. Alumina refractories are known for their high maximum temperatures and their resistance to thermal shock.

In slagging coal combustion systems, a refractory may be exposed to temperatures above $1400^{\circ} \mathrm{C}$, but in conventional fluidized-bed combustors, temperatures are several hundred degrees lower. Therefore, it is important to understand the interactions between refractories and coal ashes in a range of temperatures. Once the mechanisms of corrosion have been identified, methods to reduce the corrosion, such as coal additives or materials improvements, can be investigated.

- Silicon Carbide-Based Refractories

\section{- Background}

The literature describes experiments performed on silicon carbide (SiC) structural ceramics $(1,2)$ and $\mathrm{SiC}$ refractory bricks (3). The corrosion of structural SiC ceramics by acidic coal slags at $1230^{\circ} \mathrm{C}$ resulted in localized corrosion by iron silicides (1). The corrosion by high-calcium, basic slags at $1240^{\circ} \mathrm{C}$ was characterized by uniform corrosion by the dissolution of a protective $\mathrm{SiO}_{2}$ layer by $\mathrm{CaO}$ in the slag to form calcium silicate compounds (2). The corrosion of SiC refractory bricks by acidic and basic slags at $1500^{\circ} \mathrm{C}$ involved the formation of iron silicides, and the basic slag corroded the $\mathrm{SiC}$ more rapidly than the acidic slags

Although the literature describes corrosion of SiC ceramics and refractory bricks, little information exists on the corrosion of monolithic $\mathrm{SiC}$ refractories by coal ash. Monolithic refractories are nonbrick materials that are usually mixed with water at the application site, applied to a surface in a cement-like form, and fired to sinter the material causing it to develop strength. Monolithic refractories are much more suitable for coatings than are refractory bricks since they can be easily applied by casting or gunning in any thickness and because they form a much more intimate contact with a heat-exchange surface than do bricks. To ensure that monolithic refractories remain in place during firing, a low-temperature binder or cement is used. Two common binder materials are phosphoric acid, which produces a chemical bond at $260^{\circ} \mathrm{C}$, and calcium aluminate, which develops a ceramic bond above $980^{\circ} \mathrm{C}$.

To determine slag corrosion mechanisms and rates, five commercially available SiC refractories were subjected to static slag corrosion tests. They included both castable and plastic monolithic $\mathrm{SiC}$ refractories and were donated by Carborundum Company, Harbison-Walker, and Premier Refractories. Much of the SiC refractory work was performed under a Combustion 2000 project for which the EERC is a subcontractor. The data from that research which are provided here are the same as those data provided in a paper accepted for presentation at the American Chemical Society conference in Chicago in August 1993 (4). The Combustion 2000 data are presented here for purposes of continuity with the Cooperative Agreement research on refractory corrosion.

- Experimental

These experiments focused on ash corrosion mechanisms and rates for corrosion of monolithic $\mathrm{SiC}$ refractories. The castable materials contained calcium aluminate binders, and the plastics contained phosphoric acid binders. The $\mathrm{SiC}$ concentrations in the 
castables that were tested ranged from $75 \%$ to $83 \%$, and the SiC concentrations in the plastics ranged from $59 \%$ to $70 \%$ (Table 3.2.1).

The samples were prepared according to manufacturer's instructions, and each sample was formed into a cup shape to hold the coal ash during the exposure. The samples were then prefired, which caused the development of vesicular glass coatings on the plastics, but the calcium aluminate-bonded refractories were not affected, so the vesicular glass formation was attributed to the phosphoric acid binders in the plastic SiC refractories.

The two coal ashes used in the corrosion experiments included a high-calcium PRB coal osh and a high-iron Illinois No. 6 ash (Table 3.2.2). Approximately 5 grams of ash was placed into the cup of each sample, then the samples were heated to temperatures of $1090^{\circ}, 1260^{\circ}$, and $1430^{\circ} \mathrm{C}$ at a rate of $120^{\circ} \mathrm{C}$ per hour. The castables were tested with both coal ashes at all exposure temperatures, and the plastics were tested only at $1430^{\circ} \mathrm{C}$ for 110 hours. All of the samples were quenched in air to determine phases present at temperature, then cross-sectioned, and examined.

\section{- Low-Temperature Exposure $-1090^{\circ} \mathrm{C}$ for 55 hours}

The two SiC castables, containing 75\% and 85\% SiC, were exposed to both ashes for 55 hours. After the exposure, the PRB ash was somewhat sintered, but porous and friable, and the Illinois No. 6 ash was well sintered and more dense than the PRB ash.

TABLE 3.2.1

Technical Data for the SiC Refractories

\begin{tabular}{|c|c|c|c|c|}
\hline $\begin{array}{l}\text { Material Name: } \\
\text { Type: }\end{array}$ & $\begin{array}{c}\text { SiC } \\
\text { Castable 1 }\end{array}$ & $\begin{array}{c}\mathrm{SiC} \\
\text { Castable } 2\end{array}$ & $\begin{array}{c}\text { SiC } \\
\text { Plastic } 1\end{array}$ & $\begin{array}{c}\mathrm{SiC} \\
\text { Plastic } 2 \\
\end{array}$ \\
\hline $\begin{array}{l}\text { Maximum Temperature } \\
\quad{ }^{\circ} \mathrm{C} \\
{ }^{\circ} \mathrm{F}\end{array}$ & $\begin{array}{l}1480 \\
2700\end{array}$ & $\begin{array}{l}1482 \\
2700\end{array}$ & $\begin{array}{l}\text { NA* } \\
\text { NA }\end{array}$ & $\begin{array}{l}1693 \\
2900\end{array}$ \\
\hline $\begin{array}{l}\text { Composition, wt\% } \\
\mathrm{SiC} \\
\mathrm{SiO}_{2} \\
\mathrm{Al}_{2} \mathrm{O}_{3} \\
\mathrm{CaO} \\
\mathrm{Fe}_{2} \mathrm{O}_{3} \\
\mathrm{P}_{2} \mathrm{O}_{5}\end{array}$ & $\begin{array}{r}83.0 \\
1.3 \\
12.5 \\
2.8 \\
0.2\end{array}$ & $\begin{array}{r}75.1 \\
1.7 \\
19.0 \\
3.4 \\
0.5\end{array}$ & $\begin{array}{r}70.6 \\
7.0 \\
18.6\end{array}$ & $\begin{array}{r}58.6 \\
7.2 \\
29.6 \\
0.1 \\
0.2 \\
4.0\end{array}$ \\
\hline $\begin{array}{l}\text { Thermal Conductivity } \\
\text { W/m॰K @1477 K } \\
\text { Btu in } / \mathrm{hr} \mathrm{ft}^{\circ}{ }^{\circ} \mathrm{F} @ 2200^{\circ} \mathrm{F}\end{array}$ & $\begin{array}{c}5.8 \cdot 8.7 \\
40-60\end{array}$ & $\begin{array}{c}4.23 \\
29.35\end{array}$ & $\begin{array}{c}6.2 \\
43.0\end{array}$ & $\begin{array}{c}4.96 \\
34.95\end{array}$ \\
\hline $\begin{array}{l}\text { Density } \\
\mathrm{g} / \mathrm{cm}^{3} \\
\mathrm{lb} / \mathrm{ft}^{3}\end{array}$ & $\begin{array}{l}2.32 \\
145\end{array}$ & $\begin{array}{l}2.31 \\
144\end{array}$ & $\begin{array}{c}2.58 \\
161\end{array}$ & $\begin{array}{c}2.56 \\
160\end{array}$ \\
\hline
\end{tabular}

* Not available. 
Neither ash adhered well to the SiC refractory substrates, indicating that soot blowing would be an effective means of ash removal at this temperature. X-ray fluorescence of the ashes after the exposure showed that they did not react with the refractory, and there was no infiltration of the ash into the refractory.

- Intermediate-Temperature Exposure $-1260^{\circ} \mathrm{C}$ for 45 hours

A similar test was conducted at $1260^{\circ} \mathrm{C}$ using the $75 \%$ and $85 \%$ SiC castable refractories. The samples were held at temperature for $\mathbf{4 5}$ hours, then quenched, and examined using optical microscopy and scanning electron microscopy with energy. dispersive X-ray analysis (SEM/EDX). Both ashes were liquid at $1260^{\circ} \mathrm{C}$ and reacted with the $\mathrm{SiC}$ refractories.

\section{Powder River Basin Coal Ash}

Each castable sample contained a 3. to $4 \cdot \mathrm{mm}$ layer of dark gray slag, which contained a few small vesicles, approximately $0.5 \mathrm{~mm}$ in diameter, indicating gas evolution during the exposure. The slag contained a continuous, red reaction layer, 0.5 mm thick, at the undulating, slag/refractory interface. Figure 3.2.1 shows several circuiar, metallic phases, ranging up to $0.25 \mathrm{~mm}$ in diameter, at the interface. The circular nature of these phases, which were high in iron, indicates that they were liquid at $1260^{\circ} \mathrm{C}$ and immiscible with the slag. The maximum depth of penetration of the slag into both refractorles was $1 \mathrm{~mm}$.

TABLE $3.2 \cdot 2$

Compositions of the Powder River Basin Ash and the Illinois No. 6 Ash Used in the Corrosion Experiments

\begin{tabular}{lcc}
\hline Oxide & Powder River Basin Ash, wt\% & Illinois No. 6 Ash, wt\% \\
\hline $\mathrm{Na}_{2} \mathrm{O}$ & 2.52 & 1.18 \\
$\mathrm{MgO}$ & 9.44 & 2.50 \\
$\mathrm{Al}_{2} \mathrm{O}_{3}$ & 15.93 & 18.50 \\
$\mathrm{SiO}_{2}$ & 31.08 & 57.80 \\
$\mathrm{P}_{2} \mathrm{O}_{3}$ & 1.77 & 0.00 \\
$\mathrm{SO}_{3}$ & 0.00 & 0.00 \\
$\mathrm{~K}_{2} \mathrm{O}$ & 0.30 & 0.62 \\
$\mathrm{CaO}$ & 33.00 & 3.74 \\
$\mathrm{TiO}_{2}$ & 1.03 & 1.03 \\
$\mathrm{FeO}$ & 4.40 & 14.62 \\
& & \\
Base/Acid* & 1.03 & 0.29 \\
\hline Base/Acid $=\left(\mathrm{FeO}+\mathrm{CaO}+\mathrm{MgO}^{2}+\mathrm{Na}_{2} \mathrm{O}+\mathrm{K}_{2} \mathrm{O}\right) /\left(\mathrm{SiO}_{2}+\mathrm{AJ}_{2} \mathrm{O}+\mathrm{TiO}_{2}\right)$.
\end{tabular}




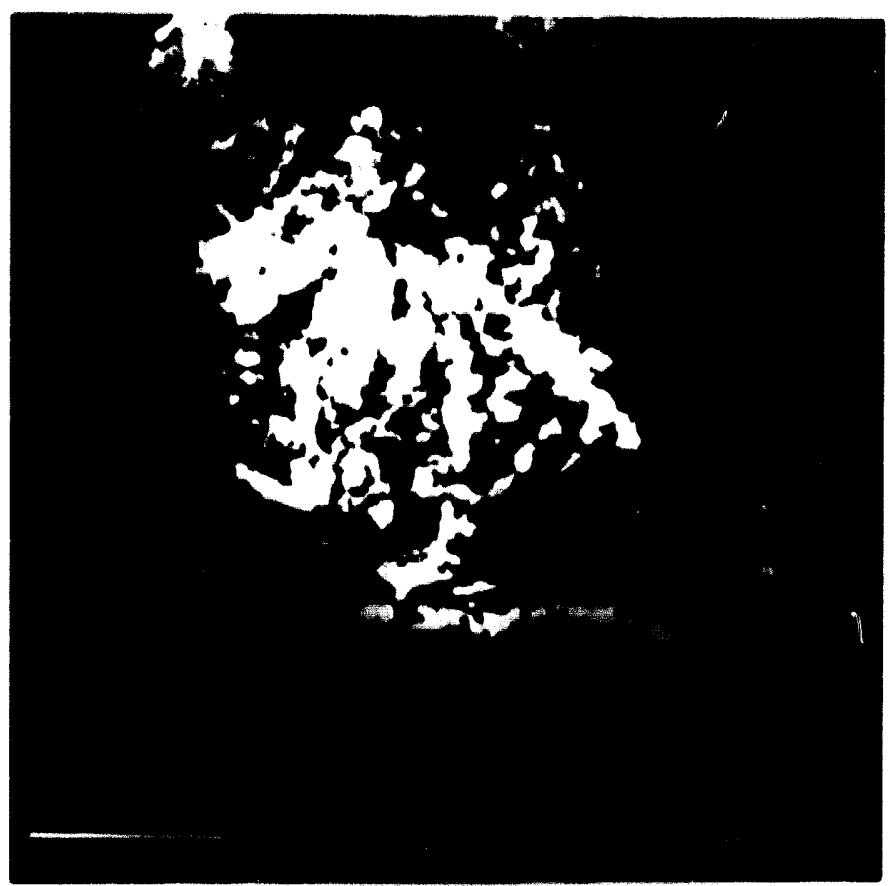

Figure 3.2.1. SEM micrograph of the reaction layer between the slag and an SiC castable refractory exposed to a PRB coal ash at $1260^{\circ} \mathrm{C}$ for 46 hours.

A few of the high-iron grains at the refractory/slag interface contained mainly $\mathrm{Fe}$ (55 wt\%) and $\mathrm{O}_{2}$ (40 wt\%), but several other grains contained $\mathrm{Fe}$ (60 wt\%), Si (up to 10 $w t \%$ ), and $P$ (up to $20 \mathrm{wt} \%$ ), which is similar in composition to iron silicides described in other studies $(1,2)$, although phosphorus is not mentioned. Iron silicides are stable only under nonoxidizing conditions, and their presence indicates that portions of the slags had low partial pressures of oxygen during the exposure. The iron oxide in the slag reacts with the $\mathrm{SiC}$ to form the iron silicide. This reaction also causes gas evolution of $\mathrm{CO}$ or $\mathrm{CO}_{2}$, as indicated by vesicles in the slags.

The remaining slags in both samples were very similar in composition (Table 3.2.3). In comparison with the original ash (Table 3.2.2), the slags contained less calcium oxide and more silica. The decrease in calcium is difficult to explain because no high-calcium phases were identified, but the increase in silica can be explained by the oxidation and dissolution of SiC grains from the refractory into the slag.

\section{Illinois No. 6 Coal Ash}

The slags remaining in the castable samples ranged from 5 to $6 \mathrm{~mm}$ thick and were black in color. Many 0.5. to 2.mm-diameter vesicles were present at the top of the slags, with a few smaller vesicles present at the slag/refractory boundaries, which were probably formed from $\mathrm{CO}$ or $\mathrm{CO}_{2}$ evolution during the oxidation of the $\mathrm{SiC}$. The samples exposed 
to the PRB ash contained only a few vesicles, indicating that the refractory reacted less with the PRB ash to produce fewer vesicles or that the PRB slag was less viscous at this temperature, as indicated from the higher base/acid ratio, and allowed vesicles that formed to escape rapidly from the slag.

The maximum depth of corrosion reached $0.25 \mathrm{~mm}$, but corrosion and surface pitting of the refractories were uneven and occurred in isolated areas, unlike the samples exposed to the PRB ash, which caused an even reaction layer. The slag/refractory interfaces contained discontinuous, red reaction layers and circular, iron-rich phases, 0.25 to $0.5 \mathrm{~mm}$ in diameter (Figure 3.2.2). The iron phases were composed of $\mathrm{Fe}(75.80 \mathrm{wt} \%)$ and $\mathrm{Si}(15.20$ wt\%), with little or no $\mathrm{O}_{2}$ or $\mathrm{P}$.

The resultant slag compositions were similar in both samples and differed only slightly from the original ash composition (Table 3.2.3). The slag contained less iron oxide than the ash, but the other major oxides were present in almost equal amounts.

\section{- High-Temperature Exposure $-1430^{\circ} \mathrm{C}$ for 40 Hours}

Both castable SiC refractories were subjected to a corrosion test with the PRB and Illinois No. 6 ashes at $1430^{\circ} \mathrm{C}$ for 40 hours. The samples were quenched and analyzed after the exposure. Reaction between the slags and refractories seemed to be more extensive at this temperature than observed at $1260^{\circ} \mathrm{C}$.

\section{Powder River Basin Coal Ash}

The residual slag layers in the castable SiC refractories ranged from 1 to $3 \mathrm{~mm}$ thick. The slags were tan in color and highly vesicular with the vesicles ranging in size from 0.5 to $2 \mathrm{~mm}$ in diameter. The slag was able to penetrate $2.5 \mathrm{~mm}$ into the refractory

TABLE $3.2 \cdot 3$

Resultant Slag Compositions for the $1260^{\circ} \mathrm{C}, 46 \cdot$ hour Exposure

\begin{tabular}{lcc}
\hline Oxide & Powder River Basin Slag, wt\% & Illinois No. 6 Slag, wt\% \\
\hline $\mathrm{Na}_{2} \mathrm{O}$ & 0.6 & 0.9 \\
$\mathrm{MgO}$ & 5.0 & 0.9 \\
$\mathrm{Al}_{2} \mathrm{O}_{3}$ & 16.7 & 20.7 \\
$\mathrm{SiO}_{2}$ & 52.0 & 62.3 \\
$\mathrm{P}_{2} \mathrm{O}_{3}$ & 0.0 & 0.1 \\
$\mathrm{SO}_{3}$ & 0.2 & 0.1 \\
$\mathrm{~K}_{2} \mathrm{O}$ & 0.2 & 1.4 \\
$\mathrm{CaO}$ & 23.4 & 5.1 \\
$\mathrm{TiO}_{2}$ & 0.5 & 0.8 \\
$\mathrm{FeO}$ & 0.5 & 7.6 \\
$\mathrm{Base} /$ Acid & 0.4 & 0.2 \\
\hline
\end{tabular}


materials, and the penetration was aided by dissolution of the refractory binder and the incorporation of $\mathrm{SiC}$ grains into the slag. Some of these incorporated SiC grains were coated with red reaction rims that contained high amounts of iron and silicon. These rimmed grains indicate that the iron in the slag can be reduced to elemental iron and react with the $\mathrm{SiC}$ to produce iron silicides. Only a few circular, iron-rich grains were present in the slag and ranged from 0.25 to $1.0 \mathrm{~mm}$ in diameter. These phases contained $70 \mathrm{wt} \% \mathrm{Fe}, 10 \mathrm{wt} \% \mathrm{Si}$, and $10 \mathrm{wt} \% \mathrm{P}$.

Chemical analyses of the slag remaining in the $\mathrm{SiC}$ refractory samples are given in Table 3.2.4. In general, the slag contained less calcium and magnesium and more silica than the original ash composition (Table 3.2.2). The increase in silica content resulted from oxidation and dissolution of $\mathrm{SiC}$ grains by the slag.

\section{Illinois No. 6 Coal Ash}

The castable SiC samples contained layers of residual slag that ranged from 3 to $5 \mathrm{~mm}$ thick and the slag/refractory interfaces were undulating. Many vesicles, from 0.25 to $3 \mathrm{~mm}$ in diameter, were present along the top surfaces of the slags. Several circular metallic grains were present at the refractory/slag interfaces and were approximately 0.25 to $0.5 \mathrm{~mm}$ in diameter. These grains contained $75 \mathrm{wt} \% \mathrm{Fe}, 20 \mathrm{wt} \% \mathrm{Si}, 5 \mathrm{wt} \% \mathrm{O}_{2}$, and less than $2 \mathrm{wt} \% \mathrm{P}$ and were present in isolated areas along the slag/refractory interface. The maximum depth of slag penetration was $0.75 \mathrm{~mm}$.

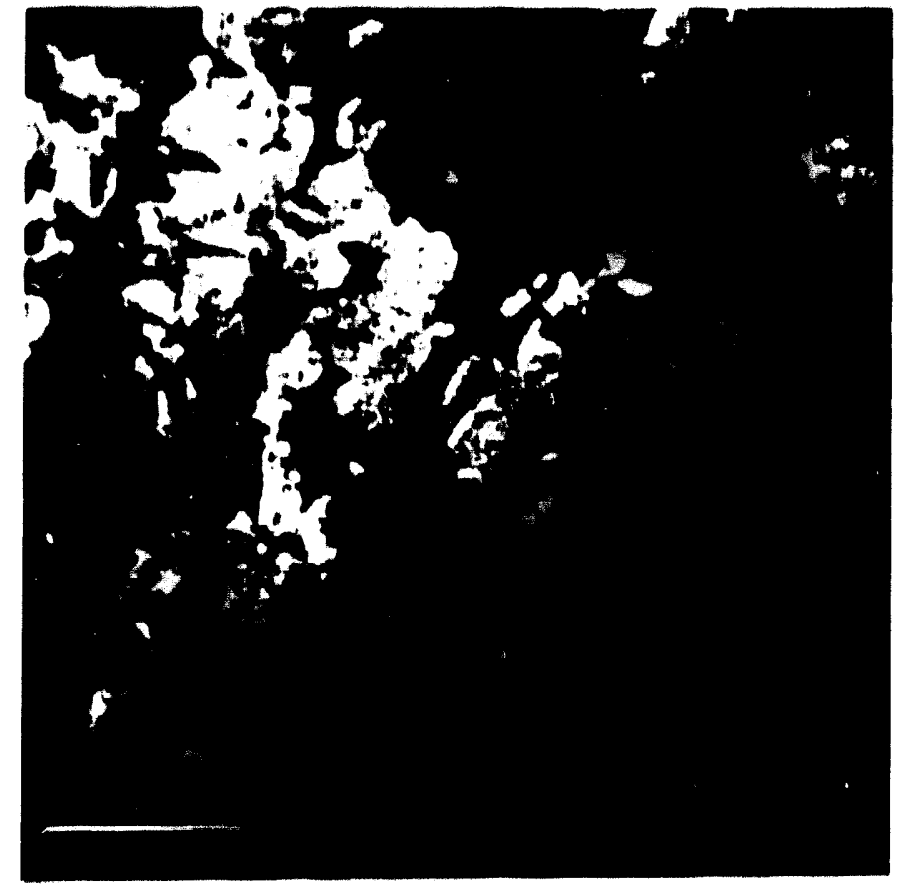

Figure 3.2.2. SEM micrograph of the slag/refractory boundary in an SiC castable refractory exposed to an Illinois No. 6 coal ash at $1260^{\circ} \mathrm{C}$ for 45 hours. 
The castables seemed to react less with the Illinois No. 6 ash than the PRB ash, but some reaction occurred to alter the slag composition (Table 3.2.4). The resultant slag contained less iron and more calcium and silica than the original ash. The reduction of iron in the slag resulted from the formation of iron silicides during the dissolution of the $\mathrm{SiC}$ refractory.

- High.Temperature Exposure $-1430^{\circ} \mathrm{C}$ for 80 Hours

\section{Powder River Basin Coal Ash}

The samples contained residual slag layers 1 to $3 \mathrm{~mm}$ thick. The slags were transparent and highly vesicular, with vesicles ranging from 1 to $2 \mathrm{~mm}$ in diameter. The slag/refractory interfaces of both samples were marked with a red reaction layer, which contained small $\left(0.25 \mathrm{~mm}\right.$ in diameter), iron-rich phases (70 wt\% $\mathrm{Fe}, 10 \mathrm{wt} \% \mathrm{Si}, 8 \mathrm{wt} \% \mathrm{O}_{2}$, 9 wt\% P). The maximum depth of slag penetration was $4 \mathrm{~mm}$, which is about twice the depth of penetration for the samples exposed for 40 hours.

SEM analysis indicated that the ash reacted with the refractory materials to produce a resultant slag similar in composition to the slag of the 40 -hour $1430^{\circ} \mathrm{C}$ exposure (Table 3.2.4). The slags contained more silica and less calcium and magnesium than the original ash. The decreases in calcium and magnesium may be related to the formation of calcium-magnesium phases that were not detected, but other explanations may account for their decreases. The increase in silica was caused by the oxidation and dissolution of $\mathrm{SiC}$ grains by the slag.

\section{Illinois No. 6 Coal Ash}

A 2. to 3.mm layer of slag was present in both of the castable samples after the 80 hour exposure. The slags contained a few isolated vesicles $(0.25$ to $0.5 \mathrm{~mm}$ in diameter $)$ at

\section{TABLE 3.2-4}

Resultant Slag Compositions for the $1430^{\circ} \mathrm{C}, 40$-hour Test

\begin{tabular}{lcc}
\hline Oxide & Powder River Basin Slag, wt\% & Illinois No. 6 Slag, wt\% \\
\hline $\mathrm{Na}_{2} \mathrm{O}$ & 0.9 & 0.6 \\
$\mathrm{MgO}$ & 1.7 & 1.0 \\
$\mathrm{Al}_{2} \mathrm{O}_{3}$ & 8.9 & 21.6 \\
$\mathrm{SiO}_{2}$ & 69.4 & 66.5 \\
$\mathrm{P}_{2} \mathrm{O}_{6}$ & 0.4 & 0.0 \\
$\mathrm{SO}_{3}$ & 0.0 & 0.1 \\
$\mathrm{~K}_{2} \mathrm{O}$ & 0.1 & 1.5 \\
$\mathrm{CaO}$ & 14.5 & 6.9 \\
$\mathrm{TiO}_{2}$ & 0.8 & 0.9 \\
$\mathrm{FeO}$ & 2.9 & 0.7 \\
$\mathrm{Base} /$ Acid & 0.3 & 0.1 \\
\hline
\end{tabular}


the slag/refractory interfacus. Several, circular iron-rich grains were present at the interfaces and wol 0.25 to $1.0 \mathrm{~mm}$ in diameter. These high.iron phases contained 70 to $75 \mathrm{wt} \% \mathrm{Fe}, 20 \mathrm{wt} \% \mathrm{Si}, 5$ to $10 \mathrm{wt} \% \mathrm{O}_{2}$, and no $\mathrm{P}$. The occurrences of the iron-rich phases were isolated, which resulted in isolated surface pitting of the refractories, and the maximum depth of slag penetration was $3 \mathrm{~mm}$, which is more than twice the depth of penetration during the 40-hour exposure.

The SEM analyses indicated that the resultant slags were similar in composition to the 40 -hour $1430^{\circ} \mathrm{C}$ exposure and contained more silica and less iron than the original slag (Table 3.2.4). The decrease in iron is related to the formation of iron silicides, and the increase in silica is a result of oxidation and dissolution of the $\mathrm{SiC}$ grains by the slag.

\section{- High-Temperature Exposure $-1430^{\circ} \mathrm{C}$ for 110 Hours (PRB Ash)}

Three plastic refractories, with $\mathrm{SiC}$ compositions ranging from $58 \%$ to $70 \%$, were exposed to the PRB ash at $1430^{\circ} \mathrm{C}$ for 110 hours. After the exposure, the samples were quenched, cross-sectioned, and examined optically.

The plastic samples contained residual slag layers 3 to $4 \mathrm{~mm}$ thick. A fow small metallic grains were present within the slags, which contained vesicles ranging from 0.5 to $1 \mathrm{~mm}$ in diameter. The slag easily penetrated the plastic refractory materials, and penetration depths reached $10 \mathrm{~mm}$ in most samples.

\section{- Conclusions for SiC Refractories}

Table 3.2-5 gives the penetration rates for the castable refractories exposed to the PRB and the Illinois No. 6 ashes in the static corrosion tests. The $1090^{\circ} \mathrm{C}$ exposure showed no ash penetration and was not included in the table, and the plastics were omitted because of their rapid penetration rates. Table 3.2 .5 also shows the penetration rates relative to a $25 \cdot \mathrm{mm}(1 \cdot \mathrm{in})$ refractory layer. These penetration rates are derived from static slag corrosion tests and do not take into consideration erosional effects of flowing slag or replenishment of fresh slag in a dynamic system. In a dynamic system, penetration rates are expected to be higher than rates determined from these static tests, but these results are still useful for comparison purposes.

The corrosion of the $\mathrm{SiC}$ refractories by the PRB ash was characterized by relatively uniform surface reaction, similar to previous studies $(1,2)$. Although iron silicides were found, their formation was probably not the main corrosion mechanism for this ash. The slag attacked and dissolved the refractory binder and incorporated $\mathrm{SiC}$ grains into the slag. The $\mathrm{CaO}$ in the slag may also have dissolved the protective $\mathrm{SiO}_{2}$ layer on th: surface of the $\mathrm{SiC}$ to form calcium silicate compounds.

The Illinois No. 6 ash caused localized surface pitting by the formation of iron silicide compounds. This type of corrosion was not as rapid as penetration by the PRB ash, but was still rapid at the $1430^{\circ} \mathrm{C}$ exposures. Only the Illinois No. 6 at $1260^{\circ} \mathrm{C}$ had an acceptable corrosion rate that would require replacement of a $25 \cdot \mathrm{mm}$ layer of refractory every 6 months.

The differences in penetration rates of the two coal ashes may be related to slag viscosity, which is dependent on ash composition and temperature. The base-to-acid ratios 
indicate that the PRB slag probably had a lower viscosity at all exposure temperatures, which would facilitate the diffusion of corrosive elements ( $\mathrm{Ca}$ and $\mathrm{Fe}$ ) to the $\mathrm{SiC}$ surface. As temperature increases, viscosity decreases, which would also increase diffusion. The penetration rates also increased when the exposure time was increased from 40 to 80 hours at $1430^{\circ} \mathrm{C}$; therefore, the penetration rates are not uniform over long exposure times, and future work should focus on comparisons of short- and long-term slag corrosion experiments.

\section{- Alumina-Based Refractories}

Several alumina-based monolithic refractories were subjected to slag corrosion testing (Table 3.2-6). The materials were donated by Carborundum Company and Premier Refractories and included two high-alumina castables, Alumina 1 and Numina 2 (Carborundum and Premier Refractories), and an alumina-silica or mullite castable from Premier. The refractories were prepared according to manufacturers' instructions, which included mixing the dry refractory with water, curing the samples for 24 hours, then prefiring to several temperatures. To allow for containment of the slag during the experiment, each sample was made into a cup shape, similar to the SiC refractory tests.

- High-Temperature Exposure at $1430^{\circ} \mathrm{C}$ with PRB Ash

The Alumina 1 material was exposed to a high-calcium PRB (Powder River Basin) coal ash (Table $3.2-2$ ) at $1430^{\circ} \mathrm{C}$ for 155 hours. After the exposure, the sample was brought to room temperature at a rate of $260^{\circ} \mathrm{F}$ per hour, cross-sectioned, and examined using an optical microscope.

The high porosity of this sample allowed for extensive slag infiltration and reaction. No residual slag was on the surface of the sample because most of the slag was absorbed by the alumina refractory matrix. Sample cross sections revealed a yellowish halo around

TABLE $3.2-5$

Penetration Rates for SiC Castable Refractories Exposed to Powder River Basin and Illinois No. 6 Ashes

\begin{tabular}{lcccrr}
\hline & Temperature, & $\begin{array}{c}\text { Exposure } \\
\text { Time, } \\
\text { hours }\end{array}$ & $\begin{array}{c}\text { Penetration } \\
\text { Rate, } \\
\text { mm/100 hours }\end{array}$ & $\begin{array}{c}\text { Time for } \\
\text { Penetration of } \\
25-m m \text { Layer } \\
\text { hoursweeks }\end{array}$ \\
\hline PRB & 1260 & 45 & 2.2 & 1100 & 6.5 \\
PRB & 1430 & 40 & 6.3 & 400 & 2.4 \\
PRB & 1430 & 80 & 7.5 & 300 & 1.8 \\
Illinois No. 6 & 1260 & 45 & 0.6 & 4500 & 26.8 \\
Illinois No. 6 & 1430 & 40 & 1.9 & 1300 & 7.7 \\
Illinois No. 6 & 1430 & 80 & 3.8 & 700 & 4.2 \\
\hline
\end{tabular}


the cup of the boat, but the large alumina grains were not discolored. The sides of the refractory contained several vesicles, cracks, and microporosity. The base of the refractory had a similar appearance. The high levels of calcium in the PRB ash may have reacted with the alumina in the refractory to form calcium aluminates with higher molar volumes than the alumina causing excessive crack formation, permitting slag penetration. Due to the extensive slag infiltration, the sample was not analyzed by SEM/EDX.

The Alumina 2 and alumina-silica (mullite) castable refractories were subjected to a slag test at $2600^{\circ} \mathrm{F}$ for over 40 hours with the high-calcium PRB coal ash used in the SiC refractory tests. The mullite material was quite porous after prefiring because of the large grain sizes of this material and the absence of smaller matrix to fill the pores between grains. The alumina material did not seem to be porous after prefiring.

The refractories were quenched after 40 hours of exposure. The mullite material collapsed when it was removed from the furnace, and the slag had infiltrated the porous surfaces of the sample. The slag was also readily absorbed by the Alumina 2 refractory, which was discolored by slag infiltration. Because of the poor performance of these materials at this temperature, they were not examined by SEM/EDX.

TABLE $3.2-6$

Technical Data for Alumina-Based Refractories

\begin{tabular}{lccc}
\hline Material Name: & Alumina 1 & Alumina 2 & Mullite \\
\hline $\begin{array}{c}\text { Maxinum Temperature } \\
{ }^{\circ} \mathrm{C}\end{array}$ & 1815 & 1760 & 1538 \\
${ }^{\circ} \mathrm{F}$ & 3300 & 3200 & 2800 \\
Composition, wt\% & & & \\
$\mathrm{SiC}$ & & & \\
$\mathrm{SiO}$ & & 0.1 & 25.3 \\
$\mathrm{Al}_{2} \mathrm{O}_{3}$ & 96.0 & 97.0 & 66.6 \\
$\mathrm{CaO}$ & 3.6 & 2.7 & 5.0 \\
$\mathrm{Fe}_{2} \mathrm{O}_{3}$ & 0.1 & & \\
$\mathrm{P}_{2} \mathrm{O}_{5}$ & & & \\
Thermal Conductivity & & & \\
$\mathrm{W} / \mathrm{m}_{0.04} \cdot \mathrm{K} @ 1477 \mathrm{~K}$ & $1.7-2.0$ & $<2$ & $\mathrm{NA}$ \\
$\mathrm{Btu}$ in/hr $\mathrm{ft}^{2 \circ} \mathrm{F} @ 2200^{\circ} \mathrm{F}$ & $12-14$ & $<10$ & $\mathrm{NA}$ \\
Density & & & \\
$\mathrm{g} / \mathrm{cm}^{3}$ & 2.72 & 2.64 & 130 \\
$\mathrm{lb} / \mathrm{ft}^{3}$ & 170 & 165 & \\
\hline
\end{tabular}

- High-Temperature Exposure at $1430^{\circ} \mathrm{C}$ with Illinois No. 6 Ash

All three alumina-based refractories were exposed to a high-iron, Illinois No. 6 coal ash (Table 3.2-2) at $1430^{\circ} \mathrm{C}$ for 80 hours. After the exposure, the samples were quenched, cross-sectioned, and examined using an optical microscope. 
All samples showed extensive slag infiltration, and penetration depths ranged from 5 to $15 \mathrm{~mm}$, which correspond to relatively high corrosion rates (Table 3.2-7). The high porosity of these samples allowed the extensive slag infiltration and reaction. The cross section of the samples revealed brown and yellow halos around the penetration zones, and the bases of all samples were discolored by slag infiltration. Due to the extensive slag infiltration, the samples were not analyzed by SEM/EDX.

\section{- Conclusions for Alumina Refractories}

Table 3.2-7 gives the penetration rates for the castable refractories exposed to the PRB and the Illinois No. 6 ashes in the static corrosion tests. Table 3.2-7 also shows the penetration rates relative to a $25-\mathrm{mm}$ (1-in) refractory layer. These penetration rates do not completely reflect the performance of a refractory in a real system where erosional effects of flowing slag and replenishment of fresh slag can increase corrosion and penetration rates, but the static experiment can give information about the relative lifetimes of refractories and can be used to identify the corrosion mechanisms.

The penetration rates for the Illinois No. 6 ash were higher for both the Alumina 1 and 2 refractories. The penetration rates for the mullite refractory was high for both ashes, and the sample exposed to the PRB ash collapsed when it was removed from the furnace, which indicates that this refractory may have a tendency to spall in a real system when exposed to this type of ash.

The differences in penetration rates of the two coal ashes are probably related to reactions between the alumina in the high-alumina refractories and the coal ashes. Interactions between the slags and refractory may alter the original slag viscosities, possibly making the PRB ash more viscous than the Illinois No. 6 ash at the exposure temperature. The original base-to-acid ratios indicated that the PRB slag should have a lower viscosity at the exposure temperature, but additions of alumina into the PRB slag may have altered the viscosity, possibly by causing crystallization. SEM/EDX will be used to determine the causes for the differences in slag penetration.

\section{CORROSION PREVENTION}

\section{- New Refractory Binders}

The leading cause of monolithic refractory failure in the static slag tests reported above was excessive dissolution of the binder material by the slag. The aggregate was sometimes partially coroded, but not nearly to the extent of the binders. Therefore, a literature search, discussions with refractory manufacturers, and laboratory experimentation have begun to find binders that are less prone to slag corrosion and that can withstand higher temperatures without failure than presently available binders. Binders suitable for use with SiC-based refractories are being developed first.

Refractory binders must serve two purposes. They must hold the aggregate material in place before firing and sinter the aggregate at lower temperatures than the sintering temperature of the pure aggregate. Separate binders may be used for each task such as in the structural ceramics industry. However, binders that provide only low-temperature strength such as long-chain alcohols or glycols burn out during firing, often creating a limited amount of porosity in the remaining refractory. Although initially investigated, it 
TABLE $3.2-7$

Penetration Rates for Castable Refractories

Exposed to Powder River Basin and Illinois No. 6 Ashes

\begin{tabular}{lcccccc}
\hline & Ash & $\begin{array}{c}\text { Temperature, } \\
{ }^{\circ} \mathrm{C}\end{array}$ & $\begin{array}{c}\text { Exposure } \\
\text { Time, hours }\end{array}$ & $\begin{array}{c}\text { Penetration Rate, } \\
\mathrm{mm} / 100 \text { hours }\end{array}$ & $\begin{array}{c}\text { Time for Penetration } \\
\text { of 25-mm Layer }\end{array}$ \\
\hline Alumina 1 & PRB & 1430 & 155 & 3.9 & 640 & 3.8 \\
Alumina 2 & PRB & 1430 & 50 & 8.0 & 310 & 1.8 \\
Mullite & PRB & 1430 & 50 & 18.0 & 140 & 0.8 \\
Alumina 1 & Illinois No.6 & 1430 & 80 & 8.8 & 280 & 1.7 \\
Alumina 2 & Illinois No. 6 & 1430 & 80 & 12.5 & 200 & 1.2 \\
Mullite & Illinois No. 6 & 1430 & 80 & 15.0 & 170 & 1.0 \\
\hline
\end{tabular}

was decided to abandon the organic low temperature binders to focus on inorganic binders that provided low-temperature strength and did not burn out on firing. In addition, binders that also participate in the sintering process are preferred, because they serve both of these functions and thus keep the amount of binder in the refractory to a minimum. The size distribution of $\mathrm{SiC}$ was chosen to provide a dense packing to also keep the cement level as low as possible. Since the binder is usually a glass of low thermal conductivity as compared to the $\mathrm{SiC}$, reducing the amount of binder assures that heat transfer will be kept at a maximum. It also assures that the maximum refractory surface area will be made of relatively corrosion-resistant $\mathrm{SiC}$ and not the more soluble binder. Finally, binders exuded from the refractory normally destroy corrosion-resistant paintable coatings, but by reducing the levels of binder to prevent exudation, such coatings may be employed.

Phosphate-based binders were excluded from the test matrix on the basis of poor thermal and corrosion performance in the laboratory experiments. Instead, hydraulic cements that activate and become workable with minimum amounts of water are being investigated. In addition to being a hydraulic cement, the binder must also act as a $\mathrm{SiC}$ sintering aide with a relatively high solidus temperature. Finally, compositions are being investigated that could be expected to raise the viscosity of the coal slag into which it dissolves, thereby reducing the reaction rate between the slag and the binder.

Investigation of the last binder property provides corollary information about possible coal additives that will reduce the corrosion rate of the slag.

Binders with compositions lying in the $\mathrm{CaO} \cdot \mathrm{MgO} \cdot \mathrm{Al}_{2} \mathrm{O}_{3} \cdot \mathrm{SiO}_{2}$ system were investigated during this reporting period. With appropriate pretreatment, excellent hydraulic cements were prepared. Refractories containing $90 \% \mathrm{SiC}$ were prepared (commercially available low-cement castables contain approximately $80 \% \mathrm{SiC}$ ) that had good low-temperature strength before firing and excellent strength after firing. No binder was exuded during firing, implying that coatings could be employer. However, PRB coalslag corrosion was excessive at $1425^{\circ} \mathrm{C}$. Tests are continuing to determine the maximum usable temperature of the material. 


\section{- Coal Additives for Corrosion Prevention}

- Introduction

From the laboratory experiments, several possible corrosion mechanisms have been identified for SiC-based materials. The high-calcium PRB ashes have the potential to dissolve the protective $\mathrm{SiO}_{2}$ layer that forms on the surface of $\mathrm{SiC}$, which exposes the underlying $\mathrm{SiC}$ surface to corrosive slag species, such as iron. In the case of the Illinois No. 6 slag, the iron in the slag directly attacked the $\mathrm{SiC}$ to form iron silicide phases. The slags also dissolved the refractory binder material, which caused the incorporation of refractory grains into the slag.

\section{- Background}

A literature survey was conducted to identify coal additives that have been used in coal combustion systems to modify ash behavior. Previous additive research has focused on a variety of problems and was usually carried out in large systems over which little control was possible, making scientific evaluation difficult. Several common additives used for altering ash and slag properties include copper oxychloride, limestone, dolomite, clay minerals, and sodium compounds (5). Although the literature presents some of these additives for corrosion prevention, most are used to lower ash fusion temperatures to generate a fluid slag. Lowering slag viscosity may increase corrosion of ceramics in contact with the slag. One additive, copper oxychloride, can change crystallization properties of a slag, which may be useful in corrosion prevention, with only small additions to the coal.

Copper oxychloride $\left(\mathrm{Cu}_{2}[\mathrm{OH}]_{3} \mathrm{Cl}\right)$ was developed in the 1960 s as a coal additive to mitigate slagging problems (6). This compound is added to the coal in small doses (5-10 $\mathrm{ppm}$ ), unlike most additives which are added in quantities of a few weight percent. The combustion products of copper oxychloride $\left(\mathrm{CuO}, \mathrm{Cu}[\mathrm{OH}]_{2}, \mathrm{Cu}\right.$, and $\left.[\mathrm{CuCl}]_{\mathrm{n}}\right)$ have been shown to transform dense deposits into porous, friable deposits by promoting crystallization in slags (6). The combustion products are dispersed in the vapor phase and condense and react on the surfaces of the deposits.

A few authors have tried to explain the ability of this additive to alter slag characteristics. Kiss and others (7) suggested that copper oxidizes $\mathrm{FeO}$ in the slag to produce metallic copper, which provides nucleation centers for crystallization:

$$
\mathrm{Cu}_{2} \mathrm{O}+2 \mathrm{FeO} \rightarrow 2 \mathrm{Cu}+\mathrm{Fe}_{2} \mathrm{O}_{3}
$$

The ability of copper to oxidize iron may be useful to prevent corrosion of ceramics in contact with coal slags. Iron in coal slags has been found to attack $\mathrm{SiC}$ ceramics rapidly (2). The reaction occurs by the reduction of iron oxides in the slag by $\mathrm{SiC}$, which results in the formation of iron silicides and $\mathrm{CO}$ or $\mathrm{CO}_{2}$ :

$$
2 \mathrm{FeO}+\mathrm{SiC} \rightarrow \mathrm{Fe}_{2} \mathrm{Si}+\mathrm{CO}_{2}
$$

If the thermodynamics of the reaction are forced to the left by the presence of copper, the rate of corrosion of the $\mathrm{SiC}$ would decrease. The presence of the copper may also stimulate the crystallization of spinels, such as hercynite $\left(\mathrm{Fe}^{+2} \mathrm{Al}_{2} \mathrm{O}_{4}\right)$ which has been 
found in some deposits doped with copper (7). Hercynite is a stable high-temperature phase, and its formation would tie up the iron to prevent further reaction.

Kiss and others (7) performed laboratory experiments on the effects of copper additions on crystallization in slags. They determined that in the range of $950^{\circ}$ to $1400^{\circ} \mathrm{C}$, the presence of copper oxychloride enhances crystallization of slags. The initial effect of copper oxide in the slag would be to reduce viscosity, but by triggering crystallization, the viscosity would then increase. The phases that crystallize in iron-rich slags are usually hercynite and maghemite $\left(\gamma \cdot \mathrm{Fe}_{2} \mathrm{O}_{3}\right)$, and the removal of iron from the residual melt would also increase slag viscosity (7).

The additive copper oxychloride may be beneficial to corrosion prevention in several respects. The copper would promote the oxidation of the iron in the slag, which would prevent it from being reduced to metallic iron through reaction with the SiC. The metallic copper would promote the crystallization of hercynite and iron-alumina spinel in the slag, which would tie up the iron in stable phases. The removal of the iron from the slag and the crystal formation will increase slag viscosity, thus decreasing migration of corrosive species to the ceramic surface. It would be preferable to have crystallization occur only at the lower slag temperatures found near the surface of the heat exchanger to prevent undue slag buildup. If buildup is a problem, then shot doses of the material could be used.

Laboratory experiments initially will focus on the effects of small additions of copper oxychloride in coal slags with varying iron contents. The research will determine the effects of copper additions on the viscosity, crystallinity, and corrosiveness of the slag. Detailed mineral and chemical studies will focus on the phases formed and the stability of these phases at temperature. Other copper additives will be investigated to determine if the form of copper affects the slag properties.

\section{- Slag Viscosity Modifications}

In addition to chemically tying up the corrosive species in the slag, changing the slag viscos: $y$ at the interface with a ceramic heat exchanger can be used to decrease the corrosion rate of the ceramic. A case may be presented for both decreasing slag viscosity and increasing slag viscosity to protect ceramic materials from corrosion. In an oxidizing atmosphere, a thin layer of $\mathrm{SiO}_{2}$ forms on the surface of $\mathrm{SiC}$ ceramics which can act as a protective coating. The formation of the $\mathrm{SiO}_{2}$ depends on the partial pressure of oxygen at the ceramic surface, which can be influenced by the thickness of the slag layer (2). A thick, viscous slag layer would slow oxygen circulation to the ceramic surface, and the diffusion of oxygen would be impeded by the formation of bridging oxygens in the melt.

The transport rate of corrosive species to the surface of the ceramic is also a factor in corrosion rates. The transport rates of ions are much faster in a slag with lower viscosity and fewer nonbridging oxygens. The diffusion rates of corrosive species to the ceramic surface at varying temperatures should be investigated. If the diffusion of the corrosive species is much greater than that of the oxygen, then the protective $\mathrm{SiO}_{2}$ layer may not be formed in some low-viscosity melts. But an optimum slag viscosity and slag thickness may exist to promote the formation of the $\mathrm{SiO}_{2}$ layer and to prevent diffusion of iron. 
Many types of additives, such as limestone, dolomite, sodium, iron, and boron compounds, have been used historically to change the slagging characteristics of coals (5). The main use of these additives has been to lower slag viscosity to generate a fluid slag that will not plug slag taps. The use of sodium additives can cause low-temperature fouling problems, and because of the increased awareness of air toxins, the use of boron. containing compounds is not recommended.

- Calcium

Limestone is commonly used as a coal additive to reduce slag viscosity (5).

Limestone additives have also been shown to increase the viscosity of molten ash deposits, which decreases the deposit's ability to sinter and develop strength (8). The different effects of calcium additions are related to the type of coal fired, as well as operating conditions. The ternary phase diagram of the $\mathrm{CaO} \cdot \mathrm{SiO}_{2} \cdot \mathrm{Al}_{2} \mathrm{O}_{3}$ systems indicates that in low-calcium coals, the addition of $\mathrm{CaO}$ would reduce the liquidus temperature (9). With high-calcium coals, additions of $\mathrm{CaO}$ would increase the liquidus temperature. These predictions are based on simple ternary systems and do not consider the effects of small amounts of fluxing agents, such as sodium or iron, on the liquidus temperature of the melt. Because coal ashes are multicomponent systems, with as many as five or more major oxides, predictions from three-component phase diagrams are inadequate.

To better understand the effects of $\mathrm{CaO}$ additives on coal slag behavior, controlled laboratory experiments are needed. Initially, one high-calcium coal will be investigated for the effects of additions of $\mathrm{CaO}$ on slagging properties, such as viscosity and liquidus temperature.

\section{- Aluminosilicates}

Clay sediments usually contain abundant clay minerals, such as kaolinite. Kaolinite is a hydrous aluminosilicate $\left(\mathrm{Al}_{2} \mathrm{Si}_{2} \mathrm{O}_{5}[\mathrm{OH}]_{4}\right)$ that forms fine particles in sedimentary rocks. Kaolinite has been an effective coal additive to reduce ash deposit strength (10). Due to its relatively high alumina to silica ratio, it also has the ability to increase the liquidus temperature of some deposits (5). This may aid in corrosion prevention of a ceramic surface. The formation of a viscous slag layer on the ceramic may impede the migration of corrosive species to the ceramic surface. This protective layer could be maintained by intermittent additions of the additive to produce a viscous slag layer on the ceramic. The "pulse" of additive would allow a thin, protective layer to form, but would not allow the buildup of thick deposits. The bulk of the slag would be less viscous and flow freely over the "frozen" slag layer.

Laboratory experiments will focus on the effects of adding kaolinite to coal slags. The research will determine the amount of additive needed to sufficiently change the slag viscosity and document resulting changes on other slag properties, such as the reactivity of corrosive species in the slag.

\section{SLAG ATTACK ON CERAMIC MATERIALS}

A new approach has been developed for the prediction of coal slag viscosity in the case of phase separation below the temperature of critical viscosity. This phenomenon causes deviations from ideal viscosity as compared to unseparated slag of the same bulk 
composition. The new method of viscosity calculation accounts for the structural changes in the slag as phase separation begins, assuming that the viscosity depends on the degree of polymerization of the slag and the dispersion of nuclei. Arrhenian and configurational entropy models were combined to provide more accurate predictions of coal slag viscosity at temperatures below the critical temperature. The results of this work were presented at the Engineering Foundation Conference, "Impact of Ash Deposition on Coal-Fired Plants," in Birmingham, UK in June of 1993. The paper from the conference is included as Appendix 3.2.1.

\section{References}

1. Ferber, M.K.; Tennery, V.J. "Behavior of Tubular Ceramic Heat Exchanger Materials in Acidic Coal Ash from Coal-Oil-Mixture Combustion," Ceram. Bull. 1983, 62 (2), 236-243.

2. Ferber, M.K.; Tennery, V.J. "Behavior of Tubular Ceramic Heat Exchanger Materials in Basic Coal Ash from Coal-Oil-Mixture Combustion," Ceram. Bull. 1984, 63 (7), 898-904.

3. Kennedy, C.R. "Refractory/Coal-Slag Compatibility Studies: Progress to Date," Presented at the American Ceramic Society, Washington, D.C., May 3-8, 1981.

4. Strobel, T.M.; Hurley, J.P. "Coal-Ash Corrosion of Monolithic Silicon Carbide-Based Refractories," Accepted for presentation at the Fuel Division meeting at the American Chemical Society Meeting in Chicago, Aug. 1993.

5. Radway, J.E.; Hoffman, M.S. Operations Guide for the Use of Combustion Additives in Utility Boilers," EPRI CS-5527, Project 1839-3 Final Report, Dec. 1987.

6. Sanyal, A. "Copper Oxychloride as a Fireside Additive in Coal-Fired Utility Boilers," EPRI GS-6751, Project 1839-4 Final Report, Feb. 1990.

7. Kiss, L.T.; Lloyd, B.; Raask, E. "The Use of Copper Oxychloride to Alleviate Boiler Slagging," J. Inst. Fuel 1972, April, 203-223.

8. Gibb, W.H. "The Role of Calcium in the Slagging and Fouling Characteristics of Bituminous Coals," Journal of the Institute of Energy 1986, Dec., 206-212.

9. Ehlers, E.G. The Interpretation of Geological Phase Diagrams; W.H. Freeman and Company: San Francisco, 1972.

10. Lindner, E.R.; Ksminski, A.; Taylor, C.; Williams, R.G. "Effects of Additives on Fouling Behavior Characteristics of South Australian Brown Coals," In Proceedings of the Fourth Engineering Conference on Mineral Matter and Ash Deposition from Coal. 1988. 


\section{Subtask 3.3 Catalytic Gasification}

\section{Introduction}

Fuel cell technology is advancing rapidly, and a critical requirement for its application is economical hydrogen production. Coal gasification is a potential source of the hydrogen to feed the cell, provided the gas can be adequately produced and cleaned up at a reasonable cost. An expressed interest in gasifying bituminous coal resulted in its inclusion in tests currently being carried out at the EERC under the DOE-funded Catalytic Gasification project. The first part of this project involved catalyst testing with bituminous coal. It will be followed with testing of lignite coal.

\section{Objectives}

Work on catalytic gasification will be in direct support of efforts to integrate gasification and molten carbonate fuel cells. The primary goal is to identify a suitable hydrogasification catalyst to achieve coal residence times on the order of minutes in a gasifier operating on naturally reactive low-rank coal at nominal conditions of $650^{\circ} \mathrm{C}$ and 500 psi. Studies may include measurements of in-bed sulfur capture, but only as a secondary goal after a suitable hydrogasification catalyst has been selected. The existing 4- $\mathrm{lb} / \mathrm{hr}$ continuous fluid-bed reactor (CFBR) will be modified to operate at pressures over $500 \mathrm{psi}$. I ne EERC gasification model will be integrated into existing state-of-the-art codes.

\section{Accomplishments}

\section{COAL}

Catalyzed steam gasification of Illinois No. 6 bituminous coal from the River King mine was investigated by two methods. The proximate analyses of the raw coal and coal containing ca. $10 \%$ added nickel are shown in Table 3.3-1. The initial tests were carried out by thermogravimetric analysis (TGA). Catalyst screening was accomplished by comparing the kinetics of the reaction between uncatalyzed feed and steam with the kinetics of the catalyzed reaction. Those materials illustrating greatest rate enhancement by TGA and potential for reuse were selected for larger-scale testing in the integrated bench-scale gasifier (IBG).

TABLE 3.3.1

Proximate Analyses of Feed Coal and Feed Coal $+10 \%$ Ni Catalyst

\begin{tabular}{lcccc}
\hline & Moisture & Volatiles & Comb. Res. & Ash \\
\hline Raw RK & 9.9 & 34.0 & 45.3 & 10.8 \\
Raw RK + 10\% Added Nickel &.- & 37.8 & 50.2 & 12.0 \\
Raw + Cat. & 5.1 & 17.6 & 23.5 & 53.8 \\
Raw + Cat. + 10\% Added Nickel & - & 18.6 & 24.7 & 56.7 \\
\hline
\end{tabular}


Catalysts tested were potassium carbonate and nickel acetate. Several methods of application of the catalyst to the coal were tested, including dry mixing and aqueous impregnation, where the impregnation was followed by either draining the excess liquid or drying under vacuum. Nickel-clay and iron-clay were prepared at the EERC using the method of Drs. Ed Olson and Ramish Sharma $(1,2)$ and were applied by dry mixing or were introduced into the reactor prior to the introduction of the coal. Neither potassium carbonate or nickel acetate are likely to be viable for use as catalysts for gasification, but were included for comparison with the other two. The catalyst was applied to the coal such that the catalytic metal was about $10 \%$ of the coal weight.

\section{- TGA}

The TGA used in the gasification study is a DuPont model 951 module interfaced to a DuPont 2100 thermoanalyzer and data processor. The instrument is operated at ambient pressure and has a $100 \cdot \mathrm{mg}$ capacity and a maximum heatup rate of $100^{\circ} \mathrm{C} /$ minute. Measurements can be made at temperatures of up to $1200^{\circ} \mathrm{C}$. The sample compartment is a quartz tube through which carrier and selected gases flow from the balance housing toward the exit port. The quartz tube used in these experiments has a side-arm through which a $1 / 16$ inch.OD stainless steel tube is inserted to allow steam to be introduced to the sample chamber without its passing through the balance housing. The loaded samples were gasified, and weight, time, and temperature data were collected by computer for later analysis.

Approximately 50 grams of coal or coal-catalyst were loaded on the balance pan. The quartz tube was then locked in place and argon flow begun. The sample was heated at $100^{\circ} \mathrm{C} / \mathrm{min}$ to $800^{\circ} \mathrm{C}$, and the excess steam flow was introduced. The reaction was allowed to continue until approximately $50 \%$ of the carbon had been consumed or 2 hours, whichever occurred first.

\section{- IBG}

The IBG is a small batch process gasifier, with a charge capacity of nominally $70 \mathrm{~g}$ of coal. This unit provides data on the effects of bed fluidization, conversion of feedstock, reaction rate response to temperature, pressure, catalyst and feed gas composition and flow rate, and gaseous products, while providing sufficient quantities of conversion products for subsequent analysis. In this study, catalysts were screened for their effect on gasification enhancement. Although the IBG serves a similar purpose as TGA (thermogravimetric analyses), it allows a larger scale collection of multiple gas samples, plus liquid and solid products in sufficient quantities for analysis.

Although test conditions as high as $850^{\circ} \mathrm{C}$ and 100 psig were possible, in order to achieve maximum methane yields, thermodynamics requires lowest practical temperatures. However, rates at temperatures below $800^{\circ} \mathrm{C}$ were too slow to be feasible, so that most tests were carried out at $800^{\circ} \mathrm{C}$ and nominally $50 \mathrm{psig}$.

Three IBG tests (IBG065, IBG066, and IBG072) each had coal fed in two batches. During the IBG065 and IBG066 tests, approximately 55 grams coal-catalyst was fed when the reactor stabilized at the target temperature and pressure, and another similar 
quantity of coal was fed when the reactive substrate was nearly consumed, as determined by Fourier transform infrared spectroscopic (FTIR) on-line monitoring. In a later test (IBG072), 21 grams of N1.Clay catalyst was fed initially and then was hydrotreated for 20 minutes. Approximately 50 grams of raw coal feed was then introduced. A second batch of coal was introduced after approximately 2 hours.

IBG070 test was carried out with K.impregnated coal only at $850^{\circ} \mathrm{C}$ and $50 \mathrm{psig}$, and IBG071 was carried out similarly but at $800^{\circ} \mathrm{C}$ and 50 psig.

\section{RESULTS}

The reactivities determined from TGA data for catalyzed and uncatalyzed steam gasification of the Illinols No. 6 coal are shown in Table 3.3.2.

Illinois No. 6 char-steam reactions without catalyst and with admixed nickel-clay and iron.clay catalysts are shown in Figure 3.3.1. Nickel-clay was chosen for the IBG experiments. Table 3.3.3 shows the coal conversion for the IBG tests.

The results of initial IBG tests showed that about one.half of the Illinois No. 6 feed coal caked in the reactor, forming lumps which were impervious to the reactant gas and, therefore, slowed the reaction rate greatly. In later tests, the coal was impregnated with $\mathrm{KOH}(3)$ to eliminate the coal's caking tendency.

Gas bags were filled at irregular time intervals over the duration of each test, and the contents were analyzed by gas chromatography (GC). The mol\% of the three gas components of interest, $\mathrm{H}_{2}, \mathrm{CO}$, and $\mathrm{CH}_{4}$, in the product gas, corrected for carrier gas, are shown in Tables 3.3.4 to 3.3.6.

TABLE 3.3.2

First-Order Reactivities for Catalyzed and Uncatalyzed Illinois No. 6 Steam Gasification

\begin{tabular}{lccc}
\hline & \multicolumn{3}{c}{ Reactivity, hr $\mathbf{r}^{-1}$} \\
\cline { 2 - 4 } Catalyst & $800^{\circ} \mathrm{C}$ & $750^{\circ} \mathrm{C}$ & $700^{\circ} \mathrm{C}$ \\
\hline None & 0.25 & & \\
$10 \%$ Fe-Clay & 0.41 & & \\
$10 \%$ Ni.Clay 951B & 0.41 & & \\
$10 \% \mathrm{Ni}$.Clay 1008S & 0.41 & & \\
$\mathrm{~K}_{2} \mathrm{CO}$ & 9.49 & & 0.17 \\
$10 \%$ NiAc (Dry) & 0.51 & 0.37 & 0.15 \\
$10 \%$ NiAc $\left(\mathrm{H}_{2} \mathrm{O}\right)$ & 0.70 & 0.30 & 0.22 \\
$10 \%$ NiAc $\left(\mathrm{H}_{2} \mathrm{O} / \mathrm{H}_{2} \mathrm{~S}\right)$ & 0.75 & 0.39 & \\
$10 \%$ NiAc $\left(\mathrm{H}_{2} \mathrm{O} / \mathrm{Vac}\right)$ & 1.16 & & \\
\hline
\end{tabular}




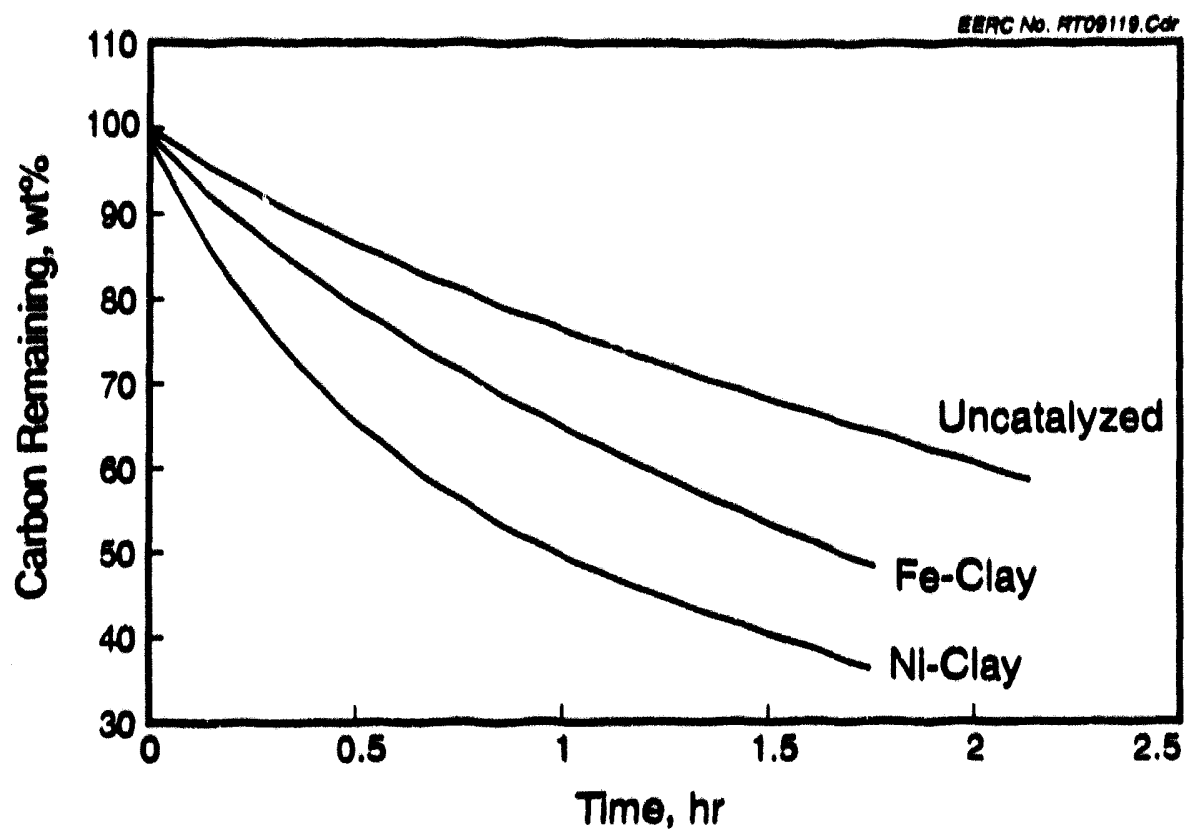

Figure 3.3-1. Metal-clay catalyzed Illinois No. 6 char-steam reaction at $800^{\circ} \mathrm{C}$. First order in carbon rate constants are shown.

TABLE 3.3-3

Coal Conversion for IBG Tests

\begin{tabular}{lccc}
\hline Sample & Feed, $\mathrm{g}$ & Recovery, $\mathrm{g}$ & Conversion, wt\% \\
\hline IBG065 & 100 & 52 & 48 \\
IBG066 & 111 & 62 & 44 \\
IBG070 & 55 & 31 & 49 \\
IBG071 & 55 & 25 & 56 \\
IBG072 & 139 & 69 & 51 \\
\hline
\end{tabular}

Nickel had a positive effect on the rate of gasification of bituminous coal. However, the agglomerating property of the coal seriously reduces steam.coal contact surface area even if catalyst-coal contact is maximized, making it difficult to evaluate the catalyst. Addition of potassium to prevent agglomeration of the coal also contributes to the catalysis of the gasification reaction as seen from Table 3.3-2, making it difficult to assess the respective effects of the individual additives. 
TABLE 3.3 .4

Percentage of Hydrogen in Product Gas

\begin{tabular}{ccccccc}
\hline & \multicolumn{5}{c}{ Test Number } \\
\cline { 2 - 7 } Time, min & IBG065 & IBG066 & IBG070 & IBG071 & IBG072b & IBG072c \\
\hline 2 & 29.58 & 0.72 & 50.93 & 59.85 & 60.23 & 41.03 \\
4 & 31.68 & & & 56.07 & & \\
6 & 41.9 & & & 52.17 & & \\
8 & & 42.21 & & & & \\
10 & 43.97 & & & 46.43 & 55.76 & \\
20 & & 43.23 & 43.83 & & & \\
30 & & & 38.38 & & 22.58 & \\
40 & & 39.78 & 38.51 & & 28.57 & \\
50 & & & & & & 48.48 \\
70 & & 37.31 & 26.09 & & & \\
80 & & 7.42 & & & & \\
90 & & 7.25 & & & & \\
101 & 34.88 & & & & & \\
103 & 36.46 & & & & & \\
108 & 48.45 & & & & & \\
130 & 31.91 & & & & & \\
16 & 13.27 & & & & & \\
\hline
\end{tabular}

TABLE 3.3.5

Percentage of Carbon Monoxide in Product Gas

\begin{tabular}{rrrrrrr}
\hline & \multicolumn{5}{c}{ Test Number } \\
\cline { 2 - 7 } Time, min & IBG065 & IBG066 & IBG070 & IBG071 & IBG072b & IBG072c \\
\hline 2 & 16.06 & 6.19 & 20.82 & 16.62 & 24.09 & 4.6 .15 \\
4 & 16.09 & & & 28.26 & & \\
6 & 14.17 & & & 27.05 & & \\
8 & & 16.80 & & 36.12 & & \\
10 & 17.24 & & & 32.18 & 34.10 & \\
20 & & 34.16 & 40.74 & & & \\
30 & & & 24.72 & & 31.61 & \\
40 & & 40.86 & 38.51 & & & \\
50 & & & & & & \\
70 & & 14.45 & 33.33 & & & \\
80 & 7.25 & & & & \\
90 & & 10.99 & & & & \\
101 & 13.99 & 11.84 & & & & \\
103 & 12.00 & & & & & \\
108 & 12.79 & & 30.00 & & & \\
130 & 11.17 & & & & & \\
162 & ND* & & & & & \\
\hline
\end{tabular}

* Not detected. 
TABLE 3.3.6

Percentage of Methane in Product Gas

\begin{tabular}{|c|c|c|c|c|c|c|}
\hline \multirow[b]{2}{*}{ Time, min } & \multicolumn{6}{|c|}{ Test Number } \\
\hline & IBG065 & IBG066 & IBG070 & IBG071 & IBG072b & IBG072c \\
\hline $\begin{array}{l}2 \\
4 \\
6\end{array}$ & $\begin{array}{l}30.99 \\
34.16 \\
29.55\end{array}$ & 7.88 & 14.13 & $\begin{array}{c}13.38 \\
\text { ND* } \\
\text { ND }\end{array}$ & 14.09 & 11.22 \\
\hline 8 & & 22.36 & & & & \\
\hline 10 & 27.87 & & & ND & ND & \\
\hline $\begin{array}{l}20 \\
30 \\
40\end{array}$ & & 16.83 & $\begin{array}{l}\text { ND } \\
\text { ND } \\
\text { ND }\end{array}$ & & $\begin{array}{l}\text { ND } \\
\text { ND }\end{array}$ & \\
\hline 50 & & & & & & ND \\
\hline $\begin{array}{l}70 \\
80 \\
90\end{array}$ & & $\begin{array}{r}27.37 \\
6.58 \\
12.06\end{array}$ & ND & & & ND \\
\hline 101 & 31.11 & ND & & ND & & \\
\hline 103 & 27.31 & & & & & \\
\hline 108 & 26.51 & & ND & & & ND \\
\hline 130 & ND & & & & & ND \\
\hline 162 & ND & ND & ND & ND & ND & ND \\
\hline
\end{tabular}

* Not detected.

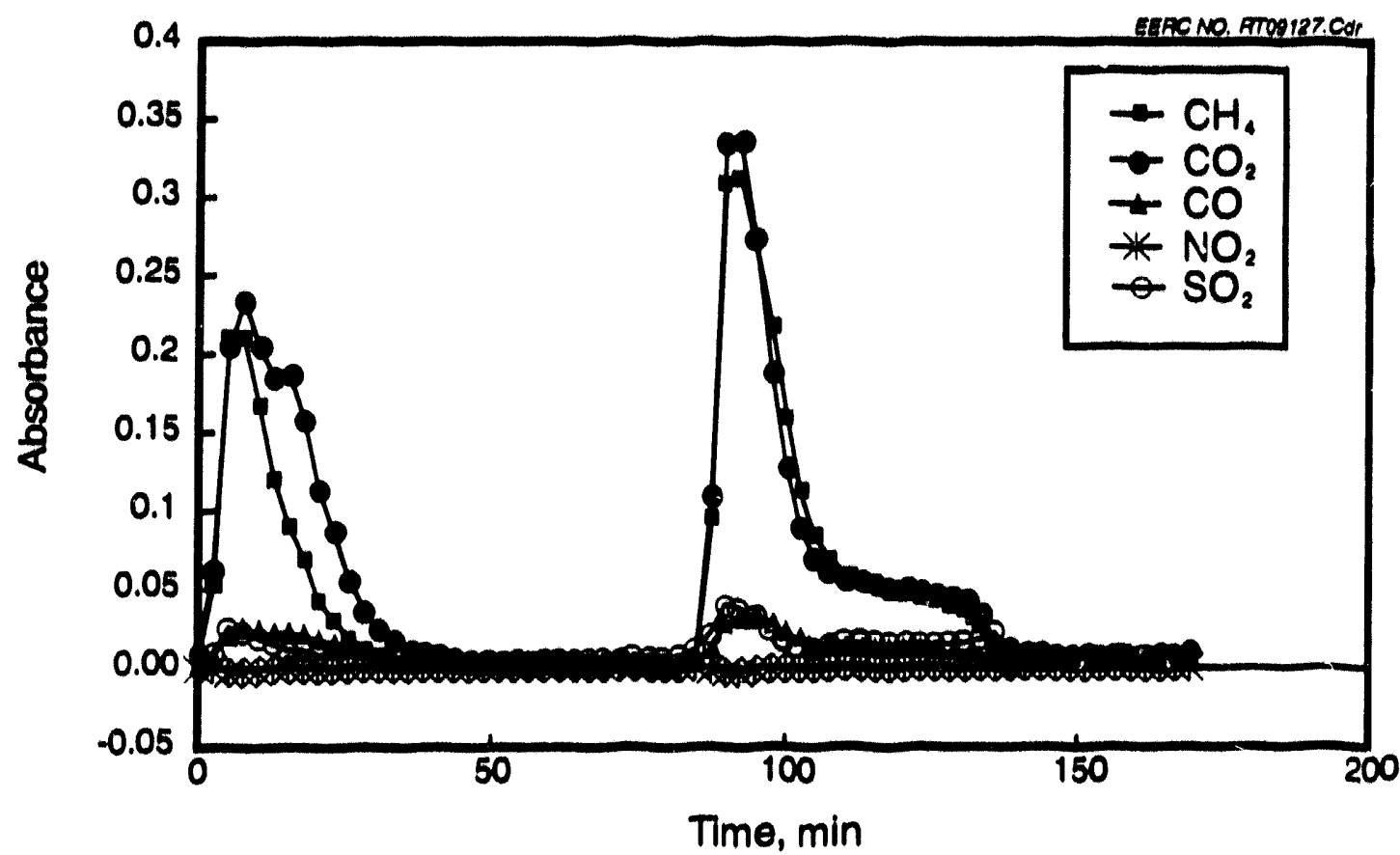

Figure 3.3-2. Gas production from Ni.clay catalyzed Illinios No. 6-steam reaction in the IBG at $800^{\circ} \mathrm{C}$ and nominally 50 psig. 
Methane production appears to be principally a result of py rolysis rather than a chemical reaction between hydrogen and carbon monoxide, as suggested by Figure 3.3-2. Spectral data from other tests suggested a similar conclusion.

The results of this study indicate that Illinois No. 6 coal is not a suitable feedstock for gasification because of its caking tendency. Future tests will involve a low-rank coal.

- FUTURE WORK

- Prepare large batch of Ni.Clay catalyst for additional testing

- Perform IBG catalytic gasification tests with Center lignite

- Collect and reuse Ni-clay catalyst

\section{$\underline{\text { References }}$}

1. Heinerman, J.J.L.; Frericks, I.L.C.; Gaff, J.; Pott, G.T.; Coqlegen, J.G.F. Journal of Catalysis 1983, 80, 145.

2. Olson, E.S.; Sharma, R.K. Semiannual Technical Progress Report for the Period January-June 1991; EERC publication, 1991.

3. Kalina, T. et al. (Exxon Research and Engineering Co.). "Exxon Catalytic Coal Gasification Process Predevelopment Program," final project report; USDOE Contract No. E(49-18)-2369, Dec. 1978. 


\section{Subtask 3.4 Hot-Gas Cleaning}

\section{Introduction}

Many prototype high-efficiency coal-fired power systems require stringent removal of particulate ash from the high-pressure/high-temperature gas stream to prevent erosion of turbine blades or plugging of fuel cells. At present, ceramic candle filters and cross-flow filters have shown the capability to reduce particle loadings in coal-fired gas streams to acceptable levels. However, long-term thermal and chemical degradation of the filters has prevented their reliable use at the relatively high temperatures required. One of the principal degradation mechanisms is vapor-phase alkali attack of aluminosilicate materials or the silicon in silicon carbide or silicon nitride materials. The alkali interaction usually leads to the formation of new phases that have different specific volumes or thermal expansion coefficients. The differences lead to spalling of surface reaction layers, permitting further attack of the underlying material. However, the research into the performance of ceramic materials in hot gases produced during coal firing has been limited. As yet, an adequate database that would permit material selection based on coal properties is not available. Also, no database is available on the rates of corrosion and strength loss of the materials, nor is a fundamental understanding of the mechanisms of vapor-phase alkali corrosion developed.

\section{Objectives}

The overall objective of the Hot-Gas Cleanup task is to develop reliable methods of removing particulate matter from high-temperature/high-pressure gas streams produced from coal combustion. The primary area of research will involve determinations of rates and mechanisms of alkali and ash corrosion of ceramic filter materials. The research will focus on reactions occurring at approximately $1800^{\circ} \mathrm{F}$.

The ceramic corrosion research will be performed primarily in the laboratory. It will consist of testing large numbers of candidate materials in a muffle furnace in the presence of alkali vapor and ash to determine rates and mechanisms of corrosion, as well as rates of strength loss. In addition, existing computer models will be enhanced to include development of methods to calculate thermodynamic data for reactions for which there is no experimental data exist.

\section{Accomplishments}

\section{- MODELING}

To provide emissions control and turbine protection from gas- and solid-phase contaminants in direct coal-fired turbine systems, a variety of methods are being advanced and tested: ash and sulfur minimization through coal beneficiation, in situ sulfur sorption, staged combustion to limit $\mathrm{NO}_{\mathrm{x}}$ formation, impactive slag removal, inertial particle entrainment, and barrier filtration in the combustor cleanup train. All these approaches address the requirements of environmental and turbine lifetime standards. But more importantly, all these approaches also bring out the critical need for and the basis of the current modeling efforts, viz., the design and performance of the static and reactive aspects of the materials used in the fabrication of the hot-gas cleaning equipment. 
The scope and goals of the current modeling efforts have been designed to address the issues of the structural and chemical stability of the materials used in hot-gas cleanup devices. Since in many cases, the power generation systems demand high performance from materials that are, as yet, undeveloped, the main thrust of the modeling is directed towards the establishment of an object-oriented knowledge base of the chemical and physical properties of materials and the interactions that they may undergo with the products of coal combustion. Once the construction of the knowledge base is complete, a multitude of design, performance, and optimization issues can be resolved, ranging from the solution of task specific problems to the comparative assessment of overall design strategies.

The Materials Knowledge Base section below details the proposed methodology for the construction of the materials knowledge base, its organization and design rationale, the status of the preliminary literature survey conducted. (A more formal report of the preliminary literature survey is slated for release in November 1993.) A major portion of the materials thermal properties area of the knowledge base is very close to completion and is discussed in the $C_{p}$ Database section. The Conclusions and Future Work section then concludes and summarizes the modeling work to date.

\section{- Materials Knowledge Base}

The term "knowledge base" or "knowledge base management system" (KBMS) is used to denote a system that (1):

- Provides a database management system (DBMS), i.e., provides support for efficient access, transaction management, etc.

- Provides a declarative language that defines and manipulates the data it manages.

On the other hand, "object base" and "object-oriented database management system" (OO-DBMS) refer to a DBMS that (1):

- Provides support for construction of complex, hierarchical or nested, data types.

- Provides support for data encapsulation (or data "hiding").

- Provides support of object identity by allowing the user to distinguish between instances of the same object.

A system that combines the features of a knowledge base DBMS and an object base DBMS is an object-oriented knowledge base management system (OO-KBMS). From the database perspective, the materials knowledge base is required to possess a wide range of material properties. These can be classified into two broad categories, namely, thermal and physicochemical. Under the thermal properties sector, the areas of interest are

- Specific heats (isobaric and isochoric)

- Enthalpy

- Entropy

- Free energy 
- Critical points (melting, boiling, and other phase transition points)

- Molar volume

- Vapor pressure

- Thermal conductivity

- Isentropic compressibility

- Coefficient of thermal expansion

Under physicochemical properties, the areas of interest are:

- Molecular properties (structure, symmetries, dispersion spectra, etc.)

- Elastic properties (stress-strain tensor and/or all elastic moduli)

- Tribological properties (adhesivity, abrasivity, erosivity, etc.)

- Rheological properties (viscosity, diffusivity, mobility, etc.)

It must be emphasized that the above lists are meant to be representative rather than exhaustive and that the design of the knowledge base is geared to be flexible from the outset, so that subsequent additions or modifications can be effected with relative ease. In addition, the properties of interest need not necessarily be purely numerical, but can be algorithms or just logical relations among properties. This is precisely the reason for constructing this database as a OO-KBMS, since these algorithms or logical declarations are "executed" on demand to provide the requisite numerical values.

The compilation of the list of properties noted above was the objective of the preliminary literature survey carried out as the first task of the modeling agenda. This preliminary survey is nearing completion, and a formal report of the survey will be presented November 1993 detailing the current status of methods for the determination and computation of the properties of interest. Based on the results of the preliminary survey, the design and organization of the knowledge base will be finalized. The compilation and construction of the knowledge base will then be initiated by the acquisition of more literature, data, and pertinent software packages and programs.

The database "acquires" knowledge in two different ways. The first method is the more conventional rule-based representation: here, the system's knowledge is encapsulated in a series of rules or facts, and a rule analyzer or inference engine then analysis the rules to deduce conclusions. The second method is inductive: here, the system "learns" from a series of examples and is taught to recognize patterns or trends completely analogous to the training phase of neural networks. Once the training is complete, the system can then be queried to present conclusions based on its training and related interpolations and extrapolations. Both the inductive and deductive methods are useful and necessary in order for the system to be effectively "knowledgeable." A number of ways exist to implement both deductive and inductive knowledge systems. Since the needs of the knowledge base will grow in the future, the implementation details need to be fairly flexible, adaptable, and expandable. The pros and cons of various implementation strategies are currently being examined, and a decision is expected to be arrived at in the very near future.

The demands of the project are such that the KBMS must itself be very robust, flexible, and capable of handling large and extensive knowledge bases. Of the current commercially available management systems, only a very few meet these criteria; they are also quite expensive. On the other hand, some superb DBMS packages are developed 
for the TSNIX environment that will be more than adequate for the task at hand. The ceasibility, cost, and time of porting it to a DOS-based environment is presently being analyzed.

\section{- Cp Database}

As mentioned in the previous section, one set of materials properties which is extensively applicable is the isobaric specific heat and the thermodynamic functions derivable from it, such as the enthalpy, entropy, (Gibbs) free energy, and equilibrium constants. The isobaric (or constant pressure) specific heat is an easily measurable property of a chemical compound, whereas the isochoric (or constant volume) specific heat has theoretical significance. The relationship between these two specific heats is easily obtained as

$$
\mathrm{C}_{\mathrm{p}}-\mathrm{C}_{\mathrm{v}}=\alpha^{2} \kappa_{\mathrm{T}} \mathrm{VT}
$$

where $C_{p}$ is the isobaric specific heat, $C_{v}$ is the isochoric specific heat, $V$ is the volume, $T$ the temperature, $\alpha$ is the isobaric thermal expansion coefficient and is given by the specific rate of change of volume with respect to temperature:

$$
\alpha=\frac{1}{\mathrm{~V}} \frac{\partial \mathrm{V}}{\partial \mathrm{T}}
$$

and $\kappa_{\mathrm{T}}$ is the isothermal bulk modulus. However, reliable estimates of high-temperature thermal expansion and bulk modulus can be obtained through anharmonic modeling from the room-temperature properties and the experimental $C_{p}$ and calculated $C_{v}$ data as described below.

A harmonic solid will not undergo thermal expansion. Thus the term in the right hand side of Equation 3.4-1 represents an anharmonic contribution that is usually found to be significant at higher temperatures. Although the difference between $\mathrm{C}_{p}$ and $\mathrm{C}_{v}$, in the harmonic approximation, are very small up to about $1000 \mathrm{~K}$, the deviation between $\mathrm{C}_{v}$ and the Dulong.Petit limit of $3 R$, where $R$ is the gas constant becomes larger depending on the specific compound in question. For instance, $C_{v}$ tends to the Dulong.Petit limit for periclase and lime, while for forsterite, a $5 \%$ deviation is already observable at $2000 \mathrm{~K}$ (2).

Various approaches exist, to the calculation of the isochoric specific heat $\mathrm{C}_{\mathrm{v}}$, ranging from the very simple Einstein model to the sophisticated lattice dynamics computations. Ultimately, all of them depend on knowing the normal modes of the system (and thus knowing the structural characteristics of the system) since $\mathrm{C}_{\mathrm{v}}$ is given by the temperature derivative of the internal energy of the system:

$$
C_{v}=\frac{\partial E}{\partial T}
$$

where the internal energy $E$ is a weighted sum over the normal modes

$$
E=\sum_{i} e_{i} e^{\frac{-\theta_{i}}{k_{n} T}}
$$


The Gruneisen parameter $\gamma$, also calculable from a knowledge of the normal modes of the system, is the other macroscopic parameter needed to compute $\mathrm{K}_{\mathrm{T}}$ and $\alpha$. Macroscopically, this parameter is:

$$
\gamma=\frac{\alpha \mathrm{K}_{\mathrm{T}} \mathrm{V}}{\mathrm{C}_{\mathrm{v}}}
$$

while, in terms of microscopic parameters, it is given by

$$
\gamma=\mathrm{K}_{\mathrm{T}} \sum_{\mathrm{i}} \frac{\partial \ln \nu_{\mathrm{i}}}{\partial \mathrm{P}} \times \frac{\mathrm{C}_{\nu \mathrm{i}}}{\sum_{\mathrm{j}} \mathrm{C}_{i j}}
$$

It should be pointed out that the calculation of the Gruneisen parameter must be carried out from the structure equilibrated at the appropriate temperature and pressure to prevent the calculated value in Equation 3.4-6 from underestimating the macroscopic value from Equation 3.4-5.

The relationships between the thermal functions derivable from the isobaric specific heat data are as follows:

$$
\begin{gathered}
H=\int_{0}^{T} C_{p} d T \\
S=\int_{0}^{T} C_{p} d(\ln T) \\
G=H-T S
\end{gathered}
$$

where $\mathrm{H}$ is the enthalpy, $\mathrm{S}$ the entropy, and $\mathrm{G}$ the Gibbs free energy of the system. The equilibrium constant (which in this context is the formational equilibrium constant) is simply the negative exponential of the non-dimensional Gibbs free energy,

$$
\ln K_{0}=\frac{-G}{R T}
$$

where $K_{0}$ is the equilibrium constant and $R$ is the universal gas constant.

The compilation of the isobaric specific heat database-the $\mathrm{C}_{\mathrm{p}}$ database-which has been undertaken in conjunction with another DOE project, is very close to completion. The $\mathrm{C}_{\mathrm{p}}$ data for the entire set of species in the two-volume set of the JANAF tables (3) have been entered and validated. The $C_{p}$ data for the species in the two volumes of Barin and Knacke (4) are now in the process of being entered into the database. The completion of the entry of the Barin and Knacke data will mark the end of the $C_{p}$ database compilation with a total of approximately 6000 chemical species. It is expected however that, depending on the needs of other projects, data for hydrocarbons and other organic and inorganic specios will be included sporadically into the database. 
The organization of the $C_{p}$ database is relatively straightforward. It is a relational database. Each tuple in the database represents a chemical compound and comprises the following attributes:

- Compound name

- Formula

- Data reference source or citation

- Melting point, $\mathrm{C}_{\mathrm{p}}$ of fusion, and enthalpy of fusion

- Boiling point, $\mathrm{C}_{\mathrm{p}}$ of vaporization, and enthalpy of vaporization

- Other transition points and associated enthalpies

- Phase name or symbol

- $\mathrm{C}_{\mathrm{p}}$ temperature range and corresponding $\mathrm{C}_{\mathrm{p}}$ values for that range

It should be noted that the $C_{p}$ temperature ranges and the corresponding $C_{p}$ values for those ranges are entered for each possible phase of the compound so that some of the attributes listed above are instanced in the tuple as many times as is needed. (Of course, the normalization of the database results in a different logical and physical organization.)

In many cases, the $C_{p}$ values for a phase are available only within the temperature range of the existence of that phase. In some cases however, in gases for example, $C_{p}$ values are available for temperatures well into the metastable regimes of the phase: this proves to be extremely useful in utilizing this data in free energy minimization programs as well as in other areas of thermodynamic and combustion modeling. The DBMS has the capability however, of extrapolating the $\mathrm{C}_{\mathrm{p}}$ data into metastable regimes for those phases for which such data are lacking. A separate technical report detailing the $C_{p}$ database and its DBMS is being prepared. It is expected to be widely disseminated, especially to other researchers in the area, before the end of the next reporting period.

- Conclusions and Future Work

The accomplishments during this period have been substantial. The preliminary literary survey to assess the status of various fields related to materials used in hot-gas cleanup systems is ahead of schedule and is nearing completion. A formal report of the survey will be released in November of 1993 in accordance with Task 3.4.1.

The basic principles and modus operandi of the materials property knowledge base have been worked out and a list of properties of interest compiled. This list will be circulated among the various groups within the EERC (and possibly to other outside groups as well) and finalized before the end of the next semiannual reporting period. Discussions with commercial software vendors have been conducted with a view to a selection of a robust and viable KBMS. At present, it appears that commercial KBMSs are not viable. Additional work needs to be done here.

Another important accomplishment is the compilation of the $\mathrm{C}_{\mathrm{p}}$ data in the JANAF tables. The $C_{p}$ database is a major and integral part of the materials property knowledge base, and its completion will be a major milestone in its successful fruition. The Barin and Knacke (4) tables are currently being entered. Once the data entry is completed, the database needs to be cross-checked and validated. A user manual and technical report on the database is also being prepared and will be distributed by the end of the next reporting period. 


\section{SODIUM GETTERING}

Although most of the elements that reach the vapor-phase during combustion condense as ash and sometimes deposit, small portions of the more volatile elements remain in the vapor phase. In particular, sodium and potassium sulfates, chlorides, and hydroxides can reach concentrations of several hundred parts per million by weight at the exit of the combustor. These vapors can cause corrosion of combustor surfaces, hot-gas cleanup systems, or turbine blades. To prevent corrosion, it may be necessary to remove a large portion of the vapor-phase alkali from the gas stream. One method is to use coal additives or beds of materials known as alkali getters to absorb irreversibly the alkali. Absorption works through two mechanisms. Materials such as kaolinite, emathlite, and montmorillonite absorb the alkali by chemically incorporating it into their structures. Other materials like bauxite tend to serve as nucleation sites for condensation of the alkali.

In addition to composition, the degree of interaction between the getter and the combustor gas will affect its efficiency of absorbing alkali. The most efficient absorption will occur through extensive interaction between the vapor and the getter. Maximum interaction will occur if the gas stream is very turbulent or if the particles are small and have a high surface area to volume ratio. Turbulence in the gas stream is a function of system design, but it can be induced in the vicinity of the getter by keeping the getter in a fixed or fluidized bed through which the gases must pass. However, bed operation is difficult and adds significantly to the capital cost of the system. Particle size is more easily controlled. To prevent excessive getter deposition in the system, particle aerodynamic diameter should be kept below 10 microns. However, to enhance collectability (especially in a wet scrubber system) and minimize the opacity of particulate emissions, aerodynamic diameters should be kept above 1 micron. Finally, the getter should have a composition that is not likely to become sticky once it has absorbed sodium.

Of all of the gettering candidates reported in the literature (5-8), kaolin clay best meets these requirements. Therefore, its efficiency was tested in both atmospheric and pressurized combustion conditions in the EERC pressurized drop-tube furnace (PDTF) system as reported in the January through June 1992 Semiannual Technical Progress Report of the project entitled "Hot-Gas Cleanup" (9). Kaolin is usually composed of platelets that have diameters of between 1 and 5 microns. As long as it is deagglomerated before or during combustion it will naturally fall into the perfect size range for gettering. Deagglomerating such particles before combustion is nearly impossible without slurrying, so the degree of deagglomeration during combustion was measured in combustion tests. Also, kaolin is composed of approximately $1 / 2$ alumina and $1 / 2$ silica, so that after absorption of sodium it will have a much higher solidus temperature than if a pure silicate like emathlite is used. Because the easiest method to employ a getter in a utility combustor is to mix it with the coal, that method was used in the combustion tests. However, it is the least efficient method of inducing getter/gas interaction so that the combustion tests that we employed provide a minimum value for gettering efficiency of kaolin.

During this reporting period, TEACH was used to predict the equilibrium concentrations of vapor-phase sodium as functions of gas temperature and getter concentration in a boiler system burning a high-sodium coal. The data was compared to the results of PDTF tests of the gettering efficiency of kaolin. The TEACH package was 
specifically tailored to the analysis of combustion and combustion-related problems for these comparisons. One such "tailoring" - the ability to conduct parametric studies (i.e., perform simulations) of the thermodynamic behavior of the system-has made TEACH very useful in the understanding of the alkali vapor sorption mechanisms as well as in the assessment of the efficiencies of various sorber reagents. This modification has made TEACH a design tool that can be used to optimize sorption efficiency in terms of system operating parameters, fuel amounts and compositions, and sorber amounts and compositions. Although many of the reactions occurring in combustion systems are kinetically limited and may not be fully equilibrated, the equilibrium behavior determines the dominant reactions and the maximum extent of the reactions. Thus equilibrium chemistry governs both the alkali vapor production and maximum sorber efficiency.

- Results and Discussion

- Experimental Work

As reported in the January through June 1992 Semiannual Technical Progress Report of the Hot-Gas Cleanup project (9), tests of the gettering efficiency of kaolin clay were performed with the EERC pressurized drop-tube furnace system. A high-sodium subbituminous coal from the Spring Creek Mine, Montana, was burned in a total of four tests: two at atmospheric pressure and two at 109 psig. For each pressure, one run was made with raw coal and the other with ground kaolin mixed with the coal in a ratio of one part kaolin to two parts ASTM coal ash. The ash was collected after combustion with Cyclones 2 and 5 and a final filter of the EERC multicyclone system to aerodynamically size the ash as it was collected. Gas velocity through the cyclones were held constant at both pressures so that for all tests, the aerodynamic diameters of the particles collected were greater than 10 microns for Cyclone 2, between 1 and 10 microns for Cyclone 5, and less than 1 micron on the filter.

To determine the efficacy of the kaolin additions in gettering, the weight distribution of elements among the different size ranges must be used. Figure 3.4-1 shows two combination bar-line graphs that illustrate the weight percent of the major elements that were collected for each test in each size fraction. Two graphs are used: one for the pressurized tests the other for the atmospheric tests. The bars represent the values for the raw coal tests; the lines represent the values for the test of the coal/kaolin blend. For each element, the three data points are for the larger cyclone ( $>10$ microns), the smaller cyclone (1.10 microns), and the filter ( $<1$ micron), moving from left to right.

Silicon, aluminum, and calcium all tend to be predominantly concentrated in the larger particles, with negligible fractions present in the submicron particles. In contrast, large percentages of the sodium, sulfur, and chlorine are found in the smallest particles. Sulfur and sodium were bimodally distributed. It is believed that the sulfur was present primarily as calcium sulfate in the largest particles and as sodium sulfate in the smallest particles. The distribution of sodium shows that about $1 / 2$ of it is gettered by the larger ash particles, most likely as sodium silicates and sodium aluminosilicates, and the other half is in a vapor phase, condensing as submicron sodium sulfate particles during sampling. 


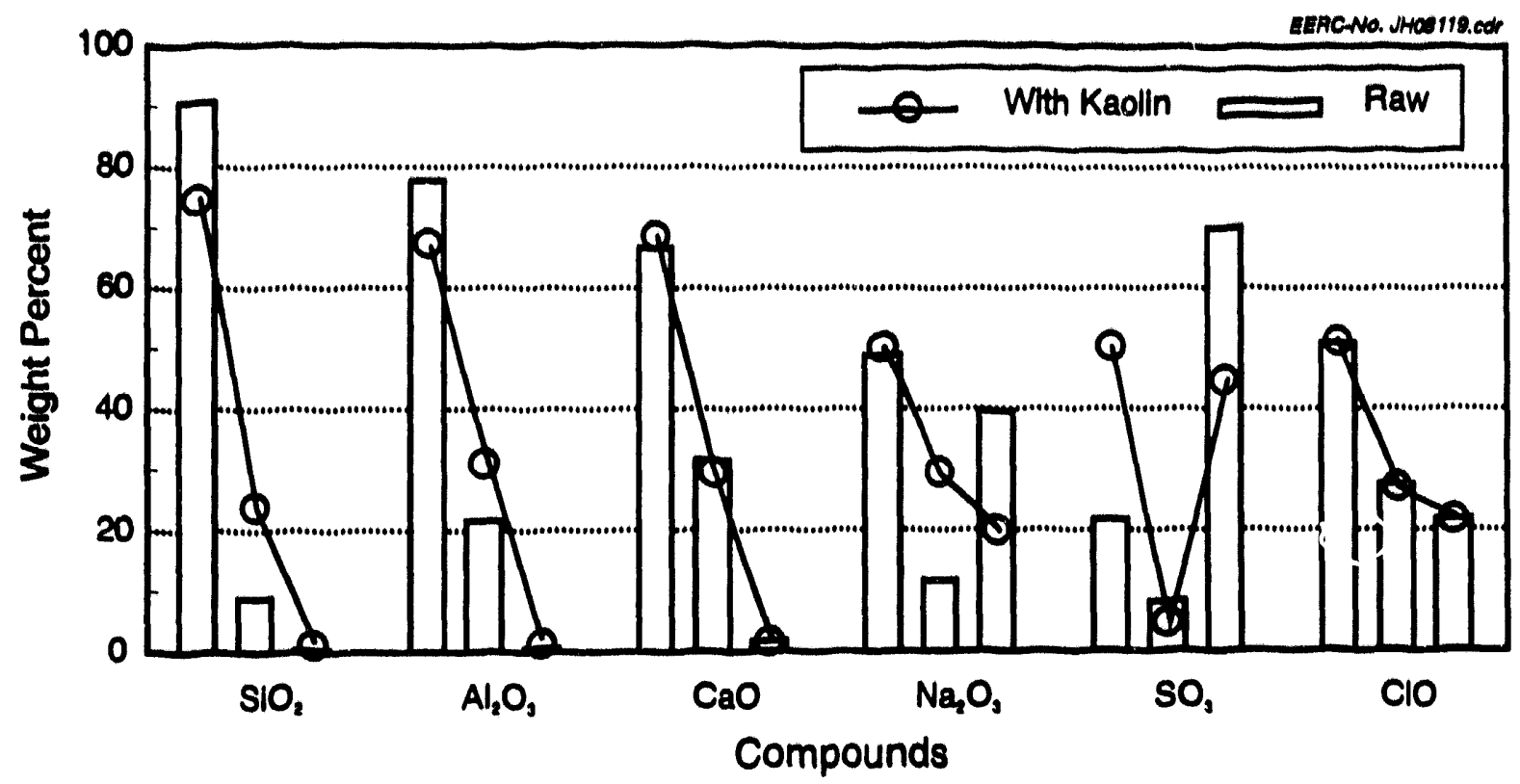

Cluster order is Cyclone 2, Cyclone 5, filter.

(A)

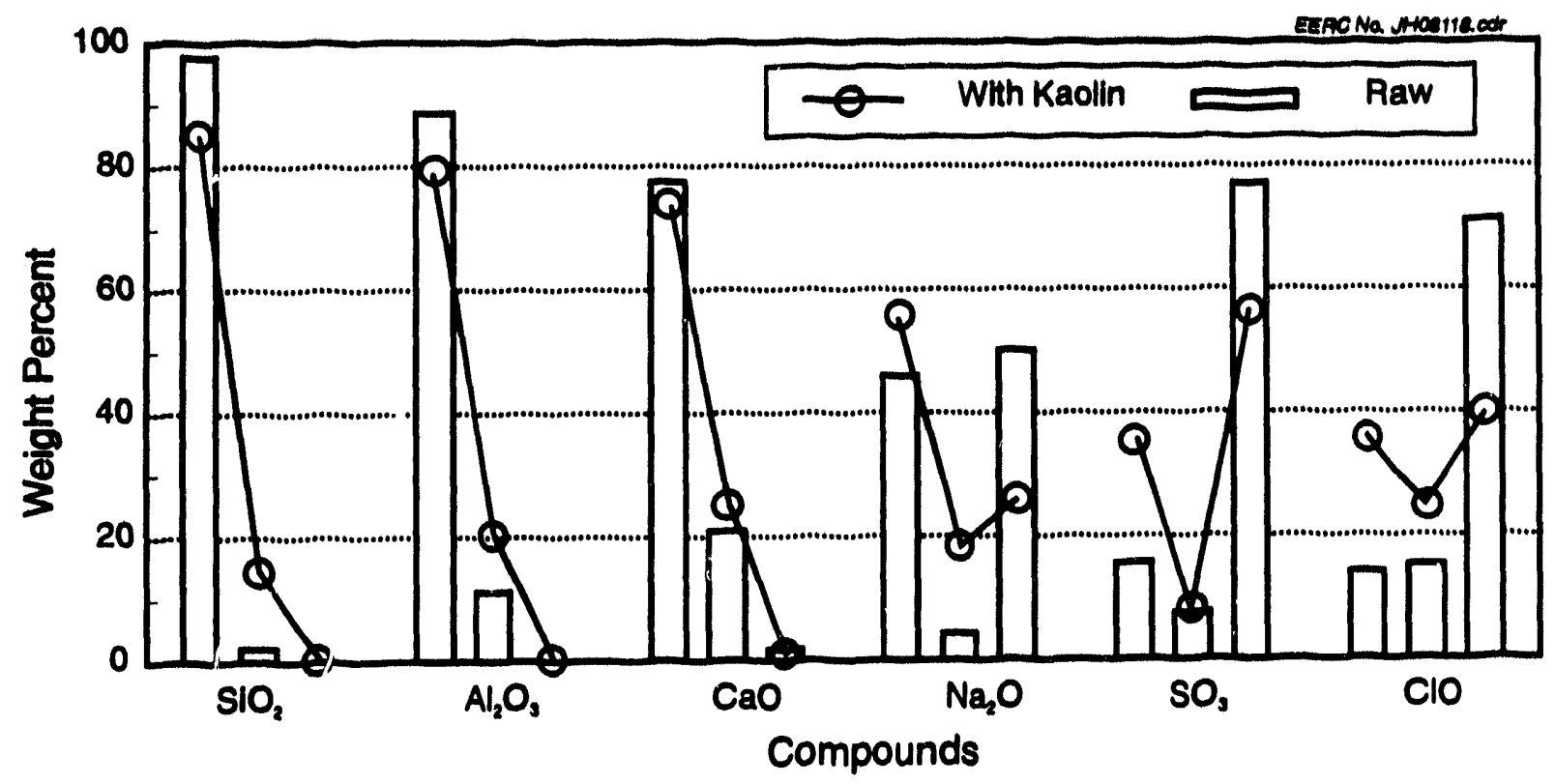

Cluster order is Cyclone 2, Cyclone 5, filter.

(B)

Figure 3.4-1. The weight percent of each element collected in each size fraction for the tests of kaolin as an alkali getter in the A) atmospheric and B) high. pressure tests. 
Pressure has little effect on the size distributions of the elements except for chlorine, which shifts from larger to smaller particles at higher pressures. The chlorine-containing particles in the smallest size range probably formed during quenching of the gas during sample collection, indicating that at higher pressure more of the chlorine condensed from the gas phase upon cooling than at atmospheric pressure. The effect is much stronger in the raw coal case than when kaolin is added, possibly because in the raw coal case more sodium vapor is present to permit. sodium chloride, as well as sodium sulfate, to condense in the smallest particles.

When kaolin is added to the system, sodium and sulfur are shifted strongly away from the smallest to larger particles at both pressures. If we assume that the sodium sulfate in the smallest size fraction formed when the gas was quenched during collection, then one-half of the sodium was removed from the gas phase due to the kaolin addition, both at atmospheric and higher pressure. Most of the sodium was shifted to the 1- to 10 . micron size range, which is where the kaolin is concentrated. The shift in sulfur from the smallest to the largest size ranges indicates that the sulfur did not follow the sodium. This implies that the shifted sodium was chemically combined with the kaolin, probably in the high-temperature zone and that the kaolin did not merely serve as a condensation surface for sodium sulfate. Because much of the sodium was removed from the gas phase, the sulfur shifted to the largest size range by sulfating additional quantities of the calcium-rich particles. This effect also accounts for the shift in chlorine when kaolin is added at higher pressures. However, at atmospheric pressure, the addition of kaolin has no effect on the distribution of chlorine because most of it stays in the vapor phase even during quenching.

\section{- Computer Modeling of Gettering Efficiency}

In order to determine the best way to add a getter to a system, it is helpful to determine the maximum equilibrium efficiency of the getter and to compare that value to a measured value for a given addition method. If the calculated equilibrium efficiency matches the experimental, then improvements in efficiency are not possible, unless some method of superequilibrium absorption can be devised. Figure 3.4-2 shows the total equilibrium concentration of all vapor-phase sodium-containing species, calculated by the TEACH code to be in the products of combustion of Spring Creek coal, as functions of temperature and the ratio of kaolin added to coal ash. The data were calculated assuming $20 \%$ excess air used for combustion and on a dry coal and dry air basis. Chlorine was not included in the input data, so a plot at higher pressures was not made because the experimental data showed that the effect of kaolin addition on chlorine concentration was significant at $109 \mathrm{psig}$, while it was not significant at atmospheric pressure.

The graph shows that the calculated total vapor-phase sodium concentration at just below $1500^{\circ} \mathrm{C}$ (such as in the experimental work) is approximately $310 \mathrm{ppm}$ (mass). Calculations of the mass of vapor-phase sodium, based on the assumption that the submicron sodium measured in the PDTF tests came from vapor-phase sodium hydroxide, indicates that $480 \mathrm{ppm}$ (mass) was in the vapor phase in the PDTF, showing that the calculated was off by $35 \%$. Also, the calculations illustrated in the figure indicate that approximately one-half of the vapor-phase sodium species can be gettered by the addition of kaolin at a ratio to ash of 0.5 . This is approximately the same as that measured in the tests, showing that simple mixing of the kaolin with the coal is sufficient to provide the maximum possible equilibrium absorption of sodium species. The graph shows that at 


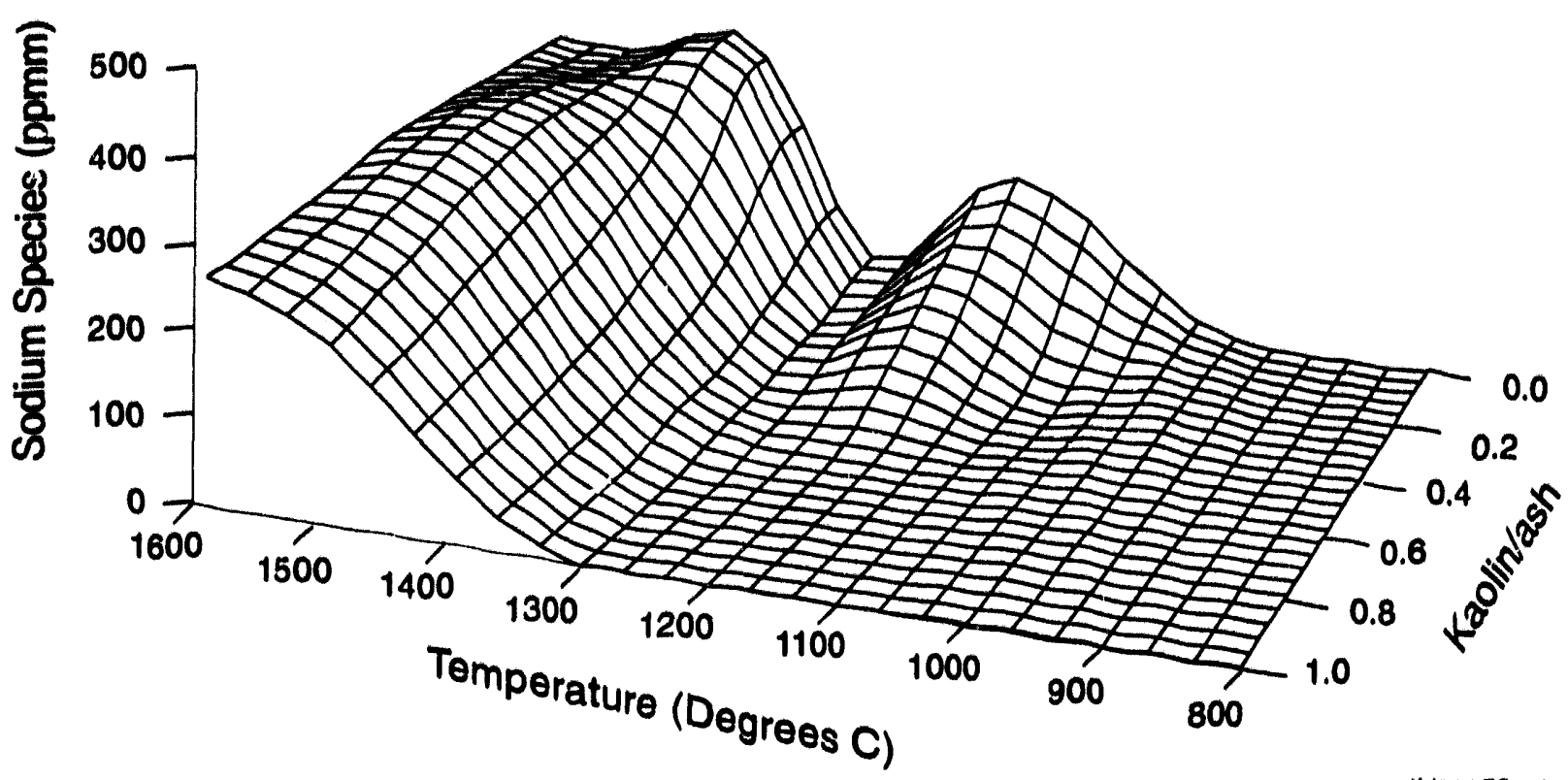

JHog058.cor

Figure 3.4-2. The calculated concentrations of vapor-phase sodium species versus temperature and ratio of kaolin added to ASTM ash.

lower temperatures and with greater levels of kaolin addition, less sodium is present at equilibrium in the vapor phase. At $1000^{\circ} \mathrm{C}$ and with no kaolin added, a situation such as that near a hot-gas cleanup device in a system burning Spring Creek coal, approximately 50 parts per billion by mass ( $\mathrm{ppbm}$ ) sodium species are at equilibrium in the gas phase, primarily as sodium hydroxide and sodium sulfate. This is double what is presently permitted by some high-efficiency turbine manufacturers for the inlet to the turbine. However, at a kaolin addition rate of one-half of the ASTM ash rate, the vapor-phase sodium species drop to $13 \mathrm{ppbm}$ at $1000^{\circ} \mathrm{C}$. They stay about this low all the way to $1300^{\circ} \mathrm{C}$ when kaolin is added at the same rate as the ASTM ash.

The peak at low kaolin additions and $1170^{\circ} \mathrm{C}$ is caused by a maximum in vaporphase sodium hydroxide, followed by a factor-of-three reduction in its concentration at $1300^{\circ} \mathrm{C}$, then a rapid rise at higher temperatures. Coincident with the drop in sodium hydroxide is a shift in condensed phase species from sodium sulfate and albite $\left(\mathrm{NaAlSi} \mathrm{O}_{8}\right)$ at lower temperatures, to nepheline $\left(\mathrm{NaAlSiO}_{4}\right)$ above $1300^{\circ} \mathrm{C}$. The peak at $1170^{\circ} \mathrm{C}$ is caused by an insufficient amount of silica in the system to condense all of the vapor phase sodium, since the $\mathrm{Si} / \mathrm{Na}$ ratio is only one at the higher temperatures but is three at lower temperatures. As kaolin is added though, the peak at $1170^{\circ} \mathrm{C}$ disappears because sufficient silicate becomes available. This result is preliminary at present and is being checked in the literature of experimental data. 


\section{- Conclusions}

Experiments with kaolin as an alkali getter at atmospheric and pressurized conditions show that it can effectively getter about one-half of the sodium species from the vapor phase when added in a kaolin/ash ratio of 0.5 . The kaolin chemically absorbs the sodium and does not simply act as a condensation site for sodium sulfate and hydroxide. The kaolin addition also shifts the sulfur concentration to larger particles at both atmospheric and pressurized conditions and shifts the chlorine concentration to larger particles at pressurized conditions. At atmospheric pressure, much of the chlorine is believed to stay in the vapor phase upon quenching.

Thermodynamic equilibrium modeling of sodium gettering shows that under the conditions tested, simple mixing of the kaolin with the coal is sufficient to provide the maximum equilibrium amount of gettering. The calculations also show that additions of 1 part kaolin per 1 part ASTM ash are sufficient to getter enough sodium species to keep their concentrations below the most stringent propused by turbine manufacturers, at temperatures of up to $1300^{\circ} \mathrm{C}$. Additions of 0.5 part kaolin to 1 part ash will keep the sodium species below required levels at $1000^{\circ} \mathrm{C}$.

\section{ASH/ALKALI CORROSION OF HOT.GAS CLEANUP FILTER MATERIALS}

- Introduction

High-temperature chemical corrosion and thermal stresses are known to cause degradation of ceramic particulate filters in direct coal-fired turbine systems. Severe chemical corrosion occurs in the presence of both gaseous alkali, ash, and steam. Also, corrosion is possible from $\mathrm{SO}_{2}, \mathrm{H}_{2} \mathrm{~S}$, and other low-level gas contaminants.

At the present time hot-gas clean-up filters operate at temperatures up to $1000^{\circ} \mathrm{C}$. Ceramic candles are formed by bonding ceramic fibers made from $\mathrm{SiC}$ and/or grains of alumina-silica bound together by an aluminosilicate-based binder. Ceramic cross-flow filters made from either cordierite or a mixture of mullite, cordierite, and alumina are constructed from multiple layers of thin porous plates that contain ribs to form gas flow channels. Fabric filters are flexible filters made from ceramic fibers (silica-alumina-boria, SiC, quartz, $\mathrm{ZrO}_{2}$, zirconia-silica, and alumina) formed into a mat or woven cloth, and fabricated into bag filters $(10,11)$.

Candle filters must be cleaned approximately 2 to 20 times each hour throughout their life (12). The thermal stresses created by blowing cool, pressurized air through the filters to clean them are significant. Cracks are especially formed near the flange region from which the filter is supported (13). Degradation mechanisms include both short-term ( $<1000$ hours) stress effects and long-term ( $>1000$ hours) corrosion effects.

The purpose of the present research is to determine the relative corrosion resistance of commercially available barrier filter materials and to determine the mechanisms of corrosion so that new filter materials (principally binders) and filter coatings can be developed to increase the corrosion resistance of the filter materials. SiC-based filters are focused on. Three types of corrosion are considered: corrosion by vapor-phase alkali as 
represented by sodium compounds, corrosion by steam, and corrosion by ash. Three major factors for binders are taken into account:

- Corrosion resistance,

- High adhesion of binder with $\mathrm{SiC}$ that results !n the formation of extended interdiffusion zones,

- Reasonable ratio of plastic/elastic components in the binder to reduce both tensile stresses resulted from cooling or creep during exposure of the filter to high temperature.

Two major properties of protective coatings are cunsidered:

- Corrosion resistance and

- Generation of stresses at substrate/coating interface due to thermal expansion mismatch

- Summary of Literature Survey

The silicon carbide/clay binder materials are most frequently used in field of coal. fired turbine applications. SiC has been recognized to have an excellent oxidation resistance in air, strength retention to high temperatures, high wear resistance, high thermal conductivity, and good thermal shock resistance. The thermal expansion coefficient is $\alpha=6.5^{-1} 10^{\circ}{ }^{\circ} \mathrm{C}^{-1}$ in the temperature range of $25^{\circ} .1500^{\circ} \mathrm{C}$. However, the axial thermal expansion coefficient of $\mathrm{SiC}$ is affected by structural changes resulting from polytypes structure (14). Because of the high percentage of covalent bonding, it is difficult to sinter SiC to high densities without binders and/or external pressure.

In addition, silicon nitride has excellent high-temperature strength and creep resistance, lower oxidation resistance than $\mathrm{SiC}$, good thermal shock resistance, and good dimensional stability over a wide temperature range. The thermal expansion coefficient for $\alpha$ and $\beta$ polymorphs are 2.9 and $2.3 \times 10^{-6} \mathrm{C}^{-1}$, respectively, in the temperature range of $25^{\circ} \cdot 800^{\circ} \mathrm{C}$.

Mullite and cordierites are mostly applied as binders to join $\mathrm{SiC}$ and/or $\mathrm{Si}_{3} \mathrm{~N}_{4}$ powders. They do not have high resistivity for high-temperature alkali attack. Thermal expansion coefficients for mullite and cordierite are $5.62\left(25^{\circ} .1500^{\circ} \mathrm{C}\right)$ and $24.5 .5 \times 10^{\circ}{ }^{\circ} \mathrm{C}^{-1}$ $\left(25^{\circ} \cdot 1.000^{\circ} \mathrm{C}\right)$, respectively.

\section{- Physical Properties of Mullite}

Physical properties of mulliteis considered to be a candidate for use at high temperature because mullite matrix materials exhibit low thermal expansion, low thermal conductivity and excellent creep resistance $(15,16)$. Mullite has the general formula $\mathrm{Al}_{1+2 \mathrm{x}} \mathrm{Si}_{2.2 \mathrm{O}} \mathrm{O}_{10 . \mathrm{x}}(0.2<\mathrm{x}<0.5)$, with the most frequently occurring compositions at about $\mathrm{x}=0.25\left(3 \mathrm{Al}_{2} \mathrm{O}_{3} \cdot 2 \mathrm{SiO}_{2}\right)$ and $\mathrm{x}=0.40\left(2 \mathrm{Al}_{2} \mathrm{O}_{3} \cdot \mathrm{SiO}_{2}\right)$. The mullite structure is able to incorporate considerable amounts of transition metal ions. The most important species are $\mathrm{Ti}^{3+}, \mathrm{Ti}^{\mathrm{t+}}, \mathrm{V}^{\mathrm{s+}}, \mathrm{V}^{4+}, \mathrm{Cr}^{3+}, \mathrm{Mn}^{3+}$, and $\mathrm{Fe}^{3+}$ ions. Trivalent chromium ions may 
substitute for $\mathrm{Al}^{3+}$ up to $12 \mathrm{wt} \% \mathrm{Cr}_{2} \mathrm{O}_{3}$ and also may occur in interstitial sites in the structural channels of mullite. Structural channels are formed by six-membered rings of tetrahedra occupied by $\mathrm{Al}$ and $\mathrm{Si}$ atoms.

Crystalline mullite is known for very good creep resistance. The diffusional creep rate of polycrystalline mullite (grain size $\approx 3$ to $4 \mu \mathrm{m}$ ) is $\sim 6 \times 10^{8} / \mathrm{s}$ at $1400^{\circ} \mathrm{C}$ at $90 \mathrm{MPa}$ and is associated with grain-boundary sliding (17). Mullite with some glassy phase in the grain boundaries shows plastic deformation up to about $11 \%$ strain at $1400^{\circ} \mathrm{C}$. The diffusional flow of mullite may be facilitated by addition of $\mathrm{ZrO}_{2}$ (18). For some zirconia/mullite ratios, the composite may exhibit superplastic deformation. Low plastic deformation of the binder is desirable to obtain good thermal-shock resistance.

\section{- Physical Properties of Cordierite}

Cordierite $\left(2 \mathrm{MgO} \cdot 2 \mathrm{Al}_{2} \mathrm{O}_{3} \cdot 5 \mathrm{SiO}_{2}\right)$ and cordierite-based glass-ceramics are used as structural materials due to their low thermal expansion, the resulting thermal-shock resistance, low density, and low thermal conductivity (19). The fracture strength of cordierite may be enhanced by dispersing $\mathrm{ZrO}_{2}$ particles as a second phase from 110 to $260 \mathrm{MPa}$. Also, the thermal-shock resistance increases from $350^{\circ}$ to $500^{\circ} \mathrm{C}$ by dispersing $15 \mathrm{wt} \%$ of $\mathrm{ZrO}_{2}$ in the cordierite matrix. However, the thermal expansion coefficient increases gradually with increasing $\mathrm{ZrO}_{2}$, and for $15 \mathrm{wt} \%$ of $\mathrm{ZrO}_{2}$, increases $0.2 \%$.

Alkali ions such as $\mathrm{Na}, \mathrm{K}$, and even $\mathrm{Cs}$ can be incorporated into structural channels, and cause framework deformation (20).

\section{- Alkali Corrosion of Silicate Binders}

Sodium appears to begin to react with the clay and mullite binders at about $825^{\circ} \mathrm{C}$ (21). At higher temperatures, a reaction zone forms on the surface which extends into the binder. It contains high-expanding alkali phases that quickly lead to thermal spalling. The absorption capacity of sodium can be increased by a factor of 2.8 in the presence of water vapor at $850^{\circ} \mathrm{C}$ and a pressure of 11 bars (22). Additionally, the water slowly reacts with silica in the binder and causes its depletion (13).

Generally, loss of binder is caused by:

- Liquefaction resulted from the decrease of viscosity (21).

- Erosion/spalling.

\section{- Corrosion of Silicon Carbide}

The resistance of $\mathrm{SiC}$ to high temperature oxidation results from the formation of a continuous, adherent surface coating of $\mathrm{SiO}_{2}(23,24)$. Vitreous silica is protective in clean oxidizing environments. However, above $1100^{\circ}-1200^{\circ} \mathrm{C}$, it is less protective as it begins to crystallize with the formation of a cristobalite phase. This causes the generation of high tensile stresses during temperature cycling, and thereafter an extensive spalling of the crystobalite layer occurs. Alkali corrosion of silicon carbide is caused by the destruction of this protective $\mathrm{SiO}_{2}$ surface layer. The concept of acid-base chemistry has been introduced to describe the corrosion of $\mathrm{SiC}$ (25). An acidic solution is defined as one 
with low free oxide ion activity; a basic solution is, conversely, one with relatively high free oxide ion activity. Thus the corrosion rate is attributed to the oxygen ion diffusivity, expressed by the following reactions:

$$
\begin{aligned}
& \mathrm{SiO}_{2}+\mathrm{O}^{-2} \longrightarrow \mathrm{SiO}_{3}^{-2} \\
& \mathrm{SiO}_{2}+2 \mathrm{O}^{-2} \rightarrow \mathrm{SiO}_{4}^{4}
\end{aligned}
$$

A basic oxide (e.g., $\mathrm{Na}_{2} \mathrm{O}$ ) readily transfers its oxygen to the coordination sphere of an acid oxide $\left(\mathrm{SiO}_{2}\right)$ to stabilize a silicon anion (26). The presence of basic salt solutions coupled with an oxidizing agent such as $\mathrm{O}_{2}$ and $\mathrm{H}_{2} \mathrm{O}$ will result in catastrophic attack of SiC. The normally stable, protective $\mathrm{SiO}_{2}$ layer becomes unstable in these solutions. Some authors proposed the reason water vapor accelerates the oxidation of $\mathrm{SiC}$ is that water vapor promotes the crystallization of amorphous silica scale into crystobalite which creates grain boundaries. The major rate-determining step for $\mathrm{SiC}$ corrosion is the inward diffusion of water and outward diffusion of $\mathrm{CH}_{4}$ through the silica scale. Steam can also dissolve silica from refractories.

The protective $\mathrm{SiO}_{2}$ layer is very resistant to attack by $\mathrm{SO}_{2} \cdot \mathrm{SO}_{3} \cdot \mathrm{O}_{2}$ gas mixtures below $1000^{\circ} \mathrm{C}$ (27). There is no evidence of sulfate formation, and there is no thermodynamic data for silicon sulfate. However, deposits of salts such as $\mathrm{Na}_{2} \mathrm{SO}_{4}$ tend to enhance the gaseous corrosion below $1000^{\circ} \mathrm{C}$. The activity of $\mathrm{Na}_{2} \mathrm{O}$ in the sulfate is inversely proportional to the $\mathrm{SO}_{3}$ pressure. The extensive degradation of the protective layer of vitreous silica by sodium is caused by the devitrification of silica. The corrosion of vitreous silica under reducing conditions (low oxygen atmosphere) with the excess of $\mathrm{H}_{2} \mathrm{~S}$ may occur by the formation of SiS vapor (28). A major problem for refractories in petrochemical applications is the removal of silica by hydrogen-rich gases. Stringer (29) has reviewed the problem associated with refractory and ceramic construction materials in petrochemical and coal gasification environments.

It was found that resistance to alkali attack of various aluminosilicates is increased by increasing the alumina content up to $50 \%$. Sodium may react with alumina, forming sodium aluminates at temperatures above $1100^{\circ} \mathrm{C}(30)$.

Summarizing, high-temperature alkali corrosion research has focused primarily on the following structural ceramics: silicon carbide (31-38), silicon nitride $(33,34,38)$, cordierite silicon nitride (39), mullite, alumina, aluminum titanate, zirconia and fiberglass (40).

\section{- Reduction in Mechanical Strength of Candle Filters}

Mechanical degradation of candle filters is caused by the differential pressure across the filter, vibrations, thermal gradients, installation and handling, the weight of the candle, and accumulated dust (13). The major source of mechanical degradation is believed to be caused by thermal shock from pulse cleaning resulting from the generation of thermal stresses at the $\mathrm{SiC} /$ binder interface due to the mismatch of linear thermal expansion coefficients. Thermal stresses may increase if alkali chemically reacts with the binders. Table 3.4-1 shows the effect of sodium content on the variation of linear thermal expansion coefficients for selected aluminosilicate glasses (41). These changes are expected to occur in binders in case of sodium absorption. Some of the silicates are 
already used as binders. The viscosity of selected silicates seems to be high, about $10^{10}$ poise, but not high enough to avoid plastic deformation. It is known that the creep occurs around the softening point of glass. The softening point of glass is the temperature at which the viscosity is approximately $10^{7.6}$ poise. At this viscosity, a rod about $24 \mathrm{~cm}$ long and $0.7 \mathrm{~mm}$ in diameter elongates $1 \mathrm{~mm} / \mathrm{min}$ under its own weight. Under constant gas pressure, the plastic deformation may occur at higher viscosities.

TABLE 3.4-1

Thermal Expansion Coefficients and Viscosities for Selected Silicate Glasses Taken from the Handbook of Glass Properties

\begin{tabular}{|c|c|c|c|c|c|}
\hline \multicolumn{3}{|c|}{ Composition (mol\%) } & \multicolumn{2}{|c|}{$\begin{array}{c}\alpha \times 10^{-6},{ }^{\circ} \mathrm{C}^{-1} \quad \log \eta, \text { Poise } \\
\frac{\left(20^{\circ}-300^{\circ} \mathrm{C}\right)}{}\end{array}$} & \multirow{2}{*}{$\begin{array}{c}\text { Temperature } \\
{ }^{\circ} \mathrm{C} \\
\end{array}$} \\
\hline $\mathrm{Na}_{2} \mathrm{O}$ & $\mathrm{B}_{2} \mathrm{O}_{3}$ & $\mathrm{SiO}_{2}$ & p. 155 & p. 275 & \\
\hline 2 & 28 & 70 & 3.6 & 10 & 634 \\
\hline 4 & 21 & 75 & 3.2 & 10 & 765 \\
\hline 6 & 24 & 70 & 4.1 & 10 & 716 \\
\hline 8 & 22 & 70 & 4.7 & 10 & 711 \\
\hline \multirow[t]{2}{*}{10} & 20 & 70 & 5.6 & 10 & 648 \\
\hline & & & \multicolumn{2}{|c|}{$\left(20^{\circ} .400^{\circ} \mathrm{C}\right)$} & \\
\hline $\mathrm{Na}_{2} \mathrm{O}$ & $\mathrm{ZrO}_{2}$ & $\mathrm{SiO}_{2}$ & p. 168 & & \\
\hline 10 & 10 & 80 & 4.9 & & \\
\hline 10 & 20 & 70 & 4.9 & 12.5 & 548 \\
\hline 15 & 5 & 80 & 7.0 & & \\
\hline 25 & 5 & 70 & 10.5 & & \\
\hline \multirow[t]{2}{*}{30} & 5 & 65 & 12.0 & & \\
\hline & & & \multicolumn{2}{|c|}{$\left(25^{\circ}-600^{\circ} \mathrm{C}\right)$} & \\
\hline $\mathrm{MgO}$ & $\mathrm{Al}_{2} \mathrm{O}_{3}$ & $\mathrm{SiO}_{2}$ & p. 169 & p. 296 & \\
\hline 20.3 & 18.3 & 61.4 & 4.31 & & \\
\hline 25 & 15 & 60 & 3.7 & 10 & 1500 \\
\hline \multirow[t]{2}{*}{35} & 15 & 50 & 4.5 & & \\
\hline & & & \multicolumn{2}{|c|}{$\left(20^{\circ}-100^{\circ} \mathrm{C}\right)$} & \\
\hline $\mathrm{Na}_{2} \mathrm{O}$ & $\mathrm{Al}_{2} \mathrm{O}_{3}$ & $\mathrm{SiO}_{2}$ & p.156 & & \\
\hline 17 & 15 & 68 & 7.6 & 10 & $670-780$ \\
\hline 20 & 37 & 43 & 7.7 & & \\
\hline 25.3 & 28.0 & 46.7 & 10.5 & & \\
\hline
\end{tabular}


Thermal stresses in the SiC-binder system can lead to decohesion when critical values are exceeded, which manifests itself in stable growth of interfacial cracks and separation along the $\mathrm{SiC} /$ binder interface. Separation at the interface occurs when loading direction is depended on: either the tensile stresses perpendicular to the interface exceed a critical value $\left(\delta_{i}\right)$, or the interfacial shear stresses exceed a critical value $\left(\tau_{i}\right)$. Tensile normal stresses can arise during cooling when the thermal expansion coefficient of the binder is higher than that of the $\mathrm{SiC}$ or as a consequence of tensile deformation of the $\mathrm{SiC} /$ binder system by external forces. Local tensile stresses at the interface, detected by the existing defects and/or formed as a result of inhomogeneities, stimulate the nucleation of cavities, leading to predamage that lowers the adhesive strength. Compressive stresses can arise if a thermal expansion coefficient of the binder is lower than that of the SiC and external forces.

Generally, tensile stresses in the binder (a larger thermal expansion coefficient than the substrate) are relevant to the propagation of cracks in a brittle substrate (42). Also, the compressive stresses in the binder parallel to interface may lead to tensile stresses perpendicular to the interface at the SiC. This may cause a lift of binder from, the SiC and binder separation. The latter effect is mostly detected during corrosion of metals (43).

The above analysis of stresses at the binder/SiC interface is used to predict trends in binder decohesion. The effects of binder thickness, elastic properties, and SiC toughness are not taken into consideration.

Table 3.4-2 lists two additional potential binders that may be employed in SiC-based barrier filters (44).

- The Role of Additives and Coatings in Corrosion Protection of SiC/Clay Materials

As earlier mentioned, the densification of $\mathrm{SiC}$ to high density is extremely difficult to accomplish. However, additives such as boron, carbon, and a wide variety of rare earth oxides, usually in combination with $\mathrm{Al}_{2} \mathrm{O}_{3}$, promote densification at temperatures around $2000^{\circ} \mathrm{C}$ (45). The major problems with these additives result from the formation of volatile components such as $\mathrm{CO}$ and $\mathrm{SiO}$ during oxidation of the $\mathrm{SiC}$. In the use of silicon carbide in harsh environments, it is necessary for the $\mathrm{SiC}$ to develop a vitreous coating to prevent rapid oxidation. The inward diffusion of corrosive gases through the vitreous coatings is lower than that along the grain boundaries in most crystalline coatings. To improve the corrosion resistance of $\mathrm{SiC}$ in highly corrosive industrial stack gas environments, plasma-sprayed ceramic coatings, including single-layered mullite and multilayered coatings of mullite $\left(3 \mathrm{Al}_{2} \mathrm{O}_{3}-2 \mathrm{SiO}_{2}\right)$, zircon $\left(\mathrm{ZrO}_{2}-\mathrm{SiO}_{2}\right)$, alumina, yttria, chromia, mullite $/ \mathrm{Al}_{2} \mathrm{O}_{3}$, mullite $/ \mathrm{Y}_{2} \mathrm{O}_{3}$, and yttria-stabilized zirconia have been applied $(46,47)$. The coatings were more adherent to $\mathrm{SiC}$ bounded by binders than to the sintered $\mathrm{SiC}$. Criteria for well-adherent, corrosion-resistant coatings for $\mathrm{SiC}$ up to about $1300^{\circ} \mathrm{C}$ are: to be similar to the $\mathrm{SiC}$ coefficient of thermal expansion, to have a low modulus of elasticity, and to be a precursor available to a commercial plasma spray powder (48). Recently, for turbine engines a two-layer system incorporating a plasma-sprayed $\mathrm{Y}_{2} \mathrm{O}_{3}$. stabilized zirconia over an underlying plasma-sprayed $\mathrm{NiCoCrAJ} Y$ bond coat has been investigated. Also, india $\left(\operatorname{In}_{2} \mathrm{O}_{3}\right)$ was selected as a candidate resistant to high- $\operatorname{comperature}$ reactions with $\mathrm{SO}_{3} / \mathrm{Na}_{2} \mathrm{SO}_{4}$ and vanadate melts. Results of these tests are not yet available. 
TABLE 3.4-2

Physical Properties of Materials That May Be Used as Binders for SiC

\begin{tabular}{cccc}
\hline Material & $\begin{array}{c}\text { Melting } \\
\text { Temperature, }{ }^{\circ} \mathrm{C}\end{array}$ & $\begin{array}{c}\text { Thermal Expansion } \\
\text { Coefficient, } \\
(\mathrm{x} \mathrm{10}),{ }^{\circ} \mathrm{C}^{-1}\end{array}$ & $\begin{array}{c}\text { Temperature Range, } \\
{ }^{\circ} \mathrm{C}\end{array}$ \\
\hline SiC (reference) & 2500 & 5.12 & $25-1000$ \\
Zirconia Mullite & 1743 & $0.65 \%$ & $20-1130$ \\
$\mathrm{ZrSiO}_{4}$ & $1760\left(\mathrm{~T}_{\mathrm{d}}\right)$ & 4.2 & $25-700$ \\
\hline
\end{tabular}

Some coatings, such as alumina, are excellent in the absence of sulfur compounds. Severe degradation of $\mathrm{Al}_{2} \mathrm{O}_{3}$ may occur because of the reaction with molten $\mathrm{Na}_{2} \mathrm{SO}_{4}$ film which may proceed by acidic or basic fluxing reactions (27):

$$
\begin{gathered}
3 \mathrm{Na}_{2} \mathrm{SO}_{4(1)}+\mathrm{Al}_{2} \mathrm{O}_{3} \longrightarrow \mathrm{Al}_{2}\left(\mathrm{SO}_{4}\right)_{3}+3 \mathrm{Na}_{2} \mathrm{O} \\
\mathrm{Na}_{2} \mathrm{SO}_{4(1)}+\mathrm{Al}_{2} \mathrm{O}_{3} \longrightarrow 2 \mathrm{NaAlO}_{2}+\mathrm{SO}_{3(\mathrm{~g})}
\end{gathered}
$$

Researchers at the Virginia Polytechnic Institute, Center for Advanced Ceramic Materials, have reported a new high-temperature barrier material based on the composition $\left(\mathrm{Ca}_{1 \cdot x}, \mathrm{Mg}_{\mathrm{x}}\right) \mathrm{Zr}_{4}\left(\mathrm{PO}_{4}\right)_{8}(\mathrm{CM} \mathrm{ZP})(49)$. The CMZP materials have near-zero bulk thermal expansion and low crystal anisotropy, adjustability from positive to negative thermal expansion coefficients by controlling composition and processing parameters, very low thermal conductivity, thermal stability at $1500^{\circ} \mathrm{C}$, excellent thermal-shock resistance, and good resistance to alkali attack (49). These materials are postulated for coatings to protect silicon-based ceramics for alkali corrosion. Information is not yet available about the adhesion of CMZP materials to silicon-based ceramics.

\section{- SiC and Metallic Binders}

In the past five years, $\mathrm{SiC} /$ metal composites have been increasingly studied. Most studies were conducted with pure $\mathrm{Ni}, \mathrm{Fe}, \mathrm{Ni}-\mathrm{Fe}$ alloys, $\mathrm{Ti}, \mathrm{Cr}$, and with $\mathrm{Ni}-\mathrm{Cr}$ and $\mathrm{Ni}-\mathrm{Cr}$ $\mathrm{Al}$ alloys $(50,51)$. These metals react with carbon and silicon by forming a broad class of reaction products such as carbides and silicides, respectively (52). The mechanical, thermal, and chemical stability of the systems during service critically depends on the integrity of the interface between the metallic and ceramic components. The adhesion in such systems increases with increasing metal affinity of the metal for carbon. There are a limited number of ceramic-metal bonds that are stable at high temperatures. Two major restrictions: the high thermomechanical stresses and the excessive reaction layers, appear to limit the utilization of metals as binders for structural ceramics. Reaction layers usually have inferior properties compared with the joined materials, thereby reducing the possible stability and strength of the joint. More recent work has focused on other promising binding alloys, such as $\mathrm{MoSi}_{2}$, that may improve high-temperature mechanical properties and oxidation resistance of composites (53). A disadvantage to this alloy is poor thermal-shock resistance during rapid heating. 


\section{- The Future Research Program}

As mentioned, the obiective of this project is to test existing materials and apply new technologies for the preparation of materials resistant to alkali vapor, ash, and steam corrosion.

\section{- Materials}

Corrosion tests will be performed both on samples of relatively pure commercially available and experimental binder materials, as well as on C-rings of commercially available filter materials. Initial binders to be considered will consist of those donated by companies that are manufacturing barrier filters, as well as mullite, Cr-doped mullite and mullite/zirconia composite, $\mathrm{ZrSiO}_{4}$, cordierite, and $\mathrm{Cr}$-doped cordierite. It is expected that $\mathrm{Cr}$-doped mullite and cordierite will demonstrate higher resistance for alkali attack than mullite. It is known that for alumina-chromia refractories, as the chromia content increases from $7 \%$ to $32 \%$, the corrosion decreases substantially (54). In Cr-doped mullite and cordierite, $\mathrm{Cr}^{3+}$ substitutes $\mathrm{Al}^{3+}$, and this will protect chromium before its oxidation to volatile $\mathrm{CrO}_{s}(27)$ and/or solubility in coal slag (55). Zirconia in mullite will improve the ductility of candle filters, which is desired for thermal-shock resistance.

Thereafter, corrosion tests will be conducted on model binder/aggregate composites and C-rings of commercially available materials.

\section{- Effect of Atmosphere on Alkali Corrosion}

Since the alkali release in the vapor-phase is higher under gasification than under combustion conditions, we expect that the corrosion mechanism strongly depends on the sodium components, $\mathrm{Na}_{2} \mathrm{~S}, \mathrm{Na}_{2} \mathrm{SO}_{4}, \mathrm{NaCl}, \mathrm{NaOH}$, and $\mathrm{Na}_{2} \mathrm{CO}_{3}$ (56). Also, water vapor causes changes in physical and chemical properties of silicates, usually decreasing the viscosity and increasing the ion mobility in silicates in the temperature range $900^{\circ}$. $1400^{\circ} \mathrm{C}$ (57). Alkali silicates with $>20-\mathrm{mol} \%$ alkali have poor resistance to $\mathrm{H}_{2} \mathrm{O}$ attack, so, that they can be completely dissolved in water to form water glass (58). In addition, the effects of ash corrosion in the presence of sodium species and steam will be determined.

The kinetics of corrosion of binders alone and barrier filter materials will be measured in sodium and water vapor under combustion and gasification conditions in the presence of sulfur compounds and chlorides both in the presence of ash and without ash. The kinetics of corrosion will enable the definition of corrosion rates and possibly diffusion parameters.

\section{- Morphology tests}

SEM point count analysis will be applied to determine the distribution of sodium and other elements in surface layers and grain boundaries in barrier filter materials. In case of higher segregation of elements in grain boundaries, Auger and ESCA spectroscopies will be employed. 


\section{EXPERIMENTAL WORK WITH $\mathrm{Ta}_{2} \mathrm{O}_{5}$ CORROSION-RESISTANT COATINGS FOR SILICON CARBIDE}

\section{- Introduction}

High-temperature corrosion of ceramic materials in hot-gas cleanup systems, heat exchangers, and other ceramic components used in coal combustion systems has lead to an ever-increasing need for new materials and technology as new government regulations on hazardous emissions come into effect. Much of the research in this area has focused on the mechanisms involved in the corrosion of advanced high-temperature ceramics such as silicon carbide (SiC). It has been found that a large part of the corrosion is due to the alkalies present in the coal ash and the alkali vapor present in the gas stream. In efforts to prevent the alkali attack, work has been done to find coatings for $\mathrm{SiC}$ materials to protect them from alkali vapor and molten coal ash. In this section, we report on progress made in the development of tantalum pentoxide applied by physical deposition techniques as a corrosion-resistant coating for $\mathrm{SiC}$.

\section{- Background}

At high teinperatures, silicon carbide forms a protective oxidation layer of $\mathrm{SiO}_{2}(59)$. In the presence of alkali vapor, this layer reacts to form alkali silicate glasses such as sodium silicate. This sodium can then react with the silicon carbide causing corrosion (60, 61 ). In order to prevent corrosion, coating materials must be able to resist reaction with sodium compounds. Also, because the coating will undergo thermal cycling from room temperature to as high as $1000^{\circ} \mathrm{C}$ in a hot-gas cleanup system, it must have a thermal expansion coefficient similar to $\mathrm{SiC}$ to prevent spalling.

Of all the coating materials that have previously been tested, the two which seem to hold the most promise for resistance to sodium compounds are mullite $3 \mathrm{Al}_{2} \mathrm{O}_{3} \bullet 2 \mathrm{SiO}_{2}$ and tantalum pentoxide $\left(\mathrm{Ta}_{2} \mathrm{O}_{5}\right)$. Although mullite has a coefficient of thermal expansion of $5.7 \times 10^{-6} /{ }^{\circ} \mathrm{C}$, very close to $\mathrm{SiC}$ of $5.5 \times 10^{-8} /{ }^{\circ} \mathrm{C}$, its corrosion resistance is dependent upon the formation of stoichiometric mullite. Free $\mathrm{SiO}_{2}$ in nonstoichiometric mullite would corrode and dissolve the native $\mathrm{SiC} \cdot \mathrm{SiO}_{2}$ oxide layer. Since forming stoichiometric mullite may prove to be difficult, $\mathrm{Ta}_{2} \mathrm{O}_{5}$ was chosen as the first coating to study. Phase equilibrium diagrams of the $\mathrm{Ta}_{2} \mathrm{O}_{5} \bullet \mathrm{Na}_{2} \mathrm{O}(62)$ and $\mathrm{Ta}_{2} \mathrm{O}_{5} \cdot \mathrm{SiO}_{2}(63)$ systems indicate no liquid phases of sodium tantalate below $1625^{\circ} \mathrm{C}$ and no liquid tantalum silicates below $1550^{\circ} \mathrm{C}$. Also, $\mathrm{Ta}_{2} \mathrm{O}_{6}$ has a low coefficient of thermal expansion of $3.6 \times 10^{-6} /{ }^{\circ} \mathrm{C}$, ensuring that the coating will be in compression at temperature.

Tantalum and tantalum pentoxide have long been used in thin film microelectronic devices (64-69). Several methods exist for deposition of dense uniform $\mathrm{Ta}_{2} \mathrm{O}_{5}$ films, including chemical vapor deposition (CVD) (70-72), physical vapor deposition (PVD) (7376 ), anodic deposition (77, 78), and thermal oxidation (79) of tantalum metal films. Research at Oak Ridge National Laboratory is currently being done to develop a technique for chemical vapor deposition. This has lead to some degree of success; however, crystalline films are produced, some of which have a columnar grain structure that could provide a path for diffusion of sodium to the SiC surface. Work there has now turned to optimizing the coating morphology to produce smaller more equiaxed crystal grains (70). 
Research at the EERC during this reporting period has been to develop techniques to produce coatings using physical deposition, namely, electron beam deposition and anodic deposition. In electron beam deposition, a high-power beam of electrons is accelerated inside a vacuum chamber with a high voltage and focused onto the material to be deposited. The kinetic energy of the electrons converts to thermal energy upon striking the material, causing it to vaporize and deposit on anything in its line of sight.

The electron beam evaporator is capable of vaporizing any known substance. Compounds may be stoichiometrically evaporated and deposited providing they do not decompose or disassociate, unless the dissociated species are made to recombine in the vapor state or at the surface of the substrate to be coated. Reactive evaporation (80) is also possible in which two or more materials are evaporated simultaneously, which then react witı each other or a purge gas that can be introduced into the vacuum through a leak valve to maintain the required partial pressure of a reactive gas. In this way, many metal nitrides, oxides, carbides, silicides and other compounds, including $\mathrm{Ta}_{2} \mathrm{O}_{5}$, are routinely evaporated to produce optical coatings and microelectronic devices (81-86).

Large electron beam evaporation systems are commercially available that can coat anything from aluminum onto plastic cellophane, or aircraft engine turbine blades. Leybold AG designed and built a system capable of deposition rates of from 0.001 to 1000 $\mathrm{nm} / \mathrm{sec}(73)$. The deposition rate is easily controlled by simply varying the power to the electron beam. Because this technique has such a wide range of applicability and is commercially available it should prove to be a good candidate for applying anti-corrosion coatings to $\mathrm{SiC}$ and other materials used in hot-gas corrosive environments.

In anodic deposition, the material to be coated becomes the anode of an electrolytic cell. The material is first coated with the desired metal and the metal is then anodized in the cell to form a metal oxide film. Interest in anodization of tantalum dates back to the early fifties from work on making capacitors in the electronics industry. Anodization of tantalum results in the tantalum being converted to an amorphous film of $\mathrm{Ta}_{2} \mathrm{O}_{5}(77,78)$ rather than the granular film that forms during chemical vapor deposition.

During this reporting period, a procedure was developed to anodize a film of tantalum that had been evaporated by electron beam onto a $\mathrm{SiC}$ substrate. In the course of the experiments, it was found that $\mathrm{SiC}$ conducts electricity well enough to short out the electrolytic cell, causing anodization to stop. Thus no successful anodic tantalum pentoxide films have been produced to date on SiC. Future work to produce these coatings will require the $\mathrm{SiC}$ substrate to be completely covered by a uniform tantalum metal coating preventing the contact of $\mathrm{SiC}$ with the electrolyte in the cell, which causes cell shortage. A small fixture is being developed that will allow the SiC sample to be rotated in the chamber of the evaporator. This will allow the substrate to be coated with tantalum on both sides. When placed in the electrolytic cell, only the tantalum will be exposed to the electrolyte, allowing its complete anodization.

\section{- Experimental}

The electron beam evaporator used in producing the coatings was donated by Vacuum Technology Corporation of Minneapolis, MN. It was manufactured by CHA industries and has a power supply capable of producing a 6 -kilowatt beam of $10 \mathrm{keV}$ electrons at a current of 600 milliamperes. It has a high vacuum oil diffusion pump that 
produces an ultimate vacuum of $10^{-8}$ torr in the evaporation chamber. An array of five 1200-watt quartz infrared heaters in the chamber provides 6000 watts of power to heat the substrates up to $450^{\circ} \mathrm{C}$. A needle valve was installed on the system to allow introduction of gases for reactive evaporation.

The system is equipped with an Inficon XTC quartz crystal thickness monitor that measures evaporation rate and film thickness. Sample mounting fixtures supplied with the instrument are motor-driven and provide a means of a planetary rotation of the samples around the evaporant for more uniform coatings.

The tantalum used to produce $\mathrm{Ta}_{2} \mathrm{O}_{5}$ and tantalum coatings was donated by Tosoh SMD, Inc., and was of $99.9 \%$ purity. To make the $\mathrm{Ta}_{2} \mathrm{O}_{5}$, the tantalum was cut into small pieces and oxidized in air at $1000^{\circ} \mathrm{C}$. The tantalum oxide emerged in a powder form and was placed into the water-cooled copper crucible which serves as the hearth for the evaporant in the electron gun. Carborundum Company supplied small, approximately 1 inch in diameter, Hexoloy SA SiC washers that were quartered into four pieces and used as substrates for coating.

Two sections of the $\mathrm{SiC}$ washer were prepared for coating. One sample was etched in $49 \%$ reagent-grade $\mathrm{HF}$ acid for three minutes to remove the native $\mathrm{SiO}_{2}$ layer, rinsed, and stored in methanol until it was mounted in the vacuum chamber. The other sample was simply cleaned with methanol. This was done to see if the $\mathrm{SiO}_{2}$ layer would promote or degrade the adherence of the coating. It has been shown that tantalum readily reacts with $\mathrm{SiC}$ upon heating and forms a mixed layer of tantalum carbides and silicides at temperatures as low as $400^{\circ} \mathrm{C}(64)$. Just prior to evaporation, these samples were mounted in the chamber to the planetary fixturing along with one microscope slide covered with aluminum to allow a later independent verification of film thickness using a Fizeau interferometer and another microscope slide for possible later determination of thickness and index of refraction of the film using ellipsometry. An oxygen supply was attached to the needle valve to allow introduction of an oxygen partial pressure of $2 \times 10^{-4}$ torr.

The system was then pumped down to a pressure of $2 \times 10^{-6}$ torr, at which time liquid nitrogen was added to the cold trap and the substrate heaters were turned on to outgas the chamber. The chamber was heated to $400^{\circ} \mathrm{C}$ for 20 minutes for outgassing, and then the substrate heaters were set to maintain a substrate temperature of $250^{\circ} \mathrm{C}$, as measured by a $\mathrm{K}$-type thermocouple located near the sample holders. The needle valve was then set to bleed in oxygen until a pressure of $2 \times 10^{-4}$ torr was reached. Maintaining an oxygen partial pressure is a standard technique used to recombine dissociated tantalum at the surface of the substrate. A shutter was then placed over the hearth, and the electron beam was turned on. The beam current was brought up slowly to outgas the oxide and achieve a homogeneous melt. After a steady state had been achieved, the shutter was opened and deposition commenced.

The beam current was maintained at 200 milliamperes throughout the evaporation except when it had to be turned down to avoid excessive arcing through the local plasma caused by the high voltage. At this current, a deposition rate of approximately 1.1.5 angstroms per second was measured using the Inficon XTC monitor. The evaporation continued for $\mathbf{4 5}$ minutes at which time the monitor indicated a thickness of 3953 angstroms ( 0.4 micron) and the shutter was closed. The samples were then allowed 
to cool to room temperature and be removed for examination. A visual inspection showed the film to be hard, dense, and optically transparent with a light brown tint. The measured thickness was 0.74 microns using a Fizeau interferometer. This discrepancy between that measured by the XTC monitor and the interferometer is likely due to an incorrect calibration factor in the XTC monitor.

The coated SiC samples were then tested for corrosion resistance with an Illinois No. 6 ash for 132 hours at $1260^{\circ} \mathrm{C}$. The samples were placed in small alumina crucibles filled with the ash and slowly heated at $4^{\circ} \mathrm{C}$ per minute in a high-temperature furnace. The samples were cooled slowly and removed for sectioning and SEM analysis.

\section{- Results and Discussion}

Upon sectioning, large voids were observed in the slag which were apparently produced from gas bubbles forming upon melting which did not escape the crucibles due to the high viscosity of Illinois No. 6 ash. The samples, therefore, had very poor coverage by the slag. SEM micrographs showed no uniform coating by either the slag or the tantalum pentoxide films and as a result little or no corrosion. A small area of slag adhesion was found on the sample which was not etched with HF. Figure 3.4-3 is a backscattered electron image of the area where a large concentration of tantalum grains are present within the slag. The continuous gray phase at the bottom of the figure are the $\mathrm{SiC}$, the medium gray areas above it are slag, and the bright areas are tantalum oxide.

Figure 3.4-4 is a secondary electron image of the tantalum oxide grains. Table 3.4-3 shows the composition of the tantalum oxide grains and the composition of the adjacent slag. The grains are composed mainly of tantalum, iron, and silicate phases. The slag adjacent to them appears to have dissolved some amount of tantalum oxide. At $1260^{\circ} \mathrm{C}$ for 132 hours, it may be reasonable to conclude that some solid-state reactions have taken place with the iron oxide in the slag and tantalum pentoxide coating. Phase equilibrium diagrams for the $\mathrm{Fe}-\mathrm{Ta}-\mathrm{O}$ system show these reactions take place at as low as $1200^{\circ} \mathrm{C}(87)$. These solid solutions may then diffuse into the adjacent slag resulting in the compositions shown.

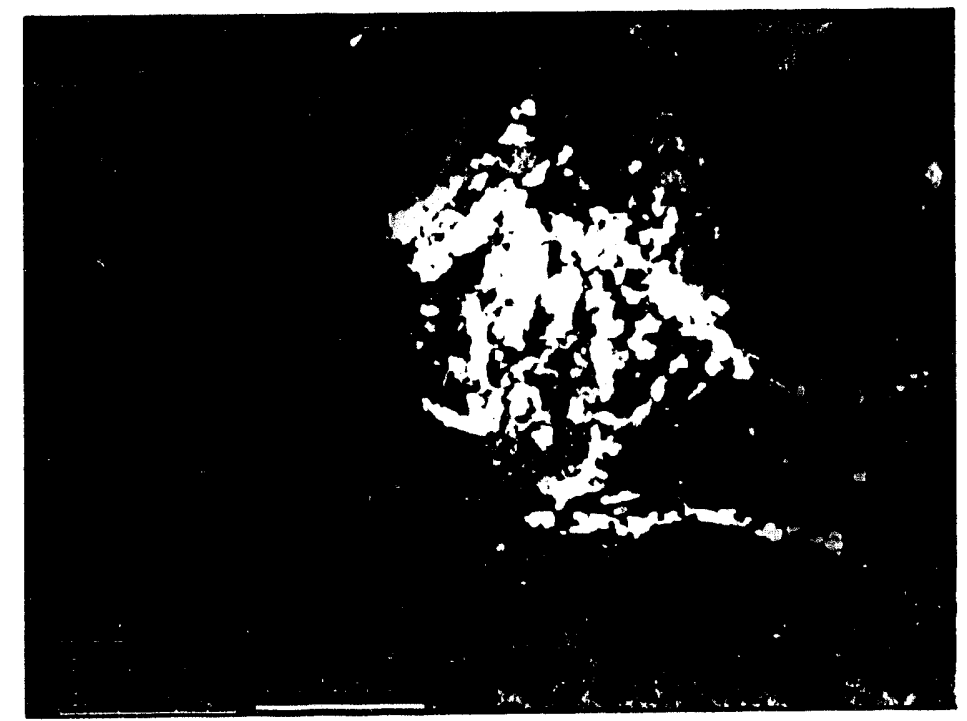

Figure 3.4-3. SEM backscattered electron image of the SiC/slag interface showing the remains of the tantalum pentoxide film. 


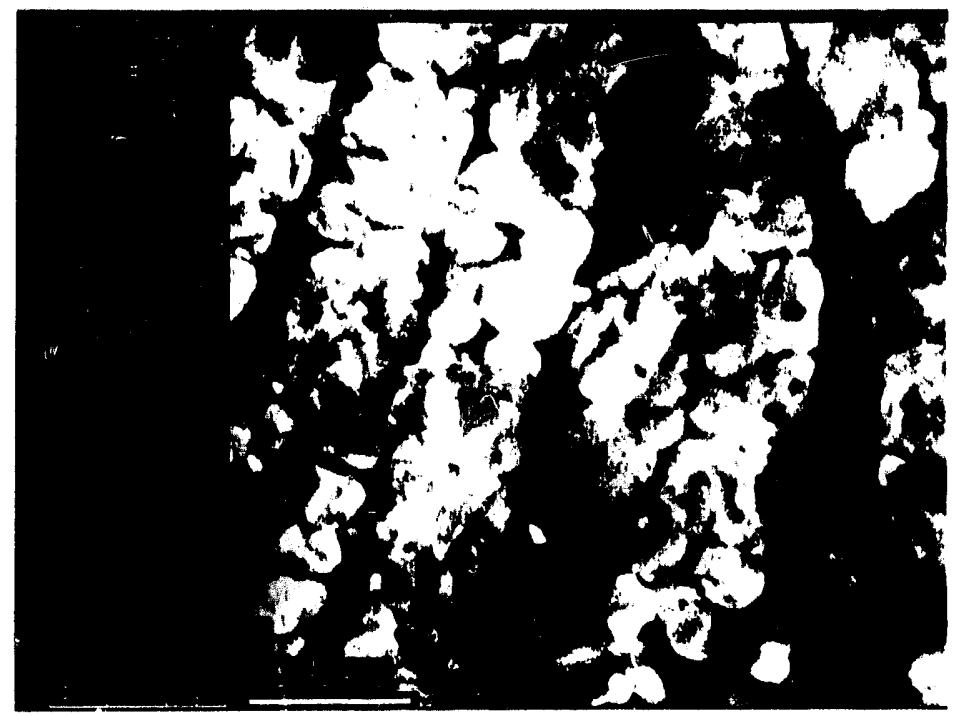

Figure 3.4-4. SEM secondary electron image of the tantalum pentoxide grains at higher magnification.

TABLE 3.4-3

Composition of the Tantalum Oxide Grains and Adjacent Slag

\begin{tabular}{lccc}
\hline Oxides & Illinois No. 6 Ash, wt\% & Slag, wt \% $^{\prime}$ & $\begin{array}{c}\text { Tantalum Grains, } \\
\text { wt\% }\end{array}$ \\
\hline $\mathrm{Na}_{2} \mathrm{O}$ & 1.18 & 1.18 & 0.19 \\
$\mathrm{MgO}$ & 2.50 & 0.71 & 0.33 \\
$\mathrm{Al}_{2} \mathrm{O}_{3}$ & 18.50 & 16.15 & 1.82 \\
$\mathrm{SiO}_{2}$ & 57.80 & 61.38 & 9.22 \\
$\mathrm{~K}_{2} \mathrm{O}$ & 0.62 & 2.50 & 0.00 \\
$\mathrm{CaO}$ & 3.74 & 4.08 & 0.28 \\
$\mathrm{TiO}_{2}$ & 1.03 & 0.29 & 2.10 \\
$\mathrm{FeO}$ & 14.62 & 5.68 & 16.23 \\
$\mathrm{NiO}$ & $\ldots$ & 0.89 & 0.00 \\
$\mathrm{Ta}_{2} \mathrm{O}_{5}$ & $\ldots$ & 7.02 & 69.65 \\
\hline
\end{tabular}


The coating along the slag/SiC interface appears to be still intact. What may be a corrosion pit appears directly beneath the coating with what appears to be a gas bubble emanating from it. This is probably $\mathrm{CO}$ or $\mathrm{CO}_{2}$ formed from carbon released during formation of a thermally growing $\mathrm{SiO}_{2}$ layer liberating carbon from the $\mathrm{SiC}$. Gas formation at the $\mathrm{SiC} /$ coating interface would be detrimental to any kind of coating; this may be what caused the films to break apart. For future work it is suggested to first oxidize the $\mathrm{SiC}$ at high temperature in air to grow the $\mathrm{SiO}_{2}$ as thick as possible before film deposition. Also, in future corrosion tests, the slags should be premelted and homogenized to prevent bubble formation due to volatiles in the ash.

\section{- Conclusions}

The technique of electron beam deposition is a useful technique for applying coatings of a very wide range of materials that may be useful as coatings to protect refractory materials such as $\mathrm{SiC}$ from corrosion. Although it may be argued to be economically unfeasible to use on an industrial scale, it will allow the study of interactions of candidate coating materials with $\mathrm{SiC}$ and other refractory materials in hot-gas conditions. Further work is continuing to determine the capability of tantalum pentoxide to protect $\mathrm{SiC}$ from corrosion in hot-gas conditions. The results of experiments conducted thus far are inconclusive; more work is necessary to determine its corrosion prevention abilities. Also, mullite is another possible coating material. Future work may include attempts to evaporate mullite for use as a coating on SiC.

\section{$\underline{\text { References }}$}

1. Ullman D. Database and Knowledge-Bases; Computer Science Press: Chicago, IL, 1988.

2. Richet, P.; Gillet, P.; Fiquet, G. "Thermodynamic Properties of Minerals: Macroscopic and Microscopic Approaches," In Thermodynamic Data: Systematics and Estimation; Saxena, S.K., Ed.; Springer-Verlag: New York, 1992.

3. Chase, M.W.; Davies, C.A.; Downey, J.R., Jr.; Frurip, D.J.; McDonald, R.A.; Syverud, A.N. JANAF Thermochemical Tables, 3rd ed.; American Chemical Society and American Institute of Physics: New York, 1986.

4. Barin, I.; Knacke, O.; Kubaschewski, O. Thermochemical Properties of Inorganic Substances; Springer-Verlag: New York, 1977.

5. Lee, S.H.D; Johnson, I. "Removal of Gaseous Alkali Metal Compounds from Hot Flue Gas by Particulate Sorbents," Journal of Engineering for Power 1980, 102, 397-402.

6. McLaughlin, J. "The Removal of Volatile Alkali Salt Vapours from Hot Coal-Derived Gases" Ph.D. Thesis, Department of Chemical and Process Engineering, University of Surrey, Guildford, England, 1990. 
7. Newby, R.A.; Alvin, M.A.; Bachovichin, D.M.; Yang, W.C.; D'Amico, N.; Smeltzer, E.E.; Lippert, T.E. "Integrated Low Emissions Cleanup System for Direct CoalFueled Turbines" DOE/MC/2457--2927, 1990.

8. Shadman, F.; Peterson, T.W.; Wendt, J.O.L.; "Mechanism of Surface Enrichment and Adhesion of Coal Combustion Particulates," DOE/PC/90505-T9, 1992.

9. Jones, M.L.; Haley, J.S.; Hurley, J.P.; Ljubičić, B.R.; Ramanathan, M. "Hot-Gas Cleanup," Semiannual Technical Progress Report for the Period Jan. - June 1992, DOE/METC, DE-FC21-86MC10637, July 1992.

10. Alvin, M.A.; Sawyer, J. "Long-Term Temperature Degradation Mechanisms in Pcrous Ceramic Filters," In Proceedings of American Filtration and Separation-Providing Solutions to the Technical Problems of the 1990s; March 18. 22, 1990, p. 287.

11. Sawyer, J.; Vass, R.J.; Brown, N.R.; Brown, J.J. "Corrosion and Degradation of Ceramic Particulate Filters in Direct Coal-Fired Turbine Applications," Trans. ASME, 1990, 1.

12. Stinton, D.P.; Riester, L.; Dellinger, D. "Characterization of Fiber-Reinforced Particulate Filters," Metals and Ceramics Division Oak Ridge National Laboratory, ORNL/TM-11197, May 1989.

13. Sawyer, J. "Assesment of the Causes of Failure of Ceramic Filters for Hot-Gas Cleanup in Fossil Energy Systems and Determination of Materials Research and Development Needs," final report Jan. 1989. For Oak Ridge National Laboratory; Contract No. DE-AC05-840R21400.

14. Li, Z.; Bradt, R.C. "Thermal Expansion and Thermal Expansion Anisotropy of SiC Polytypes," J. Amer. Ceram. Soc. 1987, 70, 445.

15. Rager, H.; Schneider, H.; Graetsch, H. "Chromium Incorporation in Mullite," Amer. Mineral. 1990, 75, 392.

16. Ikeda, K.; Schneider, H.; Akasaka, M.; Rager, H. "Crystal-Field Spectroscopic Study of Cr-Doped Mullite," Amer. Mineral. 1992, 77, 251.

17. Dokko, P.C.; Pask, J.A.; Maziyasni, K.S. "High-Temperature Mechanical Properties of Mullite under Compression," J. Am. Ceram. Soc. 1977, 60, 150.

18. Yoon, C.K.; Chen, I.W. "Superplastic Flow of Two-Phase Ceramic Containing Rigid Inclusions-Zirconia/Mullite Composites," J. Am. Ceram. Soc. 1990, 73, 1555.

19. Hirano, M.; Inada, H. "Preparation and Characterization of Cordierite-Zirconia Composites from Co-Precipitated Powder," J. Mater. Sci. 1993, 28, 74.

20. Daniels, P. "Structural Effects of the Incorporation of Large-Radius Alkalies in High Cordierite," Amer. Mineral. 1992, 77, 407. 
21. Silicon Carbide-1973; Marshall, R.C.; Faust, Jr. J.W.; Ryan, C.E., Eds. Proceedings of the Third Intern Conf on Silicon Carbide; Miami Beach, FL, Sept., 17-20, University of South Carolina Press: Columbia, SC, 1974.

22. Tressler, R.E., McNallan, M., Eds. Ceramic Transactions, Corrosion and Corrosive Degradation of Ceramics; The American Ceramic Society, Westerville, 1989.

23. Sawyer, J.; Brown, J.J.; Brown, N. "Thermal Chemical Degradation of Ceramic Candle Filter Materials," Contractors Review Meeting, Morgantown, West Virginia, 1989, p 139.

24. Pintsch, S.; Gudenau, H.W. "Alkaline Hot-Gas Cleaning in Combined Cycle Processes," VGB Kratwerkstechnik, 1991, 1, 40.

25. Arendt, R.H.; Curran, M.J. "Corrosion of Dense Silicon Carbide in Basic Molten Salt Solutions," In Metal-Slags-Gas Reactions and Processes; Foroulis, A.S.; Smeltzer, W.W., Eds.; Electrochemical Society: New Jersey, 1975, p 636.

26. Navrotsky, A. "Crystal Chemical Constraints on the Thermochemistry of Minerals," Reviews in Mineralogy 1985, 14, 120.

27. Blachere, J.R.; Petit, F.S. High-Temperature Corrosion of Ceramics; Noyes Data Corporation: Park Ridge, 1989.

28. Van der Biest, O.O.; Barnes, J.; Corish, J.; Norton, J.M. "Corrosion of a SilicaBearing Ceramic in Sulfur-Oxygen Atmospheres," J. Am. Ceram. Soc. 1987, 70, 456.

29. Stringer, J. "Materials of Construction in Coal Gasification Systems; U.S.

Experience. II. Refractory and Ceramic Materials," In High-Temperature Materials Corrosion in Coal Gasification Atmospheres; Norton. J.F., Ed.; Elsevier Applied Science Publishers: London, 1984, p 117.

30. Farris, R.E.; Allen, J.E. "Aluminous Refractories-Alkali Reactions," Iron and Steel Eng. 1973, 50 (2), 67.

31. Buchner, E.; Rubisch, O. Silicon Carbide-1973; Marshall, R.C., Faust, J.W., Ryan, C.E., Eds.; Proceedings of the Third International Conference on Silicon Carbide; Miami Beach, FL Sept. 17-20, 1973, University of South Carolina Press: Columbia, 1974, p 428.

32. McKee, D.W.; Chatterji, D. "Corrosion of SiC in Gases and Alkaline Melts," J. Am. Ceram. Soc. 1975, 59, 441.

33. Tressler, R.E.; Meiser, M.D.; Yonushonis, T. "Molten Salt Corrosion of $\mathrm{SiC}$ and $\mathrm{Si}_{3} \mathrm{~N}_{4}$ Ceramics," J. Am. Ceram. Soc. 1976, 59, 278.

34. Becher, $\mathrm{P}$. "Strength Degradation in $\mathrm{SiC}$ and $\mathrm{Si}_{9} \mathrm{~N}_{4}$ Ceramics by Exposure to Coal Slags at High Temperatures," J. Mater. Sci. 1984, 19, 2805. 
35. Ferber, M.K.; Ugle, J.; Tennery, V.J.; Henson, T. "Characterization of Corrosion Mechanism Occurring in Sintered SiC Exposed to Basic Coal Slą's," J. Am. Ceram. Soc. 1985, 68, 191.

36. Jacobson, N.S.; Smialek, J.S. "Hot Corrosion of Sintcred $\alpha$-SiC," J. Am. Ceram. Soc. $1985,68,432$.

37. Jacobson, N.S.; Sterans, C.A.; Smialek, J.L. "Burner Rig Corrosion of Silicon Carbide at $1000^{\circ} \mathrm{C}, "$ Adv. Ceram. Mater. 1986, 1, 154.

38. Fox, D.S.; Jacobson, N.S.; Smialek, J.L. "Hot Corrosion of Silicon Carbide and Silicon Nitride," In Ceramic Transactions, Corrosion and Corrosive Degradation of Ceramics; Tressler, R.E., McNallan, M., Ed.; Amer. Ceram. Soc. 1989, p 227

39. Sawyer, M.J.; Cleveland, J. "Cordierite Silicon Nitride Filters," Contractors' Review Meeting, Morgantown, WV, 1991, p 161.

40. Pickrell, G.R.; Sun, T.; Brown, J.J. "High-Temperature Alkali Corrosion of Ceramics in Coal Gas," Quarterly Progress Reports from Center for Advanced Ceramic Materials, Virginia Polytechnic Institute and State University, Blacksburg, VA, 1992-1993.

41. Bansal, N.P.; Doremus, R.H. Handbook of Glass Properties; Academic Press: Orlando, 1986, p 223.

42. Droby, M.D.; Thouless, M.D.; Evans, A.G. "On the Decohesion of Residually Stressed Thin Films," Acta Metall. Mater. 1988, 36, 2019.

43. Schültze, M. "Stresses and Decohesion of Oxide Scales," Mater. Sci. Technol. 1988, 4, 407.

44. DeRenzo, D.J., Ed., Ceramic Raw Materials; Noyes Data Corporation: Park Ridge, 1987.

45. Mulla, M.A.; Karstic, V.D. "Low-Temperature Pressureless Sintering of $\beta$-Silicon Carbide with Aluminum Oxide and Yttrium Oxide Additives," Ceramic Bull. 1991, 70, 439.

46. Price, J.R.; van Roode, M. "Corrosion Resistant Coatings for Silicon Carbide", Ceram. Trans., vol. 11 p 169-188, 1990.

47. Federer, J.I. "Alumina Base Coatings for Protection of SiC Ceramics," J. Mater. Eng. 1990, 12, 141.

48. Geiger, G. "Ceramic Coatings," Amer. Ceram. Soc. Bull. 1992, 71, 1473.

49. Li, T. "Sol-Gel Processing of CMZP Coatings for High-Performance Ceramics," Ceramic News 1993, IV (2). 
50. Larker, R.; Nisse, A.; Pejryd, L.; Loberg, B. "Diffusion Bonding Reactions Between an $\mathrm{SiC} / \mathrm{SiC}$ Composite and Two Superalloys during Joining by Hot Isostatic Pressing," Acta Metall. Mater. 1992, 40, 3129.

51. Kieschke, R.R.; Somekh, R.E.; Clyne, T.W. "Sputter-Deposited Barrier Coatings on SiC Monofilaments for Use in Reactive Metallic Matrices-I, Optimization of Barrier Structure," Acta Metall. Mater. 1991, 39, 427.

52. Backhaus-Ricoult, M. "Solid-State Reactions between Silicon Carbide and (Fe,Ni,Cr)Alloys: Reaction Paths, Kinetics and Morphology," Acta Metall. Mater. 1992, 40 (Suppl.), S95.

53. Geiger, G. "Progress Continues in Composite Technology," Ceramic Bull. 1991, 70, 212.

54. Fraser, R.M. "Development and Application of Chromia-Alumina Refractories," Ceram. Eng. Sci. Proc. 1988, 9, 1.

55. Kennedy, C.R. "Refractory/Coal-Slag Compatibility Studies: Progress to Date," Materials Science Division Argonne National Laboratory, CONF-810528-17, DE83 007742.

56. Mojtahedi, W.; Backman, R. "Thermodynamic Study of Alkali Release in Pressurized Fluidised-Bed Combustion and Gasification of Peat," PFBC/G Seminar, Espoo, Finland, November, 23-24k, 1987.

57. Zanadian, V.; Flory, J.S.; Taulor, D. J. Brit. Cer. Trans. 1991, 90, 59.

58. Wu, C.K., J. Amer. Ceram. Soc. 1980, 63, 453.

59. Costello, J.A.; Tressler, R.E. "Oxidation Kinetics of Hot Pressed and Sintered AlphaSiC," J. Am. Ceram. Soc. 1981, 64 (6), 327-31.

60. Jacobson, N.S.; Smialek, J.L. "Hot Corrosion of Sintered Alpha-SiC at $1000^{\circ}$ C," J. Am. Ceram. Soc. 1985, 68 (8), 432-39.

61. Jacobson, N.S.; Stearns, C.A.; Smialek, J.L. "Burner Rig Corrosion of SiC at $1000^{\circ} \mathrm{C}, "$ Adv. Ceram. Mater. 1986, 1, 154-61.

62. Levin, E.M.; McMurdie, H.F. In Phase Diagrams for Ceramists; 1975 Supplement, American Ceramic Society: Westerville, OH, 1975, p 92.

63. Levin, E.M.; McMurdie, H.F. In Phase Diagrams for Ceramists; 1975 Supplement, American Ceramic Society: Westerville, OH, 1975, p 167.

64. Geib, K.M.; Wilson, C.; Long, R.G.; Wilmsen, R.G. "Reaction Between SiC and W, Mo, and Tantalum at Elevated Temperatures," J. Appl. Phys. 1990, 68 (6), 2796-800. 
65. Nishioka, Y; Kimura, S; Shinriki, H; Mukai, K. "Dielectric Characteristics of Double Layer Structure of Extremely Thin $\mathrm{Ta}_{2} \mathrm{O}_{8} / \mathrm{SiO}_{2}$ on Si," J. Electrochem. Soc.: Solid State Science and Technology 1987, 134 (2), 410-15.

66. Revesz, A.G.; Kirkendall, T.D. "Film Substrate Interaction in $\mathrm{Si} / \mathrm{Ta}$ and $\mathrm{Si} / \mathrm{Ta}_{2} \mathrm{O}_{5}$ Structures," J. Electrochem. Soc.: Solid State Science and Technology 1976, 123 (1), 1514-19.

67. Revesz, A.G.; Allison, J.; Kirkendall, T.D.; Reynolds, J. "Oxidation of Tantalum Film on Silicon," Thin Solid Films 1974, 23, S63-S66.

68. Kato, T.; Ito, T. "Interfacial Oxidation of Silicon Substrates Through $\mathrm{Ta}_{2} \mathrm{O}_{5}$ Films," J. Electrochem. Soc.: Solid State Science and Technology 1988, 135 (10), 2586-90.

69. Seki, S.; Unagami, T.; Tsujiyama, B. "Electrical Characteristics of Tantalum Pentoxide-Silicon Dioxide-Silicon Structures," J. Electrochem. Soc.: Solid State Science and Technology 1985, 132 (1) 199-202.

70. Graham, D.W.; Stinton, D.P. "Chemical Vapor Deposition of $\mathrm{Ta}_{2} \mathrm{O}_{5}$ Resistant Coatings," 1992 Coatings for Advanced Heat Engines Workshop, Navel Postgraduate School Monterey, CA, Aug. 3-6 1992.

71. Takahashi, T.; Itoh, H. "Formation of Tantalum Oxide by Chemical Vapor Deposition," J. of Less Common Metals 1972, 38, 211-19.

72. Kaplan, E.; Balog, M.; Frohman-Bentchkowsky, D. "Chemical Vapor Deposition of Tantalum Pentoxide Films for Metal-Insulator-Semiconductor Devices, " J. Electrochem. Soc.: Solid State Science and Technology 1976, 123 (10).

73. Lammermann, H.; Kienel, G. "PVD Coatings for Aircraft Turbine Blades," Adv. Mat. Proc. 1991, pp 18-23.

74. Gieger, G. "Ceramic Coatings," Am. Ceram. Soc. Bull. 1992, 71 (10), 1470-81.

7.. Reisch, M.S. "Paints and Coatings Top $\$ 11$ Billion," $C \&$ EN 1992, 36-61.

76. Schiller, S.; Jaesch, G.; Neumann, M. "High Rate Electron Beam Evaporation," Thin Solid Films 1983, 110, 149-164.

77. Vermilyea, D.A. "The Kinetics of Formation and Structure of Anodic Oxide Films on Tantalum," Acta Metall. 1983, 1, 282-94.

78. Young, L. "Anodic Oxide Films on Tantalum Electrodes," Trans. Faraday Soc. 1954, 50, 153-171.

79. Lugomar, S; Kerenovic, M.; Stipanicic, M.; Lekic, S. "Comparative In Situ Study of Tantalum Thin Film Oxidation in Isothermal and Nonisothermal Conditions," Vacuum 1988, 38 (1), 15-19. 
80. Heitmann, W. "Reactively Evaporated Films of Scandia and Yttria," Applied Optics 1973, 12 (2), 394-97.

81. Hass, G.; Ramsey, J.B.; Thun, R. "Optical Properties of Various Evaporated Rare Earth Oxides and Fluorides," J. Opt. Soc. Am. 1959, 49 (2), 116-20.

82. Khawaja, E.E.; Tomlin, S.G. "The Optical Properties of Thin Films of Tantalum Pentoxide and Zirconium Dioxide," Thin Solid Films 1975, 30, 361-369.

83. Herrmann, W.C., Jr. "E-Beam Deposition Characteristics of Reactively evaporated $\mathrm{Ta}_{2} \mathrm{O}_{5}$ for Optical Interference Coatings," J. Vac. Sci. Tech. 1981, 18 (3), 1303-5.

84. Stetter, F.; Esselborn, R.; Harder, N.; Friz, M.; Tolles, P. "New Materials for Optical Thin Films," Applied Optics 1976, 15 (10), 2315-27.

85. Smith, D.; Baumeister, P. "Refractive Index of Some Oxide and Fluoride Coating Materials," Applied Optics 1979, 18 (1), 111-115.

86. Lewis, B. "The Deposition of Alumina, Silica, and Magnesia Films by Electron Bombardment Evaporation," Microelec. 1964, Rel. 3, 109-20.

87. Turnock, A.C. J. Am. Ceram. Soc. 1965, 48 (5), 259. 
APPENDIX 3.2-1

\section{A NEW APPROACH TO CALCULATING COAL ASH VISCOSITY}




\section{A NEW APPROACH TO CALCULATING COAL ASH VISCOSITY}

Jan W. Nowok, John P. Hurley, and Edward N. Steadman

Energy \& Environmental Research Center

University of North Dakota

Grand Forks, North Dakota 58202-9018 USA

A new approach has been developed for the prediction of coal slag viscosity in tha case of phase separation below the temperature of critical viscosity. This phenomenon causes deviations from ideal viscosity as compared to unseparated slag of the same bulk composition. We discuss the cause of viscosity deviation in slags and introduce a new method of viscosity calculation that accounts for the structural changes in th: slag as phase separation begins. It is assumed that the viscosity depends on the degree of polymerization of the slag and the dispersion of nuclei. Above the critical temperature, viscosity is calculated from both Arrhenian and configurational entropy models. Both models are modified as the base/acid ratio crosses a value of 0.2 .

\section{INTRODUCTION}

In order to predict the bulk viscosity of liquid mixtures consisting of simple flow units, the Arrhenius equation can be applied. However, if the flow units become more complicated, as in polymerized silicates, and the number of volume-dependent degrees of freedom decreases, the Arrhenius approach may not be useful any longer. This led Gibbs (1960) to focus attention on the configurational entropy $\left(S_{\text {cont }}\right)$ as the primary extensive variable affecting the liquid viscosities.

Configurational entropy is the excess entropy of a liquid over that of the crystalline phase. $S_{\text {cont }}$ tends to zero if viscosity reaches values in excess of $10^{13}$ poise. The connection between viscosity and the configurational entropy was formulated by Adams and Gibbs (1965) as follows:

$\eta_{\text {cont }}=A \exp B / T S_{\text {cont }} \quad(T$ in $K)$

where $A$ is a preexponential factor and $B$ is a censtant containing a free energy barrier.

Most phenomenological models (Urbain et al., 198.2) of silicate-based slag viscosity rely on finding an algebraic expression for viscosity as a function of ash composition and temperature expressed in terms of several constants. An example is an equation of the form:

$\log n=\log \mathrm{C}+10^{3} \mathrm{DT}^{\cdot 1} \quad(\mathrm{~T}$ in $\mathrm{K})$

where $C$ and $D$ are constants defined by the composition of coal ash. Many attempts (Hoy et al., 1965; Kalmanovitch and Frank, 1990; Jung and Schobert, 1992; Srinivasachar et al., 1993) were made to improve correlation of the experimental values with predicted ones using multiple linear regression analysis. However, as the temperature drops, a critical temperature is reached below which

$$
3.2-1--1
$$


the relationship is no longer linear. Much of the deviation is due to structural changes in the melt. Generally, structural changes are caused by the changes in the degree of polymerization of the melt resulting from phase separation and further formation of crystalline nuclei. This is observed by systematic increases of Arrhenian activation energy when the temperature decreases. Thus the overall viscosity-versus-temperature curve is quite sensitive to both the composition and structural changes of the melt.

Generally, melts can be classified as Newtonian and non-Newtonian liquids. Viscous flow of Newtonian melts requires the formation of a volume "hole" into which the flow unit moves when the hole exceeds some critical volume (Turnbull and Cohen, 1961). In this model, the transport of matter can occur as a jump of flow units. In an attempt to predict viscosity in the Newtonian region, an Arrhenius equation may be applied:

$\eta=\eta_{0} \exp [E / k T]$

where n, represents zero-shear viscosity, also known as a preexponential factor, and $E$ is an activation energy. Zero-shear viscosity in aluminosilicates is a structure-sensitive parameter. Thus this property can help to identify molecular properties, and it is needed to fit certain composition-based equations to experimental flow rate data. In addition, an activation energy is associated with local slag structure and its composition.

The temperature at which the flow changes from Newtonian to non-Newtonian is known as the temperature of critical viscosity $\left(T_{\text {ev }}\right)$. As slags cool past $T_{\text {evv }}$ solid assemblies and less polymerized "residual slag" form (Nowok and Benson, 1992). Thus the slag is composed of a two-phase mixture. The temperature of critical viscosity can be viewed as a temperature at which the stoichiometries of polymers in the melt mimic those of crystalline phases that appear at the liquids. Below that temperature, the number of melt species may be compounded. These melt species will form crystalline phases as the temperature drops below the liquids (Burnham. 1981).

The viscosity of slag near $T_{\text {ov }}$ may rise sharply due to a fraction of the volume being blocked from flow by solid particles. For this system, the viscosity depends on the volume fraction of dispersed solid assemblies (u), their shapes (disks, spheres, or rods), viscosity of "residual slag" $\left(\eta_{1}\right)$, and the mutual hydrodynamic interaction of solid/melt and fractional processes (Goldsmith and Mason, 1967):

$n_{\max }=n_{1}\left(1+c u+d v^{2}\right)$

where $c$ and $d$ are constants related to the shape of dispersant and solid/melt interaction, respectively. Prediction of slag viscosity using Equation 4 is difficult because of the large number of assumptions required concerning the variables.

In this paper we consider:

- The relation between the composition of ash slag as described by the base/acid ratio and its bulk viscosity in the Newtonian region. which may be expressed by an Arrhenius-type equation.

- The effect of local structure and composition on slag viscosity, using the configurational model of Adams and Gibbs (1965).

$$
\text { 3. 2-1--2 }
$$


- Deviation from ideal viscosity determined by Arrhenius and Gibbs equations caused by structural changes of a melt at temperatures below $T_{\text {eve }}$.

\section{ASH SLAG VISCOSITY AND FACTORS AFFECTING CALCULATIONS OF RELATIVE VISCOSITIES USING AN ARRHENIUS EQUATION}

Figure 1 illustrates the variation of activation energy with base/acid ratio for model glasses and ash slags. Data for model glasses were taken from literature (Bansal and Doremus, 1986; Clark, 1966; Dingwell and Virgo, 1988; Vores et al., 1985; Scarfe et al., 1983) and data for ash slags from our own measurements. Base/acid ratio was calculated from the composition of coal ashes:

$\frac{\text { Base }}{\text { Acid }}=\frac{\mathrm{Na}_{2} \mathrm{O}+\mathrm{K}_{2} \mathrm{O}+\mathrm{CaO}+\mathrm{MaO}+\mathrm{FeO}}{\mathrm{SiO}_{2}+\mathrm{Al}_{2} \mathrm{O}_{3}+\mathrm{Fe}_{2} \mathrm{O}_{3}+\mathrm{TiO}_{2}}$

The non-linear regression parameters calculated for model glasses and for ash slags are 0.61 and 0.95 , respectively. The lower value for model glasses is likely caused by the systematic increase of activation energy as the base/acid ratio drops below 0.2 .

It becomes obvious that for these melts, the Arrhenian activation energy taken from the plot of linear relationship of $E_{\text {eot }}$ with base/acid ratio does not represent its original value. The new value of $E_{\text {eot }}$ may be obtained by introducing a dimensionless parameter " $m$ " (Eq. 6):

$E_{\text {act }}=[60-28(\text { base } / \text { acid })]^{(1+\mathrm{m})} \quad(\mathrm{kcal} / \mathrm{mol})$

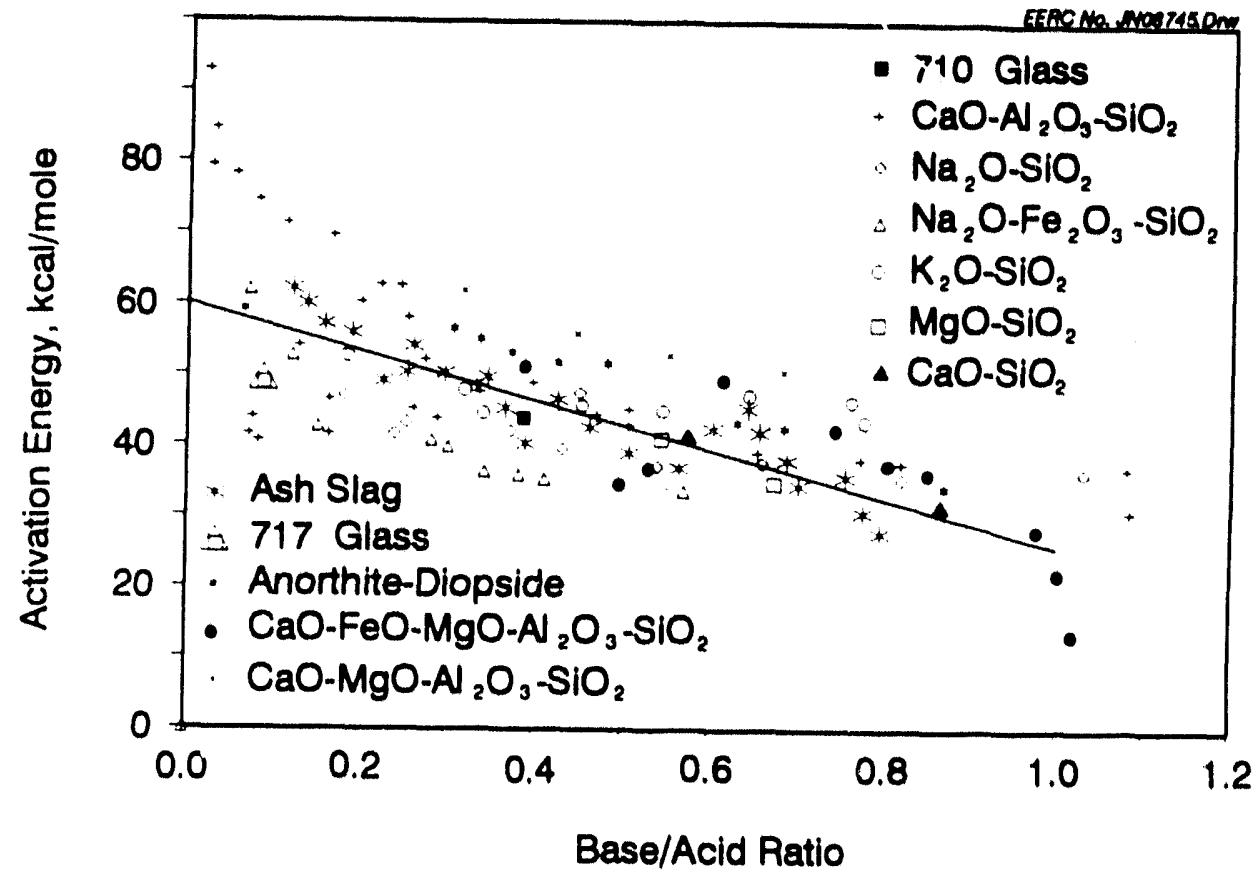

FIGURE 1. Activation energy and base/acid ratio relationship on the model glasses and coal ash slags. 
It is important to note that $m$ is equal to zero for glasses and ash slags with a base/acid $>0.2$. For melts with a base/acid $<0.2$, the value of $m$ increases with the decrease of base/acid ratio and thus modifies an Arrhenian activation energy. It is likely that the value of $\mathrm{m}$ is affected by the charge imbalance of $\mathrm{Al}^{3+}$ and $\mathrm{Fe}^{3+}$ ions, by alkali and alkaline earth cations, and by the entropy of mixing. Table 1 lists zero-shear viscosities and $m$ values for calculations of ash slag viscosities.

Figure 2 demonstrates the temperature dependence of viscosity calculated for coal ash slag with a base/acid ratio $=0.18$ using the two Arrhenius models previously discussed, as well as the Kalmancvitch-Urbain model. The accuracy of the predicted viscosity values is highe: if activation energy correction is included. An ideal Arrhenian model may be used for slags with a homogeneous structure.

\section{VISCOSITY-TEMPERATURE RELATIONS PREDICTED FROM CONFIGURATIONAL ENTROPY AND FREE ENERGY BARRIER IN ALUMINOSILICATE GLASSES AND COAL SLAGS}

For most aluminosilicatgs the change of viscosity with temperature cannot be represented by an Arrhenius plot. Typically, the deviations from Arrhenian behavior increase with the temperature dependence of $S_{\text {eont }}$ (Richet, 1984). For simple systems, the change of cenfigurational entropy can be calculated from the integrated excess heat of capacity and/or directly from the viscosity data. We have selected a method that refers to viscosity data.

Figure 3 illustrates the variation of configurational entropy with temperature. Two regions of entropy change, above and below about $900^{\circ} \mathrm{C}$, may be distinguished. At higher temperatures, the increase in $S_{\text {cont }}$ makes possible the cooperative rearrangements of melt structure into different configurations. It is unlikely that this rearrangement may correspond with the glass transition temperature. Usually,

TABLE 1. Zero-Shear Viscosity (in Poise) and " $m$ " Parameter for Coal Ash Slags

\begin{tabular}{llllll}
\hline $\begin{array}{l}\text { Base/Acid } \\
\text { Ratio }\end{array}$ & $\begin{array}{l}n_{0} \\
(\times 10.0)\end{array}$ & $\begin{array}{l}\text { "m" } \\
\text { Parameter }\end{array}$ & $\begin{array}{l}\text { Base/Acid } \\
\text { Ratio }\end{array}$ & $\begin{array}{l}\eta_{0} \\
(\times 10.0)\end{array}$ & $\begin{array}{l}\text { "m } \\
\text { Parameter }\end{array}$ \\
\hline 0.12 & 3 & 0.06 & 0.44 & 18 & 0.00 \\
0.14 & 4 & 0.04 & 0.46 & 18 & 0.00 \\
0.16 & 5 & 0.028 & 0.48 & 19 & 0.00 \\
0.18 & 6 & 0.015 & 0.50 & 20 & 0.00 \\
0.20 & 7 & 0.00 & 0.52 & 23 & 0.00 \\
0.22 & 7 & 0.00 & 0.54 & 26 & 0.00 \\
0.24 & 7 & 0.00 & 0.56 & 29 & 0.00 \\
0.26 & 7 & 0.00 & 0.58 & 37 & 0.00 \\
0.28 & 8 & 0.00 & 0.60 & 41 & 0.00 \\
0.30 & 9 & 0.00 & 0.62 & 47 & 0.00 \\
0.32 & 11 & 0.00 & 0.64 & 50 & 0.00 \\
0.34 & 14 & 0.00 & 0.66 & 55 & 0.00 \\
0.36 & 14 & 0.00 & 0.68 & 61 & 0.00 \\
0.38 & 15 & 0.00 & 0.70 & 67 & 0.00 \\
0.40 & 17 & 0.00 & 0.72 & 75 & 0.00 \\
0.42 & 17 & 0.00 & 0.74 & 82 & 0.00 \\
\hline
\end{tabular}




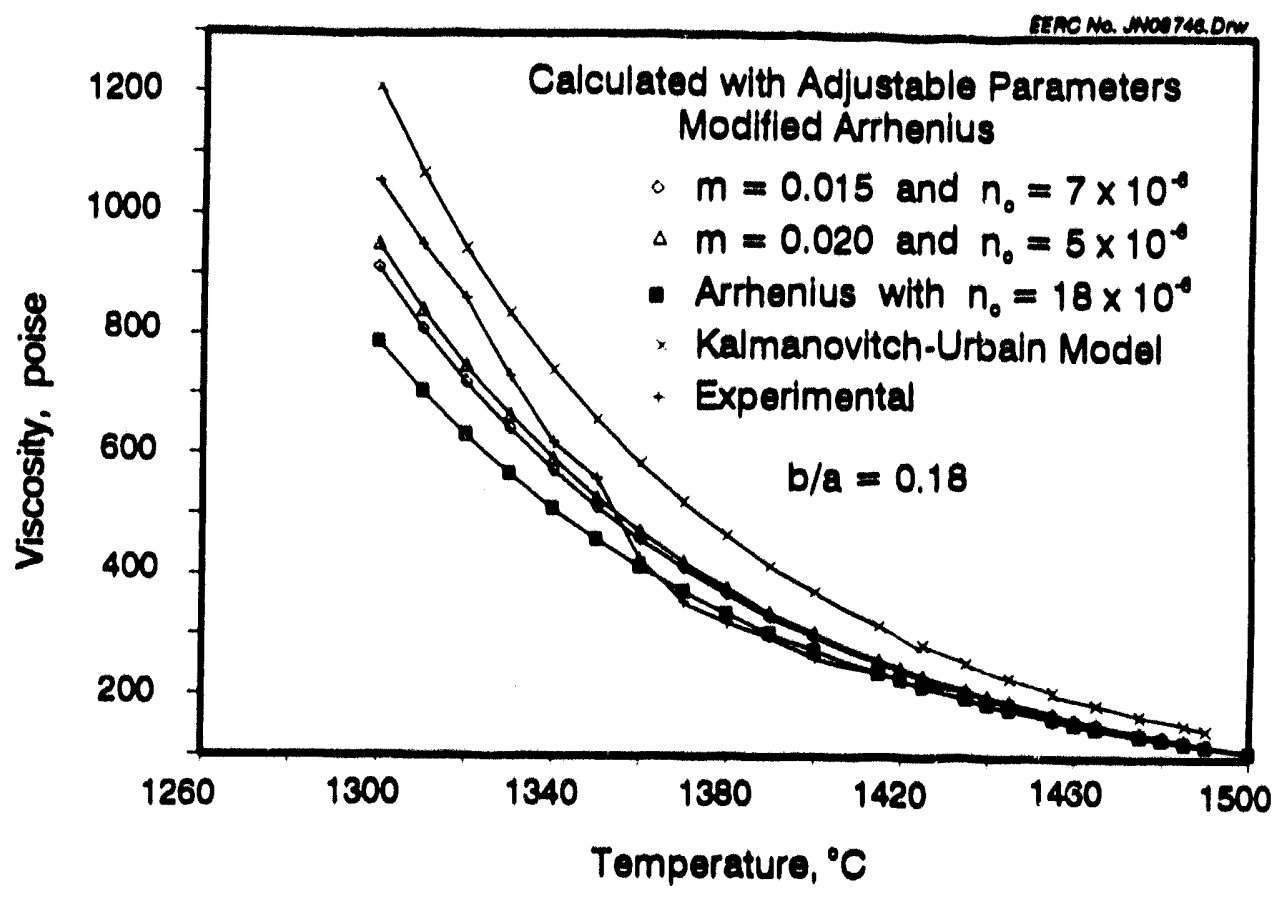

FIGURE 2. Calculated and measured viscosities for coal slag with base/acid $=0.18$. The Arrhenian relation represented by curve $(\square)$ is calculated on the assumption that $m=0$.

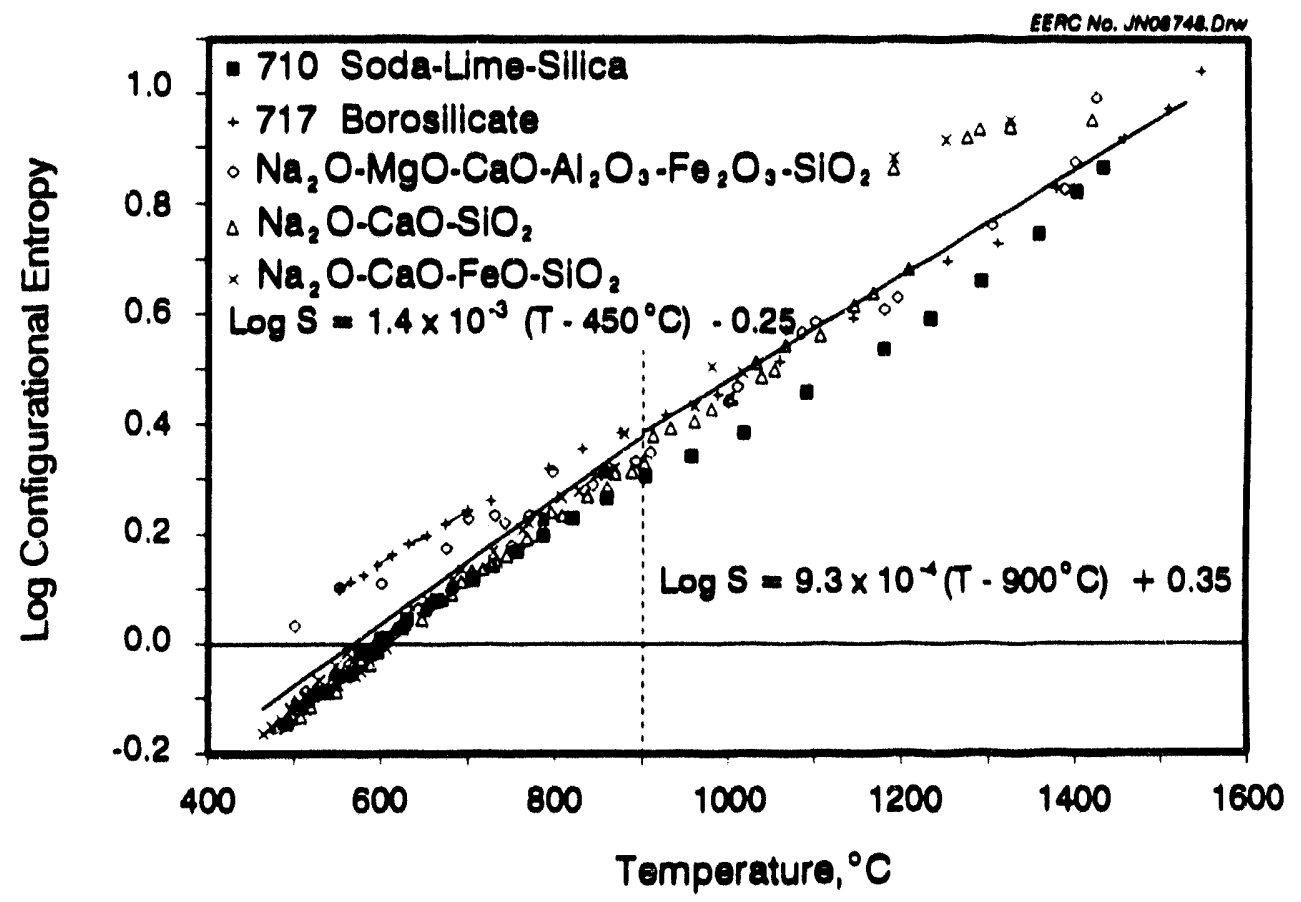

FIGURE 3. The variation of configurational entropy with temperature for selected silicate systems. 
at the glass transition, the configurational entropy tends to zero, and viscosity reaches values in excess of $10^{13}$ poise. In silicates, $S_{\text {cont }}$ is $2.99 \pm 0.36 \mathrm{cal} / \mathrm{mol}$ per tetrahedrally coordinated silicon. If aluminum substitutes for silicon in the network, $S_{\text {eont }}$ decreases to $1.98 \pm 0.03 \mathrm{cal} / \mathrm{mol}$. Also, iron and titanium may substitute for silicon and result in a $S_{\text {cont }}$ change. At the present time, we do not know about $S_{\text {cont }}$ change caused by iron and titanium in aluminosilicates. However, the ratio of $\left(\mathrm{SiO}_{2}+\mathrm{TiO}_{2}\right) /\left(\mathrm{Al}_{2} \mathrm{O}_{3}+\mathrm{Fe}_{2} \mathrm{O}_{3}\right)$ is not strongly affected by base/acid ratio. It varied from 1.11 to 1.80 for the 23 coal slags that we tested. Thus, the effect of ash composition on $\mathbf{S}_{\text {ean }}$ is minor, relative to the effects of temperature changes.

The free energy barrier and preexponential factor remain to be accounted for in viscous silicate glass and ash slag phenomenology. With increasing base/acid ratio, the free energy barrier is sensitive to melt composition, as is the Arrhenian activation energy. The barrier for glasses varies according to the following equation:

$B=[29-28$ (base $/$ acid $)] \quad(\mathrm{kcal} / \mathrm{mol})$

Equation 7 has been derived from the $B$ versus base/acid ratio plot such as it has been proposed for an Arrhenius model (Figure 1). Unfortunately, our consideration of $B$ in glasses is limited to a base/acid ratio between 0.1 and 0.6 due to the lack of experimental data. For aluminosilicate glasses, B ranges from 12 to $160 \mathrm{kcal} / \mathrm{mol}$ and usually increases with the degree of polymerization of the melt (Richet, 1984). The preexponential factor is expressed in poise and ranges between 15 and 30 .

Figure 4 shows the calculated viscosity for model glass in the temperature range of $400^{\circ}$ to $1400^{\circ} \mathrm{C}$. Experimental data fit well to predicted data. This implies that calculated viscosities for model glasses, based on the configurational entropy approach, may also be used to produce reasonable structural models for silicate and aluminosilicate glasses in coal ash slags, which are quite sensitive to both glass composition and structure.

The $B$ expression for ash slag is different from that for model glasses and is given as:

$B=[36-10 \text { (base/acid) }]^{(1+\mathrm{m})} \quad(\mathrm{kcal} / \mathrm{mol})$

where the $m$ factor has values similar to thuse in an Arrhenian equation if the base/acid ratio ranges from 0 to 0.2 (see Table 1). Also, the preexponential factor has different values, as shown in Table 2.

A comparison of predictions of the viscosity of ash slag with base/acid $=0.18$ for this and previous methods is illustrated in Figure 5. The results indicate a good relationship between experimental results and applied models. This high accuracy between predicted and measured viscosities is only observed in ash slags with base/acid ratios below 0.2 . For these systems, high viscosity does not allow the rearrangement of the melt structure to occur. Also there is not any significant difference between the modified Arrhenius and the Adams and Gibbs equations. Unfortunately, there is a deviation between predicted and measured viscosities in ash slags with base/acid $>0.2$ that increases with base/acid ratio. Both relations bring the same uncertainty in predicted viscosity values.

$$
3.2-1--6
$$




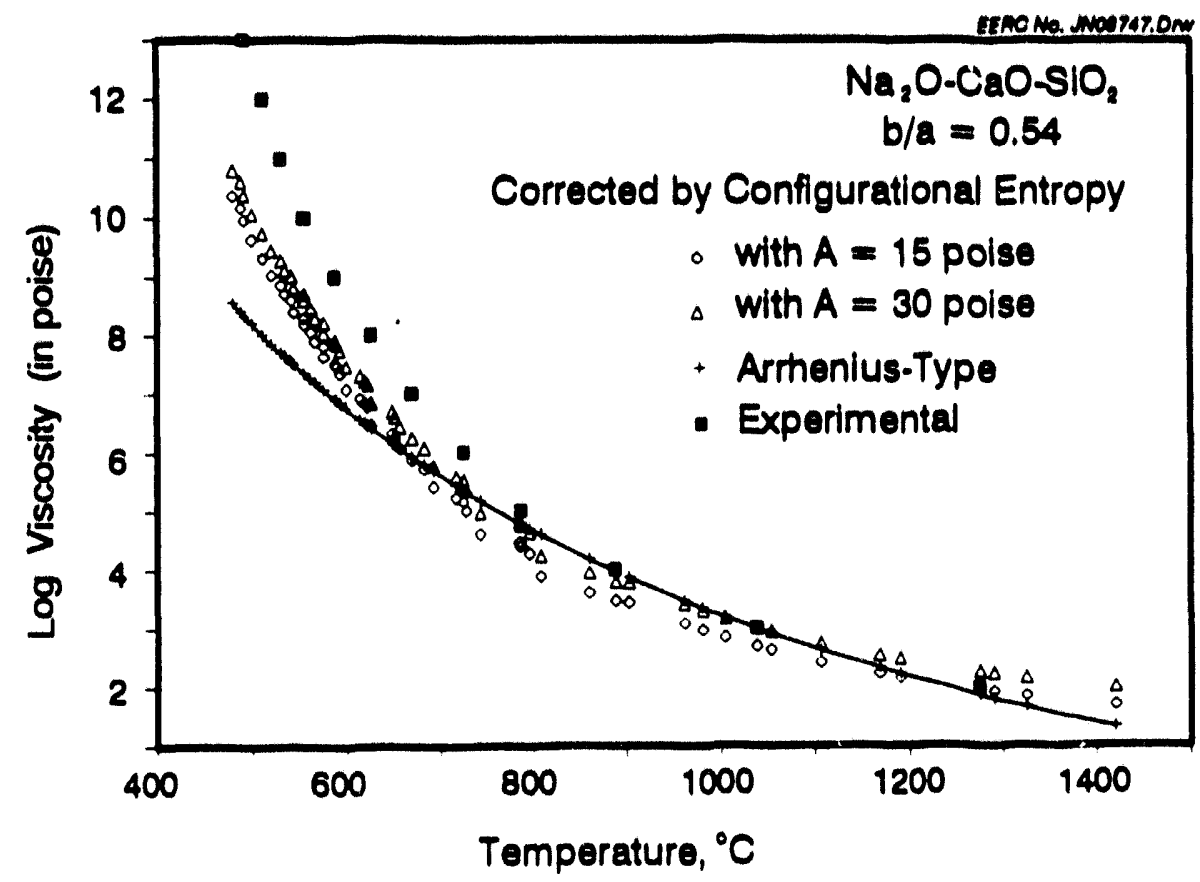

FIGURE 4. Example of calculated viscosity based on the configurational entropy approach.

TABLE 2. Preexponential Factor $A$ as a Function of Base/Acid Ratio.

\begin{tabular}{llll}
\hline Base/Acid & A & Base/Acid & A \\
\hline 0.14 & 35.0 & 0.39 & 2.5 \\
0.17 & 22.0 & 0.43 & 1.5 \\
0.18 & 11.0 & 0.47 & 1.5 \\
0.19 & 4.0 & 0.51 & 1.2 \\
0.26 & 3.0 & 0.57 & 1.2 \\
0.32 & 2.5 & 0.61 & 1.2 \\
0.35 & 3.0 & 0.64 & 1.2 \\
0.37 & 2.0 & 0.73 & 1.0 \\
\hline
\end{tabular}

\section{DEVIATION FROM IDEAL VISCOSITY DUE TO STRUCTURAL CHANGES IN THE MELT}

Many slags show deviations from ideal viscosities as they cool. The viscosities are usually somewhat larger than those calculated from Adams and Gibbs and/or Arrhenian equations as temperature is lowered. The larger values are believed to be due to blocking a portion of the slag volume from flow as a consequence of phase separation and nucleation. The tendency towards phase separation and nucleation increases with the decrease of the slag viscosity. The degree of nucleation is related to both composition and temperature. Of course, the rapid increase of viscosity with falling temperature effectively prevents nucleation. In those cases where the difference between measured and calculated viscosity $(\Delta \eta)$ is the same for slags with the same base/acid ratio, the difference can be used to infer the degree of phase separation/nucleation in the slag. 


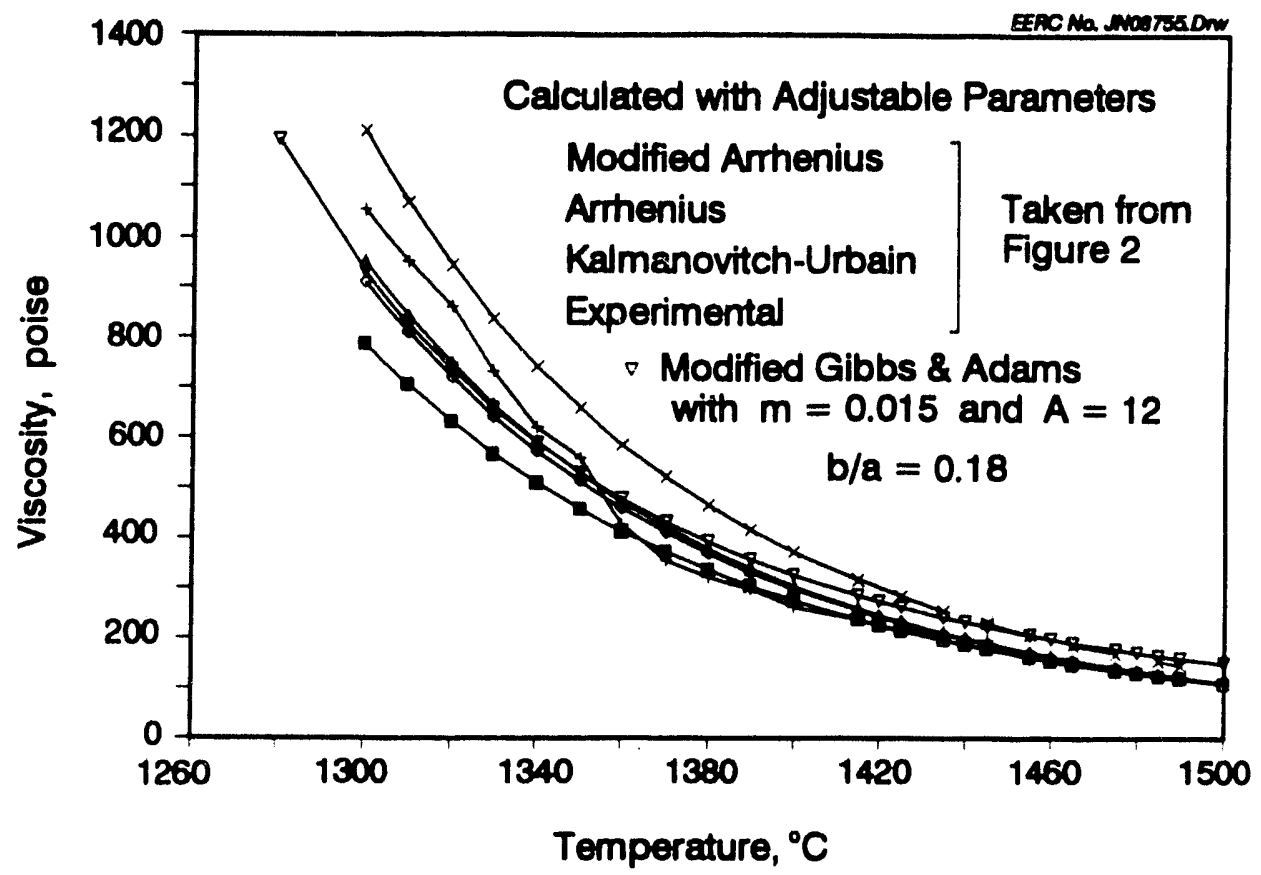

FIGURE 5. Viscosity of ash slag predicted using configurational entropy approach and models discussed earlier.

The viscosity difference increases with base/acid ratio. This, however, appears to depend on the temperature of critical viscosity. Figure 6 illustrates the variation of critical viscosity with base/acid ratio derived from our viscosity resulis. In this sense, the problem of predicting viscosity for slag with suspended nuclei and/or particles as a function of temperature is to define the relation between $\Delta n$ and base/acid as well as $\left(T_{c v}-T\right)$, where $T_{c v}>T$. Also, the variation of temperature of glass transformation for some phases in coal slags with base/acid ratio is shown in Figure 6. Postulating that $T_{e v}$ corresponds with nucleation and further crystallization of some phases, the increase of $T_{0}$ implies the increase of viscosity. Figure 7 shows the change in $\Delta \eta$ as a function of $\left(T_{c v}-T\right)$ (base/acid). The formulation of $T_{c v}$ and $\Delta \eta$ allows calculation of viscosity at temperatures below the temperature of critical viscosity. Thus the viscosity for nonideal slags may be given by the following equation:

$\eta=\eta_{\text {eont }}+\Delta \eta$

and finally:

$\eta=\eta_{\text {cont }}+r\left(T_{\text {ev }}-T\right)$ (base/acid)

where $n_{\text {cont }}$ is given by Equation 1, and $r=9.2$ [poise/deg.].

Results of predicted viscosity for ash slags with and without structural changes are shown in Figure 8. No differences in viscosities are observed at $1300^{\circ} \mathrm{C}$. It is clear that higher temperatures stabilize slag structure. Most of the deviation that occurs at lower temperatures results from structural changes. The predicted 


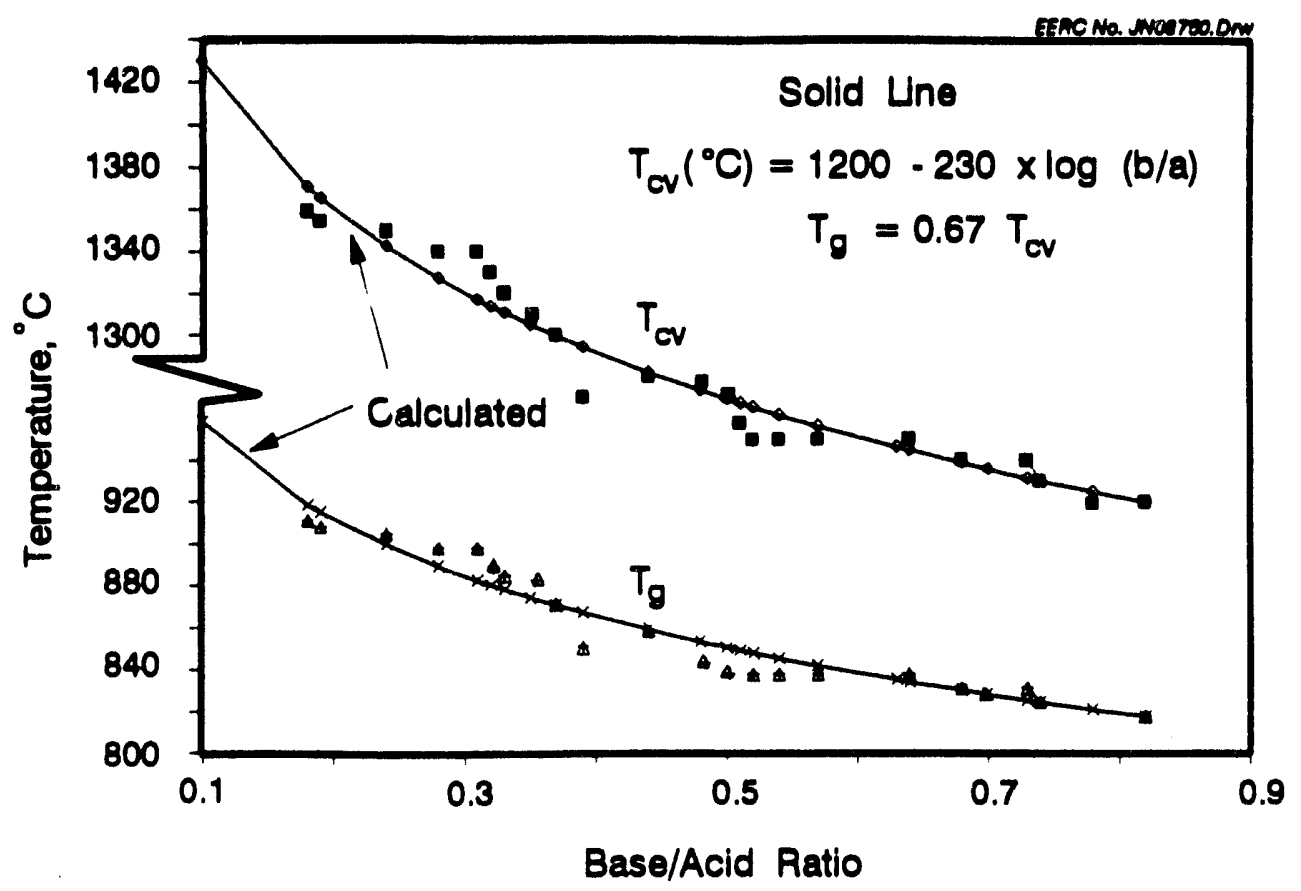

FIGURE 6. Change of temperatures of critical viscosity and glass transformation in ash slags.

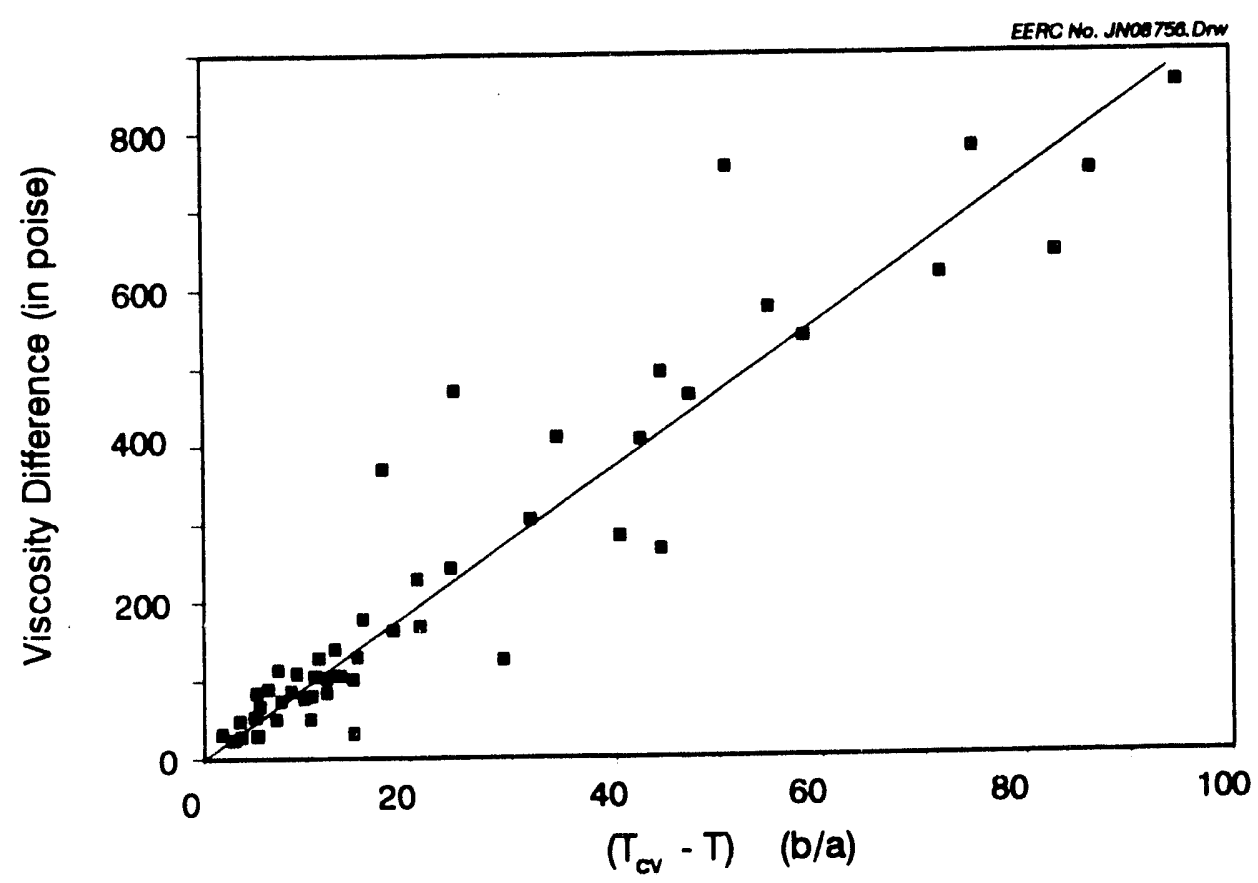

FIGURE 7. Relationship between viscosity difference and $\left(T_{c v}-T\right)$ (base/acid). 


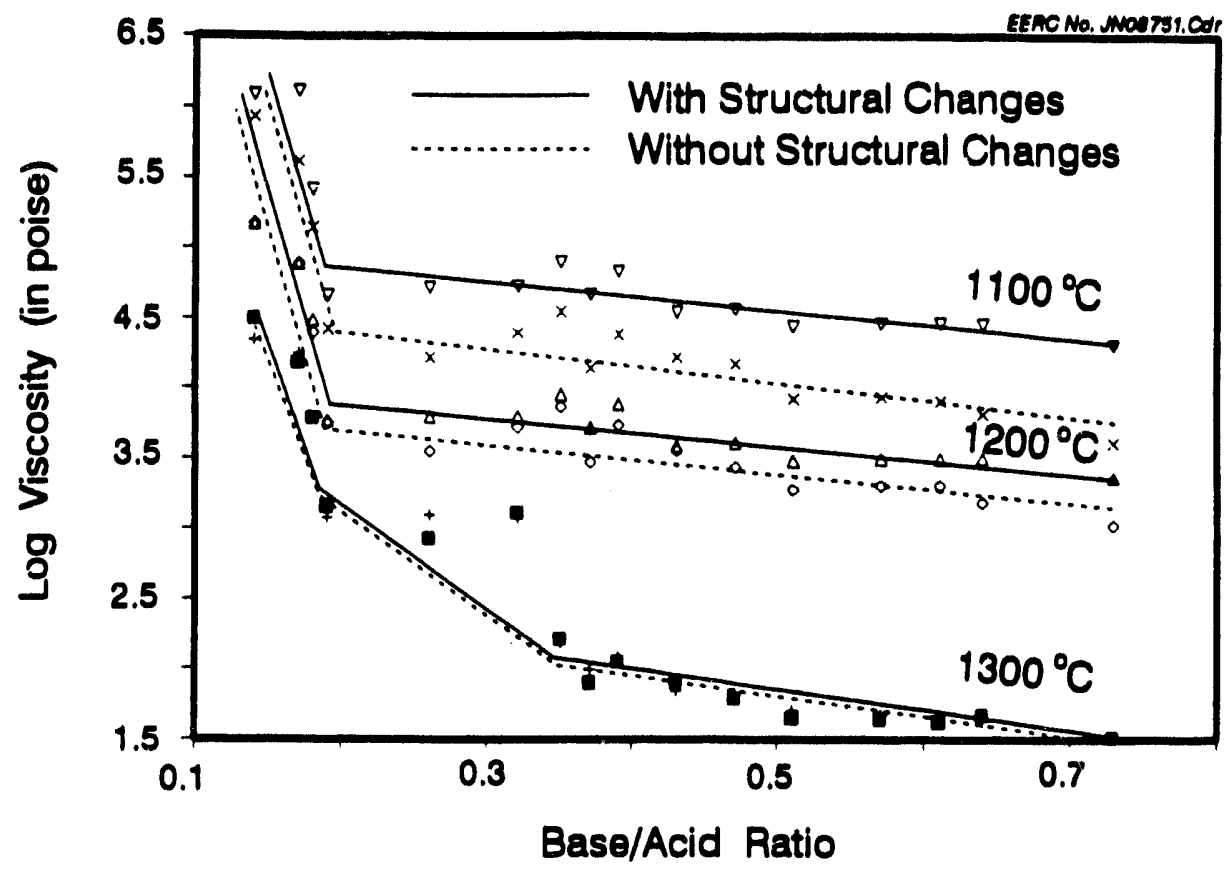

FIGURE 8. Log n-base/acid relations for ash slags calculated at various temperatures.

viscosities are in good agreement with those of commercially important aluminosilicates cited in literature (Bansal and Doremus, 1986). Usually, the viscosity at $1000^{\circ} \mathrm{C}$ is about $10^{\circ}$ poise, and at $900^{\circ} \mathrm{C}$ about $10^{\circ}$ poise.

\section{ASH VISCOSITY AND FOULING TENDENCY}

Ash particles with a liquid surface that strike heat exchanger tubes may stick and will sinter with time. The viscosity distributions of the ash particle surfaces play a major role in determining the fouling tendency of the ash. Figure 9 illustrates an example of slag viscosity changes with base/acid ratio at $900^{\circ}, 1000^{\circ}$, and $1100^{\circ} \mathrm{C}$. Coal ashes with base/acid $<0.2$ have higher viscosities at a given temperature than those with higher base/acid ratios, which coincides with the decrease of the sticking probability and the fouling tendency of the ash. The sticking probability is inversely proportional to viscosity for a given particle mass and velocity.

\section{CONCLUSIONS}

A new approach to calculating coal ash viscosity represents a portion of our wide interest in physical properties of coal ashes and slags. Generally, the viscosity of the bulk material is a controlling factor for sticking phenomena, sintering and slagging propensities, corrosion of refractories, crystallization of ash slags, as well as wall heat flux. Thus the prediction of accurate values of bulk viscosity, in the range of temperature starting from the temperature of glass transition $\left(T_{0}\right)$ up to about $1500^{\circ} \mathrm{C}$, is important. 


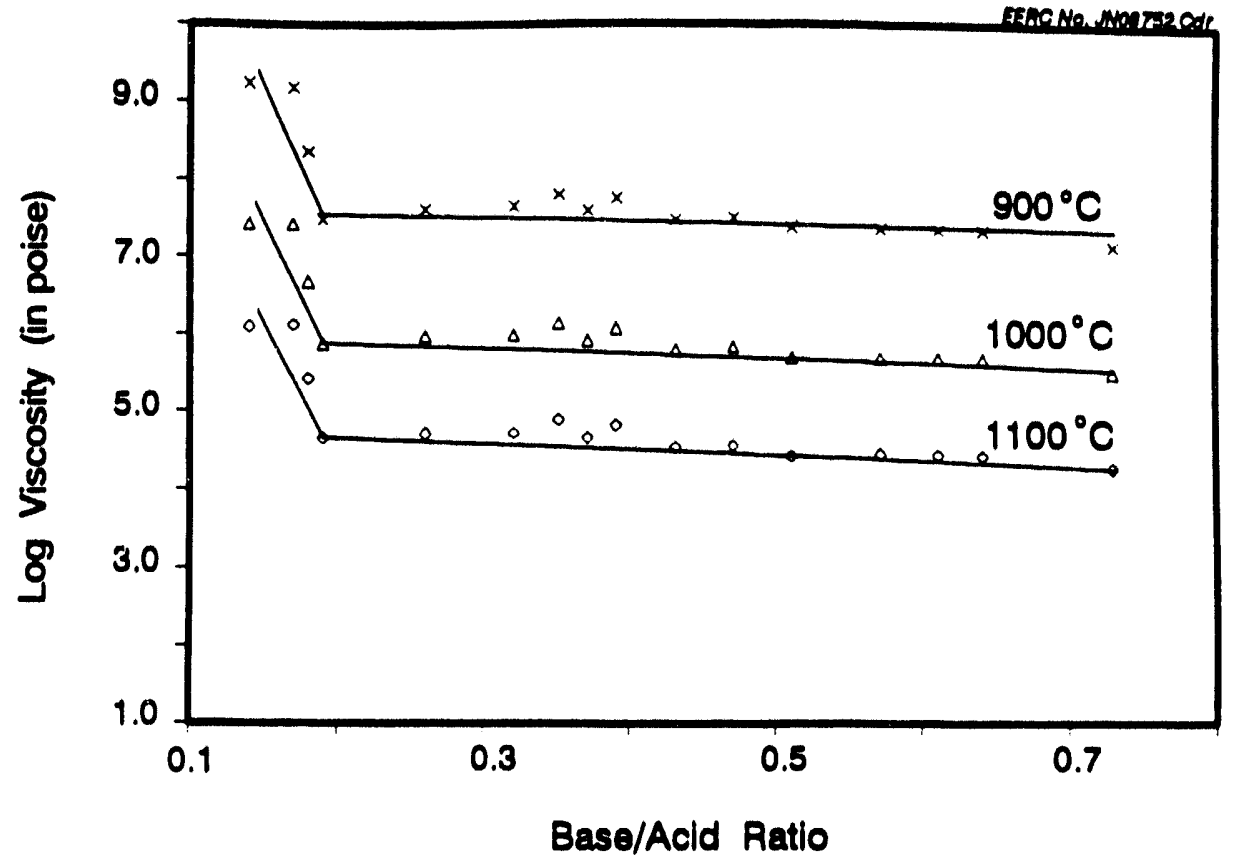

FIGURE 9. Log $\eta$-base/acid relations for ash slags calculated at fouling temperatures.

Both Arrhenian and configurational entropy models were employed to calculate bulk coal slag viscosity. Both models gave predictions that deviated from ideal viscosities below the temperature of critical viscosity $\left(T_{c v}\right)$ due to phase separation and further nucleation. The differences between measured and calculated viscosities increased with base/acid ratio of coal ashes. Also, the temperatures of critical viscosities are affected by base/acid ratio and tend to decrease with an increase in base/acid ratio. These relationships were used to modify the Arrhenian and configurational entropy equations to improve the accuracy in predicting bulk slag viscosities. The modified configurational entropy approach provides more accurate predictions of viscosity of coal slags versus temperature below $T_{\text {ev }}$ than equations based on the Urbain model or the modified Arrhenius-type equation.

\section{ACKNOWLEDGMENTS}

This work was performed under DOE contract number DE-FC21-86MC10637.

\section{REFERENCES}

Adams, G., and Gibbs, J.H., 1965, On the Temperature Dependence of Cooperative Relaxation Properties in Glass-Forming Liquids, Journal of Physical Chemistry, vol. 43, pp. $139-146$

Bansal, N.P., and Doremus, R.H., 1986, Handbook of Glass Properties, Ch. 9, Academic Press, Orlando. 
Burnham, C.W., 1981, The Nature of Multicomponent Aluminosilicate Melts, in Chemistry and Geochemistry of Solutions at High Temperatures and Pressures, ed. by D.T. Rickard, and F.E. Wickman, pp. 197-226.

Clark, S.P., Jr., 1966, in Handbook of Physical Constants, ed. by S.P. Clark, Jr., Sec. 12, Publ. Geol. Soc.

Dingwell, B.D., and Virgo, D., 1988, Viscosities of Melts in the $\mathrm{Na}_{2} \mathrm{O}-\mathrm{FeO}-\mathrm{Fe}_{2} \mathrm{O}_{3}$ $\mathrm{SiO}_{2}$ System and Factors Controlling Relative Viscosities of Fully Polymerized Silicate Melts, Geochim. Cosmoch. Acta, vol. 52, pp. 395-403.

Gibbs, J.H., 1960, Modern Aspects of the Vitreous State, Butterworths, London, Ch.7.

Goldsmith, H.L., and Mason, S.G., 1967, Rheology, Theory and Applications, Academic Press, New York.

Hoy, H.R., Roberts, A.G., and Wilkins, D.M., 1965, Behaviour of Mineral Matter in Slagging Gasification Process, in Chemistry of Coal Utilization, ed. by M.A. Elliott, p. 444.

Jung, B., and Schobert, H.H., 1992, Improved Prediction of Coal Ash Slag Viscosity by Thermodynamic Modeling of Liquid-Phase Composition, Energy \& Fuel, vol. 6, pp. 387-398.

Kalmanovitch, D.P., and Frank, M., 1990, An Effective Model of Viscosity for Ash Deposition Phenomena, in Mineral Matter and Ash Deposition from Coal, ed. by R.W. Bryers, and K.S. Vorres, pp. 89-101, United Eng. Trustees Inc.

Nowok, J.W., and Benson, S.A., 1992, Correlation of Interfacial Surface TensionNiscosity Ratio, Nonbridging Oxygen Factor, and Compressive Strength Development in Coal Ashes, in Inorganic Transformations and Ash Deposition during Combustion, ed. by S.A. Benson, pp. 405-424, New York.

Richet, P., 1984, Viscosity and Configurational Entropy of Silicate Melts, Geochim. Cosmoch. Acta, vol. 48, pp. 471-483.

Scarfe, C.M., Cronin, D.J., Wenzel, J.T., and Kauffman, D.A., 1983, ViscosityTemperature Relationships at 1 Atm in the System Diopside-Anorthite, Am. Mineral., vol. 68, pp. 1083-1088.

Srinivasachar, S., Senior, C.L., Helble, J.J., and Moore, J.W., 1993, A Fundamental Approach to the Prediction of Coal Ash Deposit Formation in Combustion Systems, in press.

Turnbull, D., and Cohen, M.H., 1961, Free-Volume Model of Amorphous Phase: Glass Transition, Journal of Physical Chemistry, vol. 34, pp. 120-125.

Urbain, G., Bottinga, Y., and Richet, P., 1982, Viscosity of Liquid Silica, Silicates and Aluminosilicates, Geochim. Cosmoch. Acta, vol. 46, pp. 1061-1072

Vorres, K.S., Greenberg, S., and Poeppel, R.B., 1985, Viscosity of Synthetic Coal Ash Slags, Argonne National Laboratory, Argonne, Illinois, ANL/FE-85-10. 
\begin{tabular}{l|l}
\hline 1. Program/Prolect Identification No. & 2. Program/Project Thlo \\
DE.FC21.93MC30097 & 3.0 Advanced Power Syetems \\
\hline
\end{tabular}

4. Neme and Addrees Energy and Environmental Reseerch Center Univeraity of North Dakota

P.O. Box 9018 , Grand Forks, ND 68202.9018

1701) 777.6000

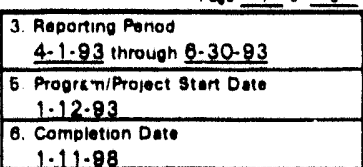

\begin{tabular}{|c|c|c|c|c|c|c|c|}
\hline $\begin{array}{l}\text { 7. FY } \\
93\end{array}$ & \multicolumn{7}{|c|}{ 8. Monthe of Quertere } \\
\hline \multicolumn{2}{|c|}{$\begin{array}{l}\text { 9. Cost } \\
\text { Status }\end{array}$} & \multicolumn{6}{|c|}{$\begin{array}{l}\text { a. Doliare Expreseed in } \\
\text { Thousands }\end{array}$} \\
\hline \multicolumn{8}{|c|}{ 10. Cout Chart } \\
\hline \multirow{2}{*}{\multicolumn{2}{|c|}{$\begin{array}{l}\text { Fund } \\
\text { Source }\end{array}$}} & & & inter & & \multirow{2}{*}{$\begin{array}{l}\text { Cum. } \\
\text { to } \\
\text { Dote }\end{array}$} & \multirow{2}{*}{$\begin{array}{l}\text { Tot. } \\
\text { Plan }\end{array}$} \\
\hline & & let & 2nd & 3rd & ath & & \\
\hline \multirow{2}{*}{ DOE } & P & 265 & 286 & 254 & 254 & 630 & 1038 \\
\hline & A & 197 & 180 & & & 377 & \\
\hline & $p$ & & & & & & \\
\hline & A & & & & & & \\
\hline & $p$ & & & & & & \\
\hline & A & & & & & & \\
\hline & $\mathbf{P}$ & & & & & & \\
\hline & A & & & & & & \\
\hline \multicolumn{2}{|c|}{ Total P } & 265 & 286 & 254 & 254 & 530 & 1038 \\
\hline \multicolumn{2}{|c|}{ Total A } & 197 & 180 & & & 377 & \\
\hline \multirow{2}{*}{\multicolumn{2}{|c|}{ Vanance }} & 63 & 85 & & & 153 & \\
\hline & & $P=$ & Planne & A & Actual & & \\
\hline & \multicolumn{3}{|c|}{ Total Planned Coute for Program/Project } & $\mathrm{m} /$ Pros & & & \\
\hline
\end{tabular}

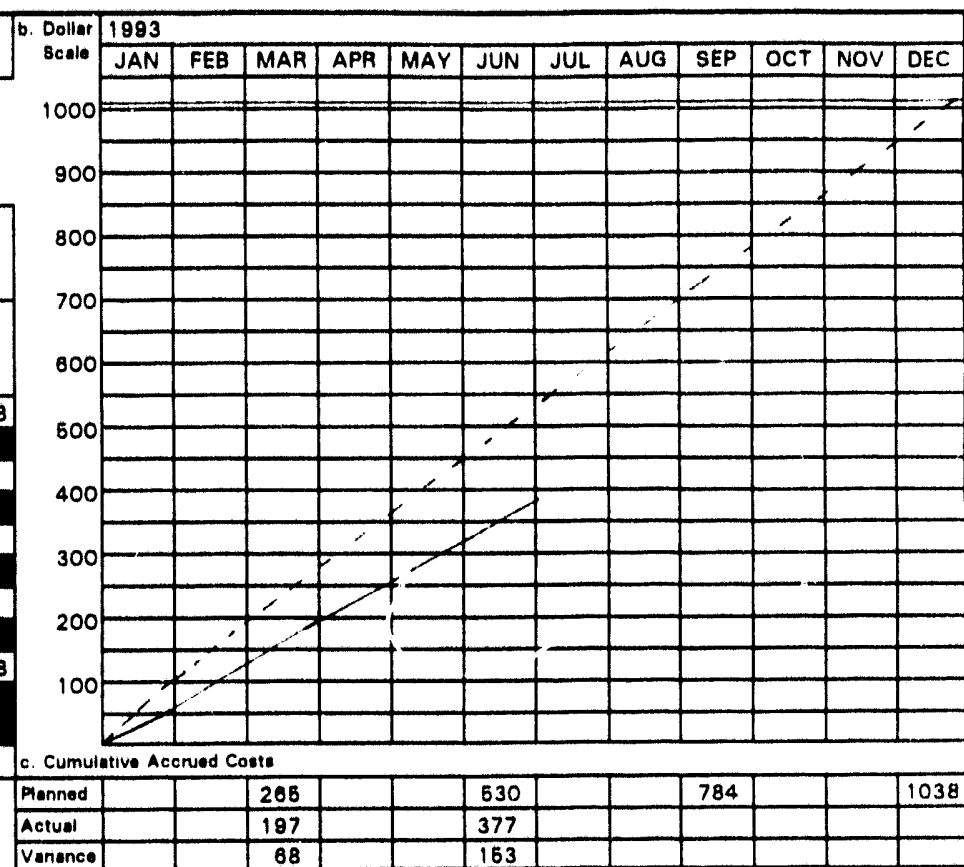

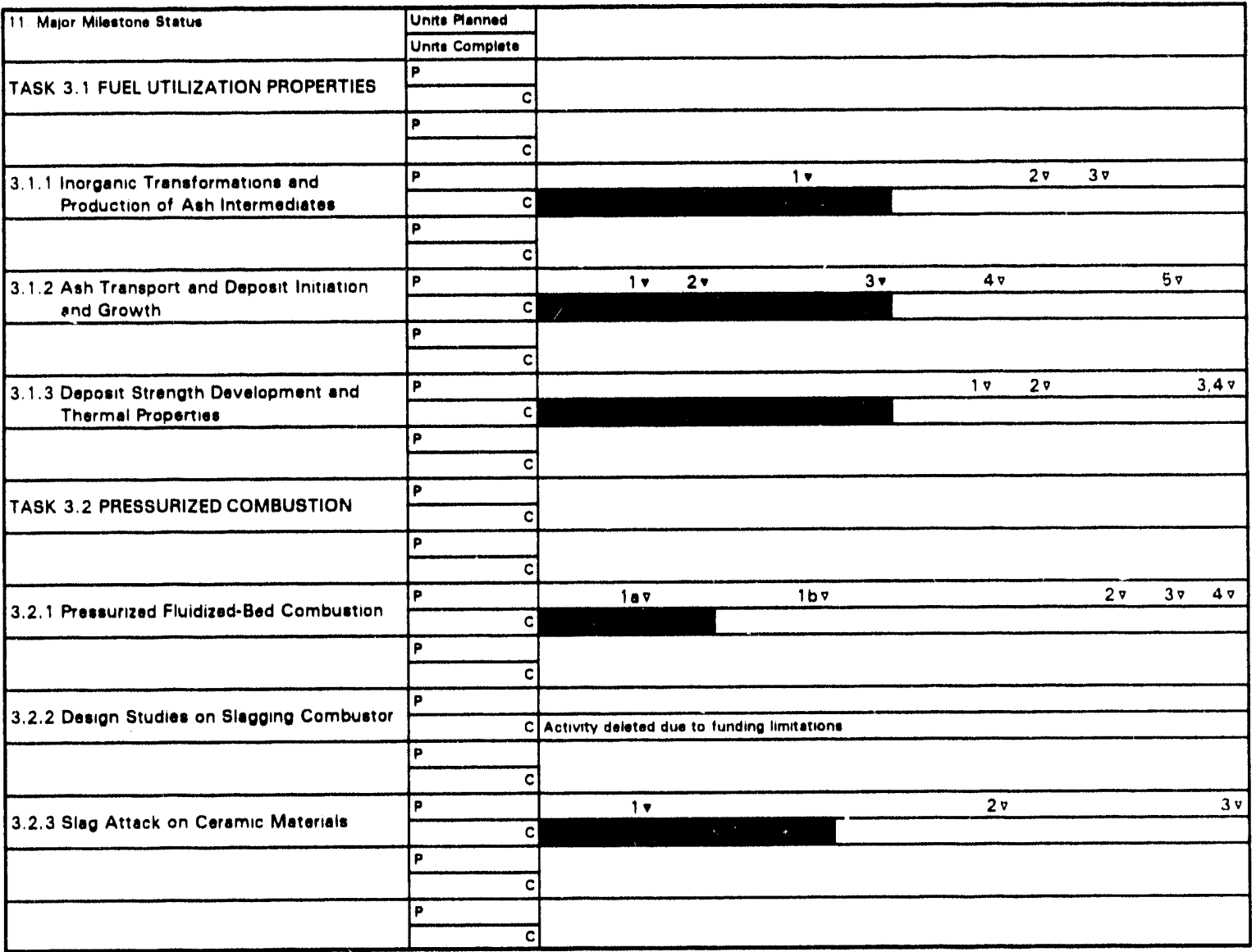

12. Remark: 


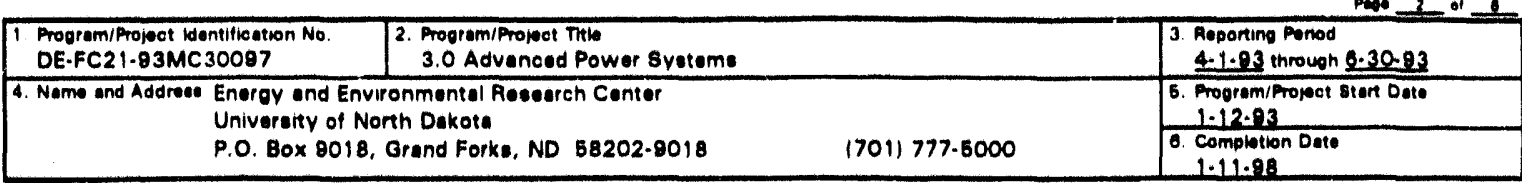

\begin{tabular}{|c|c|c|c|c|c|c|c|}
\hline $\begin{array}{r}7.9 y \\
93\end{array}$ & B. 1 & \multicolumn{6}{|c|}{ Monthe of Quarters } \\
\hline \multicolumn{2}{|c|}{$\begin{array}{l}\text { 9. Cost } \\
\text { Stutue }\end{array}$} & \multicolumn{4}{|c|}{$\begin{array}{l}\text { 1. Dollere Exproesed in } \\
\text { Theueande }\end{array}$} & & \\
\hline \multicolumn{8}{|c|}{ 10. Cost Chart } \\
\hline \multirow{2}{*}{\multicolumn{2}{|c|}{$\begin{array}{l}\text { Fund } \\
\text { Souree }\end{array}$}} & & & & & \multirow{2}{*}{$\begin{array}{l}\text { Cum } \\
\text { to } \\
\text { Dato }\end{array}$} & \multirow{2}{*}{ Tot } \\
\hline & & tst & 2nd & 3 rd & 4th & & \\
\hline \multirow{2}{*}{ DOE } & P & & & & & & \\
\hline & $\boldsymbol{A}$ & & & & & & , \\
\hline & $\mathbf{P}$ & & & & & & \\
\hline & $A$ & & & & & & \\
\hline & $\mathbf{P}$ & & & & & & \\
\hline & A & & & & & & \\
\hline & P & & & & & & \\
\hline & A & & & & & & \\
\hline \multicolumn{8}{|c|}{ Totol P } \\
\hline \multicolumn{2}{|c|}{ Total A } & & & & & & \\
\hline Vone & & & & & & & \\
\hline
\end{tabular}
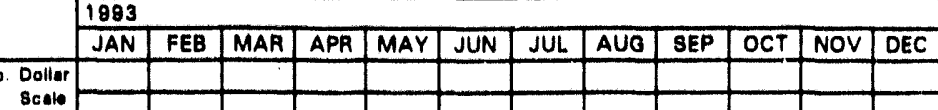

Total Panned Coete for Progrem/Project
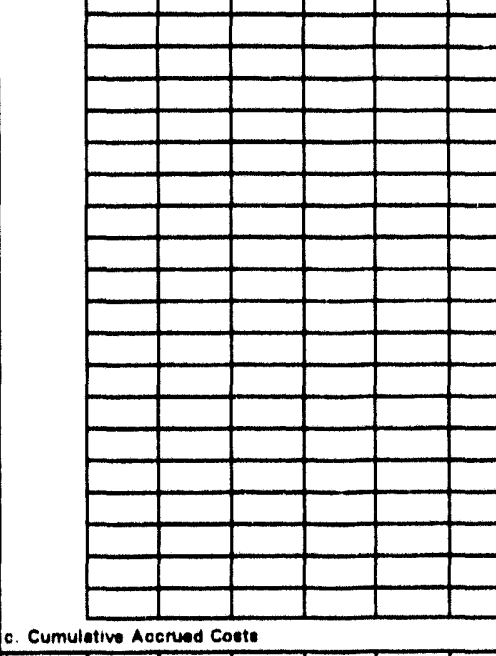

c. Cumulativo Accrued Cost:

$$
\begin{array}{|l|l|}
\hline \text { Actual } \\
\hline \text { Vertance } \\
\hline
\end{array}
$$

Vartance

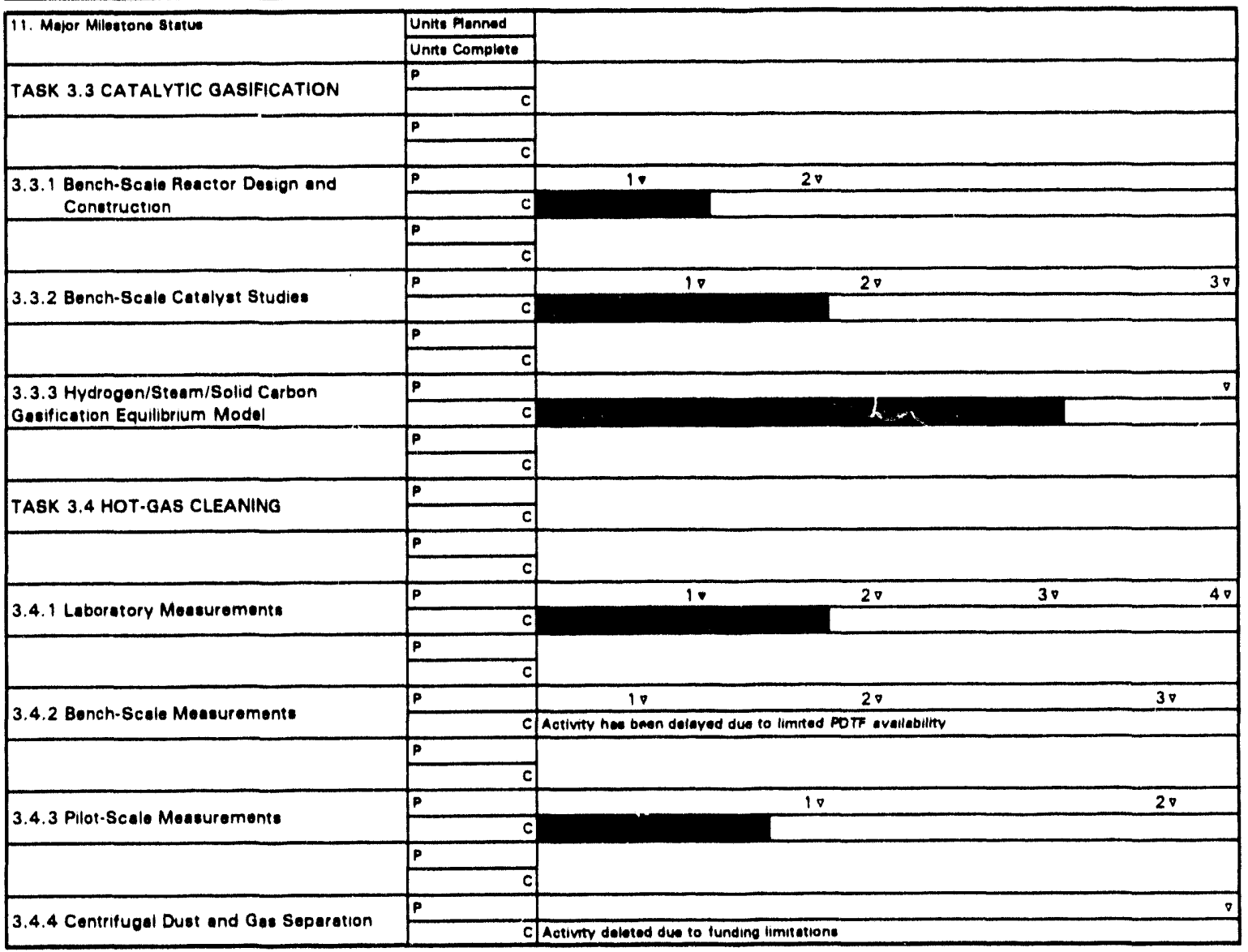

12. Romarks 


\begin{tabular}{|c|c|c|c|c|}
\hline \multicolumn{3}{|c|}{ 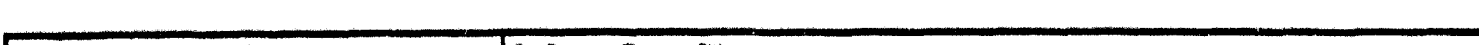 } & & - or \\
\hline $\begin{array}{l}\text { 1. Proprem/Proper lounter } \\
\text { DE.FC.93MC3C }\end{array}$ & 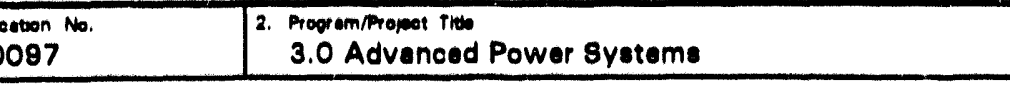 & & 41.93 thr & $\begin{array}{l}\text { Perrod } \\
\text { h } 6-30-93\end{array}$ \\
\hline \multirow[t]{2}{*}{ 4. Nomo and Addrem } & \multirow{2}{*}{\multicolumn{2}{|c|}{$\begin{array}{l}\text { Energy and Environmental Research Center } \\
\text { University of North Dakota } \\
\text { P.O. Box } 9018 \\
\text { Grand Forks, ND } 58202-9018 \quad 1701) 777.6000\end{array}$}} & \multicolumn{2}{|c|}{$\begin{array}{c}\text { 8. Prooram/Propet ster Dote } \\
1.12 .83\end{array}$} \\
\hline & & & \multicolumn{2}{|c|}{$\begin{array}{l}\text { C. Completion Dute } \\
1.11 .98\end{array}$} \\
\hline $\begin{array}{l}\text { Milestone } \\
\text { ID. No. }\end{array}$ & Description & $\begin{array}{l}\text { Planned } \\
\text { Completion } \\
\text { Date }\end{array}$ & $\begin{array}{l}\text { Actual } \\
\text { Cumpletion } \\
\text { Date }\end{array}$ & Comments \\
\hline TASK 3.1 & FUEL UTILIZATION PROPERTIES & & & \\
\hline Subtask 3.1 .1 & Inorganic Transformations and Production of Ash Intermediates & & & \\
\hline (1) & DTF inorganic transformations & $5 / 15 / 93$ & $5 / 15 / 93$ & \\
\hline (2) & Modeling fly ash properties & $9 / 15 / 93$ & & \\
\hline (3) & Analytical methods development & $10 / 15 / 93$ & & \\
\hline Subtask 3.1 .2 & Ash Transport and Deposit Initiation and Growth & & & \\
\hline (1) & Modification of ODTF to add second furnace & $2 / 28 / 93$ & $2 / 28 / 93$ & \\
\hline (2) & Literature review on ash transport and deposit initiation & $3 / 31 / 93$ & $3 / 31 / 93$ & \\
\hline (3) & Deposit initiation & $6 / 30 / 93$ & $6 / 30 / 93$ & \\
\hline (4) & Growth rates for deposits & $8 / 31 / 93$ & & \\
\hline (5) & Development of transport algorithms & $11 / 30 / 93$ & & \\
\hline Subtask 3.1 .3 & Deirosit Strength Development and Thermal Properties & & & \\
\hline (1) & Literature review on silicate and sulfate sintering & $8 / 15 / 93$ & & \\
\hline (2) & Sintering and deposit thermal conductivity experiments & $9 / 15 / 93$ & & \\
\hline (3) & $\begin{array}{l}\text { First-order correlation between deposit porosity, composition, } \\
\text { degree of sulfation, liquid phase viscosity with deposit growth } \\
\text { rates, strength development, and removability }\end{array}$ & $12 / 15 / 93$ & & \\
\hline (4) & $\begin{array}{l}\text { Develop first version of algorithm for predicting deposit } \\
\text { conductivity }\end{array}$ & $12 / 15 / 93$ & & \\
\hline TASK 3.2 & PRESSURIZED COMBUSTION & & & \\
\hline Subtask 3.2 .1 & Pressurized Fluidized-Bed Combustion & & & \\
\hline (1a) & Complete construction of bench-scale PFB reactor & $2 / 28 / 93$ & $6 / 30 / 93$ & \\
\hline (1b) & $\begin{array}{l}\text { Complete shakedown of PFB reactor and alkall and particulate } \\
\text { sampling probes }\end{array}$ & $5 / 31 / 93$ & & \\
\hline
\end{tabular}




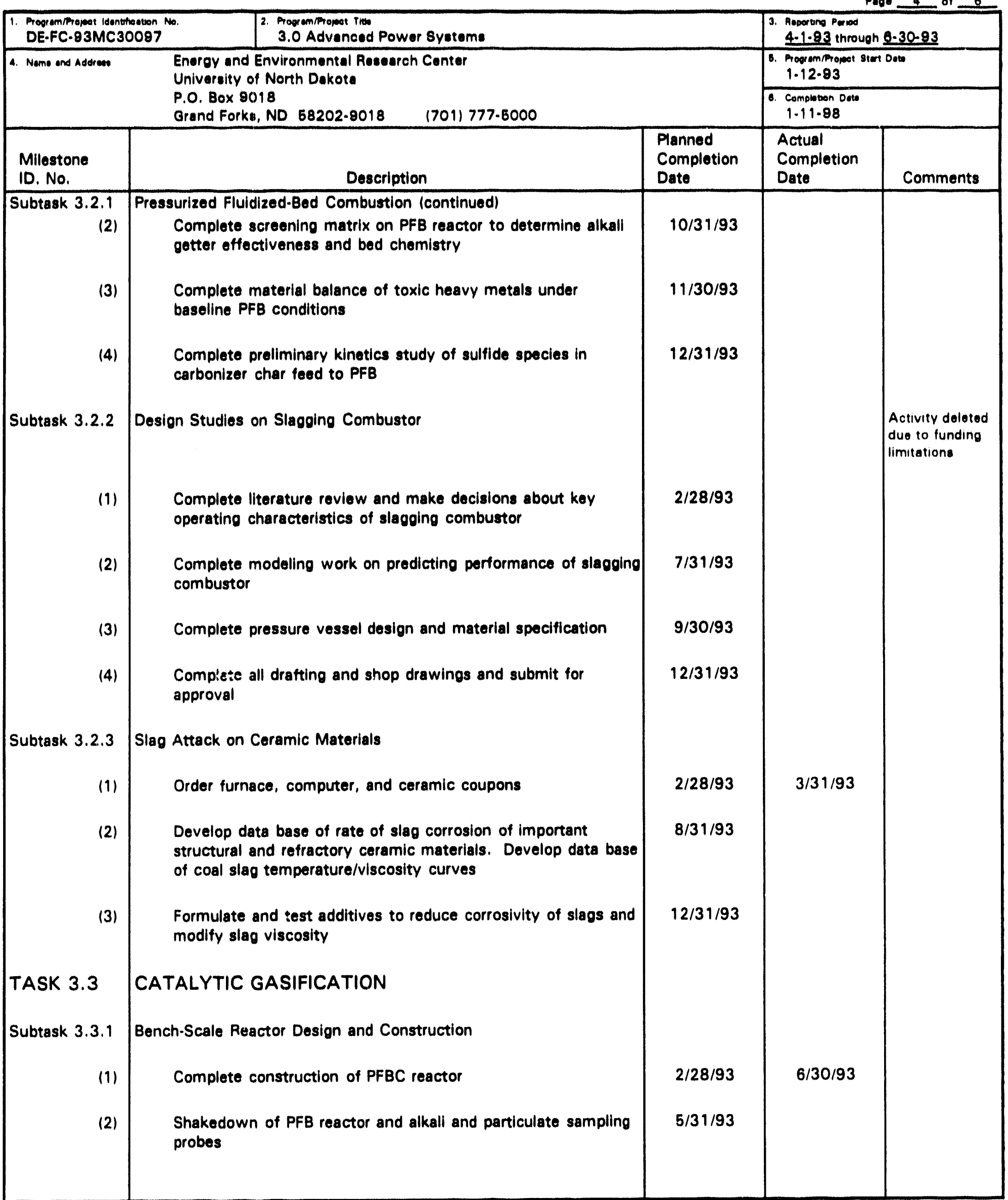


U.8. DEPARTMRNT OF ENEROY

4. Nemo and Adtere Eneroy and Environmental Researoh Center Univaratty of North Dakota P.0. Box 8018

Grand Forke, ND 58202.9018

ID. No.

Subtask 3.3.2

(1)

Subtask 3.3.3

\section{TASK 3.4}

Subtask 3.4.1

Bench-Scale Measurements

Pilot-Scale Measurements

Complete 100-hour tests of four ceramic filters as selected from laboratory studies

Complete modification of PDTF to incorporate ceramic filter on end of particulate sampling probe

Complete shakedown testing of ceramic filter test apparatus in PDTF

availability of submodels to be used in the EERC model for performing theoretical determinations of thermodynamic data for ceramic systems

\section{Complete second series of alkall corrosion tests}

$12 / 31 / 93$

$3 / 31 / 93$

$6 / 30 / 93$

$12 / 31 / 93$

$12 / 31 / 93$

$3 / 31 / 93$

$3 / 31 / 93$

$6 / 30 / 93$

9/30/93

$2 / 28 / 93$

$6 / 30 / 93$

$11 / 30 / 93$

$5 / 31 / 93$

Modify sampling system
Activity has boen delayed due to limited PDTF avallability

Delayed pending TRDU completion
1.12 .83 1.11 .98

Actual

Completion Date Comments 
U.8. DEPARTMENT OF ENEROY

\begin{tabular}{|c|c|c|c|c|c|}
\hline \multicolumn{2}{|c|}{$\begin{array}{l}\text { 1. Prowem/Promet idontheneon No. } \\
\text { DE.FC.93MC30097 }\end{array}$} & \multicolumn{2}{|c|}{$\begin{array}{l}\text { 2. Prowem/Froper Treb } \\
\text { 3.0 Advanced Power Systems }\end{array}$} & \multicolumn{2}{|c|}{$\begin{array}{l}\text { 3. Roporting Perood } \\
4-1.93 \text { through } 0.30-93\end{array}$} \\
\hline \multirow[t]{2}{*}{ 4. Namo und Adeterom } & \multirow{2}{*}{\multicolumn{2}{|c|}{ 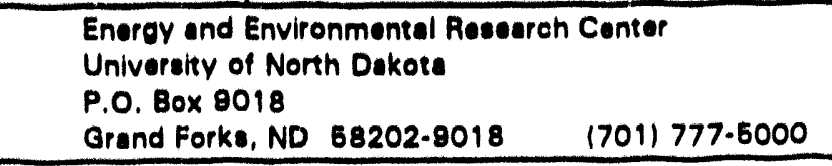 }} & & \multicolumn{2}{|c|}{$\begin{array}{l}\text { 8. Prow um/Proper sure Dote } \\
1.12 .93\end{array}$} \\
\hline & & & & $\begin{array}{l}\text { - Compoweon Dow } \\
1.11-98 \\
\end{array}$ & \\
\hline $\begin{array}{l}\text { Milestone } \\
\text { ID. No. }\end{array}$ & \multicolumn{2}{|r|}{ Description } & $\begin{array}{l}\text { Planned } \\
\text { Completion } \\
\text { Date }\end{array}$ & $\begin{array}{l}\text { mal } \\
\text { mpletion } \\
\text { ute }\end{array}$ & Comments \\
\hline Subtask 3.4 .4 & \multicolumn{2}{|c|}{ Centrifugal Dust and Gas Separation } & $12 / 31 / 93$ & & $\begin{array}{l}\text { Activity deleted } \\
\text { due to funding } \\
\text { limitations }\end{array}$ \\
\hline
\end{tabular}



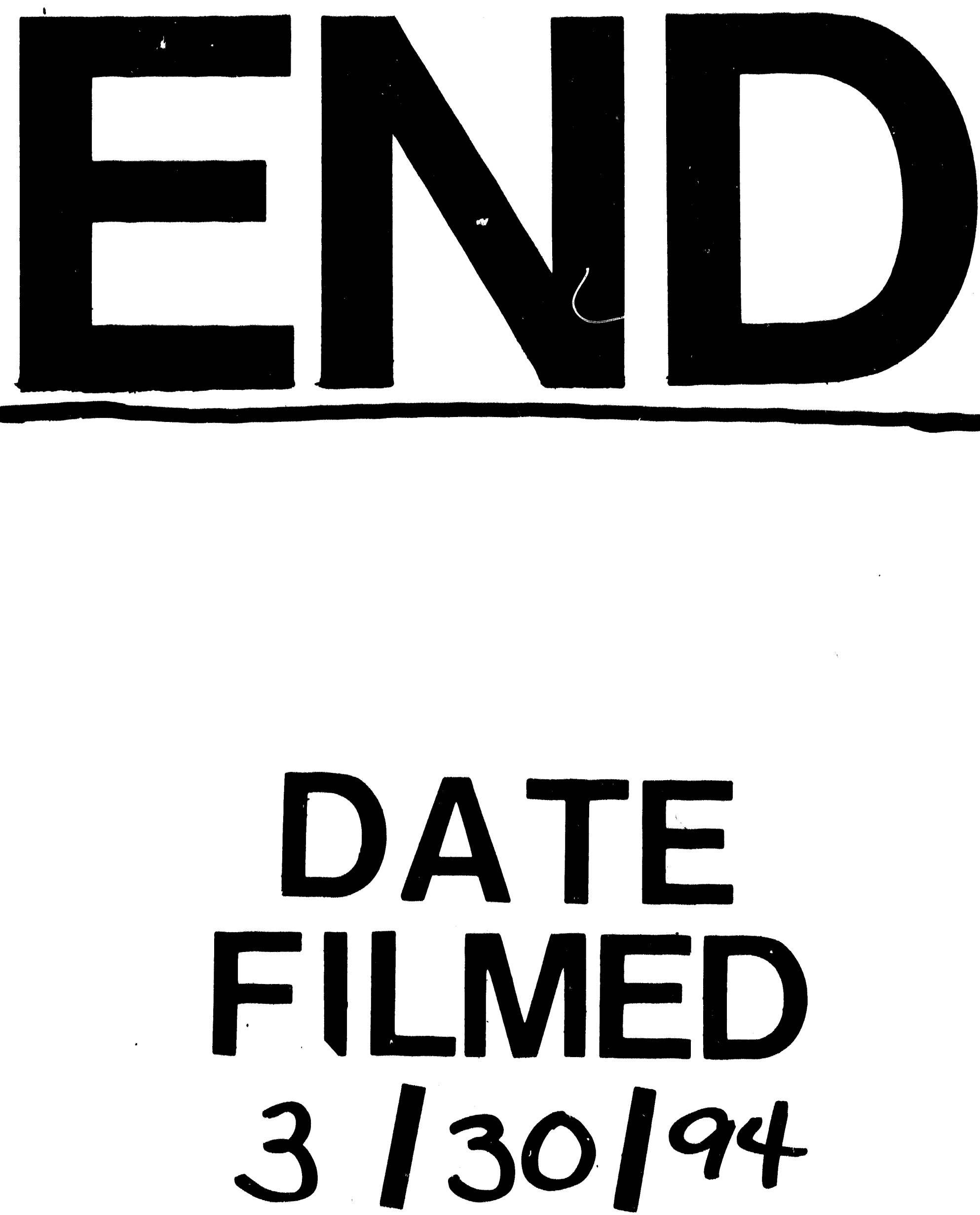


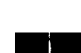
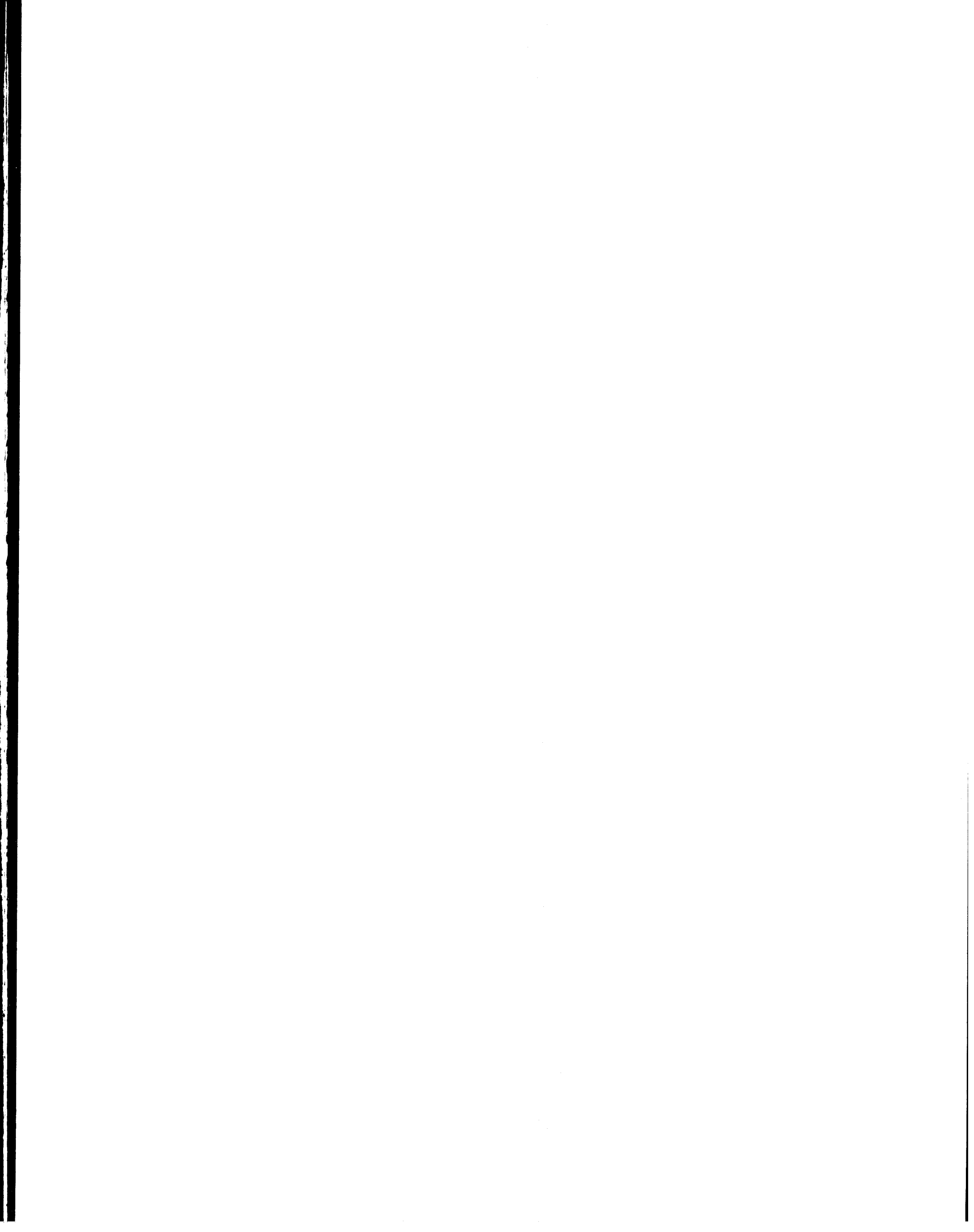